ANTHEM FRONTIERS OF GLOBAL POLITICAL ECONOMY

\title{
Central Banking at a Crossroads
}

Europe and Beyond

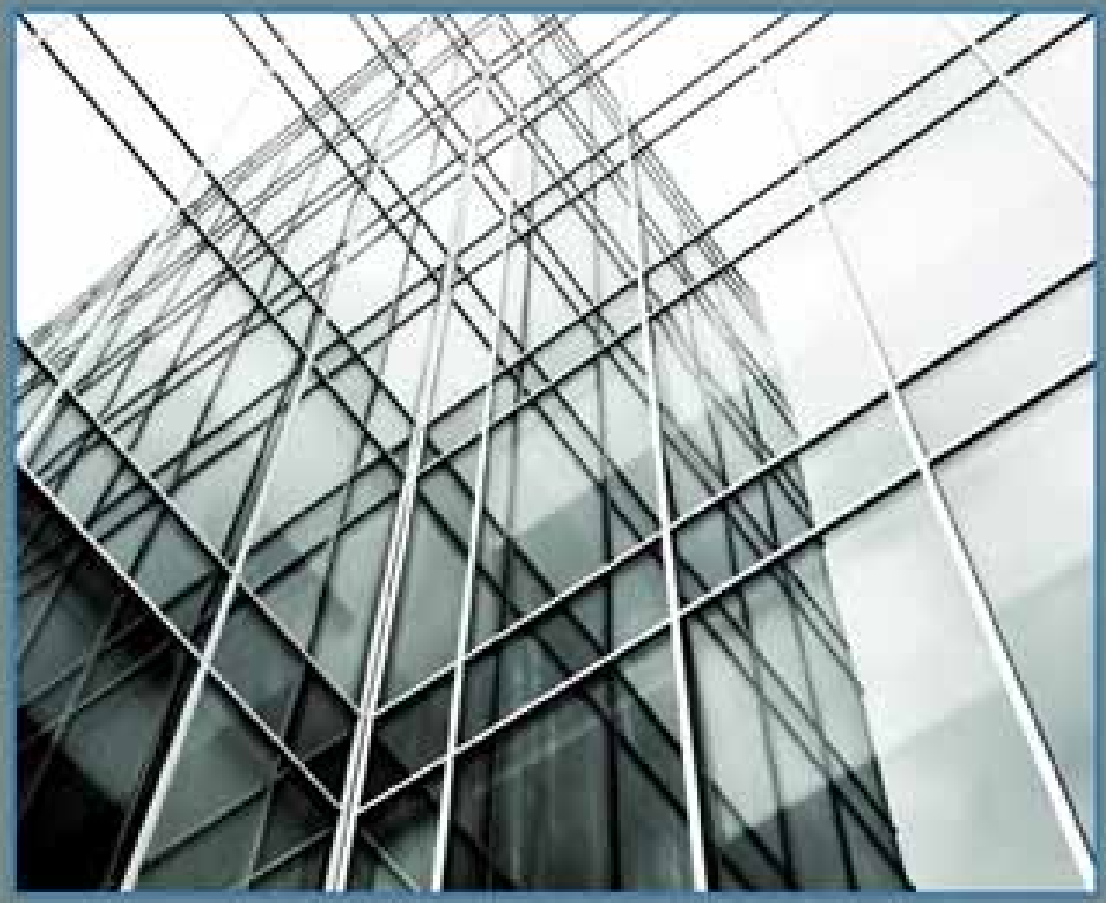

Edited by Charles Goodhart,

Daniela Gabor, Jakob Vestergaard and Ismail Ertürk

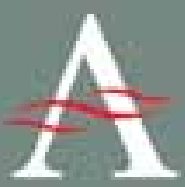


Central Banking at a Crossroads 


\section{Anthem Frontiers of Global Political Economy}

The Anthem Frontiers of Global Political Economy series seeks to trigger and attract new thinking in global political economy, with particular reference to the prospects of emerging markets and developing countries. Written by renowned scholars from different parts of the world, books in this series provide historical, analytical and empirical perspectives on national economic strategies and processes, the implications of global and regional economic integration, the changing nature of the development project, and the diverse global-to-local forces that drive change. Scholars featured

in the series extend earlier economic insights to provide fresh interpretations that allow new understandings of contemporary economic processes.

\section{Series Editors}

Kevin Gallagher - Boston University, USA Jayati Ghosh - Jawaharlal Nehru University, India

\section{Editorial Board}

Stephanie Blankenburg - School of Oriental and African Studies (SOAS), UK Ha-Joon Chang - University of Cambridge, UK Wan-Wen Chu - RCHSS, Academia Sinica, Taiwan Léonce Ndikumana - University of Massachusetts-Amherst, USA Alica Puyana Mutis - Facultad Latinoamericana de Ciencias Sociales (FLASCO-México), Mexico

Matías Vernengo - Banco Central de la República Argentina, Argentina Robert Wade - London School of Economics and Political Science (LSE), UK

Yu Yongding - Chinese Academy of Social Sciences (CASS), China 


\title{
Central Banking at a Crossroads
}

\author{
Europe and Beyond
}

Edited by

Charles Goodhart, Daniela Gabor,

Jakob Vestergaard and Ismail Ertürk

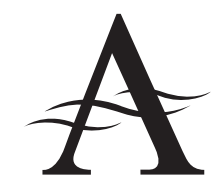

ANTHEM PRESS 


\author{
Anthem Press \\ An imprint of Wimbledon Publishing Company \\ wrew.anthempress.com \\ This edition first published in UK and USA 2014 \\ by ANTHEM PRESS \\ 75-76 Blackfriars Road, London SE1 8HA, UK \\ or PO Box 9779, London SW19 7ZG, UK \\ and \\ 244 Madison Ave \#1 16, New York, NY 10016, USA
}

(C) 2014 Charles Goodhart, Daniela Gabor, Jakob Vestergaard and Ismail Ertürk editorial matter and selection; individual chapters $\mathbb{C}$ individual contributors

The author asserts the moral right to be identified as the author of this work.

All rights reserved. Without limiting the rights under copyright reserved above, no part of this publication may be reproduced, stored or introduced into

a retrieval system, or transmitted, in any form or by any means

(electronic, mechanical, photocopying, recording or otherwise),

without the prior written permission of both the copyright

owner and the above publisher of this book.

British Library Cataloguing-in-Publication Data

A catalogue record for this book is available from the British Library.

Library of Congress Cataloging-in-Publication Data

Central banking at a crossroads : Europe and beyond / edited by Charles Goodhart,

Daniela Gabor, Jakob Vestergaard and Ismail Ertürk.

pages cm. - (Anthem frontiers of global political economy)

Includes bibliographical references and index.

ISBN 978-1-78308-304-6 (hardcover : alk. paper) - ISBN 1-78308-304-2 (hardcover : alk. paper)

1. Banks and banking, Central. 2. Banks and banking, Central-Law and legislation. I.

Goodhart, G. A. E. (Charles Albert Eric) editor.

HG1811.C45763 2014

332.1 '1-dc23

2014042341

ISBN-13: 9781783083046 (Hbk)

ISBN-10: 1783083042 (Hbk)

Cover image: Vladitto/Shutterstock.com

This title is also available as an ebook. 


\section{CONTENTS}

Preface

1. Introduction

Charles Goodhart, Daniela Gabor, Ismail Ertürk, and Jakob Vestergaard

\section{Part 1 Bank Capital Regulation}

2. Constraining Discretion in Bank Regulation

Andrew G. Haldane

3. Fallacies and Irrelevant Facts in the Discussion on Capital Regulation Anat R. Admati, Peter M. DeMarzo, Martin F. Hellwig, and Paul Pfleiderer

4. Complexity, Interconnectedness: Business Models and the Basel System

Adrian Blundell-Wignall, Paul Atkinson, and Caroline Roulet

5. At the Brink of Insolvency: Shallow Recapitalization Exercise

Fails to Bolster Europe's Ailing Banks

Jakob Vestergaard and Maria Retana

\section{Part 2 Bank Resolution}

6. Bank Resolution in Comparative Perspective: What Lessons for Europe?

Charles Goodhart

7. Resolving Problem Banks: A Review of the Global Evidence

Martin Čihák and Erlend Nier

8. Bank Resolution in New Zealand and Its Implications for Europe

David G. Mayes

\section{Part 3 Central Banking with Collateral-Based Finance}

9. Collateral and Monetary Policy

Manmohan Singh

10. The ECB and the Political Economy of Collateral

Daniela Gabor

11. The Backstory of the Risk-Free Asset: How Government

Debt Became "Safe"

Nina Boy 


\section{Part 4 Where Next for Central Banking?}

12. Central Banking Post-Crisis: What Compass for Uncharted Waters?

Claudio Borio

13. Reconceptualizing Central Bank Unconventional Policies:

Long Positions on No-Growth Capitalism

Ismail Ertürk

14. The Relationship between Central Banks and Governments:

What Are Central Banks For?

Sheila C. Dow

15. Is New Governance the Ideal Architecture for

Global Financial Regulation?

Annelise Riles

List of Contributors

Index 


\section{PREFACE}

This book has its origin in a conference held in the Axelborg Hall in Copenhagen last year. Axelborg Hall, built in 1920, was the second largest secular building in Copenhagen at the time, surpassed only by Parliament. The Danish Cooperative Bank, for which Axelborg was originally built, went bankrupt in 1925, only five years later. But the building itself survived and now boasts a colorful history of nearly one hundred years of different owners and tenants, with banking by far the dominant theme. It seemed the perfect venue for a conference on central banking at a crossroads.

However, as esteemed speakers and eager participants arrived to the venue on the morning of 29 January last year, Axelborg Hall lay shrouded in darkness, as did indeed the entire building and a few blocks around it. Helped only by the dim light of a few candles, Professor Charles Goodhart delivered his opening talk masterfully to an audience of several hundred, most of whom could perhaps hear but not see much. Halfway through Goodhart's talk, the lights came back on. And from there, it was smooth sailing.

A generous reading of post-crisis central banking would say that an exceptionally difficult situation was handled just as masterfully. Out of a dark and dangerous event, came a stronger mode of central banking, reinvented and with new resilience. Others will say that in the world of central banking, darkness is still the order of the day, as we chase systemic risk and try to tame phenomena of which we still have only insufficient understanding.

The contributions in this book fall between these two poles, perhaps with a slight bias towards a worried take on the trajectory of central banking in recent years. While a certain measure of concern may be shared by all contributors, the approaches taken and conclusions reached by different authors vary considerably. This was a defining feature of the talks given at the conference too, in which many (but not all) of the chapters originate.

We hope the book will reach a wide audience. And we hope that you, the reader, will get beyond page twelve. This is how far the average reader of the e-book version of Tomas Piketty's Capital in the Twenty-First Century gets, according the e-reader statistics. The odds that we achieve this may not exactly be great, perhaps. But it's more likely, at least, than beating Piketty on copies sold.

We have little doubt that many of those in attendance of the conference will remember the event for Goodhart's candlelit keynote. Reading a book on central banking is unlikely to produce similarly poetic imagery. But perhaps you will remember it for the elegant cover page? Or, for the exceptional set of high-profile experts in the field, and how we managed to blend in a few up-and-coming scholars? More likely, you won't remember 
it at all! Don't worry; as Ingrid Bergman famously said, "happiness is good health and a bad memory".

Finally, we should like to take this opportunity to say a few words of gratitude. The conference - without which there would have been no book - was sponsored by the Danish Central Bank, the European Cooperation in Science and Technology (COST), Danske Bank, Nordea, Nykredit, the Danish Bankers' Association, and the Danish Institute for International Studies (DIIS). We thank all of these organizations for their generous support. And without the efforts of colleagues at DIIS - especially those of María Retana, Signe Terney Larsen and Jette Kristensen - there wouldn't have been a conference to sponsor, nor would there have been candles to get it started. So the final word of gratitude goes to María, Signe and Jette.

On behalf of the editors, Jakob Vestergaard, Copenhagen, 14 October 2014 


\section{Chapter 1}

\section{INTRODUGTION}

\section{Charles Goodhart, Daniela Gabor, Ismail Ertürk, and Jakob Vestergaard}

\section{Background and Key Themes}

Since the collapse of Lehman Brothers, central banks and regulatory authorities in general have been confronted with difficult questions. The global financial crisis made apparent that the analytical models of the Great Moderation period failed to capture the changing nature of financial intermediation and the complex business models of transnational banks operating across different jurisdictions. In turn, despite few theoretical certainties with which to draw upon, central banks have played key roles in responding to the crisis and in trying to devise more adequate modes of regulation and intervention. First, in the immediate aftermath of the crisis, it was the central bank governors of Basel Committee member countries that amended the existing Basel II rules and methodologies for capital adequacy. Second, it was the Financial Stability Board, with much the same country membership as the Basel Committee and with central bank governors gathered around the negotiating table, which identified principles and guidelines for the resolution of distressed banks. And last but not least, it was the central banks that replaced conventional tools with new instruments and practices that extend their mandate and blur the traditional separation from private financial markets. For the past five years, central banks have intervened in both public and private debt markets, taking on functions of market makers or dealers of last resort. In this book, we propose to explore these developments and set them in the context of the European crisis.

The most comprehensive national regulatory response to the crisis came from the USA, where the Dodd-Frank Act specifically aimed at regulating the business models of banks by removing the risky proprietary trading from the investment banking activities in bank conglomerates and moving over-the-counter derivatives trading to the exchanges. The Vickers Report in the UK, too, aimed at separating investment banking from the retail banking activities of universal banks, but in a less clear way, by proposing the ring fencing of retail from investment banking. Such ring fencing would involve different capital-adequacy rules for retail and investment banking activities within the same bank holding company. Technically, the Dodd-Frank and the Vickers initiatives have many differences, but both have the common goal of protecting both retail depositors and taxpayers from risky investment banking activities in universal banks. Such regulatory 
interventions obviously will have significant implications for bank business models as they will have a direct impact on how profits are generated in investment banking activities. In the EU, the Liikanen Report, too, was primarily driven by the need to keep retail banking safe from such risky investment banking activities.

The book is divided into four sections. The first, "Bank Capital Regulation," examines in detail the Basel III agreement, identifying the key novelties vis-à-vis its predecessor, Basel II, as well as its main shortcomings. While Basel III introduces several useful regulatory tools - notably, a leverage ratio, liquidity requirements, and a countercyclical capital buffer - significant weaknesses remain. The continued predominance of ratios of capital to risk-weighted assets is unfortunate, particularly in the context of an industry that operates on dangerously low levels of equity capital, and has proven the ability to improvise practices of regulatory arbitrage that can counteract the intended consequences of Basel risk calculations. In addition to an in-depth assessment of the Basel III agreement, chapters in this section question the notion that increasing the equity capital of banks would be costly to society and critically review alleged efforts to recapitalize Europe's banks.

The second, "Bank Resolution," explores key questions raised and lessons learnt from the global financial crisis. Its starting point is that authorities lacked the necessary tools to intervene effectively and quickly enough, resulting in resolutions that were both messy and costly - and where taxpayers were often left to foot the bill. Several specific questions will be explored: What are effective regimes for regulating and resolving (ailing) banks? How does the political context influence these regimes and what lessons can be learned from new models adopted in different parts of the world? Last but not least, how can regulators overcome the challenges of resolving banks operating across different jurisdictions?

The third, "Central Banking with Collateral-Based Finance," develops two interconnected themes: the challenges that market-based finance pose for the conduct of central banking in periods of economic stability as well as during crises; and, through a critical theoretical angle, the increasing role that governments play for financial markets as manufacturers of high-quality collateral or safe assets. Contributors to this section examine several different mechanisms through which market-based financial systems interact with the conduct of central banking. What are the defining features of marketbased finance that make it imperative to reassess the established models of central banking? How can central banks manage the relationship between money and collateral? How did debt, and in particular government debt, itself become the most common form of collateral in the financial system? How do practices of collateral intermediation affect financial stability and systemic risk? Are these practices different across jurisdictions and how relevant are these differences for central banks? What broader political questions about the governance of markets does collateral raise for central banks and governments?

The fourth, "Where Next for Central Banking?" examines fundamental issues about the trajectory of central banking and its new, central role in sustaining capitalism. The global financial crisis has shaken the foundations of the deceptively comfortable precrisis central banking world. Although the traditional lender-of-last-resort role of central banks is short-term and transitional, the new unconventional balance sheet policies of 
central banks that have been performed through a series of quantitative easing $(\mathrm{QE})$ programs are indeterminate in duration and size. The US Federal Reserve has announced that quantitative easing will continue until unemployment reaches a desirable level and, similarly, the European Central Bank is prepared to do "whatever it takes" to save the euro. These new modes of intervention have significant allocative and distributive consequences, and yet they remain outside democratic control. Central banks today hence face not only economic, intellectual, and institutional challenges, but also the challenge of introspection. Can the traditional principles of central bank independence survive the shift to market-based finance? If not, what form should the relationship between central banks and governments take? Can such challenges be addressed independently, or is global coordination through new institutions such as the Financial Stability Board the answer to the global nature of financial markets?

There are important analytical connections between the four sections. The new regimes for regulation and resolution may encourage financial innovation to produce safe assets and high-quality collateral, while a rethink of central banking models beyond the traditional lender of last resort will have regulatory consequences. The quintessential task of the central bank, as Borio puts it in his contribution, is no longer only to react to changes in inflation with interest rate measures. Since the crisis, central banks' liquidity provision - through standard facilities as well as through unconventional measures such as quantitative easing - has taken center stage. Yet, liquidity regulation is also one key priority of the Basel III Liquidity Rules, with the explicit purpose of shifting funding models onto longer-term sources. Thus, a return to interest rate instruments may require central banks to take into account, through their liquidity management operations, the regulatory demands for liquidity in Basel III. This goes to the heart of ongoing debates about how to integrate monetary policy and financial stability concerns, suggesting that the current consensus on macroprudential policies may need further refining to consider possible overlaps, or even conflicts, between policy objectives.

Another cross-cutting theme engages with the distinctive challenges that the financial crisis and its regulatory aftermath have raised for governments. Across the contributions in the book, governments appear in different guises. Through a resolution lens, governments may be forced to bear the costs of poorly designed resolution regimes, particularly when these involve cross-border banks under ill-defined supervisory responsibilities. Discussions of regulation and collateralized finance conceive of governments as manufacturers of high-quality liquid assets to be held under Basel III liquidity requirements or used as collateral to raise market funding. A legitimate, if not often-posed question in this respect is whether regulatory and market initiatives may be overburdening governments as much as crisis responses appear to have overburdened central banks. For example, some governments may not be supplying enough government bonds for their banking sector to be able to comply with Basel LCR (Norway, Denmark). Should that translate into exemptions from Basel rules for such banks? Conversely, since the European sovereign debt crisis, the "risk-free" status of some (high-income) sovereigns has come under question, often because repo markets stopped treating their bonds as high-quality collateral because of the burden that bank rescues posed on government finances (e.g. Ireland). Can and should governments, in their guise of collateral manufacturers, be 
entrusted with financial stability when their fiscal positions are exposed to automatic stabilizers and bank rescue costs? Or rather, is it the case that new forms of coordination between central banks and governments are necessary to preserve stability in the financial markets of the future, dependent on high-quality liquid assets?

Interconnectedness within and across borders, between banks and non-bank intermediaries, also matters. Fragile connections within the financial sector may result in systemic risk, particularly where these reflect business models based on leverage, and driven by tax and regulatory arbitrage. Thus, regulatory structures and bank resolution procedures may need to become more complicated when banking institutions are closely interconnected on and off the balance sheet through cross-border networks of complex credit claims.

The crisis has dispelled the illusions that central banking could be a scientific endeavor, firmly grounded in rigorous models, supported by communicative strategies whose ultimate goal was to train financial markets to interpret the central bank's interest rate signals adequately. Rather, the rapid pace of financial innovation, including the growth of the shadow banking sector, has posed significant challenges to the existing institutional and political order, challenges that scholars will be researching in detail over the next decade. Central bankers now live in a world of multiple instruments (interest rates, collateral framework, macroprudential tools, forward guidance) and multiple objectives (price stability, unemployment and financial stability). Resolving potential conflicts between these objectives will require technocratic, and for some deeply political, judgments that throw into question the dominant paradigm of central bank independence. Cross-border coordination, the crisis has shown, is crucial, while the institutional architecture to enable such coordination is yet to be developed. Researchers will have to theorize the mechanisms through which central banks with competing domestic priorities - most pressing, at this point, the pace of exiting unconventional measures - can cooperate to contain cross-border spillovers, and the extent to which, in the absence of cooperation, the careful use of capital controls will become the new normal in the post-crisis global financial system. Finally, the structural implications of the ongoing efforts to re-regulate finance are yet to be fully understood. What would central banking look like in a world where intermediation moves from highly regulated banks into the shadow banking world?

\section{Overview of Chapters}

\section{Part 1: Bank Capital Regulation}

Andrew Haldane notes that since the mid-1990s, banking regulators globally have allowed banks the discretion to use their own models to calculate capital needs. Most large banks today use these models to scale their regulatory capital. This self-regulatory shift was made with the best of intentions. Yet its consequences have been predictable. Self-assessment has created incentives to shade reported capital ratios. As elsewhere, a regulatory regime of constrained discretion has given way to one with too much unconstrained indiscretion. Incentives will always exist to shift risk to where it is cheapest. 
No tax or regulatory system can fully avoid those incentives. However, some regimes may be better at constraining those incentives than others. The current mix of complexity and self-regulation may provide too few constraints. Complexity has meant that avoidance and arbitrage can flourish behind a curtain of opacity. In addition, self-regulation has meant that even as one wormhole is closed, others can be created in their place.

This calls for regulatory repair. Without change, the current regulatory system risks suffering, like the LIBOR fixers, from reputational damage. Fortunately, there are early signs that regulatory change is afoot to place tighter constraints on this (in) discretion. Making greater use of simple, prudent regulatory metrics could restore faith, hope, and clarity to the financial system to the benefit of banks, investors, and regulators alike.

Admati, DeMarzo, Hellwig, and Pfleiderer examine what they see as the fallacies and irrelevant facts in debates about bank capital regulation (Chapter 3). In so doing, they particularly counter the pervasive view that "equity is expensive," which leads to claims that high capital requirements are costly and would affect credit markets adversely. The authors find that arguments made to support this view are either fallacious, irrelevant, or very weak. For example, the return on equity contains a risk premium that must go down if banks have more equity. It is thus incorrect to assume that the required return on equity remains fixed as capital requirements increase. It is also incorrect to view higher taxes paid by banks as a social cost. Policies that subsidize debt and indirectly penalize equity through taxes and implicit guarantees are distortive. Any desirable public subsidies to banks' activities should be given directly and not in ways that encourage leverage. Admati and colleagues conclude that bank equity is not socially expensive, and that high leverage is not necessary for banks to perform all their socially valuable functions, including lending, deposit taking, and issuing money-like securities. On the contrary, better-capitalized banks suffer fewer distortions in lending decisions and would perform better. The fact that banks choose high leverage does not imply that this is socially optimal, and high leverage may not even be privately optimal for banks. Setting equity requirements significantly higher than the levels currently proposed would entail large social benefits and minimal, if any, social costs. To achieve better capitalization quickly and efficiently, and prevent disruption to lending, regulators must actively control equity payouts and issuance. If the remaining challenges are addressed, more prudent and properly designed capital regulation in which banks are forced to rely on significantly more equity and less debt funding can be a powerful tool for enhancing the role of banks in the economy.

In "Complexity, Interconnectedness:Business Models and the BaselSystem"(Chapter4), Blundell-Wignall, Atkinson, and Roulet argue that the main hallmarks of the global financial crisis were too-big-to-fail institutions taking on too much risk with other people's money: excess leverage; default pressure resulting from contagion and counterparty risk; and the lack of regulatory and supervisory integration and efficient resolution regimes. From this point of departure, the authors look at whether the Basel III agreement addresses these issues effectively. Basel III has some very useful elements, notably a (much too light "backup" only) leverage ratio, a capital buffer, a proposal to deal with pro-cyclicality through dynamic provisioning based on expected losses, and 
liquidity and stable-funding ratios. However, the authors show that Basel risk weighting and the use of internal bank models for determining them leads to systematic regulatory arbitrage that undermines its effectiveness. Empirical evidence about the determinants of the riskiness of a bank (measured in this study by the distance to default) shows that a simple leverage ratio vastly outperforms the Basel T1 ratio. Furthermore, business model features (after controlling for macro factors) have a huge impact. Derivatives origination, prime broking, etc. carry vastly different risks to core deposit banking. Where such differences are present, it makes no sense to have a one-size-fits-all approach to capital rules. Capital rules make more sense when fundamentally different businesses are separated.

Vestergaard and Retana examine the alleged recapitalization of Europe's banks, demonstrating that the procedures orchestrated by the European Banking Authority (EBA) were little but a smokescreen for regulatory inaction (Chapter 5). When publishing the results of the recapitalization exercise, the EBA reported that European banking had been successfully recapitalized and now was in a much stronger position, with a much strengthened capital base and overall resilience. Vestergaard and Retana question this assessment. The recapitalization orchestrated by the EBA was based on a capital assessment methodology that has been subject to considerable criticism. The methodology of basing regulatory capital requirements on risk-weighted assets is a less reliable indicator of banks' soundness and resilience than ratios of capital to total assets. The chapter compares the assessments undertaken by the EBA - all of which are based on risk-weighted assets - with data on leverage ratios, defined as equity capital to total assets. By equity capital criteria, the recapitalization of European banks was insufficient at best. Only 7 out of 24 banks actually increased their ratio of equity capital to total assets. Second, the least well-capitalized banking sector among the larger Eurozone countries is not Spain or Italy, but Germany, closely trailed by France. The banking sectors of Spain and Italy have equity to total assets roughly double the size of those of Germany and France. Third, European banking remains far below the levels of equity capital recommended by scholars - and hence, remains vulnerable to shocks, and dependent on various forms of state subsidies, guarantees, and bailouts. Finally, the EU's new capital requirement regulation and directive, CRD4, will institutionalize the European reluctance to recapitalize its banks, and hence impede rather than improve the resilience of European banks.

\section{Part 2: Bank Resolution}

In "Bank Resolution in Comparative Perspective" (Chapter 6), Charles Goodhart notes that one key lesson of the recent financial crisis has been that standard bankruptcy procedures are inappropriate in the case of a bank. Instead, we need a special resolution regime (SRR) for banks, Goodhart argues, enabling the financial authorities to intervene in a failing bank to handle its demise in a variety of ways as might seem best. The establishment of an SRR is to be buttressed with two further reforms. The first is that the ratio of potentially loss-absorbing capital to (risk-weighted) assets should be greatly increased. The second reform involves making advance plans for periods of extreme 
difficulties for large and systemic banks, in the shape of recovery and resolution plans (RRPs). The first part, the "recovery" segment, requires the bank to think how it might be able to survive periods of extreme pressure (e.g. by selling assets or by borrowing, perhaps by establishing some kind of contingent put option). The second part, the "resolution plan," requires the bank to organize its affairs in such a way as to facilitate and expedite intervention by the official agency established under the SRR for the purpose of resolving failed banks (should the recovery part of the RRP prove insufficient). Even with such arrangements in place, considerable complications remain, however. Goodhart discusses strengths and weakness of single versus multiple entry point approaches as well as issues relating to the timing of intervention, the scope of deposit insurance, and mechanisms for bail-in. He concludes that the future of not only the process for bank resolution, but also of the structure of the wider financial system, remains in doubt. We may know what kind of ultimate equilibrium state, for the financial system, we might like to attain, but the empirical evidence clearly suggests that we have very little clear idea of how best to get from here to there.

Martin Čihák and Erlend Nier undertake a review of the global evidence on resolving problem banks (Chapter 7). In response to the global financial crisis, many countries are considering or have made changes in their regimes for resolving problem banks, Čihák and Nier note. In most cases, this has involved carving banks out of general bankruptcy regimes, and moving toward early intervention and resolution regimes specifically designed for banks. Such special regimes typically give more powers to central banks and other financial authorities, and reduce the involvement of the judicial system. This chapter provides a critical review of the reforms in bank resolution regimes around the globe, building on updated information from recent global surveys, including the updated Bank Regulation and Supervision Survey organized by the World Bank. The chapter identifies features of a well-designed and well-implemented bank resolution regime that can be helpful in containing the fiscal costs and limiting the impact of a bank failure on financial stability, both in the home country and in foreign jurisdictions. It highlights the issue of rules versus discretion: these regimes provide wide discretion to financial authorities to act in resolving the problem bank, but they also need to contain clear rules to ensure that timely action occurs, and that it withstands subsequent legal challenges. The chapter notes that while the conceptual reasons for SRRs for banks are strong, such regimes are not a panacea, and need to be complemented by other measures. In addition, real-life resolution regimes have important limitations and shortcomings that reduce their effectiveness. Indeed, Čihák and Nier's review of the post-crisis reforms suggests that legal and regulatory changes, while going in the right direction, have not fully addressed the underlying incentive breakdowns highlighted by the global financial crisis.

Focusing on "Bank Resolution in New Zealand," David Mayes considers whether the proposals for a bail-in of creditors that is currently being implemented as a way to resolve systemically important banks in New Zealand would also work in the EU/EEA(Chapter 8). This method, labeled "open bank resolution," but more appropriately described as "bank creditor recapitalization," is particularly relevant in the light of the resolution procedures adopted in Cyprus in March 2013, which have many aspects in common, Mayes argues. While New Zealand is unusual in having a highly concentrated banking sector owned 
by Australian banks, aspects of the scheme are transferable. However, other aspects of the scheme make it unlikely that it will actually be used, mainly because there is no deposit insurance, and hence ordinary depositors would be part of the compulsory bail-in. This not only increases financial instability by encouraging a bank run before insolvency, but is unlikely to be politically acceptable at the time, as depositors are voters. The chapter considers five key issues: first, the New Zealand requirement that the parts of the crossborder bank be divisible along jurisdictional boundaries and capable of operating on their own immediately on resolution; second, whether resolution can be successful if home and host countries do not cooperate; third, whether the writing down of creditor claims is the best method of bailing in; fourth, whether such a resolution can actually be completed rapidly enough so that the bank can, in effect, remain "open"; last, whether it can actually operate without provoking an early bank run. Mayes concludes that while the proposals appear practically feasible and transferable to other jurisdictions, particularly given the concerns of the Liikanen and Vickers Reports over the division of banking groups' activities, it is unlikely that bailing in ordinary depositors would be preferred to the bailing in of bondholders after the resources of the shareholders, subordinated debt holders, and other junior creditors have been exhausted.

\section{Part 3: Central Banking with Collateral-Based Finance}

In his chapter, Manmohan Singh asks what happens when central banks become important players in collateral markets. Quantitative easing programs change the relative price(s) of money and collateral, and in doing so reshape what Singh calls the "collateral space." In the old collateral space, private financial actors, typically non-banks, could meet growing collateral demand from the financial system by reusing collateral. Collateral thus flows at a velocity that allows it to support various repo transactions simultaneously. In contrast, the new collateral space is characterized by increased complexity and is complicated by new actors: central banks, regulators, and collateral custodians. These have a differentiated impact on collateral velocity, and therefore on financial lubrication. Thus, central banks' purchase of high-quality assets, through quantitative easing, slows collateral flows since central banks hold these in silos with zero velocity by definition. Regulatory demands for high-quality assets are expected to similarly drain collateral from financial markets.

Singh explores various channels through which collateral shortages may be alleviated in the future. He first notes that manufacturers of AAA securities, although lower in number since the European sovereign debt crisis, will continue to increase supply. Fine-tuning some regulatory demands may also play an important role. Central banks may follow the example of the Reserve Bank of Australia, and engage in collateral transformation. In the medium term, assuming no major dislocation in financial markets, central banks can unwind sizable good collateral from their balance sheet and alleviate shortages (if any). However, release of collateral from central bank balance sheets may not be as easy as quantitative easing, since repo rates cannot exceed policy rates, especially where central banks continue to price excess reserves/money favorably. The US Federal Reserve strategy to release collateral through reverse repos has doubtful 
effects on financial lubrication since it does not permit onward re-pledging. Thus, for some key jurisdictions (e.g. the USA), fine-tuning the price of money and the price of collateral will remain a challenge.

Daniela Gabor explores the importance of collateralized bank-funding strategies for the design of monetary policy measures during the crisis (Chapter 10). In so doing, the chapter first provides a taxonomy of crisis measures that distinguishes between marketbased and bank-based crisis measures. Until 2012, the US Federal Reserve and the Bank of England deployed the first (quantitative easing), while the European Central Bank (ECB) preferred bank-based measures (long-term refinancing operations) that it argued would fit better with the bank-based nature of the European financial system. Gabor argues that this distinction is moot where banks rely on collateralized funding, as large European banks do. The chapter highlights a crucial policy challenge in monetary unions with integrated funding markets: banks' access to market funding depends on existing portfolios of marketable collateral; in the Eurozone, these are mainly composed of sovereign bonds. This is an important, if yet underexplored structural change in the actors and trading strategies in sovereign bond markets with crucial implications for the conduct of central banking during a crisis. Collateral management is intimately linked to leverage and relies on mark-to-market risk management strategies. This sharpens the pro-cyclicality of sovereign bond markets, and in doing so, ties bank-funding conditions to the sovereign's funding conditions. Yet the institutional architecture of central banks is ill-suited to deliver bank stability under these conditions. Political and institutional factors constrain the central bank's ability to stabilize the most important market for collateral, the sovereign bond market. This worsens "two-way risks" between the counterparty (bank) and the collateral (sovereign bond), further deteriorating both bank and sovereign funding conditions, particularly under a limited degree of internationalization of collateral portfolios. For this reason, the ECB's outright monetary transactions (market-based) succeeded where successive rounds of long-term refinancing operations (bank-based) failed.

Nina Boy takes a step back from the immediate question of how collateral impacts the conduct of central banking. She instead unpacks the assumption that sovereign debt should be treated as a safe asset, an assumption that has guided regulatory initiatives such as Basel III. How did debt, and in particular government debt, itself become the most common form of collateral in the financial system? In other words, how did government debt become "safe"?

The safety of sovereign debt corresponds to the establishment of sovereign creditworthiness: from sovereign bonds being charged a significantly higher interest rate than commercial loans in the Middle Ages, to them circulating as "unsecured"- that is, no longer requiring additional security in the form of either collateral or a high interest rate, but trading merely on "full faith and credit." Corporate bonds, by contrast, when unsecured, have to compensate with a higher interest rate or, if secured, imply the pledge of specific assets as collateral, and the issuer "paying" for the extra safety by receiving a lower interest rate than on a comparable, unsecured bond. As such, sovereign safety has underwritten the rise of collateralbased finance, and plays a crucial role for both financial lubrication and financial stability. But the question receives additional interest with the "increased questioning of sovereign debt representing a genuine risk-free rate" (BlackRock 2011) following the sovereign debt crisis. 
Going beyond the standard assumption underpinning modern finance theory and standard economics that sovereign debt is safe, the chapter first offers an economic historian's account of the establishment of sovereign creditworthiness. In order to grasp a critical dimension of this process of accreditation, attention must be turned to the wider cultural context, in particular that from which the discipline of history has traditionally sought to distinguish itself: literary fiction. Drawing on influential studies in the field of the "new economic criticism," the chapter traces the role of fictional realism in making the financial fictions of fiat money and sovereign bonds creditworthy.

\section{Part 4: Where Next for Central Banking?}

Claudio Borio notes that the global financial crisis has shaken the foundations of the deceptively comfortable pre-crisis world of central banking (Chapter 12). Pre-crisis, the quintessential task of central banks was seen as quite straightforward: keep inflation within a tight range through control of a short-term interest rate, and everything else will take care of itself. Everything was simple, tidy, and cozy. Post-crisis, many certainties have gone. Price stability has proven no guarantee against major financial and macroeconomic instability. Central banks have found themselves reaching well beyond interest rate policy, aggressively deploying their balance sheet in a variety of "unconventional" monetary policies. As a result, the line between monetary and fiscal policy has become blurred precisely at a time when public sector debts are ballooning and sovereign risk is rising again. And many increasingly question the very ability of central banks to maintain inflation within acceptable ranges, notably to avoid deflation.

Central banks now face a threefold challenge, Borio argues: economic, intellectual, and institutional. Borio puts forward a compass to help central banks sail in these largely uncharted waters. First, the tight interdependence between monetary and financial stability will need to be fully recognized and policy frameworks adjusted accordingly. This, in turn, will require bolder steps to develop analytical frameworks in which monetary factors play a core role, not a peripheral one as hitherto - an intellectual rediscovery of the roots of monetary economics. Second, there should be a keener awareness of the global as opposed to the purely domestic dimensions of those tasks. The common view that keeping one's house in order is sufficient for global stability should be reconsidered. This calls for an intellectual shift that is analogous to the one that has already occurred in financial regulation and supervision, from a microprudential to a macroprudential perspective. Finally, the autonomy of central banks will need to be protected and strengthened.

The ballooning of central bank balance sheets after the 2007 crisis in core capitalist countries has attracted the critical attention of economists and financial media, notes Ismail Ertürk. Monetarist economic theory instinctively problematizes such an expansion of central bank balance sheets as an inflationary phenomenon. A Minskian perspective that questions the neutrality of money in neoclassical economics, on the other hand, justifies central bank activism as necessary to bring capitalism back to stability after inevitably destabilizing endogenous credit expansions. Regardless of these different theoretical framings, there clearly is a policy convergence in both liberal 
market economies and coordinated market economies, whereby central banks use unconventional monetary policies to generate growth and employment. In his chapter, Ertürk proposes an alternative framing of unconventional central bank policies after the 2007 crisis by shifting the focus to the role of central banks as holders of long positions on sovereign debt and non-tradable bank assets. In the process of injecting liquidity to the dysfunctional post-crisis banking system through quantitative easing programs, central banks have ended up investing in sovereign risk and bank credit risk with unintentional allocative and distributive consequences. This so-called central bank put is on a capitalism that hardly achieves positive growth rates in core capitalist countries. The risks of holding long positions on low-growth capitalism include unknowable exit costs to the economy and society in core capitalist countries.

Sheila Dow argues that the problem of insufficient collateral for the financial system is a product of weak economic conditions and financial instability, which has eroded confidence in the valuation of assets, and that this has been compounded by central bank independence (Chapter 13). In order to consider further the relationship between central banks and governments, it is necessary to go back to first principles and consider what society needs from central banks, Dow stresses. The role of the central bank is then explored as being to provide a stable financial environment as a basis for real economic activity. This involves the provision of a safe money asset; proactive regulation, monitoring, and supervision of (institutionally separated) retail banks which supply this asset, as well as the wider banking system; and lending to government as required, subject to maintaining the value of the currency. The evolution of this traditional role in relation to banks and government is analyzed in terms of collateral, emphasizing their interdependencies. As a result, it is argued that central banks should not be independent of government, but rather that the traditional, constructive, mutual relationships between central banks, retail banks, and government be restored.

Annelise Riles addresses a central challenge for international financial regulatory systems today: the management of the impact that global systemically important financial institutions (G-SIFIs) have on the global economy, given the interconnected and pluralistic nature of regulatory regimes. Her chapter focuses on the Financial Stability Board (FSB) and proposes a new research agenda for the FSB's emerging regulatory forms. In particular, it examines the regulatory architecture of the new governance $(\mathrm{NG})$, a variety of approaches that are supposed to be more reflexive, collaborative, and experimental than traditional forms of governance. A preliminary conclusion is that $\mathrm{NG}$ tools may be effective in resolving some kinds of problems in a pluralistic regulatory order, but they are unlikely to be suitable for all problems. As such, this chapter proposes that analyses of the precise conditions in which NG mechanisms may or may not be effective are necessary. It concludes with some recommendations for improving the NG model.

\section{References}

BlackRock. 2011. Introducing the BlackRock Sovereign Risk Index: A More Comprehensive View of Credit Quality. New York: BlackRock Investment Institute. 



$$
\text { Part } 1
$$

\section{BANK CAPITAL REGULATION}





\title{
Chapter 2
}

\section{CONSTRAINING DISGRETION IN BANK REGULATION}

\author{
Andrew G. Haldane
}

\section{Introduction}

Marking your own exams is a perilous pursuit. Stephen Levitt of Freakonomics fame looked at abnormalities in test scores in Chicago public schools when these tests were marked by the schools' own teachers (Jacob and Levitt 2003). He found systematic evidence of upgrading of scores in elementary schools by teachers marking, in effect, their own exams.

More recently, the LIBOR scandal has exposed many of the same self-regulatory problems. The incentives to shade their self-assessed LIBOR exam grades have proved to be too much, for too many, for too long. As we now know, systematic misreporting resulted. The self-regulatory model was again found wanting.

Yet there is one area of finance where self-regulation continues to stage a last standbank capital standards. Since the mid-1990s, banking regulators globally have allowed banks the discretion to use their own models to calculate capital needs. Most large banks today use these models to scale their regulatory capital. In doing so, they are, in essence, marking their own exams.

This self-regulatory shift was made with the best of intentions. Yet its consequences have been predictable. Self-assessment has created incentives to shade reported capital ratios. As elsewhere, a regulatory regime of constrained discretion has given way to one with too much unconstrained indiscretion.

This calls for regulatory repair. Without change, the current regulatory system risks suffering, like the Chicago teachers and the LIBOR fixers, from reputational damage. Fortunately, there are early signs that regulatory change is afoot to place tighter constraints on this (in)discretion.

\section{The Emergence of Self-Regulation}

To understand how we ended up here, it is useful to explore the historical contours of the regulatory debate. This is a history in roughly four chapters.

Chapter 1 covers the period prior to the agreement of the first Basel Accord in 1988. Until then, a patchwork of national regulatory frameworks for capital adequacy operated. 
Some countries set capital adequacy standards based on simple measures of bank equity to assets - a leverage ratio. Others, including in the USA, used risk-based standards with risk weights set by regulators for a small set of asset categories.

Chapter 2 begins with the introduction of the Basel Accord. This was a landmark agreement: the first-ever genuinely international banking accord, based around an 8 percent bank capital ratio, with internationally set risk weights applied to a small set of banks' assets. The accord was explicitly designed to lean against an international "race to the bottom" in capital-adequacy standards (Goodhart 2011). It also helped ensure a level international playing field.

Chapter 3 commences with the Market Risk Amendment to Basel I in 1996 and continues through to the Basel II agreement of 2004. These were a direct response to the perceived failings of Basel I. In particular, the lack of granularity in risk weights under Basel I was felt to have created arbitrage possibilities, with risk migrating to lower riskweighted asset categories.

Permitting the use of banks' own internal models to calculate risk weights provided for such granularity. It also aligned regulatory capital with banks' own economic capital calculations, thereby prospectively reducing arbitrage incentives. By setting internal model-based capital charges below those from simple standardized approaches, Basel II provided banks with strong incentives to upgrade their risk management technology.

The move from regulator-set to model-set capital charges had two significant side effects. First, it added materially to complexity. For a large, complex bank, the numbers of calculated risk weights rose from five to hundreds of thousands, perhaps millions. Second, the use of models moved decision-making on risk weights from regulators to banks. Once a model was admitted, the system was essentially selfregulatory.

The final chapter, Basel III, commences in 2010. Experience during the financial crisis demonstrated both that capital had been set too low and that it had been defined too broadly. Basel III raised the level, and narrowed the definition of bank capital. In those respects, it was a very significant improvement over its predecessors. At the same time, the complexity and self-regulatory aspects of Basel II remained in Basel III.

Each of these historical chapters was a logical response to the perceived problems of the day. Even with the benefit of hindsight, these steps seem like sensible ones. In particular, there appear to have been three key objectives behind the evolution of international bank regulation over the period.

- First, to level the international playing field and prevent a race to the bottom in capital adequacy standards, in particular under Basel I.

- Second, to align regulatory capital with risk by improving the risk sensitivity of capital standards, in particular under Basel II and III.

- And third, to reduce incentives to engage in regulatory arbitrage and create incentives to upgrade risk management, in particular under Basel II and III.

All of these responses were understandable and, in concept, laudable. The question is whether, with the benefit of hindsight, they have been successful. 


\section{Unfulfilled Ambitions}

\section{Leveling the playing field}

The rationale for the original Basel Accord was that it would effectively defuse an international race to the bottom by setting a common, internationally set capital standard. But the use of risk weights, in particular those based on internal models in calculating banks' capital ratios, provided an alternative avenue through which this race could be run. And empirical evidence suggests this race may have continued apace.

Figure 2.1 plots the average risk weight applied to the assets of 17 major international banks over the period 1993 to 2011, together with a trend line. The trend is steeply and strikingly downward sloped, falling on average by 2 percentage points each year. Banks' average risk weight (risk-weighted assets per unit of assets) has almost halved, falling from over 70 percent in 1993 to below 40 percent at the end of 2011 (see also Blundell-Wignall and Atkinson 2011).

There are three possible interpretations of this trend. One is that banks' assets, in aggregate, are around half as risky today as they were 20 years ago. A second is that banks are twice as good at managing these risks as they were 20 years ago. In the light of the crisis, which unearthed huge risks on banks' balance sheets accumulated over this period, neither proposition rings especially true.

To see why, consider the evolution of an alternative measure of risk-simple bank leverage. In the pre-crisis boom, bank leverage rose steadily to reach historically unprecedented levels. This signaled high and rising bank risk (Figure 2.2). Indeed, bank leverage and bank risk weights moved in opposite directions over this period, with a correlation coefficient of minus 0.6. While the risk traffic lights were flashing bright red for leverage, for risk weights they were signaling ever-deeper green.

Figure 2.1. Average risk weights ${ }^{(a)}$

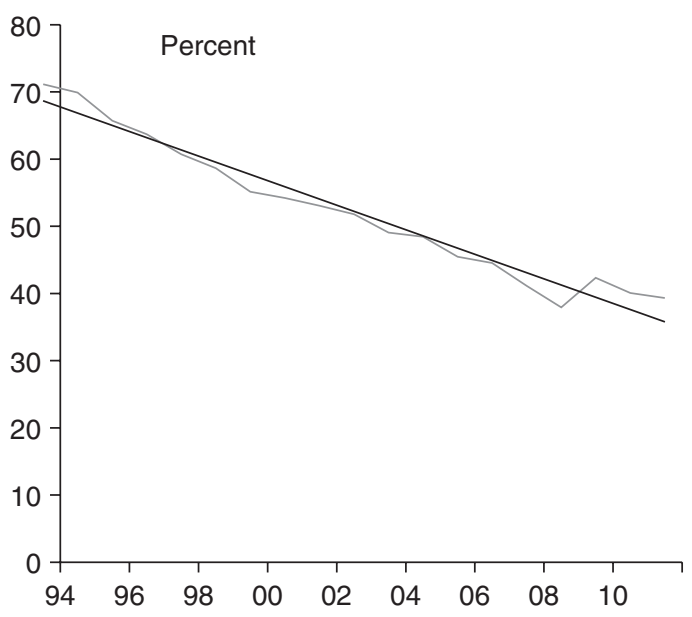

Source: Banker and bank calculations.

(a) Weighted average risk weights of Deutsche Bank, HSBC, BNP Paribas, Barclays, Citigroup, UBS, BAML, BONY, Commerzbank, ING, JPM, LBG, RBS, Santander, State Street, UniCredit, and Wells Fargo. Data are not available for the remaining G-SIBs. 
Figure 2.2. Average risk weights and leverage $\mathrm{e}^{(\mathrm{a})(\mathrm{b})}$

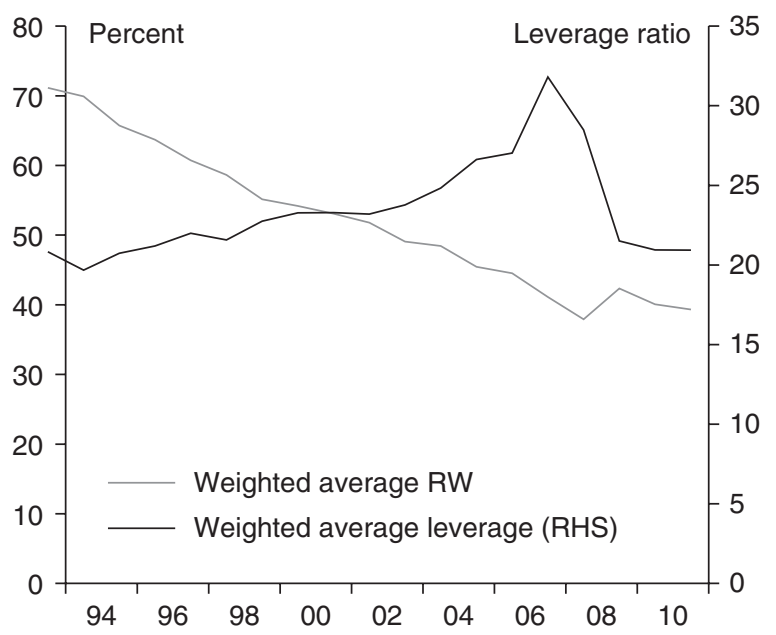

Source: The Banker and Bank calculations.

(a) Sample consists of Deutsche Bank, HSBC, BNP Paribas, Barclays, Citigroup, UBS, BAML, BONY, Commerzbank, ING, JPM, LBG, RBS, Santander, State Street, UniCredit, and Wells Fargo. Data are not available for the remaining G-SIBs.

(b) Leverage ratio is defined as total assets/Tier 1 capital.

The subsequent financial crisis has made clear which traffic light signal was at fault. ${ }^{1}$ The boom was leverage fuelled and so too has been the subsequent bust. At least at an aggregate level, bank risk weights appear to have borne, at best, a tenuous relationship with risk. At worst, they were a contrarian indicator.

That takes us to a third potential explanation for the downward trend in risk weights, one familiar from every other field of self-regulation - the system has been gamed or arbitraged (Blum 2008; Masera 2012). Under a self-assessed standard, banks may have both the incentive and the ability to shade downward risk weights, or to switch to lower risk-weighted asset categories, thereby boosting reported capital ratios. The aggregate evidence is consistent with this having occurred secularly and on a significant scale.

Firm-specific evidence is also consistent with this hypothesis. A survey by McKinsey in 2012 found that 65 percent of firms were engaged in "RWA optimization" of some form (Babel et al. 2012). And the recent US Senate investigation of the J. P. Morgan "whale" incident is the latest in a long line of identified misdemeanors sourced in model manipulation. In short, while one of the original aims of the Basel Accord was to prevent a race to the bottom, the move to risk-based capital adequacy standards may in fact have accelerated it.

What, then, of the second objective of the original Basel Accord-leveling the international playing field? From an economic perspective, a level playing field would imply that banks with equivalent portfolios should hold a broadly equivalent amount of capital. The most compelling test of this hypothesis comes from the hypothetical portfolio exercises (HPEs) recently conducted in the UK and internationally. These take 
a set of common portfolios and ask how much capital banks' internal models would set against them.

Three UK exercises have been undertaken, in 2007, 2009, and 2011, for a subset of banking assets: corporate exposures, sovereign exposures, andbanking exposures. Figure 2.3 demonstrates the range of variation in default probabilities for these three sets of asset across UK banks, while Figure 2.4 shows differences in risk weights across these portfolios in 2011, the most recent estimates.

The range of cross-bank variation is enormous. Default probabilities differ by factors of between five and ten. Risk weights differ by a factor of between three and five. There is no sign of this range having shrunk over time. The Basel III reforms will raise banks' capital standards by a factor of between three and four. These cross-bank differences would be sufficient to absorb fully those reforms.

Figure 2.3. Variability of default probability estimates $^{(a)(b)(c)(d)(e)}$

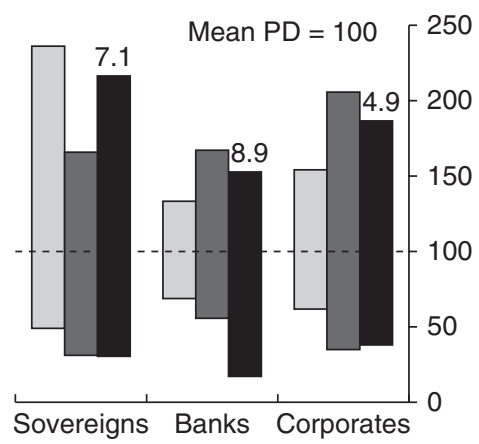

$\square$ PD 2007 口PD 2009 aD 2011
Figure 2.4. Risk-weight variability in $2011^{(\mathrm{a})(\mathrm{b})(\mathrm{c})(\mathrm{d})}$

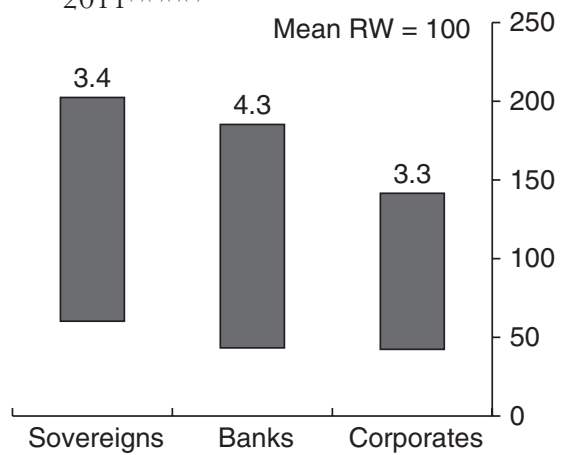

Source: FSA, and bank calculations.

Source: FSA, and bank calculations.

(a) Based on the results of the FSA's hypothetical portfolio exercises for 2007, 2009, and 2011.

(b) Results are based on portfolios comprising assets rated by all respondents in the sample (co-rated).

(c) Portfolios differ between the exercises in 2007, 2009, and 2011. Results have been normalized by the mean.

(d) Sample sizes differ: six to twelve in 2007 and seven to thirteen in 2009, depending on portfolio, and eight in 2011.

(e) The bars show the maximum/minimum ranges. The values on top of the 2011 results indicate the maximum/minimum ratio.
Based in the results of the FSA's hypothetical portfolio exercise for 2011.

(b) Results are based on portfolios comprising assets rated by all respondents in the sample (co-rated).

(c) The sample includes six banks.

(d) The bars show the maximum/minimum ranges. The values on top of the 2011 results indicate the maximum/minimum ratio.

The Basel Committee has recently undertaken its own HPE on a wider range of international banks, focusing on the trading book (Basel Committee of Bank Supervisors [BCBS] 2013). Figure 2.5 summarizes the range of variability in capital requirements for certain trading book metrics $(\mathrm{VaR}$, stressed $\mathrm{VaR}[\mathrm{sVaR}]$, and the incremental risk charge [IRC]), while Figure 2.6 focuses on the IRC charges for a set of particularly complex models. ${ }^{2}$ 
Figure 2.5. Risk weight variability in the trading book ${ }^{(\mathrm{a})(\mathrm{b})(\mathrm{c})(\mathrm{d})}$

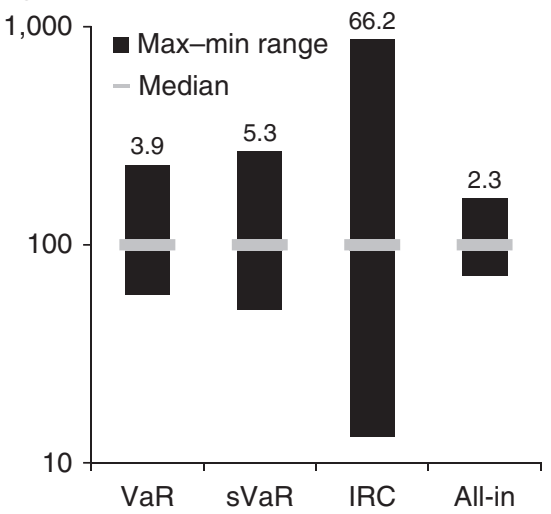

Figure 2.6. Risk weight variability in the IRC model ${ }^{(\mathrm{a})(\mathrm{b})(\mathrm{c})(\mathrm{d})}$

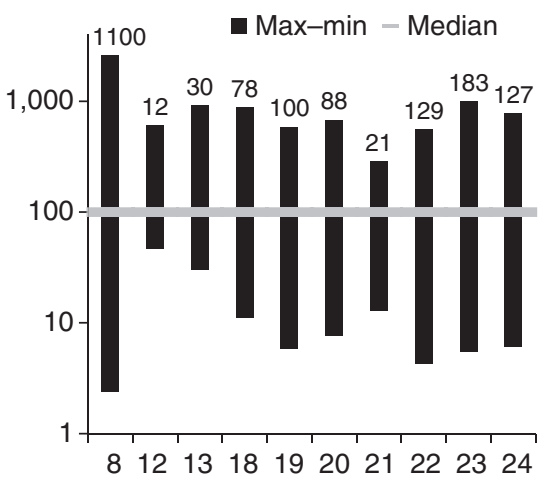

Source: BCBS.

(a) From the BCBS hypothetical portfolio exercise for the trading book.

(b) Sample consists of 15 banks.

(c) Values have been normalized by the median. For each model, the ranges represent the simple average of the normalized minima and maxima for all portfolios the model was applied to. For the all-in portfolio, the supervisory multiplier was held constant.

(d) Numbers on bars indicate maximum/ minimum ratios.
Source: BCBS.

(a) From the BCBS hypothetical portfolio exercise for the trading book.

(b) Sample consists of 15 banks.

(c) Values have been normalized by the median.

(d) Numbers on bars indicate maximum/minimum ratios.

The variation is again enormous. Calculated trading book risk weights differ by factors of three to five, even for simple metrics such as VaR. For some of the more complex metrics, such as IRG, the range of variation needs to be shown on a log scale. For some portfolios, it runs to three figures. For one, it runs to four, with one bank's model suggesting US\$1 of capital, and another's over US\$1000 for an identical exposure.

These inconsistencies are likely to be an understatement of the true problem. As they cover only a subset of the banks using internal models, these exercises may significantly underestimate variability across the bank population. The portfolios covered by existing HPE exercises have also tended to be relatively simple. More complex portfolios would probably result in wider cross-bank variability. The Basel Committee is currently undertaking an equivalent exercise for banking book assets.

There is a delicate line to tread between useful diversity in model outputs on the one hand and useless inconsistency on the other. It is clear we are currently on the wrong side of this line. If a regulatory regime can generate capital ratios of 5 percent, 10 percent, and 20 percent for three identical banks, it is not a robust basis for assessing capital adequacy. In short, the objectives of the original Basel Accord are at risk. Complex selfregulation has added speed to the race to the bottom and an incline to the international playing field. 


\section{Complexity and risk sensitivity}

One of the conceptual lynchpins of the model-based, self-regulatory approach was the desire for risk sensitivity. As a matter of principle, it is difficult to question risk-based regulation. The practical question is whether that has been achieved.

On the face of it, the very act of risk-weighting assets would appear to guarantee a greater degree of risk sensitivity than, say, using a risk-unweighted leverage ratio. Yet this intuition is wrong on two counts. It is wrong empirically because it ignores the risks that come from modeling. And it is wrong theoretically because risk across banks' whole portfolio may bear little relationship to the aggregated risk of each of its parts.

Take model risk: this pollutes the signals from a risk-based capital ratio. In work at the bank, we have explored this trade-off between model risk and risk sensitivity. If model risk is sufficiently large, a risk-based capital ratio may in fact perform worse in predicting bank default than a leverage ratio. That is because the noise associated with imprecise risk weights can drown out the signal. A leverage ratio, unpolluted by model risk, may provide clearer risk signals.

While slightly counterintuitive, this result is well understood in many fields outside of finance (Gigerenzer 2007). It is why complex, risk-weighted algorithms have been found to perform poorly out-of-sample when predicting everything from sports events to medical diagnoses, from shopping habits to portfolio choices (Haldane and Madouros 2012). Overfitting the past makes for fragile predictions about the future. Unweighted measures, without noise pollution, have often been shown to do better.

Whether they do so in bank regulation is, ultimately, an empirical question. The noise around estimated risk weights cannot be observed directly, but empirical evidence is illustrative. For example, if estimated risk weights can differ across banks by factors ranging from three to a thousand, this suggests a high, sometimes deafening, amount of model noise. Historical errors in estimated risk weights are also illuminating. For example, trading book risk weights during the crisis were found to be miscalibrated by factors of up to 50 .

A common driver behind these fragilities may be the shortness of the samples used for model estimation. It is well known that small sample problems are especially acute when the underlying distribution of outcomes is tail heavy, as with financial time series. The Basel regime imposes constraints on so-called look-back periods. For example, the minimum sample period for $\mathrm{VaR}$ models in the trading book is one year, though most models in practice use between one and two years. For the banking book, the minimum look-back period is between five and seven years, with actual samples lying between five and twenty years.

From a robustness perspective, samples this short are, quite literally, a recipe for disaster. At most, they would encompass one cycle or extreme event. Some would fail to cover even that. This would leave the tail of the risk distribution empirically underfitted and the body overfitted. In other words, estimated risk weights are very likely to be least reliable when regulators are most reliant on them. By construction, when it matters most, risk weights are likely to be of long noise and short signal. 
Theoretical objections to risk weighting are no less deep-seated. One key issue is aggregation (Masera 2012). Regulation has focused on ever-more granular and precise risk estimates for individual assets. Fewer attempts have been made to consider correlations across broad asset classes, other than in parts of the trading book. Yet it is these correlations that fundamentally determine risk across a banking portfolio. Indeed, this is perhaps the key lesson finance theory has taught us over the past half-century.

There is a cruel irony here. One of the great pre-crisis mistakes was to look at risk in the financial system institution by institution, atom by atom. Doing so resulted in regulators missing the systemic crisis of a lifetime. Yet, an asset-by-asset, atom-by-atom approach to risk measurement still lies at the heart of the post-crisis regulatory framework.

A second conceptual problem with risk weighting is that it takes no account of the collective consequences of banks' asset allocation decisions. For example, no account is taken of the externalities, positive or negative, that banks' portfolio choices may give rise to. This may lead to risk weights being miscalibrated from the perspective of the financial system as a whole and the wider economy.

As an example, take lending to the real economy-for example, to finance infrastructure, small and medium-sized enterprises (SMEs), or trade. These asset choices are likely to be positive for medium-term growth and, hence, indirectly, for credit risk in the financial system. In other words, this portfolio allocation is likely to deliver positive externalities for the wider economy.

By contrast, lending within the financial system may have the opposite effect. It raises interconnectivity in the system, thereby amplifying systemic risk (Haldane 2009). In other words, this portfolio choice may drive negative externalities for the financial system and wider economy.

In an ideal world, these risk externalities would be taken into account in the setting of risk weights - for example, by raising risk weights on intra-financial system lending and lowering it on growth-positive lending. In practice, there is scant evidence of this having happened. Indeed, if anything, the current risk-weighting system appears to generate the opposite set of incentives.

Figure 2.7 looks at the average risk weight assigned by UK banks to different counterparties, some in the financial system, and others in the wider economy. The differences are stark. Mortgage risk weights are double those on lending to financial institutions. For large companies, risk weights are treble those on lending within the financial system. For SMEs, they are quadruple. Those are probably not the risk weights a benevolent dictator, charged with supporting the economy and armed with a $\mathrm{PhD}$ in welfare economics, would choose.

The acid test of whether these empirical and theoretical concerns about risk weighting have merit comes from assessing the evidence. Do risk weights help in signaling bank failure? There have been a number of recent studies comparing the predictive performance of Basel risk-based capital ratios and simple leverage ratios for bank failure. The results are both striking and surprising.

Studies by the IMF (2009), Demirguc-Kunt et al. (2010), Haldane and Madouros (2012), Mayes and Stremmel (2012), Brealey et al. (2011), Berger and Bouwman (2013), Blundell-Wignall and Roulet (2013), and Hogan et al. (2013) perform a horserace between 
Figure 2.7. Average risk weights for major UK banks by counterparty ${ }^{(a)(b)}$

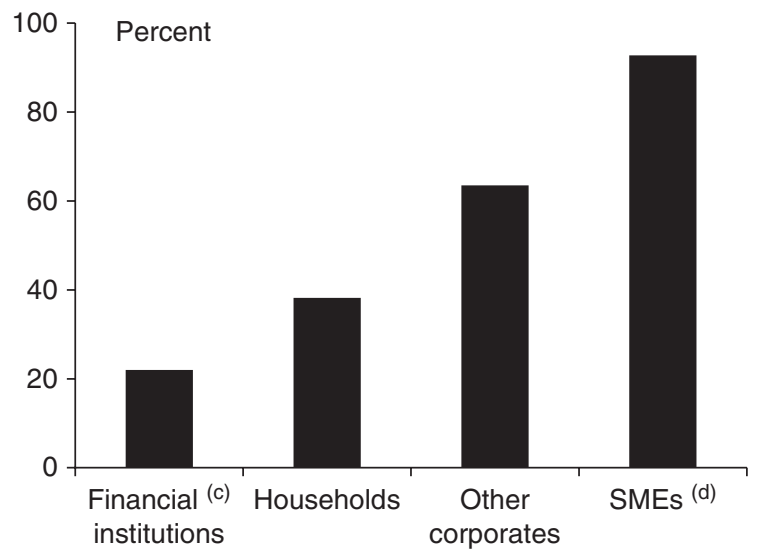

Sources: Bank of England, FSA regulatory returns and Bank calculations.

(a) Based on June 2011 data for Barclays, HSBC, LBG, Nationwide, RBS, and Santander UK.

(b) Cover credit and counterparty credit exposures.

(c) Financial firms other than regulated banks and investment firms are included within 'Other corporates'.

(d) Only includes data on SME credit exposures from internal ratings-based portfolios.

different bank solvency measures, using a variety of techniques, samples, and controls. Despite these differences, the conclusion they draw is broadly consistent: leverage ratios perform as well, and in most cases better than risk-weighted alternatives in predicting bank failure.

These results appear to be stronger for large banks, often using internal models, than for smaller banks typically using standardized approaches (Haldane and Madouros 2012). This is not altogether surprising given that model risk is largest among banks making greatest use of models and with the largest portfolios. It is also the case that no measure of bank capital adequacy, by itself, provides a full-proof forecast of impending bank failure: the predictive power of all solvency metrics, leverage or otherwise, is fairly low.

Nonetheless, these results send a sobering message. Even on risk-sensitivity grounds, risk-based capital measures may often be trumped by risk-insensitive alternatives. The noise in risk weights may be drowning out the signal. Granularity may not improve risksensitivity; it could even worsen it by amplifying model risk. And given that uncertainty, simpler metrics may often provide a more robust signal of solvency.

\section{Risk shifting and robustness}

A third argument used to justify risk-based frameworks is that they help defuse incentives to engage in "risk shifting" or other types of regulatory arbitrage (Kahane 1977; Kim and Santomero 1988). Risk shifting refers to incentives to shift portfolios toward higherrisk, higher-return assets. These incentives are likely to be strongest when risk is not well aligned with return - for example, under an equally weighted leverage ratio. Indeed, this powerful logic justified moving to risk-based capital standards in the first place. 
Historically, there have certainly been episodes when risk shifting appears to have been important. For example, the movement by banks into Latin American debt in the 1980s; the loading-up on zero-risk-weighted OECD sovereign debt in the 1990s; and the extension of zero-weighted 364-day lines of credit in the 2000s. Yet, in these cases, the problems seem to have been generic: miscalibration of risk weights.

A few studies have looked at the evidence on risk shifting more systematically. For example, Furlong (1988) looked at the behavior of around one hundred US bank-holding companies after the introduction of the leverage ratio in 1981. While banks' average riskiness increased, there was no difference in behavior between regulatory-constrained and unconstrained banks. This suggests risk shifting was not too potent a factor. Sheldon (1996) reaches the same conclusion when considering the move by international banks to Basel I.

One possible reason why risk shifting may have been difficult to detect is that riskbased capital standards coincided with the shift to a much more complex regulatory framework. Complexity has an important impact on risk-shifting incentives - and not in the ways in which some have suggested. For example, some have argued that simpler rules are easier to arbitrage. The evidence suggests the exact opposite.

Take the tax system: simple linear tax schedules are typically found to be more robust to problems of tax arbitrage than complex rules (Hindriks, Keen, and Muthoo 1999). Why? Because complexity increases the number of loopholes through which the tax avoider can slip. Indeed, evidence suggests that complexity of the tax system may be the single largest determinant of tax avoidance across countries (Richardson 2006).

The same logic carries across to financial regulation. Regulatory complexity creates wormholes. At a macro level, cross-country studies suggest that regulatory complexity, in particular the use of internal models, appears to have had an important bearing on bank failure (Čihák et al. 2012). At a micro level, the parts of the regulatory framework that have been most prone to arbitrage are those where complexity and opacity has been greatest - for example, the trading book.

Incentives will always exist to shift risk to where it is cheapest. No tax or regulatory system can fully avoid those incentives. However, some regimes may be better at constraining those incentives than others. The current mix of complexity and selfregulation may provide too few constraints. Complexity has meant that avoidance and arbitrage can flourish behind a curtain of opacity. And self-regulation has meant that even as one wormhole is closed, others can be created in their place.

Taken together, this evidence does not paint an especially encouraging picture. Many of the intended aims and purported advantages of a complex, risk-based regulatory approach may not have materialized in practice. Worse, some of the assets of the riskbased approach may even have become liabilities.

\section{Unintended Consequences}

So much for the intended consequences of the shift to self-regulatory standards. What of the unintended consequences? Three are worth noting. 


\section{Cost of compliance}

First, regulatory complexity comes at a cost - the cost of compliance. These costs are borne, in the first instance, by the regulator and regulated firms. The costs of moving to Basel II and the emergence of internal models are difficult to calculate. But external estimates put it at tens of billions of dollars.

For European banks, the costs of implementing Basel III are estimated at over seventy thousand jobs per year (Harle et al. 2010). For US banks, the costs of Dodd-Frank are also estimated to be tens of thousands of jobs. The costs of Solvency II, the new capital standard for European insurance companies, have been put at tens of billions of euros - and it is unclear even whether this standard will be implemented. At the same time, regulators have continued to bulk up their own resources in the face of a rising tide of regulatory rules.

Ultimately, these costs are borne not by regulators or regulated firms, but by general taxpayers and bank customers. These come in the form of higher taxes, lower savings rates, and higher lending rates. If system stability can be achieved in simpler ways, these are deadweight costs to society.

\section{The unlevel playing field}

A second unintended consequence of the move to a model-based regulatory framework is that it has tended to work in quasi-discriminatory ways. In particular, it has tended to discriminate both between small and large banks and between new entrants and existing incumbents in the amounts of capital they are required to hold even against identical exposures.

The reason for this is that small or new entrant banks will generally adhere to Basel I or to simple standardized approaches for measuring risk. In general, they will have neither the data nor the technology to support internal model approaches. But simpler, standardized approaches tend to require much higher amounts of capital than internal model approaches. Indeed, this was a design feature of Basel II.

Figure 2.8 demonstrates those differences among the major UK banks for a selection of portfolios. For an identical corporate exposure, a small bank on Basel I or a standardized Basel II approach holds, on average, twice as much capital as a large bank using models. For retail mortgages, these differences are larger still. Some internal model-based banks attach a risk weight to mortgages of as little as 5 percent. A standardized-approach bank would need to hold at least nine times that amount in capital.

These design features of Basel II were intended to provide incentives to banks to move to internal models and thereby improve their risk management. The link from the use of models to improved risk management is at best tenuous. But more fundamentally, this design feature may also have potentially perverse consequences for systemic risk and competition.

Under the existing approach, capital charges will tend to be highest for those small, simple banks posing least risk to the financial system as a whole. The systemic risk tax is regressive. This regressivity will tend to worsen the too-big-to-fail problem, by providing regulatory incentives for the large to become larger still. The capital surcharges recently agreed for systemically importantinstitutions, while helpful, are unlikely to retilt this balance. 
Figure 2.8. Average risk weights for major UK banks under different approaches ${ }^{(a)}$

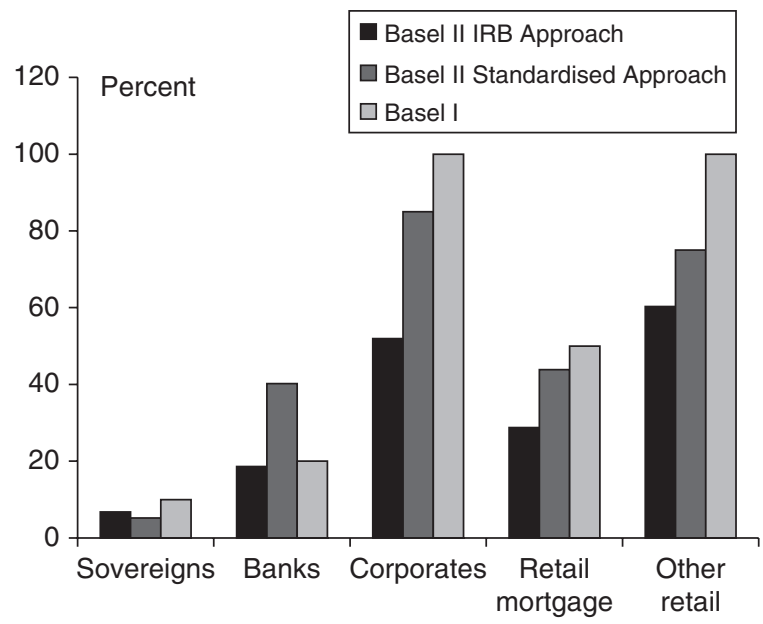

Source: Pillar 3 disclosures, bank calculations.

(a) As of end-2011. Weighted average.

Capital regulation may also have acted as a barrier to banking entry, raising the bar for new entrants. Neither outcome (higher risk and lower competition) is desirable from a societal perspective.

\section{Transparency and market discipline}

A final unintended consequence is lack of transparency. A large bank may have literally thousands of models, hundreds of thousands of outputs, and several million inputs. The height of this information mountain makes scrutiny and aggregation of regulatory capital calculations near impossible for either investors or regulators.

The combination of complexity and manipulation has led to a loss of faith by investors in model outputs, and in particular, risk weights over the past few years. Surveys of investors suggest a fairly deep-seated skepticism about risk weights, with only a small fraction believing them trustworthy (Figure 2.9). From a low base, investor faith in these risk weights has continued to fall fast (Figure 2.10).

These concerns appear to be reflected in the pricing of bank risk. Bank investors appear to have moved toward using simpler metrics, such as leverage ratios, when assessing capital adequacy. There is a positive correlation between banks' leverage ratios and their market price-to-book ratios (Hoenig 2013). No such correlation exists for banks' regulatory capital ratios. Investors seem to have begun pricing the solvency risk they best understand.

The lack of transparency about and investor trust in risk weights has important implications. For regulators, a lack of transparency can damage the power of market discipline in constraining risk taking - the so-called pillar 3 of Basel. Or, put differently, the complexity of pillar 1 of the Basel Tower (regulatory rules) risks emasculating pillar 3 (market discipline). Pillar 1 has become Popeye's forearm, Pillar 3 his bicep. ${ }^{3}$ 
Figure 2.9 Survey responses to "How Figure 2.10. Survey responses to "Has your much do you trust risk weights?”(a)

confidence in risk-weighted assets gone up or down?"(a)
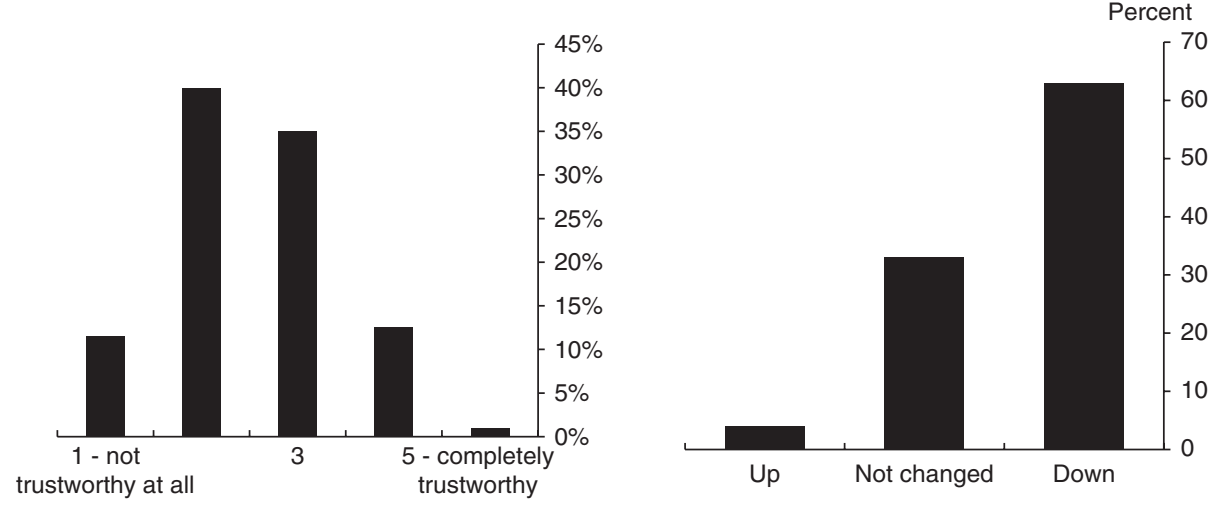

Source: Barclays Capital.

Source: Barclays Capital.

(a) Based on survey responses of over one (a) Based on survey responses of over one hundred hundred and thirty investors carried out in $\mathrm{H} 1$ 2012 of perceptions over the previous year. and thirty investors carried out in H1 2012 of perceptions over the previous year.

For investors, uncertainty about banks' true capital adequacy is priced. Where there is uncertainty, they will factor a premium into banks' cost of capital. That may be one of the reasons why many of the world's largest banks have continued to trade at a discount to their equity book value. Until the fog around banks' capital adequacy is reduced, including regulatory-induced fog, banks' cost of capital may remain high.

\section{Where Next?}

Taken together, it is difficult to escape the conclusion that the current regulatory system, however well intentioned, needs root-and-branch repair. The good news is that regulators internationally are increasingly coming to recognize that fact and have slowly begun the process of repair. In the past year, the Basel Committee has begun work to improve the "simplicity and comparability" of the regulatory framework. And earlier this year, the G20 Finance Ministers and Central Bank Governors committed the regulatory authorities to improve comparability of regulatory standards.

The practical question is what might be done to improve the credibility of the framework. In the spirit of moving forward the debate, some possible practical ingredients follow.

\section{Greater transparency}

One simple way of alleviating some of the uncertainty around the existing regulatory framework would be through improved transparency, in particular around models and risk weights. Some encouraging progress has been made on this front recently. In 2012, the Enhanced Disclosure Task Force (EDTF) of the Financial Stability Board produced 
a set of recommendations for improved bank transparency. This included greater disclosure around the models used to calculate risk weights.

At present, banks are at various stages of progress in implementing these EDTF recommendations. For example, a number of UK banks made good progress toward compliance in their end-2012 accounts. A firm future commitment by global banks to meet the EDTF recommendations would be a material step in the direction of improving transparency about regulatory capital ratios.

What the EDTF recommendations, by themselves, cannot achieve is an assurance of prudence in risk weights. This would require disclosure of alternative benchmarks for capital adequacy. For example, last year, the Swiss National Bank requested that Swiss banks publish standardized measures of credit risk as a benchmark alongside model-based measures. This would provide information on how prudent different banks were being in their model-based estimates. This, too, might be useful if thought through globally.

A more valuable set of disclosures still would come from conducting HPE on a systematic and comprehensive basis internationally-systematic in the coverage of different assets, comprehensive in the coverage of institutions. Making the results of those exercises available to bank supervisors would enable actions to be targeted at banks deviating materially from the pack. Going one step further, making those HPE results available to investors would enable them better to price (im)prudence.

Any or all of these disclosure initiatives would help reduce uncertainty. At the same time, disclosure can only ever be a partial solution. For example, by itself, it can do nothing to streamline regulatory complexities. In some instances, disclosure could even accelerate the race to the bottom - for example, if naming resulted not in shaming, but cloning.

\section{Imposing floors}

A second, more intrusive regulatory intervention would be to place greater regulatory constraints on banks' internal models. Tightening up the process around supervisory model approval might be one element of that. One practical step would be to impose much longer look-back periods than the current minima. Another would be to require an extended period of out-of-sample testing prior to model approval.

A third would be imposing direct restrictions on models - for example, by introducing floors on risk weights. Prompted by concerns about imprudently low risk weights, a number of regulators internationally have imposed floors in the past year - for example, in the UK, Hong Kong, Sweden, Norway, and Switzerland. In the USA, the Collins Amendment to the Dodd-Frank Act requires banks using internal models to meet a 100 percent floor based on a simple, standardized approach.

The imposition of floors can usefully help cut off the tail of firms, or portfolios, where low risk weights are being set. In that way, it can help prevent capital falling to imprudently low levels. But setting floors also poses some difficult calibration questions. At what level, and level of granularity, should floors be set? And based on what benchmark?

Answers to those questions can fundamentally reshape incentives. For example, if a floor is set at 100 percent of the standardized approach, this will effectively remove incentives to move to models in the first place. Anything short of a 100 percent floor, 
while improving prudence, would not curtail complexity and inconsistency in capitaladequacy standards.

\section{Prioritizing leverage ratios}

One more radical way of doing so would be to place a greater emphasis on measures that rely neither on models nor on risk weights - for example, through a simple leverage ratio. Basel III made significant headway in this regard. Once implemented, it will introduce for the first time an internationally agreed 3 percent leverage ratio as a backstop to riskbased capital measures.

The question is whether this formulation goes sufficiently far in tackling problems of consistency, incentives, and uncertainty affecting risk-based standards. Is 3 percent inadequate? And, relatedly, should the backstop instead be a front stop? A widening array of officials and academics have recently opined on both questions, often answering yes to both (Admati and Hellwig 2013; Systemic Risk Council 2012; Johnson 2013; Haldane 2012; Hoenig 2013; Fisher 2013; Norton 2013; King 2013; Stein 2013; Brown and Vitter 2013).

The recent legislative proposal by US senators Sherrod Brown and David Vitter is one of the most radical proposals to date. It advocates a tiered set of leverage ratio standards, rising to 15 percent for banks with assets in excess of US $\$ 500$ billion. Riskbased standards would be jettisoned entirely. From a simplicity and robustness perspective, it has attractions.

At the same time, the Brown-Vitter proposals clearly raise a host of practical questions. They are sufficiently far north of existing capital standards that they are perhaps at best seen as a (possibly distant) long-term resting place, not a practical nearterm objective. There is also a question of whether removing risk-based standards is necessary or desirable. Placing leverage and risk-based standards on a more equal footing might give us the best of both worlds, with them acting jointly as regulatory bookends.

Whatever the merits of particular proposals, it is entirely right that the official sector should continuously assess whether the financial system has adequate capital insurance to deal with too-big-to-fail problems. The emerging consensus, within academia, officialdom, and among market participants, is that it has not. Despite enormous progress in developing policy proposals, too-big-to-fail is an itch that remains unscratched.

Were this debate to conclude that greater capital insurance was necessary, this would pose challenges to the world's largest banks - but also opportunities. A more prudent capital rule could, over time, give regulators greater assurance. Too-big-to-fail could, over time, be removed from our lexicon. Overcomplex regulation could, over time, be streamlined from our legislatures. Supervisors and compliance officers could, over time, be re-employed as brain surgeons. And banks, over time, could be left to run themselves, albeit within predefined constraints. This is a deal a foresighted CEO, or indeed official, might wish to strike.

\section{Conclusion}

Over the course of the past 20 years, banking regulation has edged in a self-regulatory direction for understandable, but self-defeating reasons. The regulatory regime has tilted 
from constrained discretion to unconstrained indiscretion. It will be a long journey home, but that journey has started. Making greater use of simple, prudent regulatory metrics could restore faith, hope, and clarity to the financial system to the benefit of banks, investors, and regulators alike.

\section{Notes}

1 Market-based measures of bank riskiness, such as CDS spreads or credit ratings, are also consistent with this interpretation. If anything, these suggest the panel of banks is as risky or riskier today than 20 years ago.

2 The European Banking Authority (EBA) has also looked at the degree of consistency of European banks' risk weights, though not using an HPE methodology. It too found large crossbank discrepancies.

3 With thanks to Jason Kravitt.

\section{References}

Admati, A., and M. Hellwig. 2013. The Bankers'New Clothes: What's Wrong with Banking and What to Do about It. Princeton, NJ: Princeton University Press.

Aikman, D., P. Deb, F. Farag, V. Madouros, T. Neumann, V. Saporta, and K. Wagman. (Forthcoming). "Has the Quest for Risk Sensitive Capital Requirements Achieved Its Aims?"

Babel, B., D. Gius, A. Gräwert, E. Lüders, A. Natale, B. Nilsson, and S. Schneider. 2012. "Capital Management: Banking's New Imperative.” McKinsey Working Papers on Risk, no. 38.

Basel Committee on Banking Supervision. 2013. Regulatory Consistency Assessment Programme: Analysis of Risk-Weighted Assets for Market Risk. Basel: Bank for International Settlements. Online: http:// www.bis.org/publ/bcbs240.pdf (accessed August 8, 2014).

Berger, A., and C. Bouwman. 2013 (forthcoming). "How Does Capital Affect Bank Performance during Financial Crises?" Fournal of Financial Economics.

Blum, J. 2008. "Why Basel II May Need a Leverage Ratio Restriction." Fournal of Banking and Finance 32 (8): 1699-1707.

Blundell-Wignall, A., and P. Atkinson. 2011. "Global SIFIs, Derivatives and Financial Stability." OECD fournal: Financial Market Trends 2011 (1): 167-200.

Blundell-Wignall, A., and C. Roulet. 2013. "Business Models of Banks, Leverage and the Distanceto-Default." OECD Fournal: Financial Market Trends 2012 (2): 7-34.

Brealey, R., I. Cooper, and E. Kaplanis. 2011. "International Propagation of the Credit Crisis: Lessons for Bank Regulation." Fournal of Applied Corporate Finance 24 (4): 36-45.

Brown, S., and D. Vitter. "Ending Too Big to Fail: Terminating Bailouts for Taxpayer Fairness Act." US Senate bill summary. Online: http://www.brown.senate.gov/download/tbtf-billsummary (accessed August 8, 2014).

Čihák, M., A. Demirguc-Kunt, M. S. Martinez Peria, and A. Mohseni-Cherghlou. 2012. "Bank Regulation and Supervision around the World: A Crisis Update." World Bank Policy Research Working Paper Series, no. 6286.

Demirguc-Kunt, A., E. Detragiache, and O. Merrouche. 2010. "Bank Capital: Lessons from the Financial Crisis." Policy Research Working Paper Series, no. 5473.

Fisher, R. 2013. "Ending 'Too Big to Fail': A Proposal for Reform before It's Too Late.” Remarks before the Committee for the Republic, Washington, DC. Online: http://www.dallasfed.org/ news/speeches/fisher/2013/fs130116.cfm (accessed August 8, 2014).

Furlong, F. 1988. "Changes in Bank Risk-Taking." Federal Reserve Bank of San Francisco Economic Review, Spring: 45-56.

Gigerenzer, G. 2007. Gut Feelings: The Intelligence of the Unconscious. New York: Penguin/Allen Lane. 
Goodhart, C. 2011. The Basel Committee on Banking Supervision: A History of the Early Years, 1974-1997. Cambridge: Cambridge University Press.

Haldane, A. 2009. "Rethinking the Financial Network." Speech delivered at the Financial Student Association, Amsterdam.

2012. "On Being the Right Size." Speech delivered at the Institute of Economic Affairs' 22nd Annual Series, 2012 Beesley Lectures, London.

Haldane, A., and V. Madouros. 2012. "The Dog and the Frisbee." Speech given at the Federal Reserve Bank of Kansas City's 36th economic policy symposium, "The Changing Policy Landscape," Jackson Hole, WY.

Härle et al. 2010. "Basel III and European Banking: Its Impact, How Banks Might Respond, and the Challenges of Implementation." McKinsey Working Papers on Risk, no. 26.

Hindriks, J., M. Keen, and A. Muthoo. 1999. "Corruption, Extortion and Evasion." fournal of Public Economics 74: 395-430.

Hoenig, T. 2013. "Basel III Capital: A Well-Intended Illusion.” Speech delivered to the International Association of Deposit Insurers 2013 Research Conference, Basel.

Hogan, T., N. Meredith, and C. Pan. 2013. "Evaluating Risk-Based Capital Regulation.” Mercatus Center Working Paper Series, no. 13-02.

International Monetary Fund. 2009. "Global Financial Stability Report." Chapter 3. Online: http:// www.imf.org/external/pubs/ft/gfsr/2009/01/pdf/chap3.pdf (accessed August 8, 2014).

Jacob, B., and S. Levitt. 2003. "Rotten Apples: An Investigation of the Prevalence and Predictors of Teacher Cheating." Quarterly Fournal of Economics 118: 843-78.

Johnson, S. 2013. "Higher Bank Equity Is in the Public Interest." Online: http://www.bloomberg. com/news/2013-03-03/why-higher-bank-equity-is-in-the-public-interest.html (accessed August 8, 2014).

Kahane, Y. 1977. "Capital Adequacy and the Regulation of Financial Intermediaries." fournal of Banking and Finance 1 (2): 207-18.

Kim, D., and A. Santomero. 1988. "Risk in Banking and Capital Regulation." Fournal of Finance 43 (5): 1219-33.

King, M. 2013. Evidence given before the Parliamentary Commission on Banking Standards. UK House of Commons, March 6, 2013. Online: http://www.publications.parliament.uk/pa/ jt201213/jtselect/jtpcbs/c606-xl/c60601.pdf (accessed August 8, 2014).

Masera, R. 2012. "Bank Capital Standards: A Critical Review." LSE Financial Markets Group Paper Series, Special Paper no. 215.

Mayes, D., and H. Stremmel. 2012. "The Effectiveness of Capital Adequacy Measures in Predicting Bank Distress." Paper presented at the 2013 Financial Markets and Corporate Governance Conference.

Norton, J. 2013. "A More Prominent Role for the Leverage Ratio in the Capital Framework." Remarks delivered to the Florida Bankers Association, Orlando, February 6.

Richardson, G. 2006. "Determinants of Tax Evasion: A Cross-Country Investigation." fournal of International Accounting, Auditing and Taxation 15: 150-169.

Sheldon, G. 1996. "Capital Adequacy Rules and the Risk-Seeking Behaviour of Banks: A FirmLevel Analysis." Swiss Fournal of Economics and Statistics 132: 709-34.

Stein,J. 2013. "Regulating Large Financial Institutions." Remarks delivered at the IMF Conference, "Rethinking Macro Policy II," Washington, DC. Online: http://www.federalreserve.gov/ newsevents/speech/stein20130417a.pdf (accessed August 8, 2014).

Systemic Risk Council (2012), "Comment Letter re: Regulatory Capital Rules," http://www. systemicriskcouncil.org/2012/10/systemic-risk-council-letter-on-regulatory-capital-rules/

US Senate Permanent Subcommittee on Investigations, (2013), "JP Morgan Chase Whale Trades: A Case History of Derivatives Risks and Abuses", Vol. 1 (2013) http://www.gpo.gov/fdsys/ pkg/CHRG-113shrg80222/pdf/CHRG-113shrg80222.pdf, Vol. 2 (2013) http://www.gpo. gov/fdsys/pkg/CHRG-113shrg85162/pdf/CHRG-113shrg85162.pdf 



\title{
Chapter 3
}

\section{FALLACIES AND IRRELEVANT FACTS \\ IN THE DISGUSSION ON GAPITAL REGULATION}

\author{
Anat R. Admati, Peter M. DeMarzo, \\ Martin F. Hellwig, and Paul Pfleiderer ${ }^{1}$
}

\section{Introduction}

As the financial crisis of 2007-2008 has compellingly shown, highly leveraged financial institutions create negative externalities. When a bank is highly leveraged and has little equity to absorb losses, even a small decrease in asset value can lead to distress and potential insolvency. In a deeply interconnected financial system, this can cause the system to freeze, ultimately leading to severe repercussions for the rest of the economy. ${ }^{2}$ To minimize social damage, governments may feel compelled to spend large amounts on bailouts and recovery efforts. Even when insolvency is not an immediate problem, following a small decrease in asset values, highly leveraged banks may be compelled to sell substantial amounts of assets in order to reduce their leverage; such sales can put strong pressure on asset markets and prices and, thereby, indirectly on other banks.

Avoidance of such "systemic risk" and the associated social costs is a major objective of financial regulation. Because market participants, acting in their own interests, tend to pay too little attention to systemic concerns, financial regulation and supervision are intended to step in and safeguard the functioning of the financial system. Given the experience of the recent crisis, it is natural to consider a requirement that banks have significantly less leverage - that is, that they use relatively more equity funding so that inevitable variations in asset values do not lead to distress and insolvency.

A pervasive view that underlies most discussions of capital regulation is that "equity is expensive," and that equity requirements, while offering substantial benefits in preventing crises, also impose costs on the financial system, and possibly on the economy. Bankers have mounted a campaign against increasing equity requirements. Policymakers and regulators are particularly concerned by assertions that increased equity requirements would restrict bank lending and would impede economic growth. Possibly, as a result of such pressure, the proposed Basel III requirements, while moving in the direction of increasing capital, still allow banks to remain very highly leveraged (Blundell-Wignall et al., 
this volume). We consider this very troubling, because, as we show below, the view that equity is expensive is flawed in the context of capital regulation. From society's perspective, in fact, having a fragile financial system in which banks and other financial institutions are funded with too little equity is inefficient and, indeed, "expensive."

We examine various arguments that are made to support the notion that there are social costs associated with increased equity requirements. Our conclusion is that the social costs, if there were any at all, of significantly increasing equity requirements for large financial institutions would be very small. All the arguments we have encountered that suggest otherwise are weak when examined from first principles and in the context of optimal regulation. They are based either on fallacious claims, on a confusion between private costs to banks and social costs to the public, or on models that are inadequate from both a theoretical and an empirical perspective. We show that equity requirements need not interfere with any of the socially valuable activities of banks, including lending, deposit taking, or the creation of "money-like" liquid, and "informationally insensitive" securities that might be useful in transactions. In fact, the ability to provide social value would generally be enhanced by increased equity requirements, because banks would be likely to make more economically appropriate decisions. Among other things, bettercapitalized banks are less inclined to make excessively risky investments that benefit shareholders and managers at the expense of debt holders or the government. ${ }^{3}$

\section{Capital Structure Fallacies}

Capital requirements place constraints on the capital structure of the bank - that is, on the way the bank funds its operations. Any change in a bank's capital structure changes the exposure of different securities to the riskiness of the bank's assets. In this section, we take up statements and arguments that are based on confusing language and faulty logic regarding this process and its implications. The debate on capital regulation should not be based on misleading and fallacious statements; thus, it is important to ensure that they are removed from the discussion.

\section{What is capital and what are capital requirements?}

"Every dollar of capital is one less dollar working in the economy" (Steve Bartlett, Financial Services Roundtable, reported by Floyd Norris, "A Baby Step toward Rules on Bank Risk," New York Times, September 17, 2010).

Fallacy: "Capital represents money that banks must set aside and keep idle, and it cannot be used productively."

Assessment: This statement and the above quote are false and misleading. They confuse the two sides of the balance sheet. They portray capital as idle and thus costly. In fact, capital requirements address how banks are funded, not what assets they invest in or hold, and they do not require setting aside funds and not investing productively; once reserve or liquidity requirements are met, all bank capital can be deployed to make loans or otherwise invest and earn market returns or higher. 
The discussion about bank capital is often clouded by confusion between capital requirements and liquidity or reserve requirements. This confusion has resulted in routine references in the press to capital as something banks must "set aside" or "hold in reserve." Capital requirements refer to how banks are funded, and, in particular, the mix between debt and equity on the balance sheet of the banks. There is no sense in which capital is idly "set aside" by the banks. Liquidity or reserve requirements relate to the type of assets and asset mix banks must hold. Since they address different sides of the balance sheet, there is no immediate relation between liquidity or reserve requirements and capital requirements. However, if there is more equity and less debt on the balance sheet, liquidity concerns may not be as acute, because creditors have relatively fewer claims, and the probability of insolvency is smaller; hence, a run by creditors is less of a problem to be concerned about. High equity can therefore alleviate concerns about liquidity.

Equity simply represents an ownership claim in the form of common shares of stocks, such as those traded on stock markets. Equity is considered as a cushion or a buffer because its holders do not have a hard claim against the issuer; if earnings turn out to be low or even negative, the bank can lower its payout to equity holders without any notion of default.

\section{Equity requirements and balance sheet mechanics}

Fallacy: "Increased capital requirements force banks to operate at a suboptimal scale and to restrict valuable lending and/or deposit taking."

Assessment: To the extent that this implies balance sheets must be reduced in response to increased equity requirements, or that deposits must be reduced, this is false. By issuing new equity if necessary, banks can respond to increased capital requirements without affecting any of their profitable or socially valuable activities.

While one should be concerned about the effects proposed regulations might have on the ability of banks to carry out their core business activities, increasing the size of the equity cushion does not in any way mechanically limit the ability of a bank to lend. To see this, consider a very simple example.

Assume that capital requirements are initially set at 10 percent: a bank's equity must be at least 10 percent of the value of the bank's assets. ${ }^{4}$ For concreteness, suppose that the bank has US\$100 in loans, financed by US\$90 of deposits and other liabilities, and US $\$ 10$ of equity, as shown in the initial balance sheet in Figure 3.1. Now assume that capital requirements are raised to 20 percent. In Figure 3.1, we consider three ways in which the bank balance sheet can be changed to satisfy the higher capital requirement, fixing the value of the bank's current assets. One possibility is shown in Balance Sheet A, where the bank "de-levers" by significantly scaling back the size of its balance sheet, liquidating US\$50 in assets, and using the proceeds to reduce total liabilities from US $\$ 90$ to US\$40. In Balance Sheet $\mathrm{B}$, the bank satisfies the higher 20 percent capital requirement by recapitalizing, issuing US\$10 of additional equity and retiring US $\$ 10$ of liabilities, and leaving its assets unchanged. Finally, in Balance Sheet $\mathrm{C}$, the 
Figure 3.1. Alternative responses to increased equity requirements

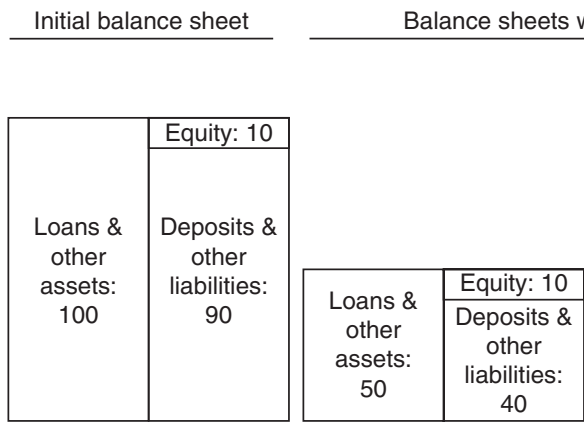

A: Asset sales

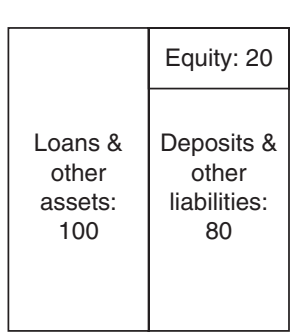

B: Recapitalization

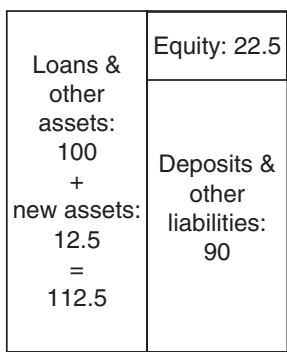

C: Asset expansion

bank expands its balance sheet by raising an additional US $\$ 12.5$ in equity capital and using the proceeds to acquire new assets.

Note that only when the bank actually shrinks its balance sheet, as shown in A, is the bank reducing the amount of lending it can undertake. In both B and C, the bank can support the same amount of lending as was supported by the original balance sheet.

In Balance Sheet B, some liabilities are replaced with equity. Specific types of liabilities, such as deposits, are part of a bank's "production function" in the sense that their issuance is related to the provision of transactions and other convenience services that the bank provides to its customers. At first glance, therefore, Balance Sheet B might seem to imply that higher capital requirements force the bank to reduce its supply of deposits, which would be socially costly if the associated services are both profitable for the bank and beneficial for the economy. In practice, however, deposits are not the sole form of bank liabilities. For example, non-trivial portions of bank finance, especially for large commercial banks, come in the form of long-term debt. Replacing a portion of this long-term debt with equity will increase bank capital without reducing its productive lending and deposit-taking activity. ${ }^{5}$ Given the fact that banks are not wholly funded by deposits, banks can meet increased capital requirements without reducing the amount of their deposits or the amount of their assets.

It is also possible for a bank to comply with higher capital requirements in a way that does not reduce the dollar value of either the liabilities or the assets. Balance Sheet $\mathrm{C}$ meets the higher capital requirements while keeping both the original assets (e.g. loans) and all of the original liabilities (including deposits) of the bank in place. Additional equity is raised and new assets are acquired. In the short run, these new assets may simply be cash or other marketable securities (e.g. Treasuries) held by the bank. As new, attractive lending opportunities arise, these securities provide a pool of liquidity for the bank to draw upon to expand its lending activity.

It is important to emphasize that, as long as the bank is currently solvent, Balance Sheet $\mathrm{C}$ is always viable; the bank should be able to raise the desired capital quickly and efficiently through, for example, a rights offering. Indeed, the inability to raise the capital needed to move to Balance Sheet C provides definitive evidence of the bank's insolvency (Admati et al. 2013). 
To summarize, in terms of simple balance sheet mechanics, the notion that increased equity capital requirements force banks to reduce lending and/or deposit-taking activities is simply false. Banks can preserve or even expand lending activities by changing to Balance Sheets B or C.

\section{Equity requirements and return on equity}

Fallacy: "Increased equity requirements will hurt bank shareholders since it would lower the banks return on equity (ROE)."

Assessment: This is false; a reduction in ROE does not indicate decreased value added. While increased capital requirements can lower the ROE in good times, they will raise ROE in bad times, reducing shareholder risk.

One concern about increasing equity capital requirements is that such an increase will lower the returns to the bank's investors. In particular, the argument is often made that higher equity capital requirements will reduce the banks' ROE to the detriment of their shareholders.

This argument presumes that ROE is a good measure of a bank's performance. Since ROE (or any simple measure of the bank's return) does not adjust for scale or risk, there are many potential pitfalls associated with this presumption. Using ROE to assess performance is especially problematic when comparisons are made across different capital structures. The focus on ROE has therefore led to much confusion about the effects of capital requirements on shareholder value.

We illustrate the consequence of an increase in equity capital on ROE in Figure 3.2. This figure shows how the bank's realized ROE depends on its return on assets (before interest expenses). For a given capital structure, this dependence is represented by a straight line. ${ }^{6}$ This straight line is steeper the lower the share of equity in the bank's balance sheet. Thus, in Figure 3.2, the steeper line corresponds to an equity share of 10 percent, the flatter line to an equity share of 20 percent. The two lines cross when the bank's ROE is equal to the (after-tax) rate of interest on debt, assumed to be 5 percent in the figure. Above that level, ROE is indeed lower with higher capital. Below the 5 percent level, however, ROE is higher with higher capital, as the cushioning effect of higher capital provides downside protection for equity holders and reduces their risk.

The figure illustrates the following key points:

- For a given capital structure, ROE does reflect the realized profitability of the bank's assets. But when comparing banks with different capital structures, ROE cannot be used to compare their underlying profitability. ${ }^{7}$

- Higher equity capital requirements will tend to lower the bank's ROE only in good times when the return on assets is high. They will raise the ROE in bad times when the return on assets is low. From an ex ante perspective, the high ROE in good times that is induced by high leverage comes at the cost of having a very low ROE in bad times. 
On average, of course, banks hope to (and typically do) earn ROE well in excess of the return on their debt. In that case, the average effect on ROE from higher equity capital requirements would be negative. For example, if the bank expects to earn a 6 percent return on its assets, then it would expect a 15 percent ROE on average with 10 percent capital, and only a 10 percent ROE on average with 20 percent capital. Is this effect a concern for shareholders?

The answer is no. Because the increase in capital provides downside protection that reduces shareholders' risk, shareholders will require a lower expected return to be willing to invest in a better-capitalized bank. This reduction in the required expected return on equity and debt will offset the reduction in the average ROE, leading to no net change in the value to shareholders (and thus the firm's share price). Indeed, in the above example, if the equity investors required a 15 percent expected return initially, we would expect their required return to fall to 10 percent due to the reduction in risk with the increase in the firm's capital. ${ }^{8}$ As shareholders continue to earn their required return, there is no cost associated with the increase in equity capital.

\section{Capital structure and the cost of capital}

Fallacy: "Increased equity requirements increase the funding costs for banks because they must use more equity, which has a higher required return."

Assessment: This argument is false. Although equity has a higher required return, this does not imply that increased equity capital requirements would raise the banks' overall funding costs.

The example of the previous section exposes a more general fallacy regarding equity capital requirements. Because the required expected rate of ROE is higher than that on debt, some argue that if the bank were required to use more of this "expensive" form of funding, its overall cost of capital would increase.

This reasoning reflects a fundamental misunderstanding of the way in which risks affect the cost of funding. While it is true that the required ROE is higher than the required return on debt, and it is also true that this difference reflects the greater riskiness of equity relative to debt, it is not true that by economizing on equity one can reduce capital costs. Economizing on equity itself has an effect on the riskiness of equity, and, therefore, on the required expected return of equity. This effect must be taken into account when assessing the implications of increased equity capital requirements for banks' cost of capital.

Figure 3.2 indicates that the random fluctuations in the bank's ROE that are induced by a given fluctuation in earnings are greater the less equity the bank issues. When the bank is funded with relatively more equity, a given earnings risk translates into less risk for its shareholders. Reflecting this reduction in risk, the risk premium in the expected ROE will be lower. Since the additional equity capital will generally reduce the bank's bankruptcy risk, the interest rate on its debt will also be lower. These reductions of risk premia in required rates of return counteract the direct effects of shifting from debt finance to equity finance, from an instrument with a low required rate of return to an 
Figure 3.2. The effect of increased equity on ROE

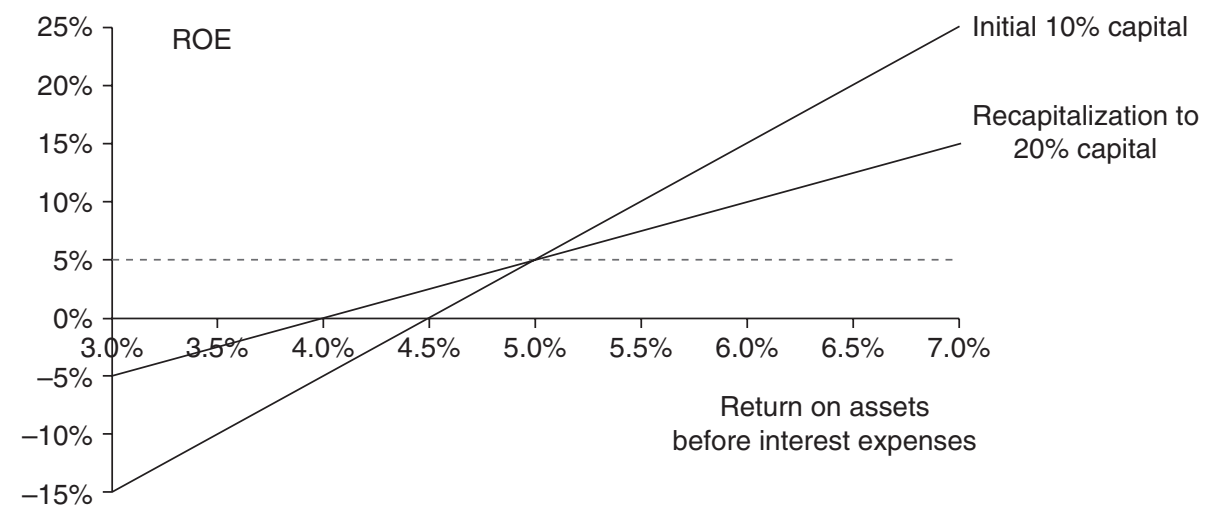

instrument with a higher required rate of return. The net effect need not increase the total funding costs of the bank at all. ${ }^{9}$

\section{Arguments Based on a Confusion of Private and Social Costs}

We now consider reasons why bank shareholders will resist attempts to increase capital. These include the loss of tax and bailout subsidies associated with debt. All of these costs to shareholders represent transfers to creditors or taxpayers. Thus, they are private rather than social costs. In assessing social costs, one must consider the immediate benefits to taxpayers and creditors that are the counterpart of the private costs to shareholders. One must also consider the costs to third parties that are due to banks being highly leveraged and therefore very risky. As was seen in 2007-2009, distress or default of banks, especially of so-called systemic banks, can have severe, negative consequences for the rest of the economy.

\section{Tax subsidies on debt}

Irrelevant fact: "Increased equity requirements increase the funding costs for banks because they reduce the ability of banks to benefit from the tax shield associated with interest payments on debt."

Assessment: When debt has a tax advantage over equity, this statement is true. However, it is irrelevant to capital regulation in the sense that both capital regulation and taxes are matters of public policy. The current tax code creates distortions by subsidizing leverage. These distortions can be eliminated, while preserving the same level of bank tax shields, at the discretion of the government. This would neutralize the tax impact of increased equity requirements.

Taxes should be structured to minimize the overall distortions they induce. In particular, taxes (and subsidies) should be set so as to encourage behavior that generates positive externalities, and to discourage behavior that generates negative externalities. By these 
criteria, refraining from requiring banks to have more equity on the grounds that this would raise their taxes makes no sense. If the prospect of saving on corporate income taxes induces banks to be highly leveraged, this generates a negative externality, because the increase in leverage raises the probability of a bank failure, weakening the financial system, and imposing losses on the broader economy. Given these externalities associated with high leverage of financial institutions, tax policy should not encourage leverage. If anything, tax policy should be designed to make banks internalize the social costs imposed by high leverage.

The current tax code can be thought of as penalizing equity rather than subsidizing debt (Mankiw, Weinzierl, and Yagan 2009; Boskin 2010). Poole (2009) estimates that reducing the corporate tax rate to 15 percent and not allowing financial institutions to deduct interest would result in the same total corporate tax expense as was actually incurred by these institutions.

More generally, even without fundamentally changing the tax code, it is quite straightforward to neutralize the impact of increased equity capital requirements on the tax liabilities of banks. Any tax subsidies lost due to a reduction in leverage can be easily replaced with alternative deductions or tax credits. If indeed it is viewed as socially desirable to subsidize bank lending to individuals or small businesses who do not have a wide array of financing options, a tax credit associated with bank lending to such borrowers would be more targeted, and would avoid the negative externalities associated with subsidizing bank borrowing.

\section{Bailouts and implicit government guarantees}

Irrelevant fact: "Increased equity requirements increase the funding costs for banks because they prevent banks from being able to borrow at the low rates implied by the presence of government guarantees."

Assessment: This statement is again correct, but it concerns only private, not social costs. Government guarantees that allow banks to enjoy cheap debt financing create numerous distortions and encourage excessive leverage and excessive risk-taking. Because of the distorted incentives as well as the difficulty for governments to commit never to bail out banks, it is challenging to neutralize this effect by charging banks for the true cost of the guarantees on an ongoing basis. In this context, equity cushions are particularly valuable, as they reduce the likelihood and cost of the guarantees.

Explicit or implicit government guarantees immunize the banks' creditors against the consequences of a default by the bank. As a result, the default risk premium in the interest rates demanded by the bank's creditors is lower and may even be zero. Institutions that benefit from such guarantees, for example, institutions that are deemed to be too big to fail, are therefore able to borrow at lower interest rates. The savings in capital costs that are thereby achieved are larger the more leverage the bank has.

The lower borrowing rates benefiting banks and their shareholders have a counterpart in the default risks borne by the taxpayer. Any consideration of social costs must encompass the costs of these risks to taxpayers. Once this is taken into account, one sees that the 
effects of government guarantees on borrowing rates provide no reason to refrain from requiring banks to have more capital. If lower borrowing rates based on government guarantees induce banks to be highly leveraged, this imposes a negative externality on the rest of the economy, because the increase in leverage raises the probability of distress, and the resulting systemic risk.

Default risk may be unavoidable, but to the extent that there is a choice, the availability of explicit or implicit government guarantees of bank debt creates a bias toward choosing risky strategies to exploit the guarantees, providing shareholders with nice returns if they succeed, and saddling the government with the losses if they fail.

As is well known, such a bias toward choosing an excessively risky strategy is present even without government guarantees. The mere existence of debt, with a payment obligation that is independent of the bank's asset returns, creates incentives for the bank's shareholders, or for its managers acting on the shareholders' behalf, to take risks according to the principle "Heads, I win; tails, the creditor loses." Explicit or implicit government guarantees can greatly reduce the need for the insured creditors to worry about their bank's strategy choices and default prospects. If the government can be expected to step in when the bank defaults, the creditors generally have no reason to refrain from lending to the bank or to demand a significant default risk premium. The resulting arrangement may be far less desirable than even second best.

Systems providing safety nets to banks, including deposit insurance, the US Fed's discount window, and lender of last resort, can (and do) play a positive role as a stabilizing force, particularly in preventing the runs that have routinely plagued banks. It is often difficult to price explicit guarantees, and implicit guarantees clearly provide a subsidy to the institution whose debt falls under the implicit guarantees. In this case, the result is that leverage is again subsidized. ${ }^{10}$ Indeed, as discussed above, the system of capital regulation is motivated by the recognition that guarantees generate distortions and moral hazards. Higher equity requirements, by requiring that those who own residual claims in the bank bear much of the bank's risk, reduce dependence on systems of guarantees, and, instead, rely more on the private sector to provide safety to the financial system. Thus, they alleviate the distortions associated with the safety net. ${ }^{11}$

\section{Debt overhang and resistance to leverage reduction}

Irrelevant fact: "Issuing equity to decrease leverage is expensive because it will lower the value of shares of existing shareholders."

Assessment: This statement is again correct but irrelevant to the policy debate. Any reduction in the value of existing shares is matched by equal benefit to either creditors or taxpayers who would be bearing less downside risk (and providing fewer other subsidies to debt).

Reducing the leverage of any firm may lower the value of existing shareholders' claims. First, given the tax advantage of debt and the subsidies associated with implicit guarantees, the share price will decline to reflect the reduction in tax benefits and default subsidies. Second, if the debt is currently risky, leverage reduction will reduce the risk to creditors, 
and, thus, increase the value of the firm's (remaining) debt, which benefits creditors (or the deposit insurance and taxpayers who insure the debt) at the shareholder's expense. The magnitude of the decline in the share price provides direct evidence regarding the decrease in default risk achieved by the leverage reduction. Clearly, however, any cost to existing shareholders is not a social cost, but rather a transfer to existing creditors or taxpayers.

When a firm is highly leveraged and faces substantial default risk, the risk to creditors is manifested through higher yields paid to borrow (or lower prices for its existing debt for a fixed, promised payment). If a borrower reduces leverage, this generally benefits existing creditors and increases the value of their claims. The gain to creditors comes at shareholder expense, and this effect, similar to that of debt overhang identified in Myers (1977), explains the strong resistance of shareholders to leverage reductions. Myers (1977) coined the term "debt overhang" to explain shareholder resistance to raising equity to make new investments. Admati et al. (2013) show that this same effect is even more pronounced in the context of recapitalizations - shareholders will resist any degree of leverage reduction, no matter how inefficient the firm's current level of leverage.

However, many bank shareholders have portfolios of shares that typically include many other companies. Instability in banking, and especially financial crises that require bailouts and harm the economy, are costly to these shareholders. Those who benefit from high leverage are likely to be the banks' managers and possibly shareholders whose entire wealth is concentrated at the bank. These individuals are not entitled to the subsidies and the upside of risks taken at the expense and harm of others. Thus, even if leverage reductions, at least in the transitions, are costly to these individuals, forcing banks to reduce leverage is in the public interest. ${ }^{12}$

\section{Equity Requirements and Bank Lending}

"More equity might increase the stability of banks. At the same time, however, it would restrict their ability to provide loans to the rest of the economy. This reduces growth and has negative effects for all." (Josef Ackermann, CEO of Deutsche Bank, November 20, 2009).

Fallacy: "Increased equity requirements would have an adverse effect on the lending decisions of banks and will inhibit economic growth."

Assessment: This statement is false. High leverage distorts lending decisions and because of this, better-capitalized banks generally make better lending decisions. In particular, less leveraged banks are less inclined to make excessively risky investments or to pass up worthwhile loans due to frictions associated with high leverage.

When assessing the claim that increased capital requirements might cause banks to cut back on lending and charge more on the loans they make, note first that for many banks, particularly the large ones, loans represent only a small part of the assets, suggesting they have plenty of capacity for increased lending simply by substituting from other asset holdings. ${ }^{13}$ 
Before attempting to analyze the claims that increased equity requirements would lead to a credit crunch, we must remember that the biggest credit crunch in recent memory, the total freezing of credit markets during the recent financial crisis, was not due to too much equity, but in fact was due to too little equity, and to the extremely high levels of leverage in the financial system. In other words, credit crunches arise when banks are undercapitalized. If all banks have sufficient equity capital, they will have no reason to pass up economically valuable lending opportunities, and the risk of future credit crunches is reduced. Quite clearly, lending was disrupted in 2007 2008 from banks having too little equity to withstand the losses due to housing price declines. Studies have shown that banks with strong balance sheets were better able to maintain lending during the crisis, and suggest that "strong bank balance sheets are key for the recovery of credit following crises" (Kapan and Minoiu 2013; see also Buch and Prieto 2012).

The fact that a highly leveraged bank is highly reluctant to raise equity to make new loans does not imply that well-capitalized banks lend less than thinly capitalized ones. The main impediment to bank lending is debt overhang and the only effective remedy is increased equity funding. ${ }^{14}$

High capital requirements will mitigate any potential debt overhang. Should a bank fall short of these requirements, a solvent bank can raise its equity level by retaining profits and issuing new shares through a rights offering. ${ }^{15}$ Doing so would increase their lending capacity and, importantly, would increase their ability to continue making loans during downturns. Banks with more equity are less prone to booms and busts, and can maintain a smoother time path in terms of lending.

In fact, we argue that if banks have significantly more equity, they are likely not only to lend more, but also to make more appropriate lending decisions. Highly leveraged banks are generally subject to distortions in their lending decisions. These distortions may lead them to make worse lending decisions than they would have made if they were better capitalized, resulting in either too much or too little lending relative to the social optimum. First, equity holders in a leveraged bank, and managers working on their behalf or compensated on the basis of ROE or other equity-based measures, have incentives to make excessively risky investments, and this problem is exacerbated when the debt has government guarantees. Second, when banks are distressed, credit markets can freeze and certain loans will not be made due to the debt overhang problem discussed earlier. Valuable loans that are not made as a result of debt overhang would be undertaken if the bank were better capitalized, since in that case the value created by the loans would be captured by those who would fund it.

More appropriate lending decisions may involve reductions in some kinds of lending. Such reductions, however, while annoying to the potential borrowers, may well be beneficial to the economy as a whole. For the economy as a whole, the objective is not to have as much lending as possible, but to have as much lending as is appropriate in view of investors' willingness and ability to bear risks. Excessive risk taking can take the form of excessive lending. This should be avoided. ${ }^{16}$

Some of the discussion of the effects that capital requirements will have on banks' lending decisions appears to involve the fundamental fallacies about capital structure 
and banks' cost of capital that were discussed above. In order to avoid these fallacies, one must be very careful to account for changes in risk properly when considering how loans are made and funded. From a normative perspective, in a world without frictions and distortions, the decision on whether to make a particular loan or not should be independent of the bank's capital structure - that is, on how the bank is funded. The decision should depend only on whether the loan rate provides the bank with a sufficient premium to make the risks associated with the loan acceptable. This latter question, in turn, should depend only on the risk characteristics of the loan and on the assessment of these risk characteristics by investors in the market. Neither the bank's other assets nor the bank's capital structure should play a role.

It is true that increased equity capital requirements will remove some of the subsidies banks capture through high leverage - namely, tax and implicit guarantees. If taking away these subsidies causes banks to lend less, or to charge higher rates than is considered desirable, it may be desirable from a public-policy perspective to subsidize bank lending. If lending needs to be subsidized because it is important for the economy, then more targeted and less costly ways must be found to provide such subsidies than encouraging banks to be highly leveraged.

\section{Policy Recommendations}

What is the appropriate equity capital requirement? Several studies have attempted to answer this question using a variety of models to estimate the costs and benefits of increased equity requirements. Discussing and assessing the various empirical models that are used in these documents is beyond our scope here. However, it appears that the methods of analysis used in most of these studies fall prey to many of the concerns identified in this paper. ${ }^{17}$

To attempt to give even a rough order-of-magnitude answer to the question of what appropriate equity requirements should be, one must take into account the complex ways that capital ratios are calculated, something that we have not addressed in this paper. Requirements mostly refer to so-called risk-weighted assets, rather than the total assets of a bank. Many important institutions have "core capital" equal to 10 percent or more of risk-weighted assets under the Basel rules, but this is often no more than 1 to 3 percent of total unweighted assets on their balance sheets. The use of risk-weighted assets for capital regulation is based on the idea that the riskiness of the assets should in principle guide regulators regarding how much of an equity cushion they should require. In the recent financial crisis, however, assets that had zero-risk weights in the banks' models could suddenly experience severe problems, and even lead to bank failures and bailouts. ${ }^{18}$ Any system of capital regulation must come to terms with these issues.

Leaving aside the issue of how one accounts for the riskiness of banks' assets, and taking as a benchmark current levels of risk, one can discuss capital requirements in terms of unweighted equity ratios - that is, equity capital relative to total assets (the off-balance sheet as well as on-balance sheet) held by the bank. Historical comparisons suggest that equity capital ratios as high as 20 percent or 30 percent on an unweighted basis should not be unthinkable (Alessandri and Haldane 2009). Such levels are considered minimal 
for corporations outside banking, without regulation, and there is no reason banks cannot or should not rely much more on equity to fund their investments.

How would banks get to the point of having much larger equity cushions? Should they be given many years to build up their equity capital? It is widely argued, and recent policy proposals recommend, that banks be given a very long time to adjust to new capital requirements. Kashyap, Stein, and Hanson (2010) based their recommendation on the claim that equity issuance might be costly if investors fear that managers issue equity only when it is overpriced, which may then make banks reluctant to issue new equity to satisfy capital requirements. This problem can be alleviated if regulators remove some of the discretion that banks might otherwise have with respect to equity issuance. By setting schedules for banks so that they must issue equity at specific times, investors will no longer be justified in making negative inferences about any particular bank based on the fact that it is issuing equity. ${ }^{19}$

Whatever the target equity ratio is, regulators should make sure to prohibit banks, for a period of time, from making any payouts to shareholders..$^{20}$ The eagerness of banks to make these payouts is, in fact, evidence of the conflict of interest between shareholders on the one hand and debt holders or taxpayers on the other, because the funds paid out to shareholders are no longer available to pay creditors. ${ }^{21}$ If done under the force of regulation, withholding dividends would not lead to any negative inference on the health of any particular bank.

Arguments against higher capital requirements often do not directly address the merits of such requirements, but are based instead on issues concerning the enforceability of higher requirements. Specifically, warnings are frequently made that financial activities will move out of the regulated part of the financial system and into the unregulated part, the so-called shadow banking system. Given that institutions in the shadow banking system may have hardly any equity at all, such a development would increase the overall fragility of the financial system.

Clearly, attempts to get around regulations were important in the buildup of risk that led to the financial crisis. For example, financial institutions from Continental Europe used conduits and structured-investment vehicles located in Ireland or in New Jerseythat is, shadow banking institutions in other jurisdictions - in order to invest in mortgagebacked securities and related derivatives on a large scale and with a highly leveraged structure. The breakdown of these shadow banking institutions in the summer of 2007 played a major role in amplifying and transmitting problems in the US real estate and mortgage sectors, and turning them into a global financial crisis.

However, these issues only demonstrate that enforcement has been ineffective, and the weakness of enforcement has been harmful. The expansion of operations in the shadow banking system that contributed so disastrously to the crisis could easily have been avoided if regulators had used the powers at their disposal. With practically no equity of their own, the shadow banking institutions involved in the recent crisis would have been unable to obtain any finance at all if it had not been for commitments made by sponsoring banks in the regulated system. These banks' guarantees enabled the unregulated shadow banks to obtain funds by issuing asset-backed commercial paper. If regulators had wanted to, they could have interfered on the grounds that the shadow banks were not really independent, 
and the lack of independence should have been recognized by putting them on their sponsoring banks' balance sheets. Alternatively, if the shadow banks were deemed to be independent, then the regulators should have ruled that the guarantees were in conflict with regulations limiting large exposures to individual parties. The fact that regulators saw fit not to interfere raises questions about the political economy of financial regulation in the past decade, but not about the ability of regulation in principle to prevent or limit regulatory arbitrage.

Regulatory arbitrage was more successful than it should have been, but it does not follow that we should avoid regulation. With such a conclusion, we would accept that we are helpless to prevent another crisis. Instead, we need to tighten both the regulations that we have and the defenses against regulatory arbitrage.

\section{Concluding Remarks}

We have shown that arguments asserting that increased equity requirements for banks entail significant social costs are flawed. Why do we hear these arguments? One possible answer is given in the table on the last page. Both bank shareholders and bank managers have some strong incentives to maintain high leverage and to resist increased equity capital requirements. Government subsidies that reward debt and penalize equity financing benefit managers and some shareholders. These subsidies would be reduced if equity capital requirements were increased. Of course, arguments made by bankers against increased capital requirements are not automatically invalid just because it might be in their interest to oppose this stricter regulation. However, policymakers should be especially skeptical when evaluating claims that are not supported by strong arguments when those who make the claims have a personal interest in making the claims. As we have shown, the arguments that have been made in this policy debate are based on fallacies, irrelevant facts, or myths based on inadequate theories. Because the social benefits of significantly reducing bank leverage are significant, and because there are no significant social costs of increasing equity requirements for banks, threats that increasing equity requirements would be harmful should not be taken seriously. High equity requirements need not interfere with any of the valuable intermediation activities undertaken by banks and transitions to higher requirements can be managed relatively quickly.

Banking institutions clearly serve an important function in the economy by providing credit and creating liquid deposits. High leverage is not required for them to be able to perform these socially valuable functions. To the contrary, high leverage makes banking institutions highly inefficient and exposes the public to unnecessary risk and harm. When the possibility of harm from the distress and insolvency of banks becomes so large that governments and central banks must step in to prevent it, additional distortions arise. Current policies end up subsidizing and encouraging banks to choose levels of leverage and risk that are excessive. Countering these forces with effective equity requirements is highly beneficial.

Threats that substantial increases in equity requirements will have significant negative effects on the economy and growth should not be taken seriously, because, in fact, it is weak, poorly capitalized banks and a fragile system that harm the economy. Transitioning 
to a healthier and more stable system is possible, and highly beneficial, and would improve the ability of the financial sector to serve a useful role in the broader economy.

We have based our analysis on an assessment of the fundamental economic issues involved. Any discussion of this important topic in public policy should be fully focused on the social costs and benefits of different policies - that is, the costs and benefits for society, and not just on the private costs and benefits of some institutions or people. Moreover, assertions should be based on sound arguments and persuasive evidence. Unfortunately, the level of policy debate on this subject has not been consistent with these standards.

\section{Notes}

1 This chapter is based mainly on Sections 3, 4 and 9 in Admati et al. (2013). Among other things, Admati et al. (2013, Sections 5-7) discusses unsupported claims that are inadequate for the policy debate (myths). It also explains (in Section 8) why equity dominates alternatives such as contingent capital and other debt-like securities that are complex, less reliable for loss absorption, and maintain distortions.

2 See, for example, Adrian and Shin (2010) and Adrian and Brunnermeier (2010).

3 The key conclusions of this paper are summarized in a letter signed by 20 academics; see "Healthy Banking System Is the Goal, Not Profitable Banks," Financial Times, November 9, 2010. For later elaboration, see Admati and Hellwig (2013a, 2013b, 2014).

4 To keep the examples straightforward, we consider simplified versions of capital requirements. The general points we make throughout this article apply to more complex requirements.

5 According to the FDIC (March 31, 2010), domestic deposits at US commercial banks totaled US $\$ 6,788$ billion, which represented 56.2 percent of total assets, while equity represented 10.9 percent of assets. This leaves 32.9 percent of the assets, which is almost US $\$ 4$ trillion in nondeposit liabilities.

6 More precisely, $\mathrm{ROE}=(\mathrm{ROA} \times \mathrm{A}-\mathrm{r} \times \mathrm{D}) / \mathrm{E}=\mathrm{ROA}+(\mathrm{D} / \mathrm{E})(\mathrm{ROA}-\mathrm{r})$, where ROA is the return on assets before interest expenses (i.e. EBIT $\times(1-$ Tax Rate) / (Total Assets)), A is the total value of the firm's assets, $\mathrm{E}$ is equity, $\mathrm{D}$ is debt, and $\mathrm{r}$ is the (after-tax) interest rate on the debt.

7 For example, a manager who generates a 7 percent ROA with 20 percent capital will have an ROE of 15 percent. Alternatively, a less productive manager who generates a 6.5 percent ROA, yet has 10 percent capital, will have an ROE of 20 percent. Thus, when capital structures differ, a higher ROE does not necessarily mean a firm has deployed its assets more productively.

8 To see why, note from Figure 3.2 that doubling the bank's capital cuts the risk of the bank's equity returns in half (the same change in ROA leads to half the change in ROE). Thus, if shareholders initially required a 15 percent average return, which corresponds to a 10 percent risk premium to hold equity versus safe debt, then with twice the capital-because their sensitivity to the assets" risk (and thus their "beta") has been halved - they should demand half the risk premium, or 5 percent, and hence a 10 percent required average return.

9 Continuing our earlier example, given 10 percent equity capital, the required return was 15 percent for equity and 5 percent for debt, for an average cost of $10 \% \times 15 \%+90 \% \times 5 \%=$ $6 \%$. With 20 percent equity capital the required return for equity falls to 10 percent (with a 5 percent cost of debt), leading to the same average cost of $20 \% \times 10 \%+80 \% \times 5 \%=6 \%$.

10 On the size and distortions associated with bailouts and the safety net, see Akerlof and Romer (1993), Alessandri and Haldane (2009), Gandhi and Lustig (2010), Haldane (2010), Kane (2010), Carbo-Valverde et al. (2013), Davies Richard and Tracey (2012), and Kelly, Lustig, and Stijn Van Nieuwerburgh (2012).

11 The safety net of the banking sector is expanding rather than contracting. Whereas 45 percent of bank liabilities in the USA were implicitly or explicitly guaranteed in 1999, this had grown to 59 percent in 2008 (Walter and Weinberg 2002; Malysheva and Walter 2010). 
12 In our work on the "leverage ratchet effect" (Admati et al. 2014), we argue that high leverage may well also be privately inefficient.

13 J. P. Morgan Chase, for instance, in June 2013 had only US\$700 billion in loans out of assets that exceeded US $\$ 2$ trillion. Indeed, its loans were actually less than the US\$1.2 trillion it had in deposits.

14 Cheap loans to banks (as in the long-term refinancing operation [LTRO] of the European Central Bank in 2012) or injections of "capital" in the form of preferred shares or subordinated debt (as in the Capital Purchase Program that was part of the Troubled Assets Relief Program [TARP] in the USA in 2008/2009) are not necessarily effective in promoting lending. This type of support does not reduce effective leverage, and hence does not reduce the debt overhang problem. Acharya and Steffen (2014) refer to the LTRO as "the greatest carry trade ever." See also Louise Armistead, "ECB's LTRO Plan Flops as Banks Cut Lending," Telegraph, March 28, 2012. Cole (2012) shows that banks receiving capital injections from the TARP failed to increase their small-business lending, and instead decreased their lending by even more than other banks.

15 If banks are unprofitable and therefore unable to raise equity, some consolidation of the industry may be called for, even if that implies less lending; in this case, less lending is likely to mean less wasteful lending.

16 Boom-and-bust cycles in lending are a constant feature of modern history. Houses that were financed with subprime mortgages, and which are now standing empty and decaying, provide just one illustration of how wasteful such excessive lending can be.

17 See BIS (2010a), Bank of Canada (2010), and IIF (2010). The methodological shortcomings of these studies are discussed in Admati et al. (2013).

18 Hellwig (2010) suggested that the notion of measuring risks is itself an illusion, and that in practice, the risk-calibration approach provides banks with too much scope for manipulating their models so as to "economize" on equity capital.

19 Requirements should be formulated in terms of amounts of equity that must be raised rather than ratios of assets. If requirements are formulated as ratios, debt overhang effects may give banks an incentive to fulfill the requirements by deleveraging rather than by raising equity.

20 Acharya et al. (2013), Acharya et al. (2011), and Goodhart et al. (2010) suggest restrictions on dividends as part of prudential capital regulation.

21 For example, the largest 19 US banks paid out US $\$ 131$ billion to their shareholders between 2006 and 2008, and these funds were not available to make loans or pay creditors as the financial crisis escalated. The US government invested about US $\$ 160$ billion in these banks starting in fall 2008 and in 2009 within the TARP program, effectively replenishing the funds in the form of preferred shares and subordinated debt.

\section{References}

Acharya, Viral V., Hamid Mehran, and Anjan Thakor. 2010. "Caught between Scylla and Charybdis? Regulating Bank Leverage When There Is Rent Seeking and Risk Shifting.” Working Paper.

Acharya, Viral V., Irvind Gujral, Nirupama Kulkarni, and Hyun Song Shin. 2011. "Dividends and Bank Capital in the Financial Crisis of 2007-2009." Working Paper.

Acharya, Viral V., and Sascha Steffen. 2013. "The 'Greatest' Carry Trade Ever: Understanding Eurozone Bank Risk.” Working Paper.

Admati, Anat R., Peter M. DeMarzo, Martin F. Hellwig and Paul Pfleiderer (2013), "Fallacies, Irrelevant Facts and Myths in the Discussion of Capital Regulation: Why Bank Equity is Not Socially Expensive," Stanford Graduate School of Business Research paper 13-7. Max Planck Institute for Research on Collective Goods 2013/23.

Admati, Anat R., Peter M. DeMarzo, Martin F. Hellwig and Paul Pfleiderer (2014), "The Leverage Ratchet Effect," Rock Center for Corporate Governance at Stanford University Working Paper No. 146 
Admati, Anat R., and Martin F. Hellwig. 2013a. The Bankers'New Clothes: What's Wrong with Banking and What to Do about It. Princeton, NJ: Princeton University Press.

2013b. "Does Debt Discipline Managers? An Academic Myth about Bank Indebtedness." Working Paper.

2014. "The Parade of Bankers' New Clothes Continues: 28 Flawed Claims Debunked." Rock Center for Corporate Governance at Stanford University Working Paper No. 143.

Adrian, Tobias, and Hyun Song Shin. 2010. "Liquidity and Leverage." Fournal of Financial Intermediation 19: 418-37.

Adrian, Tobias, and Markus K. Brunnermeier. 2009. "CoVaR.” Federal Reserve Bank of New York, Staff Report 348.

Akerlof, George A., and Paul M. Romer. 1993. "Looting: The Economic Underworld of Bankruptcy for Profit." Brookings Papers on Economic Activity, no. 2: 1-73.

Alessandri, Piergiorgio, and Andrew G. Haldane. 2009. "Banking on the State." Paper presented at the Federal Reserve Bank of Chicago 12th Annual International Banking Conference, September 25, 2009.

Bank of Canada. 2010. Strengthening International Capital and Liquidity Standards: A Macroeconomic Impact Assessment for Canada. Online: http://www.bankofcanada.ca/2010/08/strengtheninginternational-capital-and-liquidity-standards-a-macroeconomic-impact-assessment-forcanada-2/ (accessed August 28, 2014).

Basel Committee on Banking Supervision (BIS). 2010a. "An Assessment of the Long-Term Economic Impact of Stronger Capital and Liquidity Requirements." Online: http://www.bis. org/publ/bcbs 173.htm (accessed August 28, 2014).

Boskin, Michael J. 2010. "Time to Junk the Corporate Tax." Wall Street Fournal, May 6.

Buch, Claudia M., and Esteban Prieto. 2012. "Do Better Capitalized Banks Lend Less? Long-Run Panel Evidence from Germany." Working Paper.

Carbo-Valverde, Santiego, Edward J. Kane, and Francisco Rodriguez-Fernandez. 2011. "SafetyNet Benefit Conferred on Difficult-to-Fail-and-Unwind Banks in the US and EU before and during the Great Recession." Working Paper.

Cole, Rebel A. 2012. "How Did the Financial Crisis Affect Small Business Lending in the US?" Working Paper.

Davies, Richard, and Belinda Tracey. 2012. "Too Big to Be Efficient? The Impact of Implicit Funding Subsidies on Scale Economies in Banking." Fournal of Money, Credit and Banking 46, no. 1: 219-53.

Gandhi, Priyank, and Hanno Lustig. 2010. "Size Anomalies in US Bank Stock Returns." fournal of Finance, forthcoming.

Goodhart, Charles, M. U. Peiris, D. P. Tsomocos, and A. P. Vardoulakis. 2010. "On Dividend Restrictions and the Collapse of the Interbank Market." Annals of Finance 6 (4): 455-73.

Haldane, Andrew, G. 2010. "Regulation or Prohibition: The $\$ 100$ Billion Question." Fournal of Regulation and Risk North Asia 2 (2-3): 101-22.

Hellwig, Martin F. 2010. “Capital Regulation: Business as Usual?” Working Paper.

Institute of International Finance (IIF). 2010. Interim Report on the Cumulative Impact on the Global Economy of Proposed Changes in the Banking Regulatory Framework. Online: http://www.iif.com/ press/press+151.php (accessed August 28, 2014).

Kane, Edward J. 2010. "Missing Elements in US Financial Reform: The Grievous Inadequacy of the Dodd-Frank Act." Working Paper.

Kapan, Tümer, and Camelia Minoiu. 2013. "Balance Sheet Strength and Bank Lending During the Global Financial Crisis." IMF Working Paper. Washington, DC: IMF.

Kashyap, Anil K., Jeremy C. Stein, and Samuel Hanson. 2010. "An Analysis of the Impact of 'Substantially Heightened' Capital Requirements on Large Financial Institutions." Working Paper.

Kelly, Brian, Hanno Lustig, and Stijn Van Nieuwerburgh. 2012. "Too-Systemic-to-Fail: What Option Markets Imply about Sector-Wide Government Guarantees.” Working Paper. 
Malysheva, Nadezhda, and John R. Walter. 2010. "How Large Has the Federal Financial Safety Net Become?” Economic Quarterly 96, no. 3: 273-90.

Mankiw, Gregory N., Matthew C. Weinzierl, and Danny Yagan. 2009. "Optimal Taxation in Theory and Practice." Harvard Business School Working Paper. Boston, MA: Harvard Business School.

Myers, Stewart C. 1977. "Determinants of Corporate Borrowing." Fournal of Financial Economics 5: $147-75$.

Poole, William. 2009. "Moral Hazard: The Long-Lasting Legacy of Bailouts." Financial Analysts fournal, November/December: 1-7.

Walter, John R., and John A. Weinberg. 2002. "How Large Is the Federal Financial Safety Net?" Cato fournal 21 (3): 369-93. 


\title{
Chapter 4
}

\section{COMPLEXITY, INTERGONNEGTEDNESS: BUSINESS MODELS AND THE BASEL SYSTEM}

\author{
Adrian Blundell-Wignall, Paul Atkinson, \\ and Caroline Roulet ${ }^{1}$
}

\begin{abstract}
The main hallmarks of the global financial crisis were too-big-to-fail institutions taking on too much risk with other people's money: excess leverage and default pressure resulting from contagion and counterparty risk. This paper looks at whether the Basel III agreement addresses these issues effectively. Basel III has some very useful elements, notably a (much too light "backup") leverage ratio, a capital buffer, a proposal to deal with pro-cyclicality through dynamic provisioning based on expected losses, and liquidity and stable funding ratios. However, the paper shows that Basel risk weighting and the use of internal bank models for determining them leads to systematic regulatory arbitrage that undermines its effectiveness. Empirical evidence about the determinants of the riskiness of a bank (measured in this study by the distance to default) shows that a simple leverage ratio vastly outperforms the Basel T1 ratio. Furthermore, business model features (after controlling for macro factors) have a huge impact. Derivatives origination, prime broking, etc. carry vastly different risks to core deposit banking. Where such differences are present, it makes no sense to have a one-size-fits-all approach to capital rules. Capital rules make more sense when fundamentally different businesses are separated.
\end{abstract}

\section{Introduction}

The Basel Committee of Bank Supervisors (BCBS) has continued to lead the process of bank microprudential reform since the global financial crisis in 2008/9, evolving a set of proposals collectively referred to as Basel III. ${ }^{2}$ The latter is a vast improvement over Basel II, which created an across-the-board cut in capital for banks prior to the largest crisis since the 1930s. The BCBS proceeded to revise Basel II by adding onto it a vast set of complex new rules. The primary focus of the BCBS is on capital rules applied to riskweighted assets; it has not been charged with examining the structural business models of banks to which these capital rules apply. By necessity, the process has been one of 
policy "on the run," which was not able to benefit from any evidence-based research. As more and more data on banks since the crisis comes to hand, this situation is changing, and the relative importance of business model factors, and capital and liquidity rules in influencing the riskiness of banks, can be tested. This paper reviews the Basel III proposals, presents new evidence about the factors determining the riskiness of banks, and asks whether structural reform of banks' business models is a necessary part of the reform process.

There are two broad paths to bank failure: fundamental insolvency and/or liquidity crises typically arising from counterparty risk. A sudden decline in asset values (if properly marked to market) can wipe out bank capital. But the very risk of this in a crisis makes counterparties unwilling to lend, which is especially problematic when banks need cash and/or liquid securities to meet margin calls for derivatives transactions, repos, and other collateral needs. ${ }^{3}$ This depends very much on the structural business model of banks. Bad assets, on the other hand, are easier to hide, particularly when they are illiquid, rely on mark-to-model valuations, and/or are held to maturity in banking books. ${ }^{4}$ These assets may take many years to mature, at which time their true recovery value is realized. If it is below the previously reported value, write downs will follow, and this can go on for some years after a crisis. Banks in this position (latent insolvency with bank and regulatory forbearance) are often forced into deleveraging and asset sales. Less important banks are sometimes forced to fail, though this discipline has been more common in the USA than in Europe. Where banks are systemically important, governments do intervene to lessen the deadweight losses to the economy from a systemic crisis, and this sort of implicit guarantee can lead to the underpricing of risk, causing leverage and counterparty risk to be higher than it would otherwise be. The bank is rewarded if the strategy works and the taxpayer bears the risk alongside shareholders if it fails.

Historically, policymakers have at times, particularly in the USA, combined capital rules with policies that constrain the business models of banks (such as Glass-Steagall). But this was gradually undermined by the great push for deregulation in the past few decades. At the national level, regulators are implementing the capital rules in different ways, and are also combining this with some attempts to constrain certain aspects of what banks actually do-bank business models (Vickers, Volcker, Liikanen, and Swiss's "separability" requirements). This paper first looks at the Basel system historically, and then summarizes most of the key problems with it that contributed to the failure of regulation to avoid the recent global financial crisis. In Section II, the paper summarizes the recent Basel III proposals, and Section III critically analyzes them. Section IV presents new empirical evidence on leverage and business model features that make banks risky, and hence need to be addressed by regulation. This section asks whether Basel III addresses these issues appropriately. Finally, Section V, in conclusion, provides a summary of the main arguments.

\section{The Basel System Historically}

Capital regulations under Basel I came into effect in December 1992 (after development and consultations since 1988; BCBS 1988). The aims were to require banks to maintain 
enough capital to absorb losses without causing systemic problems and to level the playing field internationally (to avoid competitiveness conflicts): a minimum ratio of 4 percent for Tier 1 capital (which should mainly be equity less goodwill) to risk-weighted assets (RWA) and 8 percent for Tier 1 plus Tier 2 capital (certain subordinated debt, etc.). ${ }^{5}$ The Basel I risk weights were fixed by the BCBS. A "revised framework" known as Basel II was released in June 2004 (BCBS 2004) after many issues arose with Basel I, most notably that regulatory arbitrage was rampant (Jackson 1999). Basel I gave banks the ability to control the amount of capital they required by shifting between assets with different weights on balance sheet, and by securitizing assets and shifting them off balance sheet - a form of disintermediation. Banks quickly accumulated capital well in excess of the regulatory minimum, and capital requirements, in effect, had no constraining impact on banks' risk taking.

Basel II cut risk weights across the board and introduced an enormous moral hazard into the pillar 1 capital rules for large complex banks by letting them use their own internal risk models to determine the riskiness of assets to which risk weighting would apply. Total RWA is based on a complex system of risk weighting that applies to "credit," and adds on a calculation of market risk (MR) and operational risk (OR), which are calculated separately:

\section{Equation 4.1}

$$
\mathrm{RWA}=12.5(\mathrm{OR}+\mathrm{MR})+\sum_{\mathrm{i}} \mathrm{w}_{\mathrm{i}} \mathrm{A}_{\mathrm{i}}
$$

where: $w_{i}$ is the risk weight for asset $I$, and $A_{i}$ is asset I, OR and MR are directly measured and grossed up by 12.5 for 8 percent equivalence, and credit risk is the sum of the various asset classes, each weighted by its appropriate risk weight. Banks were to be able to choose between: first, a simplified approach (for smaller institutions without the capacity to model their business in risk terms) by using revised fixed weights; second, an approach based on external ratings; and third, an internal ratings-based (IRB) approach for sophisticated banks, driven by their own internal rating models. This paper focuses mostly on the latter banks, which are central to the issues of counterparty risk and systemic issues.

The IRB approach requires banks to specify the probability of default (PD) for each individual credit, its loss given default (LGD), and the expected exposure at default (EED). This requires highly complex modeling and aggregation, and offers banks with the necessary expertise the possibility of deriving more risk-sensitive weights. This approach requires the approval of the bank's supervisor. By proposing this system, the BCBS contributed directly to the buildup of leverage that was one of the principle causes of the crisis.

In previous studies, Blundell-Wignall and Atkinson focused on several major problems with the Basel II approach; notably, portfolio invariance (no penalty for concentration; Gordy 2003); the assumption of a single global risk factor; ${ }^{6}$ the pro-cyclicality of Basel; inconsistent internal models used for calculating risk weights and subjective inputs; unclear and inconsistent definitions (particularly capital); the inadequate treatment of interdependence risk (especially in the area of derivatives) $;^{7}$ and the failure to deal 
with business models and the problem of "too big to fail" (TBTF) (so that pillar 3 could never work). This latter TBTF aspect is important, not so much because traders and shareholders are not punished by failed strategies - they are - but rather because other risk-taking institutions can assume that their counterparty positions will not default if the bank that they deal with is TBTF. Risk taking is underpriced as a consequence. This issue relates to the structure of banks and their resolvability; while it directly affects the capital risked by a bank, it has not been the main focus of the BCBS.

\section{The Basel III Reforms}

Basel III looks to deal with the above issues by raising the quality of capital, by adding buffers for large banks, by adding charges for counterparty credit risk, and by considering a very weak leverage ratio (BCBS 2001, June). Basel III also aims to deal with liquidity coverage issues in the light of problems that arose in relation to meeting counterparty commitments (derivatives and repos in particular). It is also working on stable funding to avoid excessive dependence on short-term wholesale funding to fund long-term assets. Greater monitoring and disclosure to supervisors of risk factors (e.g. contractual mismatches) not otherwise directly addressed in the regulations are also mentioned.

The main features of capital-regulation reform are as follows:

- Raising the quality consistency and transparency of the capital base: Basel III stresses that quality equity is the best form of capital and hence requires multiple deductions from common equity (goodwill; minority interest; deferred tax assets net of liabilities; bank investments in its own shares; bank investments in other banks, financial institutions, and insurance companies with the 10 percent rule; provisioning shortfalls; and other minor deductions, such as the banks' defined-benefit pension scheme holdings of the bank's shares). Criteria for Tier 2 capital are toughened: it must be subordinate to depositors, have a five-year minimum maturity, and there must be no incentives to redeem. Tier 3 capital is abolished. Common equity T1 (CET1) as a percentage of RWA is to be phased in from 3.5 percent in 2013 to 4.5 percent by 2015, and total Tier 1 from 4.5 percent to 6 percent over the same period.

- Capital conservation buffer: Outside of periods of stress, a buffer is to be phased in to 2.5 percent above the CET1 minimum by January 1, 2019. This may be run down in periods of stress, and built up again afterwards (e.g. by reducing discretionary dividend distributions, buybacks, and staff bonus payments).

- Dealing with pro-cyclicality: To deal with this problem, largely introduced by Basel II anyway, a countercyclical buffer will apply, which can vary in a range of 0-2.5 percent, based on national authorities' assessment of excess credit growth, weighted by the operations of the bank in all its different jurisdictions. More forward-looking provisioning shortfalls to be deducted from equity should also be seen in the context of addressing pro-cyclicality, as should the longer run calibration of the PD in modeling risk. $^{8}$

- The 2019 introduction of a leverage ratio: The BCBS is proposing a parallel run (2013 to 2017) that could result in a 3 percent leverage ratio based on Tier 1 capital, maintained 
on a 3-month-ended basis from 2019. Banks have begun testing this now to see what it means for their businesses. Exposure consists of on-balance sheet assets, plus derivatives at replacement cost with positive values (plus an add-on for potential future exposure, e.g. 5 percent or 10 percent), plus securities financing, plus other off-balance sheet exposures (with a 100 percent credit conversion factor). Legally valid bilateral netting of derivative transactions is allowed for calculating derivatives exposure. ${ }^{9}$ For written credit derivatives, the full notional value is to be used in the exposure measure, but any purchased CDS on the same reference entity can be netted if its remaining maturity is equal to or greater than the written derivative. Collateral received cannot be netted against derivatives exposure; the replacement cost of derivatives must be grossed up by any collateral used to reduce its net value. This is because collateral received does not reduce leverage, as the bank can re-hypothecate the collateral received. Collateral provided must gross up the exposure measure where it would otherwise reduce on-balance sheet exposure: under IFRS, the fall in cash assets is grossed up by a rise in receivables. Under GAAP, where derivative instruments are held off balance sheet, the replacement cost is to be arrived at by summing the positive fair values. For credit derivatives, the full notional value of written contracts must be reduced by any purchased CDS of the same reference entity, where the maturity of the purchased CDS is greater than the written CDS.

Dealing with systemic risk and interconnectedness:

- The Trading Book reforms of 2008: an incremental risk charge (IRC) equal to the estimated default and migration risk of unsecuritized products over a one-year capital horizon (at the 99 percent confidence interval), to allow for credit default and migration risk in bank trading books. These types of losses cannot be captured in banks' shorter-term VaR modeling. This is aimed at providing for the sort of losses that resulted from banks unwinding trading book assets in illiquid markets in 2008; it has the effect of adding to RWA.

Subsequently, Basel III attempts further to deal with interconnectedness risk by better calibration of the capital rules:

- A capital requirement for counterparty credit risk (CCR): using stressed inputs, helping to remove pro-cyclicality that might arise from using current volatility-based risk inputs.

- Credit valuation adjustments (CVA): capital charges on positive exposures that are (therefore) associated with the deterioration in the creditworthiness of a counterparty (as opposed to its outright default), valuing counterparty risk in bond equivalents, and applying the MR regulatory charge to such bond equivalents (after deducting the IRC). Transactions with a central clearing counterparty (CCP) can be excluded, as can certain non-material securities financing transactions. The CVA is calculated within each of the netting sets and is then added across netting sets. ${ }^{10}$ Banks employ CVA desks to hedge with external counterparties to get CVA credit offsets to this charge.

- A pillar 1 capital charge for wrong-way risk: transactions with counterparties, especially financial guarantors, whose PD is positively correlated with the amount of exposure. 
This will be done by adjusting the multiplier applied to the exposure amount identified as wrong-way risk.

- An asset valuation correlation multiplier (AVC) of 1.25, to be applied to exposures to regulated financial firms with assets of at least US\$100 billion (since AVGs were 25 percent higher during the crisis for financial versus non-financial firms). This would have the effect of raising risk weights for such exposures.

- The application of tougher (longer) margining periods: as a basis for determining regulatory capital when banks have large and illiquid derivative exposures to counterparties.

- A zero risk weight for counterparty risk exposure with exchanges and CCPS: hence, creating an incentive to use exchanges and CCPs (since higher charges will apply for bilateral OTC derivatives).

Basel III deals with the liquidity coverage issues in the following way: ${ }^{11}$

- The liquidity coverage ratio: Banks are required to maintain a ratio equal to or greater than 100 percent of high-quality liquid assets (HQLAs) to total net cash outflows for the next 30 days (enough to cover a stressed event).

- HQLA consists of level 1 assets, which are mostly those used in central bank transactions, such as cash, central bank reserves, securities backed by some sovereigns and central banks; plus level 2 assets, category A (certain sovereign debt, covered bonds, and corporate debt), and category B (lower-rated corporate bonds, residential mortgagebacked securities, and certain equities). Level 2 assets can be at most 40 percent of HQLA and 2B at most 15 percent.

- Cash net outflow consists of payable liabilities (including off-balance sheet commitments) multiplied by the rates that they are expected to run down in a stressed event, less receivables times the rate at which they are expected to flow in. Inflows are capped at 75 percent of expected outflows to ensure a minimum HQLA holding. In normal periods, the ratio is maintained, but can be used with supervisory approval in the event of a stress event.

With respect to stable funding, the following proposals are under consideration:

- Net stable funding ratio: While work is still ongoing (to be reported in 2014), the proposal is that banks maintain a ratio equal to or greater than 100 percent of available stable funding to required stable funding.

- Available stable funding is defined as: Tier 1 and Tier 2 capital (100 percent) + preferred stock not in Tier 2 with maturity $\geq 1$ year $(100$ percent $)+$ liabilities $\geq 1$ year $(100$ percent $)+$ stable shorter-term retail and small-business funding (with $\leq € 1 \mathrm{~m}$ per customer) (85 percent) + less stable (e.g. uninsured non-maturity) retail and small-business funding (70 percent $)+$ unsecured wholesale funding (50 percent). Central bank discounting is excluded to avoid overreliance on central banks.

- The required stable funding ( $R S F)$ is based on on-balance sheet and off-balance sheet exposures, and is defined as: cash, securities $\leq 1$ year, loans to financial firms $\leq 1$ year $(0$ percent $)+$ unencumbered marketable sovereign, central bank, BIS, IMF, etc., AA 
or higher with a 0 percent Basel III risk weight $(20$ percent $)+$ gold, listed equities, corporate bonds $\mathrm{AA}-$ to $\mathrm{A}-\geq 1$ year, loans to non-financial corporate $\leq 1$ year (50 percent $)+$ loans to retail clients (85 percent) + all else (100 percent). Off-balance sheet exposures to be included are conditionally revocable and irrevocable credit facilities to persons, firms, SPVs, and public sector entities: a 10 percent RSF of the currently undrawn portion. All other obligations will have an RSF set by the national supervisor.

In 2012, the BCBS launched the Regulatory Consistency Assessment Program (RCAP) to monitor the consistency of the introduction of Basel III in national jurisdictions, and to provide analysis on the outcomes. The first set of findings published in January 2013 are of some concern - they show considerable variation in the risk weighting of assets held in the trading book due to factors other than risk exposure. ${ }^{12}$

\section{National approaches recognize that Basel III is not enough}

The FDIC in the USA has long pointed to the problems with the Basel risk-weighting approach, which creates only the "illusion of capital adequacy" (Hoenig 2013; Norton 2013). The Collins Amendment to the Dodd-Frank Act, drafted by the FDIC, removes trust-preferred securities from Tier 1 capital, and establishes that there should be two floors for insured deposit institutions, bank and thrift holding companies, and systemically important non-bank financial companies: (i) not less than the generally applicable riskbased capital leverage ratio requirements; and (ii) not quantitatively lower than these requirements as they were in effect for insured depository institutions as of the date of the enactment of the bill. In July 2013, the FDIC and the US Federal Reserve issued a joint statement referring to research that shows that the Basel III 3-percent leverage ratio would have done little to ameliorate the last crisis, and that eight TBTF US-insured bank-holding companies (BHCs) would have to meet a 5 percent leverage rule, and 6 percent for insured depository institutions inside such groups, in order to be considered "well capitalized" for prompt corrective-action purposes. At the same time, the Volcker Rule (discussed below) was enacted to take up the issue of separating banks from certain risky business activities - indicating agreement with those believing that bank risk could not be left to the Basel III standards alone.

The USA has introduced the Comprehensive Capital Analysis and Review (CCAR) exercise and approves the capital plans of 18 BHCs (Federal Reserve 2013). The capital required is based on rigorous stress-testing exercises. The USA has doubled the amount of capital held by these 18 BHCs (to US $\$ 792$ billion at the end of 2012 from US $\$ 393$ billion in 2008). In mid-December 2012, the USA proposed rules to deal with the operation of large foreign bank organizations (FBOs) in the USA (Federal Reserve 2012). They will be required to create intermediate holding companies (IHCs) comprising all US banking and non-banking operations, and all US rules on leverage, separation, etc. will apply to the IHCs (but not to branches). These IHCs would therefore (if the changes were implemented) face much tougher rules than in their home countries: US Basel III application, liquidity, and leverage rules. These separated IHCs would also miss out on wider group netting benefits for derivatives and repos. The equal treatment of IHCs is 
consistent with the OECD view that all financial promises should be treated equally in regulations, at least in the USA.

The UK follows Basel III, but puts more weight on national micro- and macroprudential regulation to be conducted within the Bank of England. As with the USA, recent speeches by the Bank of England have expressed grave reservations about the Basel III approach to capital rules, and the need to look at bank business models alongside them (Haldane 2012, 2013). The Prudential Regulatory Authority (PRA) is working with individual UK banks to implement capital plans consistent with the recommendations of the Bank of England's new Financial Policy Committee (FPG). Where necessary, and based on stress tests, banks have to meet capital standards more exacting than Basel III. Following Lloyds, RBS, and Nationwide reviews, the most recent plan announced for Barclays includes new capital issuance, a disclosure plan for dividends, and the achievement of a 3 percent leverage ratio by June 2014 - some four years before the Basel III implementation of such a ratio. Recognizing that Basel III leaves business model risk issues on the table, the UK authorities have approved the ring fencing of retail banking in the Vickers Report (discussed below).

Europe's CDR IV follows Basel III more closely than in most other jurisdictions. However, following the 2011 stress tests, ministers at the EU summit in October of that year agreed that a subset of 71 banks in the stress test should meet a CET1 ratio of 9 percent by June 2010. The problem here, as noted below, is that banks can meet the target easily by adjusting (with their models and use of derivatives) the ratio of RWA to total assets (TA). Europe also aims to move to a banking union with one rulebook, but it has not sorted out how supranational regulation will work without a funded resolution regime. Europe too has recognized that Basel III does not address business model risk issues with its Liikanen Report. Discussed further below, it is the proposal on separation that more than any other needs major rethinking.

The OECD believes that questions of capital and leverage must be considered alongside counterparty risk arising from banks' business model issues: they are interdependent. These views are based on detailed empirical research using large panels of bank data.

\section{Assessing Basel III}

Basel III represents an advance over Basel II, and more capital being required; the deductions from equity to improve the definition of capital, the measures to counter pro-cyclicality, the revised LCR, and the NSFR idea might be singled out in this respect. However, using the portfolio invariance principle to add linear refinements to the Basel II capital rules adds complexity without considering the business models of the banks to which they apply. This process is like creating a map on a one-to-one scale, by adding on more and more granular refinements. The above summary of some of the main features of Basel III have been accompanied by countless detailed documentation, formulas, clarifications, and extensions. This goes on continuously, and examples from mid-2013 alone include: revisions to the leverage ratio, loosening of the LCR rules, and changes to the capital regulations for exposures to CCPs; a clarification on bank equity investment in 
funds; LCR disclosure standards; updating the method for identifying global systemically important financial institutions (G-SIFIs) and suggesting higher loss-absorbency requirements for them; a consultative document for non-internal model methods for capitalizing CCR exposures; and much more. Since the Basel III reform process started, there have been literally thousands of pages of additional documentation. This certainly adds to bank administrative costs, where armies of analysts are employed in risk control and compliance divisions; but the most important question really concerns whether despite all the complexity, it is likely to be the most effective approach to avoiding future crises.

There are two very basic problems with Basel III:

- First, it is too complex, allowing large banks plenty of room to manipulate it with both their models and derivatives, thereby avoiding effective control on leverage. In this respect, the RCAP finding in January for the trading book risk-weighting variations is no surprise.

- Second, notwithstanding all of the above rules, Basel III has not dealt with bank business model issues that are at the heart of TBTF underpricing of risk and the interconnectedness that is associated with it. Instead, the BCBS puts its faith in the capital and liquidity rules, while moving derivatives toward exchanges and CCPs to handle counterparty risk, and this will alleviate the need for banks to hold capital where this is achieved.

\section{Complexity and leverage}

The financial system is a system of promises, so the most basic regulatory principle for financial markets should be that those promises are always treated in the same way, no matter how they are measured with models, transformed, and/or shifted around in the global markets with derivatives. Basel III has continued with the Basel II IRB approach relying on banks' own modeling of the riskiness of assets for the capital rule, and hence, one should not be surprised that banks will report vastly different levels of capital to support an identical portfolio of assets. In a sense, there is always going to be different Basel IIIs for every bank in the world. Furthermore, banks can still shift the promises around by transforming risk with derivatives (particularly CDS) to minimize their capital costs - including shifting them beyond the jurisdiction of bank regulators - for example, to the insurance or hedge fund sectors in a least regulated jurisdiction. While the LCR and NSFR are still under discussion, the approach suggested also relies on banks' estimated payables and receivables, and depositor behavior in crisis and non-crisis situations. It mimics the capital standards approach by constructing ratio constraints, assigning weights, and relying on bank modeling.

Risk weight optimization to reduce the ratio of RWA to TA and hence the corpus to which the capital rule applies has always been a feature of the Basel system. ${ }^{13}$ The objective of listed banks is to raise the share price, which requires management to focus on a targeted ROE. Given that net profits at any point in time are constrained 
by the bank's business model and the level of competition, the target ROE can be achieved by reducing the capital $(\mathrm{K})$ they hold, so: $\mathrm{K}^{*}=\pi / \mathrm{ROE}^{*}$. But $\mathrm{K}^{*}$ is also defined as a multiple of RWA assets in Equation 1, dependent on OR, MR, and the weights $\mathrm{w}_{\mathrm{i}}$. The latter becomes endogenous to the corporate objective of maximizing the share price. As more complexity is added, the scope for endogenization of the inputs to the capital and liquidity rules is increased. Banks can only be expected to take advantage of this. Figure 4.1 shows the ratio RWA/TA for 27 GSIFI banks (i.e. 21 GSIFI banks defined by the FSB and 6 former GSIFI banks that failed in the crisis, referred to earlier), and 564 non-GSIFI banks. The use of models and derivatives to lower this ratio is systematic - it has the effect of raising leverage per unit of capital and improving the ROE. ${ }^{14}$ Since the trading book reforms of 2008, and during all of the Basel III consultation process, these trends have continued unabated: the recent RCAP exercise showing that the capital required to support the identical portfolio of assets varies so widely between banks is entirely consistent with the time series findings shown here. ${ }^{15}$

These problems related to complexity and leverage could be removed by moving to a simple, adequate leverage ratio, and leaving banks' VaR modeling to their own internal risk controls without requiring it to be encompassed in, and hence contaminated by, the regulatory framework. Leverage, a key component of bank risk, would be controlled directly, and would depend only on appropriate accounting rules. Unfortunately, however, the 3 percent Tier 1 leverage ratio "backup" goal being considered by the BCBS for 2019 is too lax. It allows leverage of 33-times capital and, in addition, banks are permitted to net derivatives transactions when calculating the leverage ratio. This latter arrangement has always puzzled the present authors: netting is a settlement concept, particularly in the event of default, and it does not in any way protect a bank from market risk. Hence, netted derivatives are not an appropriate basis on which to base ex ante capital rules. Leverage ratios that

Figure 4.1. RWA to total assets: G-SIFI banks versus non-G-SIFI banks

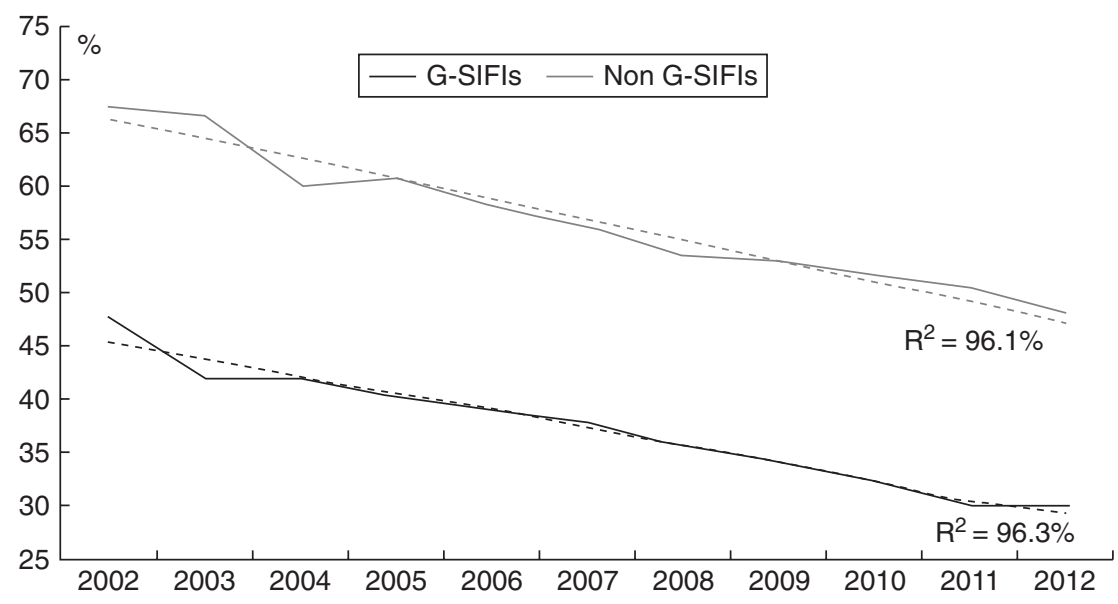

Source: Bloomberg, OECD. 
give rise to capital for ex ante market risk would be larger than those allowed under Basel III.

Figure 4.2 shows an aspect of the crisis that lies at its very core-interconnectedness risk. The broken line shows the gross credit exposure (GCE) of derivatives the gross market value [GMV] minus netting) and the collateral demanded to cover those open derivative positions, according to the ISDA. From December 2007 to December 2008, the estimated collateral demanded rose from US\$2.1 trillion to US\$4 trillion; the net rise in collateral demanded was US $\$ 1.9$ trillion; and collateral demanded has remained in the US\$3.2 trillion to US $\$ 4$ trillion range subsequently. These numbers are illustrative of the actual pressures that the banking system had to bear in the crisis years in respect to margin calls related to derivative and repo positions.

While derivatives enhance leverage and should be included in the leverage ratio, they also give rise to liquidity risk due to counterparty positions and the need to fund margin calls. New OECD empirical evidence based on a large panel of bank data sheds light on which leverage concepts matter for bank risk and which do not, and how leverage interacts with the structural business models of banks to determine overall risk. The findings show very clearly that risk weighting of assets does not addresses the structural business model issues that lead to default risk. Indeed, leverage and derivatives are shown to interact in ways that simply cannot be addressed by a reasonable single capital rule.

\section{Interconnectedness and business model risk}

The process of arbitraging the Basel capital rules and embracing the innovations in structured products resulted in the rapid growth of wholesale funding of securities (including repos) hedged by CDS.

Figure 4.2. The gross credit exposure (GMV minus netting) of derivatives and collateral

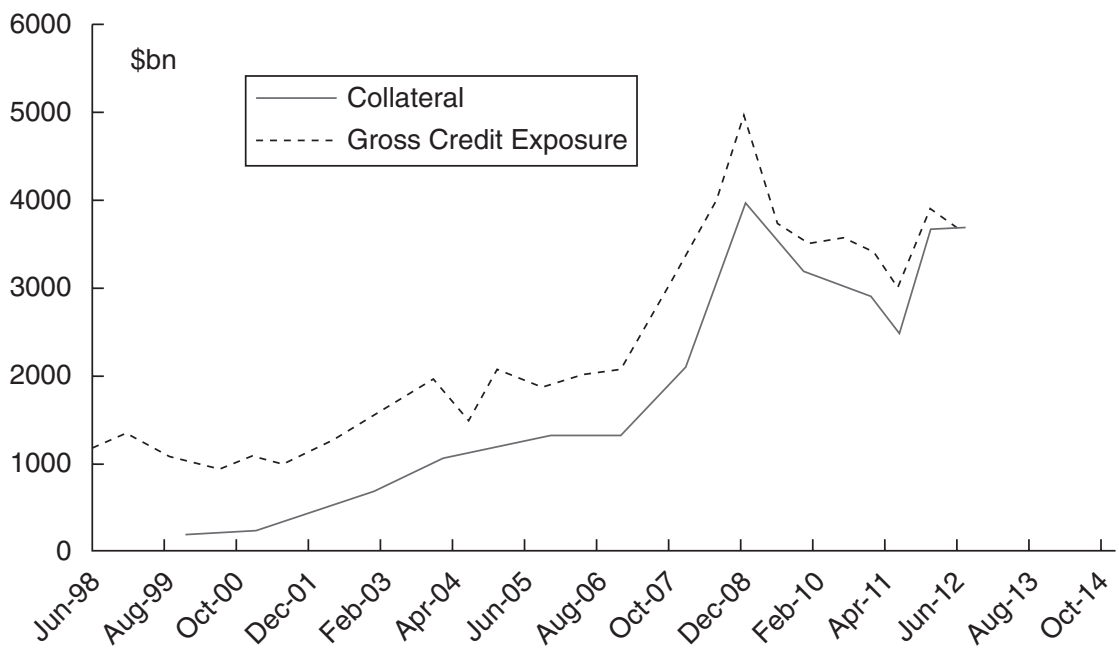

Source: BIS, ISDA, OECD. 
Derivatives had many advantages for TBTF banks:

- Shifting ownership of assets enabled both the regulatory and tax system to be arbitraged; CDS hedging to reduce capital requirements; and use of interest rate swaps and CDS to arbitrage the tax system (at the very heart of the structured products business).

- TBTF banks meant that counterparty failure was highly unlikely to result in positions not being paid out - and certainly, this belief was proved valid with the AIG bailout by the US government. Risk was underpriced. TBTF implicit guarantees affect CDS and other spreads, and these spreads are built into bank internal risk modeling, systematizing the underpricing of risk.

- With respect to defaults, both US and EU law exempted all credit collateralized with securities, and any derivatives from the "automatic stay in bankruptcy," and rules on cross-default clauses. The institutions dealing with these products could, in effect, front-run all others in the case of defaults - pushing the risk to other creditors and the taxpayer - a phenomenon certainly illustrated in the Lehman default.

While GSIFI banks are the core of the derivatives origination business, most banks were drawn into funding securities with repos, hedging them with CDS, and moving into the fee-for-sale securitization businesses. Many mortgage institutions (e.g. Countywide, see below) competed for loans to securitize assets, driving yields down, and moving into evermore marginal borrowers. In this respect, it is more correct to say that capital markets' banking caused the subprime crisis, rather than the latter causing a crisis in the former.

\section{Counterparty derivatives and repo risk that is separable from leverage rules}

In a complex capital markets' banking system, a crisis will result in asset price volatility, and a sharp rise in margin and collateral calls (see Figure 4.2). These have to be met. In normal times, the repo market and other forms of lending adjust, and the system meets all of its commitments. However, in a crisis, this lending dries up, and banks fail not because they are insolvent (even though they may well be), but because liquidity stops functioning. The central bank responses with respect to quantitative easing in the USA and LTROs in Europe need to be understood in this context - the inability to meet margin calls is the rapid path to default.

Figure 4.3 shows some elements of the interconnectedness:

- The broker-dealer bank $\mathrm{A}$ is engaging in derivative transactions with two counterparties $\mathrm{B}$ and $\mathrm{C}$. Following the pale arrows for the case of no clearing, bank A is down 100 with $\mathrm{B}$, and up 80 with $\mathrm{C}$. It is therefore exposed to a loss of 80 in the event of the default of C. For bank A, the Basel III CVA charge would apply to the netting set with $\mathrm{C}$ (no offsets in the simple example, so it applies to the 80).

- $\mathrm{A}$ is also down a net 20 when bank B is taken into account, and the crucial point is that this net 20 margin call has to be funded. Here there are choices, for example: (a) if the bank has a sufficient pool of liquid assets, in may sell them for cash, post collateral, and 
treat this as a receivable; (b) it may use cash to take on offsetting derivatives positions; and (c) it may take a short-term repo loan (shown in Figure 4.3) with a clearing bank. But in a crisis situation, the amounts may be too large, and liquidity in the repo and derivatives markets may not be available. ${ }^{16}$ If the broker-dealer cannot meet the margin call (e.g. Dexia), then it will default.

\section{Collateral calls, tripartite repos, etc.}

The typical tripartite repo transaction may involve a money market fund (MMF) earning a spread by providing finance to the broker-dealer $\mathrm{A}$, with a clearing bank intermediating and requiring securities as collateral. Liquidity can suddenly dry up due to a sharp fall in the value of the collateral pool, a refusal of the MMF to roll over a loan, or a run on the deposits of the MMF. In the event of a liquidity halt, the broker-dealer will need to have liquid assets on its balance sheet to sell or pledge to meet the call, receive central bank support, or otherwise default. The tripartite repo clearing banks centralize risk and connect multiple institutions, so that interconnectedness risk is a major feature. It is inconceivable that the authorities in a crisis could allow a clearing bank to fail. This implicit guarantee to the clearing bank itself causes risk to be underpriced.

\section{Central clearing counterparties (CCPS)}

Basel III appears to assume that counterparty risk can somehow be destroyed by shifting it to a CGP, where the CVA charge is zero. But the CCP needs capital, and it must model risk and set appropriate margins commensurate with that risk for all of its counterparties like any other player. Following the dark arrows for the CCP case in Figure 4.3, the net exposure is still 20 for the system as a whole, as opposed to gross exposures of 270. Bank A still needs to sell assets or borrow in the repo market to meet its commitment to the CCP. The ability of the CCP to guarantee the trades depends on its skill in setting initial and variation margins, as well as having sufficient capital to cover all default scenarios (the counterparties are holding a zero CVA charge for these trades). For example, with a major stress event, suppose that bank A suddenly owes a net 60, and the clearing bank

Figure 4.3. Collateral and margin calls

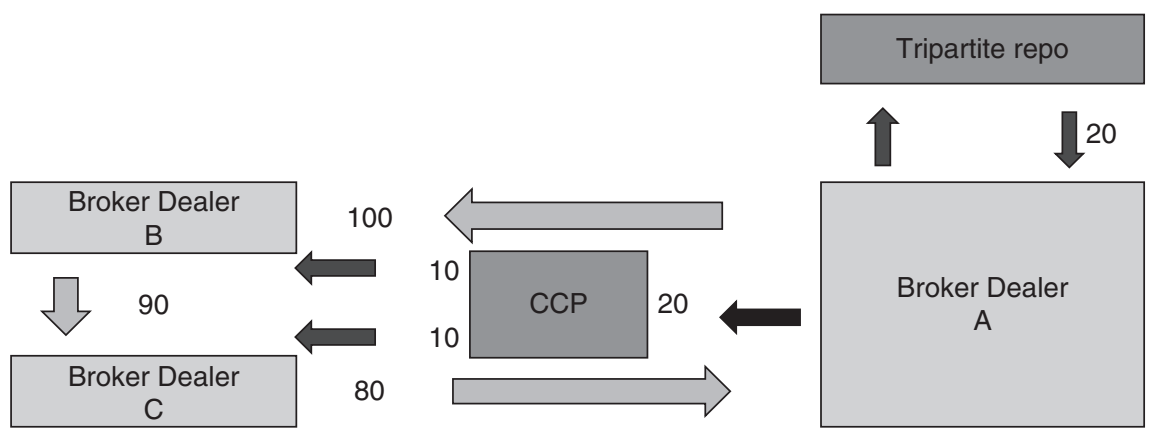

Source: OECD. 
refuses to lend it in a crisis. Bank A will fail. The CCP would have to guarantee the trades, but may not have the capital to do so.

In effect, the CCP is akin to the role of the clearing bank in a tripartite repo transaction. Market risk is not destroyed by a CCP, and the problem of the underpricing of that risk due to the TBTF implicit guarantee may be significantly worse. The CCP becomes a vital node, interconnecting multiple players in the financial system. The failure of such a node would lead to multiple contamination effects compared to bilateral trading. Governments and central banks could not allow the CCP to fail. Furthermore, since competition between CGPs can only really take the form of reducing collateral requirements to make the cost of trading cheaper for counterparties, margins may be reduced, causing systemic risk to rise rather than to fall.

It also needs to be noted that it is the least risky parts of the derivatives market that can be subject to clearing - for example, the large standardized and liquid interest rate swap market. Rather, it is the derivatives that cannot easily be cleared that were at the forefront of the problem. The non-cleared derivatives market includes, inter alia, the following:

- Very long-term interest rate swaps (e.g. 15-19 years) sought after by pension and insurance companies for liability management. A part of this market is non-standard and cannot be cleared.

- Single-name CDSs. The CDS has the potential for extreme collateral call shifts when the probability of the default of the reference entity increases. (These are popular for regulatory and tax arbitrage.)

- Swaptions - options on interest rate swaps (the rights to swap fixed and variable interest rates). This is a large market and is crucial in managing long-term interest rate risk across many industries. For example, if rates were thought to rise in the longer run, then a firm would have the option (not obligation) to exercise a swaption to pay fixed rates, and to receive the rising floating rate interest payments. These can be up to thirty years to maturity and are highly illiquid. They are not eligible for clearing.

- The forward rate agreement market for currencies with long horizons.

- Parts of the overnight index swap market. The floating rate leg is based on the reference rate of Fed funds or LIBOR, and it allows very short-term borrowers to manage interest rate risk inherent in sudden changes in the cost of funding and income received on longer-term assets.

- Many OTC commodity, energy, and equity derivatives cannot be cleared.

Consider the following example. If a user takes a position in volatility with a swaption, the trader will typically hedge the market risk in the position with the notional amount of the interest rate option equal to some percentage of the swaption (the maturity and coupon of the swap would mirror those of the swap on which the swaption is based). But if the swap is mandated to be cleared with the CCP and the swaption is executed bilaterally, there is no benefit in clearing the swap from a risk point of view. The greater complexity may raise risk, and will certainly increase collateral costs compared to keeping the swap and the swaption together bilaterally. ${ }^{17}$ 


\section{CVA approach leads to concentration bias}

Does the Basel III CVA charge deal adequately with counterparty risk? The CVA charge applies additively across netting sets. This creates an incentive for increased concentration in the derivatives market. If $\mathrm{B}$ and $\mathrm{C}$ are one bank, forming a single new netting set, then instead of exposure to a loss of 80 , bank A will be exposed only to a net loss of 20 within the netting set, and the CVA charge will be reduced (and reduced to zero if centrally cleared). The bank will be exposed to the same liquidity risk, but would hold less capital to deal with it. The Basel III CVA rule will encourage the larger broker dealers to trade with each other, raising the TBTF problem in the derivatives market and reducing competition. As noted in respect to leverage ratios, netting is a settlement concept, and it does not in any way mitigate market risk. Basing an ex ante capital rule on a settlement exposure concept makes little sense.

\section{New Empirical Evidence on Leverage and Interconnectedness Risk}

While Basel III has propelled reform of the capital rules, there has been no consensus on what to do about the risks created by the structure of bank business models. Approaches to the latter include the Vickers recommendations (Blundell-Wignall, Wehinger, and Slovik 2009; see also the Independent Commission on Banking 2011), the Volcker rule of the Dodd-Frank Act (Dodd-Frank 2010, section 619), and the Liikanen proposal, which is influencing decisions in a number of European countries, including France and Germany (Liikanen 2012). Most international organizations have focused on replacing Basel II with Basel III, on improved supervision, better disclosure, and cross-border cooperation. Better resolution regimes are proposed to deal with TBTF (e.g. IMF 2011, 2). Academics have stressed the difficulties of interpreting rules based on separation proposals (Duffie 2012), and some have been strongly against it (Goodhart 2011). However, these proposals have not been informed by empirical research on the determinants of sudden moves of banks toward the default point. This section tests the Basel Tier 1 ratio, alongside a simple leverage ratio (with no Basel II netting), and the key business model attributes of banks.

\section{The distance to default}

The starting point is to define a measure of the riskiness of individual banks that can serve adequately as the dependent variable in the panel regression study. The distance to default (DTD) is a measure that uses a combination of a bank's reported data and market information to calculate the number of standard deviations the bank is from the default point, where the market values of assets equals the book value of debt. The formula to calculate the DTD is derived from the option-pricing model of Black and Scholes (1973) and is set out as follows:

$$
D T D_{t}=\frac{\log \left(\frac{V_{t}}{D_{t}}\right)+\left(r_{f}-\frac{\sigma_{t}^{2}}{2}\right) \cdot T}{\sigma_{t} \sqrt{T}}
$$


where $V_{t}$ : market value of bank's assets at time $t$,

$r_{f}$ risk-free interest rate,

$D_{i}$ : book value of the debt at time $t$,

$\sigma_{i}$ : volatility of the bank's assets at time $t$,

$T$ : maturity of the debt.

The calculation is set out in more detail in Appendix 1 of Blundell-Wignall and Roulet (2012).

From 1997 to 2004, the DTD typically averaged 3 standard deviations in 69 large banks in the USA, UK, the Eurozone, and Switzerland. ${ }^{18}$ The weighted average DTD fell to 0 for banks in the UK and the USA, implying systemic insolvency, with many individual banks below the zero point. The average DTD fell to below 1 in Europe, with some major banks below the solvency point. The USA has recovered more quickly in 2011/12, while many European banks are still not at a safe point. Figure 4.4 shows the DTD for individual banks (shown simply with a number on the horizontal axis) for the most recent year of 2012 (the UK and Swiss banks are shown with Europe). It is very clear that the US response to the crisis, with forced capital injections following proper stress tests on bank assets, has led to US banks moving back well above the safe zone of 3 standard deviations, while European banks are more vulnerable. ${ }^{19}$

\section{Modeling the DTD}

A panel regression approach is used to explain the differences in DTDs across banks over the period 2004-12. The sample consists of more than one hundred large, US and EU, internationally active commercial banks and broker-dealer banks by equity market capitalization. In addition, six banks that failed in the crisis, but which can be considered G-SIFIs (HBOS, Merrill Lynch, Lehman Brothers, Washington Mutual, Wachovia, and Bear Stearns), are included. There are a total of 108 banks in the sample, consisting of 21 FSB G-SIFI banks (excluding Asian and non-listed banks), 6 failed former G-SIFI banks, 2 banks with a system-wide importance in their related countries (i.e. Intesa San Paolo and Banco Bilbao Vizcaya Argentaria), ${ }^{20}$ and 79 other large banks. Only publicly traded banks are included, because market data are required for the model. The data include all of the banks that carry out the counterparty activities in derivatives and other securities that are a key focus of this study.

The empirical model takes account of bank size, macroprudential influences, leverage, and business model aspects. The equation is estimated with two alternatives for leverage: the leverage ratio and the regulatory capital approach of the Basel Tier 1 ratio. The empirical model is specified in Equation 3, where the subscripts $i$ and $t$ denote the bank and the period, respectively:

\section{Equation 4.3}

$$
\begin{aligned}
D T D_{i, t}= & \propto_{i, t}+\beta_{1} T A_{i, t}+\beta_{2} K_{i, t}+\beta_{3} T D_{i, t}+\beta_{4} W F D_{i, t} \\
& +\beta_{5} G M V_{i, t}+\beta_{7} \text { BETA }_{i, t}+\beta_{8} \% H P I_{i, t}
\end{aligned}
$$


Figure 4.4. Distance to default in 2012: US versus Europe

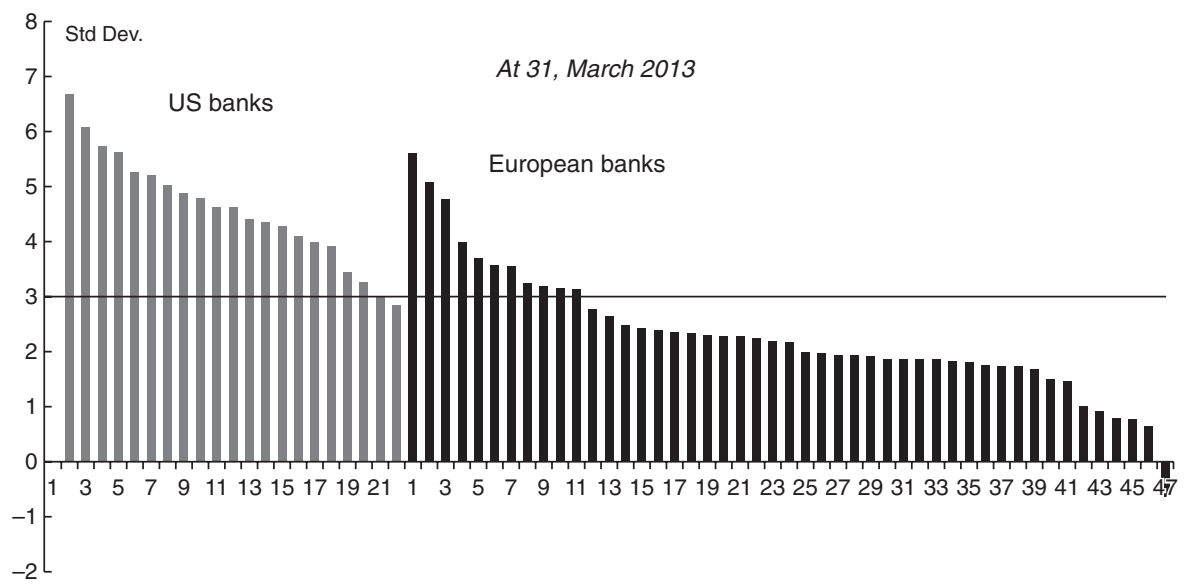

Source: OECD, Bloomberg.

TA is a size variable relating to the TBTF issue, equal to the total assets of the bank as a share of total assets in the national banking system. It is expected to be inversely related to the DTD. K corresponds to the simple rule leverage ratio (LEV), which is expected to have a negative sign, or to the Basel Tier 1 ratio (T1), which is expected to have a positive sign. The equation is estimated twice, once with LEV, excluding the Basel capital concept, and once with T1, excluding the simple leverage ratio. TD is the sum of the trading book and available-for-sale securities, and is expected to have a positive sign. The reason for this is that liquidity drives the banks' path to default in practice when margin and collateral calls cannot be delivered. Liquid assets can be sold or used as collateral. WFD refers to wholesale funding as a share of total liabilities and is expected to have a negative sign: higher wholesale funding typically at a shorter duration is less stable than deposits for funding longer-term assets. ${ }^{21}$ GMV refers to the gross market value of derivatives as a share of the banks' TA - appropriately converting all US banks to the IFRS concept for consistency. GMV is expected to have a negative sign; this is the quintessential interconnectedness variable where volatility drives rapid changes in margin requirements. BETA is a systemic importance variable, defined as the covariance of the firm's stock price with the national stock market, using daily data to calculate annual observations, divided by the variance of the national stock index. It is expected to have a negative sign on the grounds that the firm is more connected to the national macro and asset price cycle. Finally, \%HPI refers to the annual percentage change in the national house price index, and is expected to have a positive sign on the grounds that rising prices improve a borrower's equity in the home and vice versa. The two equations for the LEV and T1 alternatives are estimated for all banks, the G-SIFI banks, and the other large banks in the sample, using ordinary least squares (OLS). After testing for cross-section versus time-fixed versus random effects, and for the heteroskedasticity of error, crosssection and time-fixed effects are introduced into the regression. The regression results are shown in Table $4.1 .^{22}$ 
Causality in the model is tested with an error correction test shown at the bottom of the table: the DTD in the current year adjusts to a gap between the actual DTD and its predicted level in the previous year. ${ }^{23}$ All of the error correction terms are large coefficients (rapid adjustment within the year) and are significant at the 1 percent level.

The equation containing the Basel Tier 1 ratio (the second column for all banks) is a test of the null hypothesis that that the Basel risk-weighting approach to capital rules is related to the DTD, while the business model features are not (after controlling for the macro cycle risk factors). This hypothesis is rejected across all samples. The Basel Tier 1 ratio appears to find no support as a determinant of the DTD, while the business model features are significant mostly at the 1 percent level in the large sample, and for the G-SIFI group. The coefficient on derivatives in the second column is large compared to the equation with the leverage ratio shown in the first column, and is highly significantconsistent with the earlier observations that the Basel system does not capture the interaction between derivatives and leverage on the one hand, and derivatives and counterparty risk on the other.

The simple leverage ratio in the preferred model in the first column (without derivatives netting) is well determined at the 1 percent level for the large sample, for the G-SIFI banks, and for the non-G-SIFI panels. The macroprudential variables in house prices and the market beta are correctly signed and significant at the 1 percent level across all models. The size of a bank in its own market (TBTF) in the larger samples is significant at the 1 percent level. ${ }^{24}$

In terms or arguments relating to the business model, the GMV of derivatives and wholesale funding have the expected negative signs and are significant at the 1 percent level for the full sample, and for the G-SIFI group, though not for the non-G-SIFI banks, which have only a small derivatives component in their portfolios. Trading assets have the expected positive signs that find support at the 5 percent level for the full sample and for the G-SIFI banks, but not in a sample that excludes the G-SIFIs. Notice that in the equation with the leverage ratio in the full sample, the size of the derivatives coefficient is reduced somewhat compared to the model including the Basel Tier 1 ratio, but it remains highly significant. Two separable risks appear to be identified here: leverage (without derivatives netting) and, separately, derivatives as a counterparty and market risk argument. The positive sign for trading securities and its significance at the 5 percent level in the large sample suggests that derivative counterparty risks can be ameliorated by the holding of liquid tradable assets, which provide liquidity in the face of margin and collateral calls.

\section{No one capital rule will suffice}

When the DTD measure is back engineered to calculate the additional amount of capital that would be required by banks through the crisis period to keep the level above 3 standard deviations (a safe level, implying a less than 1 percent chance of default, where extreme market volatility does not take the bank quickly to the zero level), it becomes clear that the capital rule cannot be considered independently of the business model of the bank. In 2009, the 69 large US and European banks used in such a back-engineering 


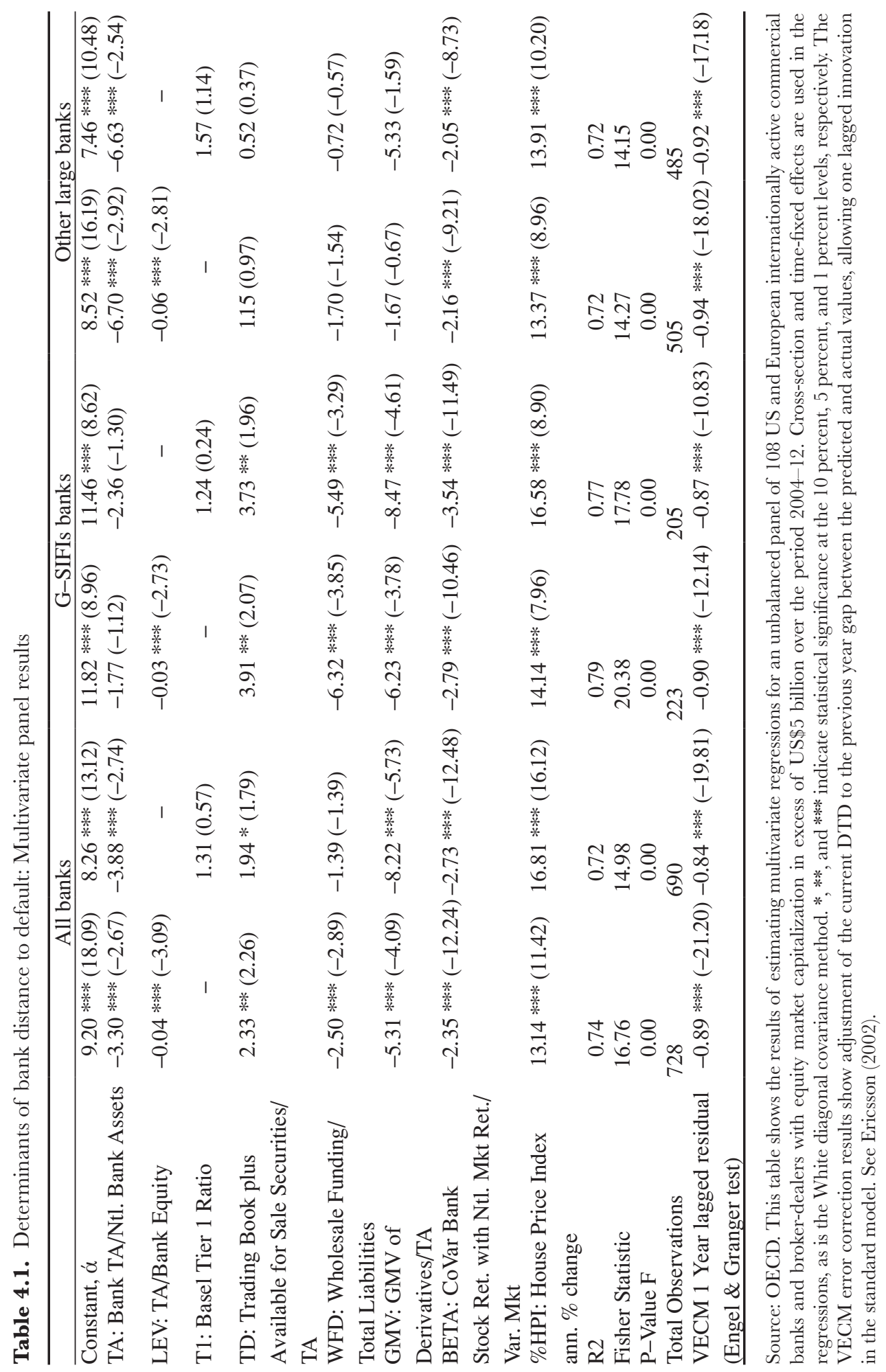


exercise had US\$1.6 trillion in capital, but those below 3 standard deviations in the DTD would have required US $\$ 4.5$ trillion more to stay at the safe level (almost a quadrupling). It is also clear that the bulk of additional capital was required by the G-SIFI banks, because of what they do in businesses unrelated to deposit taking and lending: in the capital markets, origination (including derivatives), market making (prime broking), and underwriting. These are different businesses, which bring very different risks, particularly where margin and collateral calls are concerned. To hold capital even remotely near the levels needed in the good times to be safe in a tail risk event would seem to be unreasonable.

Overall, leverage is only one aspect of risk, and where vast differences in business models are concerned, it makes no sense to aim for a one-size-fits-all capital rule. Such a single rule does not exist. It is for this reason that the OECD argues for separating the fundamentally different business model features in a non-operating holding company (NOHC), where the subsidiaries are ring fenced in a legal structure that is binding. In the case of a separation between a core deposit-taking bank and a securities subsidiary, the structure implies explicitly that the creditors of the latter cannot chase the assets and capital of the former (and vice versa). This ensures that the risks of these very different businesses will be priced according to where they are taken, without the implicit subsidy of a TBTF bank. The cost of capital and credit will rise for the securities subsidiary and the business will be smaller for the same allocation of capital from the non-operating parent. The securities subsidiary will not be TBTF.

\section{Concluding Remarks}

Basel II proposed changes to the capital requirement rules that allowed large banks to run their own internal models to calculate the riskiness of the assets to which the capital rules would apply, introduced pro-cyclicality into those rules, and did so at a time when financial innovation made it easier for banks to shift risk via securitization, CDS, and off-balance sheet exposures. Banks systematically reduced the ratio of RWA/TA and had insufficient capital to deal with the crisis as it emerged. This crisis had at its core both leverage and interconnectedness risk related to the changing business models in banking.

In reforming Basel, the BCBS sought to add linearly greater complexity to the system utilizing the Basel model properties of portfolio invariance. This complexity has made it even more difficult to bring capital rules into alignment for all financial institutions - it has not achieved the regulatory principle that the financial promises should be treated in the same way no matter where they are shifted. Furthermore, the panel regression results showed that the DTD is correlated with the simple leverage ratio, but not at all with the Basel Tier 1 ratio; yet, despite the evidence, the reform process continues to focus on allowing banks to run complex models for risk weighting to control leverage, while business model features that have strong independent effects on the DTD have not been the subject of coordinated, global reforms.

The Basel add-on proposals for interconnectedness risk and central clearing are untested, and there has been no sign that the size of derivatives businesses and repo funding in G-SIFI banks will be reduced by the Basel reforms. The CVA charge applies 
at the netting set level, and is additive across netting sets. Like other aspects of Basel, the approach does not reward diversification. A large number of netting pools will mean less scope for cross-product netting, which will add to a positive CVA charge. If larger G-SIFI banks choose to deal more and more with each other, they increase the scope for cross-product netting and reduce the CVA charge. Hence, the Basel rule encourages more concentration in derivatives; it increases the TBTF problem in derivatives rather than reducing it. Furthermore, netting is a settlement process concept; it provides no protection for market risk. Basing capital rules on the netting pool is not in the interests of the future stability of the financial system.

As noted before, the panel regression results suggest that a simple leverage ratio is essential, but it cannot compensate for the large impact on the DTD of business model features. This brings the discussion back to the necessity of structural separation and where the lines for separation should be drawn. The bank regulators' paradox is that large, complex, and interconnected banks need very little capital in the good times, but they can never have enough in an extreme crisis. Separation of fundamentally different business segments is required to deal with this problem.

\section{Notes}

1 Adrian Blundell-Wignall is the special advisor to the OECD secretary-general for financial markets, and the deputy director of the Directorate of Financial and Enterprise Affairs. Paul Atkinson is a former deputy director of the OECD and the principal of NHA Economics. Caroline Roulet is an OECD economist and analyst. The views in this paper are those of the authors and do not necessarily reflect those of any member government of the OECD.

2 See all of the BCBS references below.

3 Similarly, fear of insolvency can lead to a "run" on deposits. This can be the most rapid path to default.

4 Such as level 2 and level 3 assets.

5 Banks may use a default risk weighting or a sophisticated internal model approach to define how risk assets are - the lower the risk, the lower the weight for capital purposes. A third tier of capital is defined in the Market Risk Amendment to the original accord.

6 See Gordy (2003, 23): Almost prophetically, he says, "A single factor model cannot capture any clustering of firm defaults due to common sensitivity to these smaller scale components of the global business cycle. Holding fixed the state of the global economy, local events in, for example, France are permitted to contribute nothing to the default rate of French obligors. If there are indeed pockets of risk, then calibrating a single factor model to a broadly diversified international credit index may significantly understate the capital needed to support a regional or specialized lender."

7 See, for example, Blundell-Wignall and Atkinson (2008), Blundell-Wignall and Atkinson (2010), OECD (2009), and Blundell-Wignall and Atkinson (2011).

8 The Basel III proposals are broadly consistent with the 2009 independent Geneva Report; see Brunnermeier et al. (2009), which favors leaning into the credit cycle. However, the authors propose that microprudential policy should fall to national Financial Stability Authorities (FSAs), consolidating all financial institutions at a national level, while macroprudential policy should fall to the national central bank, which would coordinate site inspections, and other roles with the FSA. National FSAs are recommended, as national authorities pay in the case of defaults. But international coordination should be achieved with supervisory colleges. 
9 See BCBS (2013b); the sum of all positive and negative mark-to-market values, but not including any contracts with walk away clauses - e.g. where there are no obligations to a defaulter counterparty.

10 The notional of the bond is the EAD of the counterparty (treated as fixed); the maturity of the "bond" is the effective maturity of the longest-dated netting set of a counterparty; and the time horizon is one year (as opposed to the ten-day period for MR).

11 This was softened greatly compared to the original cash and government bonds focus, as it became clear that collateral shortage was a major issue. See BCBS (2013a, January).

12 See BCBS Regulatory Consistency Assessment Program (2013, January). In fact, for portfolios of identical assets, the gap between the highest to the lowest capital needed to support the portfolio was 300 percent.

13 Basel II permitted sophisticated banks to model the riskiness of their own portfolios to calculate risk-weighted assets (RWA) to which the capital rules were applied - an approach that continues under Basel III. By reducing the ratio of RWA to TA, banks are able to minimize the capital required to conduct their activities, and hence to expand leverage. The change in SEC rules in 2004 allowed investment banks to be supervised on a consolidated entities basis, in place of the strict SEC limitations on leverage. This was equivalent to the regulatory minimum that US banks would need to operate in Europe. The huge problems with the move to Basel II were at the heart of the problem. See Blundell-Wignall and Atkinson (2008, 2010, 2011, 2012), Blundell-Wignall, Atkinson, and Roulet (2012), and Blundell-Wignall and Roulet (2012).

14 The BCBS has started to look at risk weight manipulation via modeling and to take it more seriously; see BCBS (2013).

15 Variants of this chart and commentary may be found in Blundell-Wignall and Atkinson (2008, 2011).

16 It is surprising how many economists, bankers, and financial analysts point out that these clearing banks got through the crisis without failing, as though this suggested that the structures were safe. These views make no allowance for the massive support and bailouts that banks received from governments (particularly in the USA). Allowing AIG to fail, for example, could have collapsed the entire edifice. This is not the structure that is desirable for the future.

17 In other words, the delta and gamma of a long-dated interest rate hedge may end up residing in different silos.

18 This sample includes the largest publicly traded commercial banks in the USA and in Europe with TA that exceed US $\$ 50$ billion. The G-SIFI banks comprise 21 of the G-SIFI banks in the USA and Europe, as officially defined by the FSB in November 2011. Banks are left out where the data did not extend back to 1997.

19 A standard deviation of 2 implies a 5 percent chance of default, which is too high for the global financial system.

20 Their average TA and total market capitalization from 2004 to 2012 are higher than these of the smaller G-SIFI banks, as defined by the FSB (i.e. Nordea Bank).

21 This is short-term (including repo) and some longer-term debt securities that need to be rolledit excludes deposits, equity, subordinated debt, and derivative liabilities from total liabilities.

22 This set of results adds a further year to that reported in Blundell-Wignall and Roulet (2012).

23 The error correction equation takes the lagged residuals of the panel regression and allows for one lagged change in the dependent variable.

24 This is true at the level for all banks and in the other large bank samples, but not for the smaller sample of G-SIFI banks only. The reason for this appears to be that all G-SIFI banks are large and there is less size diversity compared to the larger samples.

\section{References}

Basel Committee on Banking Supervision (BCBS). 1988. "International Convergence of Capital Measurement and Capital Standards.”July. 
2004. "International Convergence of Capital Measurement and Capital Standards: A

Revised Framework." June.

2006. "International Convergence of Capital Measurement and Capital Standards: A

Revised Framework - Comprehensive Version."June.

. 2009a. "Revisions to the Basel II Market Risk Framework." Consultative document, January.

2009b. "Analysis of the Trading Book Impact Study." October.

2011. "Basel III: A Global Regulatory Framework for More Resilient Banks and Banking

Systems." Revised version, June.

. 2013a. "Basel III: The Liquidity Coverage Ratio and Liquidity Risk Monitoring Tools." January.

2013b. "Revised Basel III Leverage Ratio Framework and Disclosure Requirements." June.

BCBS Regulatory Consistency Assessment Program (RCAP). 2013. "Analysis of Risk Weighted

Assets for Market Risk." January.Black, F., and M. Scholes. 1973. "The Pricing of Options and

Corporate Liabilities." Fournal of Political Economy 81 (3): 637-54.

Blundell-Wignall, A., and P. E. Atkinson. 2008. "The Subprime Crisis: Causal Distortions and

Regulatory Reform." In Lessons from the Financial Turmoil of 2007 and 2008, edited by Kent and

Bloxham: 55-102. Australia: Reserve Bank of Australia.

2010. "Thinking Beyond Basel III: Necessary Solutions for Capital and Liquidity." OECD

Fournal: Financial Market Trends 2010 (1): 1-23.

2011. "Global SIFI's, Derivatives and Financial Stability." OECD fournal: Financial Market

Trends 2011 (1): 1-34.

2012. "Deleveraging, Traditional versus Capital Markets Banking and the Urgent Need to

Separate GSIFI Banks.” OECD fournal: Financial Market Trends 2012 (1): 1-42.

Blundell-Wignall, A., P.E. Atkinson, and C. Roulet. 2012. "The Business Models of Large Interconnected

Banks and the Lessons of the Financial Crisis." National Institute Economic Review 221: 31-44.

Blundell-Wignall, A., and C. Roulet. 2012. "Business Models of Banks, Leverage and the

Distanceto-Default." OECD Fournal: Financial Market Trends 2012 (2): 7-34.

Blundell-Wignall, A., and P. Slovik. 2010. "The EU Stress Test and Sovereign Debt Exposures."

OECD Working Papers on Finance, Insurance and Private Pensions, no. 4, August. Online: http://www.oecd.org/dataoecd/17/57/45820698.pdf (accessed August 11, 2014).

Blundell-Wignall, A., G. Wehinger, and P. Slovik. 2009. "The Elephant in the Room: The Need to

Focus on What Banks Do.” OECD Fournal: Financial Market Trends 2009 (2): 11.

Brunnermeier, M., A. Crockett, C. Goodhart, A. Peraud, and H. Shin. 2009. The Fundamental

Principles of Financial Regulation. Geneva Report. CEPR, ICMB, and VoxEU.

Dodd-Frank. 2010. Dodd-Frank Wall Street Reform and Consumer Protection Act. Pub. L. 111

203. 124 Stat. 1376. United States of America.

Duffie, D. 2012. "Market Making under the Proposed Volcker Rule." Working Paper, Stanford

University Graduate School of Business. Online: http://www.darrellduffie.com/uploads/ policy/DuffieVolckerRule.pdf (accessed August 11, 2014).

Ericsson, N. R., and J. G. Mackinnon. 2002. "Distributions of Error Correction Tests for Cointegration." Econometrics fournal 5: 285-318.

Goodhart, C. A. E. 2013. "The Optimal Financial Structure.” LSE Financial Markets Group Paper Series, Special Paper 220.

Gordy, M. B. 2003. "A Risk-Factor Model Foundation for Ratings-Based Bank Capital Rules." Fournal of Financial Intermediation 12 (3): 199-232.

Federal Reserve. 2012. "Proposed Rules to Strengthen the Oversight of US Operations of Foreign Banks." December 14.

2013. "Comprehensive Capital Analysis and Review 2013: Assessment Framework and

Results." March 14.

Federal Deposit Insurance Corporation (FDIC). 2005. "Capital and Accounting News: Basel II and the Potential Effect on Insured Institutions in the United States: Results of the Fourth Quantitative Impact Study (QIS-4).” Supervisory Insights, Winter: 27-32. 
Haldane, A. 2012. "The Dog and the Frisbee." Speech given at the Federal Reserve Bank of Kansas City's 36th economic policy symposium, "The Changing Policy Landscape," Jackson Hole, WY.

2013. "Constraining Discretion in Bank Regulation." Speech given at the Federal Reserve Bank of Atlanta conference on "Maintaining Financial, Stability: Holding a Tiger by the Tail(s)," Federal Reserve Bank of Atlanta.

Hoenig, T. 2013. "Basel III Capital: A Well-Intended Illusion.” Speech delivered to the International Association of Deposit Insurers, Basel, April.

Independent Commission on Banking. 2011 . "Interim Report: Consultation on Reform Options." April.

Jackson, P. 1999. "Capital Requirements and Bank Behaviour: The Impact of the Basle Accord." Basel Committee on Banking Supervision Working Papers, no. 1, April.

Kane, E. J. 2006. "Basel II: A Contracting Perspective.” NBER Working Papers, 12705, November. Liikanen, E. 2012. "High-Level Expert Group on Reforming the Structure of the EU Banking Sector: Final Report." Brussels, October.

Norton, J. O. 2013. "A More Prominent Role for the Leverage Ratio in the Capital Framework." FDIC Speech to Florida Bankers Association.

OECD. 2009. "The FinancialCrisis: ReformandExitStrategies." Paperpresented at the 2009London G20 Summit. Paris: OECD. Online: http://www.oecd.org/dataoecd/55/47/43091457.pdf (accessed August 11, 2014). 
Chapter 5

\section{AT THE BRINK OF INSOLVENCY: SHALLOW RECAPITALIZATION EXERCISE FAILS TO BOLSTER EUROPE'S AILING BANKS}

\section{Jakob Vestergaard and María Retana}

\section{Introduction}

"European banks have made significant progress in boosting their capital positions and in strengthening the overall resilience of the European banking system," said Andrea Enria, Chairman of the European Banking Authority, when the results of the recapitalization exercise were published. "More than $€ 200$ bn has been injected into the European banking system," he continued, and European banks "are now in a better shape to finance the real economy." (EBA 2012b, 1)

In this chapter, we show how misleading this characterization is. The recapitalization orchestrated by the European Banking Authority (EBA) was based on a questionable capital assessment methodology. ${ }^{1}$ Basing regulatory capital requirements on riskweighted assets (RWA) is a much less reliable indicator of banks' soundness and resilience than simpler ratios of capital to total assets (Acharya et al. 2011). We therefore compare the assessments undertaken by the EBA — all of which are based on RWA — with data on leverage ratios, defined as equity capital to total assets.

The key findings are as follows. First, by equity capital criteria, the recapitalization of European banks was insufficient at best, and little but a smokescreen in many cases. Only 7 out of 24 banks actually increased their ratio of equity capital to total assets. Second, the least well-capitalized banking sector among the larger Eurozone countries is not Spain or Italy, but Germany, closely trailed by France. The banking sectors of Spain and Italy have equity to total assets roughly double the size of those of Germany and France, contrary to what one might have expected. Third, European banking remains several quantum leaps away from the levels of equity capital recommended by scholarsand, hence also remains vulnerable to shocks, and dependent on various forms of state subsidies, guarantees, and bailouts. Fourth, the EU's new capital requirement regulation and directive, the CRD4, will institutionalize the European reluctance to recapitalize its banks, and hence impede rather than improve the resilience of European banks. 
Our finding that equity capital levels in European banking are far below the 15 percent of total assets recommended in the bank capital regulation literature is not surprising. What is more surprising, however, is that large parts of European banking are undercapitalized, even when the internationally agreed minimum requirement of 3 percent equity capital relative to total assets is used as the benchmark. Although this minimum equity capital requirement is not yet legally binding for banks, it is quite troubling that a large part of European banking is undercapitalized, even by a minimum standard that is widely agreed to be far too low.

The chapter is structured as follows. Section 2 reviews two approaches taken by the EBA in assessing the capitalization and resilience of European banks; Section 3 presents new empirical material, demonstrating that European banking remains dangerously undercapitalized; Section 4 discusses key limitations of the European recapitalization exercise; Section 5 reviews Europe's implementation of Basel III in Europe in the fourth Capital Regulation Directive (CRD4), noting that this legislation is likely to further institutionalize the observed reluctance to seriously recapitalize Europe's banks by imposing a de facto ceiling on capital requirements; and finally, we offer concluding remarks in Section 6.

\section{Stress Tests and Recapitalization Exercises}

To assess the health and resilience of its banking industry, European authorities launched three different initiatives in the period from early 2011 to mid-2012. First, a stress test exercise examined the resilience of European banking to an adverse macroeconomic scenario. Second, a Basel III monitoring exercise assessed capital levels in European banks under current rules vis-à-vis full implementation of Basel III rules. Thirdly, the EU capital exercise calculated which banks would need to recapitalize by what amounts of new capital if they were to meet a temporary 9 percent requirement for "Core Tier 1" (CT1) capital. In this section, we briefly review two of these efforts: the 2011 stress test exercise and the recapitalization exercise.

\section{From stress tests to recapitalization}

During the months of March and April 2011, a stress test exercise of 90 European banks was conducted by the EBA. The goal was to assess the resilience of European banks to an "adverse but plausible" scenario, involving a deterioration of macroeconomic variables as well as sovereign stress. ${ }^{2}$ The biggest banks in each country were included in the stress tests, in descending order, adding banks until at least 50 percent of each national banking sector was covered. The main findings of the stress test exercise, published in July 2011, were as follows:

- Only 8 banks fell below the 5 percent minimum threshold for CT1 capital, while 16 banks had a CT1 between 5 percent and 6 percent.

- Under the stressed scenario, 20 banks fell below the threshold of 5 percent CT1 capital.

- Only 18 of the 90 banks included in the stress test were able to maintain a ratio of CT1 capital to RWA of over 10 percent in the stressed scenario.

In the event of just a moderately stressful scenario (such as envisaged by the EBA), only one in five European banks would maintain a reasonably solid capital base. Thus, although 
only eight banks officially "failed" the stress tests, in fact, only a small proportion of European banks appeared to be well capitalized.

In October 2011, the European Council launched a "comprehensive package aimed at addressing the deterioration of macroeconomic and market conditions," including a "capital exercise" for European banks (Bisio et al. 2011). First, the EBA undertook an assessment of the capitalization of a sample of 70 European banks. These were all the banks that participated in the 2011 stress test exercise, excluding the 20 Spanish banks that participated voluntarily. Banks' capitalization levels were assessed against a benchmark of 9 percent CT1 capital ratio. The 9 percent requirement was framed as an "exceptional and temporary capital buffer" and explicitly aimed to "provide reassurance to markets about the bank's ability to withstand a range of shocks and still maintain adequate capital" (EBA 2011c, 1).

Twenty-seven banks were singled out for the recapitalization exercise. The aggregate capital shortfalls of this set of banks were estimated to amount to $€ 76$ billion. The EBA asked national authorities to require banks to strengthen their capital positions so as to meet the 9 percent requirement for CT1 capital (as a share of RWA) by June 2012. One year later, on October 3, 2012, the EBA published the final results of the EU recapitalization exercise. The total recapitalization amounted to $€ 115.7$ billion for the 27 involved banks. This was, in the view of EBA, in considerable excess of the $€ 76$ billion capital shortfall initially identified for these banks. "The vast majority of banks in the sample meet the required ratio of 9 percent," the EBA noted, and for those banks that did not meet the 9 percent CT1 ratio, "backstop measures" were being implemented (EBA 2012a, 3). The message communicated by the EBA was that by summer 2012, European banking had significantly recapitalized; all European banks now had capital bases above the 9 percent CT1 capital threshold, a criteria seen as stricter than the requirements of the recently agreed international standard, Basel III. The recapitalization had strengthened the capital base of the European banking system and had increased its overall resilience, without any significant adverse impact on lending into the real economy, the EBA contended (EBA 2012a, 4).

\section{Scapegoating Southern European banks?}

The EBA's assessment of the capital shortfall of European banks has been subject to considerable criticism, mainly on the following three grounds: the absence of a serious stress scenario, reliance on bank self-reporting, and a too modest a recapitalization target (Acharya et al. 2012; Jenkins 2011). Viral Acharya and colleagues estimated that for the recapitalization to have been adequate, the largest European banks would have needed a total of between $€ 600$ and $€ 800$ billion of additional capital - that is, between five and seven times as much as the capital shortfalls estimated by the EBA. We will discuss the adequacy of the recapitalization in much more detail in Section 3 below. For now, it is important to highlight a less discussed, but equally problematic aspect of the assessments undertaken by the EBA: the stress test data released by the EBA made the European banking crisis seem mainly Southern European, when in reality, it was not. 
Among the small group of eight banks officially failing the stress tests, all but one were Southern European. Of course, these eight banks were the ones that caught the attention of the media. For those that wanted to dig deeper, what was offered additionally by the EBA was a list of 20 banks that had less than 6 percent CT1 capital. Although this list included two German banks and one Austrian bank, it still seemed to suggest that the undercapitalization of banks was mainly a Southern European problem.

Two rather serious qualifications must be noted, however. First, the failing of a small set of Southern European banks had more to do with questionable methodological choices than with banking realities, and, second, if the average levels of capitalization of banking sectors are compared, Southern European banks fare just as well or significantly better than German and French banks, depending on the criteria applied. When undertaking its 2011 stress tests, the EBA chose to deploy a new capital category, instead of utilizing the standard capital categories of the international Basel III framework, as it had done in its stress tests the year before.

In a situation where it was widely believed that the stress test would need to be tougher than in the previous years, the EBA could have adopted a simple ratio of equity capital to total assets, it could have raised the Tier 1 ratio that it had used the year before (from 6 percent to, say, 9 or 10 percent), or it could have done both, stipulating that to pass the stress tests, banks would need to have equity capital above 3 percent of total assets and Tier 1 capital of above 9 percent of RWA. This would have been in line with recent developments in the context of the Basel III Accord, endorsed by G20 leaders just months before the European stress test exercise was set in motion. Instead, the EBA invented a new capital category: CT1 capital. The toughening of the stress tests consisted in the adoption of a stricter definition of capital than for Tier 1. But this fell far short of adopting a criterion of highest quality capital, as would have been the case if the leverage ratio had been chosen. Further, the tightening of the capital definition vis-à-vis the 2010 stress tests was compromised by a lowering of the ratio itself. The 6 percent Tier 1 capital requirement was replaced with a 5 percent CT1 capital requirement - and the net differences then became very small, to say the least.

Why did the EBA pretend to toughen the stress tests as opposed to actually toughening them? To answer that, consider what would have happened if they had indeed adopted stricter criteria. Table 5.1 shows what the results would have been if the stress tests had operated with higher ratios of capital to RWA or a leverage ratio of 3 percent (equity capital to total assets). In each of these three scenarios, quite a few large German and French banks would have failed, including Deutsche Bank, Commerzbank, BNP Paribas, and Societé Generale. ${ }^{4}$ Had such results been published, it would have been apparent to markets as well as the general public that the European banking problem was not so much a Southern European problem, but one that struck at the heart of the Eurozone.

Two reasons may explain the "methodological choices" of the EBA. First, the EBA wanted only a small set of banks to fail the stress test, and it wanted these to be relatively small banks from countries in the periphery of the Eurozone. The criteria of a 5 percent 
Table 5.1. Number of banks that would have failed the 2011 stress test according to three different benchmarks

Results of the stress test after the effects of capital issuance and mandatory restructuring plans publicly announced and fully committed by April 30, 2011

\begin{tabular}{lccc}
\hline Country & $\begin{array}{c}\text { CT1 ratio } 9 \% \\
\text { December } 2012\end{array}$ & $\begin{array}{c}\text { Tier 1 ratio 9\% } \\
\text { December 2012 }\end{array}$ & $\begin{array}{c}\text { Leverage ratio 3\% } \\
\text { December 2012 }\end{array}$ \\
Germany & 9 & 7 & 9 \\
France & 4 & 2 & 2 \\
UK & 4 & 2 & 1 \\
Spain & 4 & 2 & 1 \\
Italy & 5 & 4 & 2 \\
\hline
\end{tabular}

Source: EBA data released with the final results of the stress-test exercise.

CT1 capital ratio made it possible to argue that the criteria were now tougher than before, while at the time identifying only a handful of Southern European banks as troubled.

On closer scrutiny, it turns out that the portrayal of the banking crisis as mainly Southern European is even more misleading than what is suggested by the above data. For when the more relevant criterion of equity capital to total assets is considered (instead of various risk-weighted measures), the picture is turned upside down: German and French banks are then by far the least well capitalized in Europe, as we shall now see.

\section{The Gontinued Undercapitalization of European Banking}

A clear finding of recent studies in the bank capital regulation literature is that there should be more regulatory focus on equity capital relative to total assets than on broader measures of capital relative to RWA (more on this in Section 4). The EBA not only focused on the least informative capital ratio, the CT1 capital ratio, but also did not report leverage ratios, nor release data for total assets so that analysts could calculate non-riskweighted ratios themselves.

In this section, we estimate leverage ratios for 25 out of the 70 banks included in the recapitalization exercise, as well as aggregate estimates for the four key Eurozone countries: Germany, France, Italy, and Spain. We also report the data for the banks in the UK that account for 50 percent of total assets of the country's banking sector, as a point of reference. Before explicating the results, a brief comment on our methodology in arriving at the data is warranted.

\section{Methodology}

Our main interest is to estimate leverage ratios (equity to total assets) for all German, French, Italian, and Spanish banks involved in the recapitalization exercise, as of June 2012, so as to be able to compare this (more solid) measure of capitalization with the 
CT1 capital relative to RWA deployed by the EBA. More specifically, we make three such comparative assessments:

- What is the trend in bank capitalization from December 2011 to June 2012 (as assessed by these two different capital ratios)?

- What are the main bank-by-bank differences in capitalization levels (as assessed by these two different capital ratios), both before and after the recapitalization?

- What are the main differences across the four countries, in terms of the average level of capitalization of their banking sector (as assessed by these two different capital ratios), both before and after the recapitalization, and in the period from 2005 to 2011 ?

The two main data sources are the results released by the EBA and Bankscope, respectively. From the data released by the EBA, we have taken data on CT1 capital, common equity, and RWA, whereas leverage ratio data are from Bankscope. However, given that data on total assets as of June 2012 were not released by the EBA, and also are not available in Bankscope (where the latest available total assets figures are from late 2011), we have had to estimate this part of the dataset ourselves.

We arrived at this admittedly rough estimate of total assets by assuming that the ratio of RWA to total assets was the same in June 2012 as it was in December 2011, and then imputing total assets from the figures for RWA given by the EBA. While this may seem a somewhat crude assumption, we should like to stress that it is most likely a conservative assumption. Considering the continuous downward trend of the ratio of risk-weighted to total assets, it is more than difficult to imagine a substantial reversal of that trend over the six-month period in question. In other words, our estimate is more likely to underestimate than overestimate total assets - and hence, by implication, is more likely to overestimate than underestimate leverage ratios.

Finally, we arrived at country-level data by aggregating data for all banks that participated in the stress test exercise. Given that this set of banks covered over 65 percent of the EU banking system's total assets, and at least 50 percent of the national banking sectors in each of the member states - and also included all the largest banks for each country - we find it reasonable to assume that this procedure provides a good, and probably slightly conservative characterization of the European banking sector as a whole. ${ }^{5}$

\section{Overall results}

The first question we set out to answer in our critical assessment of the European recapitalization plan is the following question: Did the recapitalization plan have a significant impact on the leverage ratios of banks in these key Eurozone countries?

Table 5.2 shows the evolution of $\mathrm{CT} 1$ ratios and leverage ratios between December 2011 and June 2012 for the Spanish, German, French, and Italian banks that participated in the recapitalization exercise. The results are telling. All but two banks in the sample increased their CT1 ratio in the period analyzed. On the other hand, when it comes to leverage ratios, only 7 out of 24 banks in the sample improved their position, 16 banks 
Table 5.2. The failed European recapitalization exercise

\begin{tabular}{|c|c|c|c|c|c|c|c|c|}
\hline \multirow[b]{2}{*}{ Country } & \multirow[b]{2}{*}{ Bank name } & \multicolumn{3}{|c|}{ December 2011} & \multicolumn{4}{|c|}{ June 2012} \\
\hline & & $\begin{array}{l}\text { RWA/ } \\
\text { Total } \\
\text { assets* }\end{array}$ & $\begin{array}{l}\mathrm{CT} 1 \\
\text { ratio }\end{array}$ & $\begin{array}{l}\text { Leverage } \\
\text { ratio }\end{array}$ & $\begin{array}{l}\mathrm{CT} 1 \\
\text { ratio }\end{array}$ & $\begin{array}{l}\text { Increase/ } \\
\text { decrease }\end{array}$ & $\begin{array}{l}\text { Leverage } \\
\text { ratio** }\end{array}$ & $\begin{array}{l}\text { Increase/ } \\
\text { decrease }\end{array}$ \\
\hline France & BNP Paribas & 0.31 & $9.6 \%$ & $3.56 \%$ & $10.9 \%$ & + & $3.42 \%$ & - \\
\hline France & BPCE SA & 0.49 & $9.1 \%$ & $2.78 \%$ & $10.0 \%$ & + & $4.90 \%$ & + \\
\hline France & Crédit Agricole SA & 0.30 & $9.6 \%$ & $2.48 \%$ & $10.7 \%$ & + & $3.25 \%$ & + \\
\hline France & Société Générale & 0.30 & $9.0 \%$ & $3.59 \%$ & $9.9 \%$ & + & $2.92 \%$ & - \\
\hline Germany & $\begin{array}{l}\text { Bayerische } \\
\text { Landesbank }\end{array}$ & 0.38 & $9.7 \%$ & $3.47 \%$ & $10.3 \%$ & + & $3.02 \%$ & - \\
\hline Germany & Commerzbank AG & 0.36 & $9.9 \%$ & $3.79 \%$ & $12.2 \%$ & + & $4.09 \%$ & + \\
\hline Germany & $\begin{array}{l}\text { DekaBank Deutsche } \\
\text { Girozentrale }\end{array}$ & 0.19 & $11.0 \%$ & $2.50 \%$ & $11.7 \%$ & + & $2.19 \%$ & - \\
\hline Germany & Deutsche Bank AG & 0.18 & $9.6 \%$ & $2.56 \%$ & $10.2 \%$ & + & $1.80 \%$ & - \\
\hline Germany & $\begin{array}{l}\text { DZ Bank AG- } \\
\text { Deutsche Zentral- } \\
\text { Genossenschaftsbank }\end{array}$ & 0.25 & $9.5 \%$ & $1.85 \%$ & $11.6 \%$ & + & $2.84 \%$ & + \\
\hline Germany & HSH Nordbank AG & 0.34 & $10.3 \%$ & $3.75 \%$ & $10.0 \%$ & - & $3.37 \%$ & - \\
\hline Germany & $\begin{array}{l}\text { Hypo Real Estate } \\
\text { Holding AG }\end{array}$ & 0.08 & $24.2 \%$ & $2.02 \%$ & $21.6 \%$ & - & $1.68 \%$ & - \\
\hline Germany & $\begin{array}{l}\text { Landesbank Baden- } \\
\text { Wuerttemberg }\end{array}$ & 0.29 & $9.2 \%$ & $2.85 \%$ & $9.9 \%$ & + & $2.85 \%$ & $=$ \\
\hline Germany & $\begin{array}{l}\text { Landesbank } \\
\text { Berlin AG }\end{array}$ & 0.28 & $12.3 \%$ & $1.21 \%$ & $12.7 \%$ & + & $3.49 \%$ & + \\
\hline Germany & $\begin{array}{l}\text { Norddeutsche } \\
\text { Landesbank }\end{array}$ & 0.37 & $7.3 \%$ & $3.08 \%$ & $9.5 \%$ & + & $3.30 \%$ & + \\
\hline Germany & WGZ-Bank AG & 0.20 & $10.1 \%$ & $3.06 \%$ & $10.4 \%$ & + & $2.07 \%$ & - \\
\hline Spain & $\begin{array}{l}\text { Banco Bilbao } \\
\text { Vizcaya Argentaria } \\
\text { SA }\end{array}$ & 0.55 & $9.4 \%$ & $6.85 \%$ & $9.9 \%$ & + & $5.26 \%$ & - \\
\hline Spain & $\begin{array}{l}\text { Banco Popular } \\
\text { Español SA }\end{array}$ & 0.68 & $7.4 \%$ & $6.45 \%$ & $10.3 \%$ & + & $5.58 \%$ & - \\
\hline Spain & Banco Santander SA & 0.45 & $9.4 \%$ & $5.77 \%$ & $9.5 \%$ & + & $3.79 \%$ & - \\
\hline Spain & $\begin{array}{l}\text { Caja de Ahorros } \\
\text { y Pensiones de } \\
\text { Barcelona-LA } \\
\text { CAIXA }\end{array}$ & 0.53 & $9.2 \%$ & $6.24 \%$ & $11.1 \%$ & + & $5.39 \%$ & - \\
\hline Italy & $\begin{array}{l}\text { Banca Monte dei } \\
\text { Paschi di Siena }\end{array}$ & 0.44 & $9.5 \%$ & $5.28 \%$ & $10.8 \%$ & + & $3.87 \%$ & - \\
\hline Italy & Banco Popolare & 0.67 & $7.1 \%$ & $6.08 \%$ & $10.2 \%$ & + & $6.88 \%$ & + \\
\hline
\end{tabular}


Table 5.2. Continued

\begin{tabular}{|c|c|c|c|c|c|c|c|c|}
\hline \multirow[b]{2}{*}{ Country } & \multirow[b]{2}{*}{ Bank name } & \multicolumn{3}{|c|}{ December 2011} & \multicolumn{4}{|c|}{ June 2012} \\
\hline & & $\begin{array}{l}\text { RWA/ } \\
\text { Total } \\
\text { assets* }\end{array}$ & $\begin{array}{l}\mathrm{CT} 1 \\
\text { ratio }\end{array}$ & $\begin{array}{l}\text { Leverage } \\
\text { ratio }\end{array}$ & $\begin{array}{l}\mathrm{CT} 1 \\
\text { ratio }\end{array}$ & $\begin{array}{l}\text { Increase/ } \\
\text { decrease }\end{array}$ & $\begin{array}{l}\text { Leverage } \\
\text { ratio** }\end{array}$ & $\begin{array}{l}\text { Increase/ } \\
\text { decrease }\end{array}$ \\
\hline Italy & Intesa Sanpaolo & 0.50 & $10.2 \%$ & $7.87 \%$ & $10.9 \%$ & + & $5.52 \%$ & - \\
\hline Italy & UniCredit SpA & 0.50 & $8.3 \%$ & $5.97 \%$ & $10.4 \%$ & + & $5.14 \%$ & - \\
\hline Italy & $\begin{array}{l}\text { Unione di Banche } \\
\text { Italiane SCpA-UBI } \\
\text { Banca }\end{array}$ & 0.70 & $8.6 \%$ & $7.90 \%$ & $10.4 \%$ & + & $7.28 \%$ & - \\
\hline
\end{tabular}

Source: Bankscope and EBA: http://www.eba.europa.eu/capitalexercise2012/ RECAP_2012_dataset. zip. Spanish Bankia SA and Portuguese Portigon AG are excluded from the table, since both were under restructuring at the time.

Notes: $\left(^{*}\right)$ Estimated using RWA figures from the EBA and total asset figures from Bankscope. (**) Authors' estimation.

suffered a drop, and 1 bank did not experience any change. No bank was even remotely in the region of the 15 percent leverage ratio recommended in the bank regulation literature - and seven banks were below the modest 3 percent minimum requirement for equity capital to total assets stipulated by Basel III (six of these are German banks and one is French).

These data do not lend themselves easily to as optimistic an assessment as the one given by the EBA when releasing its report. On the contrary, it should give rise to considerable concern that for two out of three banks involved in the European recapitalization exercise, the ratio of equity to total assets actually fell.

\section{The core of the problem is in the core of the Eurozone: German and French banks}

This somewhat gloomy picture, based on bank-by-bank data, is further reinforced when country-level data are considered. Figure 5.1 plots the average leverage ratios by country for the period from 2005 to 2011. As is immediately evident, the banking systems in the four countries analyzed have been severely undercapitalized throughout the period when assessed against the 15 percent equity capital to total assets benchmark.

What is more surprising perhaps is that German and French banks, which seemed healthier than the Spanish and Italian banks when assessed in terms of risk-weighted capital ratios, have fared significantly worse in terms of leverage ratios throughout this period. In fact, while Spanish and Italian banks have been consistently above the Basel recommendation of a 3 percent leverage ratio, the German and French banking sectors have remained below this threshold for most of the period.

To illustrate the geographical composition of the European undercapitalization of its banks further, consider a comparison of average leverage ratios with average CT1 and average Tier 1 ratios for the same set of banks (Table 5.3). 
Figure 5.1. Evolution of average leverage ratios for the largest Banks in Spain, Germany, Italy, France, and the UK

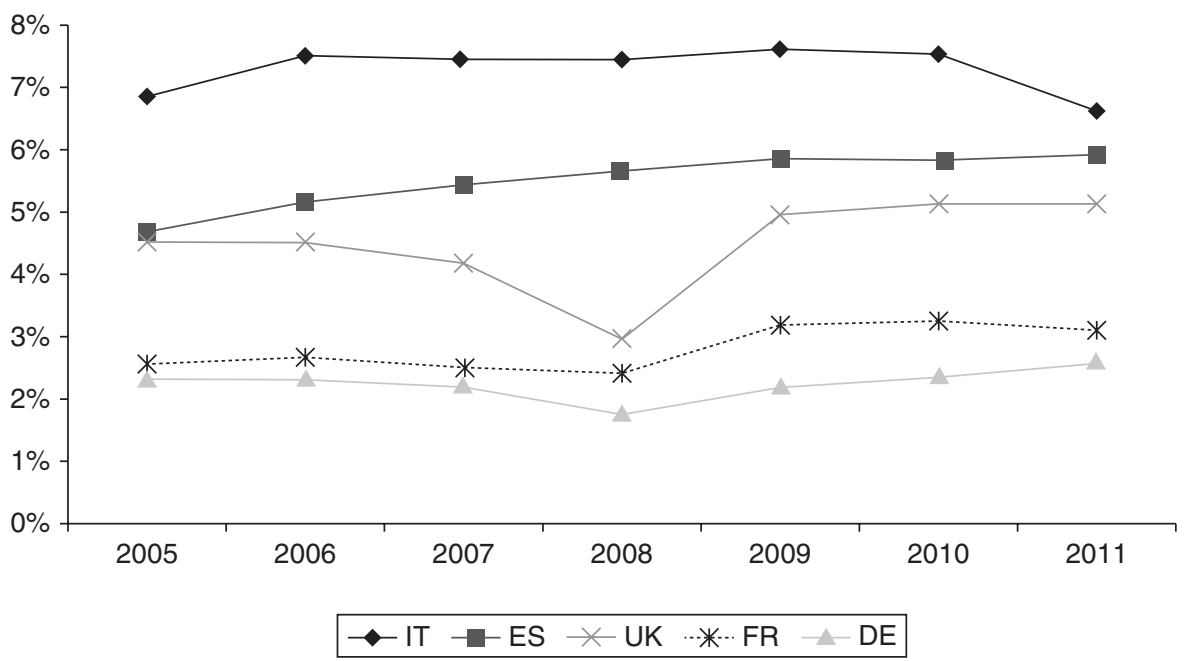

Source: Authors' calculations using Bankscope data.

Table 5.3. Average capital adequacy ratios by country for the largest banks (see Vestergaard and Retana 2013 for details)

\begin{tabular}{lccc}
\hline Country & Common equity/total assets & Core Tier l capital/RWAs * & Tier 1 capital/ RWAs ** \\
\hline Germany & $2.57 \%$ & $9.70 \%$ & $13.13 \%$ \\
France & $3.10 \%$ & $9.30 \%$ & $11.17 \%$ \\
UK & $5.13 \%$ & $10.63 \%$ & $12.49 \%$ \\
Spain & $5.92 \%$ & $9.90 \%$ & $10.55 \%$ \\
Italy & $6.62 \%$ & $9.34 \%$ & $9.86 \%$ \\
\hline
\end{tabular}

Source: Authors' calculations using Bankscope data.

German banks have a significantly higher level of capitalization than Spanish, Italian, and French banks when CT1 and Tier 1 ratios are used as a benchmark. But when the benchmark is the leverage ratio, these same German and French banks are significantly undercapitalized as compared to Italian and Spanish banks. This result is not driven by outliers. None of the German and French banks included in the sample had a leverage ratio above 3.6 percent, while no Spanish or Italian bank had a leverage ratio below 4.5 percent or 6.3 percent, respectively. ${ }^{6}$ In brief, the data make it abundantly clear that when equity capital to total assets is used instead of data on CT1 capital to RWA, German and French banks are in far deeper trouble than Spanish and Italian banks are. ${ }^{7}$

In sum, our results reveal that the devil really is in the detail: by using capital ratios based on RWA, banks characterized by low and precarious levels of capital can be made 
Figure 5.2. Average Core Tier 1 ratios versus leverage ratios for core Eurozone countries, December 2011

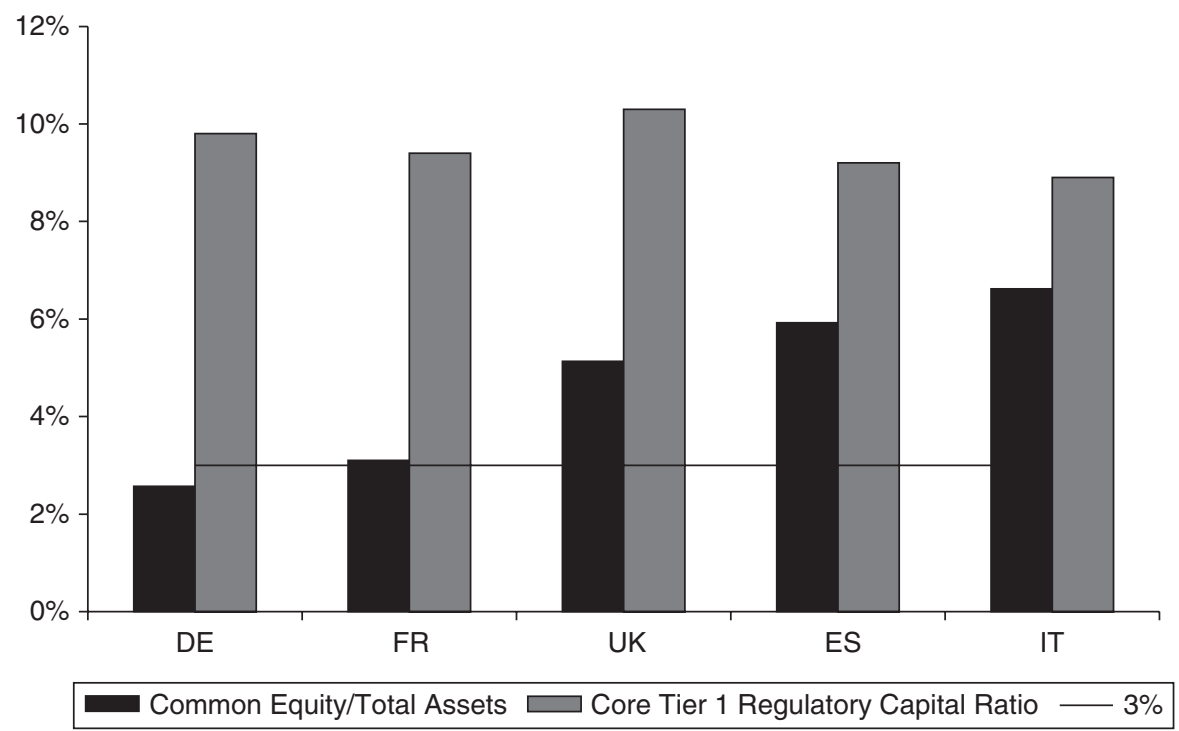

Source: Bankscope and EBA.

to look healthy and strong. In fact, Figure 5.2 illustrates that the cross-country pattern of CT1 capital data is fundamentally different from that of leverage ratios. All four banking sectors neatly meet the minimum CT1 capital ratio, with only minor cross-country differences, but when it comes to equity capital to total assets, Spanish and Italian banks have leverage ratios that are (roughly) twice as high as those of Germany and France.

The conclusion is, inevitably, that the CT1 capital data released by the EBA obscures rather than illuminates relative levels of undercapitalization in the core Eurozone countries.

\section{European Recapitalization in Perspective}

The European bank recapitalization suffered from two key limitations discussed in this book (Admati et al., this volume; Haldane, this volume). First and foremost, capital requirements continued to be based on RWA instead of total assets, despite the welldocumented unreliability of these measures. Second, capital requirements were specified in ratio terms, instead of in absolute terms, allowing banks to shrink assets instead of raising capital. ${ }^{8}$ In this section, we use as a benchmark for assessing the European recapitalization exercise the widespread consensus among scholars that equity capital requirements should be in the order of 15 percent of total assets.

\section{Capital requirements weaker than Basel III though presented as tougher}

Two key trends in the recent Basel III revisions of international standards for bank capital regulation were to adopt stricter definitions of capital, not least concerning what 
counted as high-quality capital, and to adopt a double criterion for minimum capital by adding a leverage ratio requirement (Vestergaard and Retana 2013). On both counts, the European recapitalization exercise marks a significant setback; we focus here on the latter.

Whereas Basel III requires a minimum of 4.5 percent equity capital relative to RWA, there was no explicit provision for equity capital in the European recapitalization exercise. It was left to the discretion of European banks to decide how much of the 9 percent CT1 ratio should be met by equity capital and how much by various hybrid instruments considered to be high quality. Thus, to compare the capital requirements of the European recapitalization exercise and those of the Basel III agreement, one must make assumptions to estimate the "implied leverage ratio" of the European recapitalization exercise. We calculated that a 9 percent ratio for CT1 capital corresponds roughly to a requirement of 2.7 percent equity capital to total assets (see Vestergaard and Retana 2013, 33-34). When taking into account that the Basel III requirement of 3 percent equity capital to total assets is itself widely criticized for being far too low, the European recapitalization exercise appears anything but "tough."

The CT1 capital category, invented by European authorities for the purposes of the stress test and recapitalization exercises, creates more confusion than clarity. Most importantly, it makes the European recapitalization exercise appear more progressive than it is - while at the same time obscuring whether European banks in fact have sufficient levels of (loss-absorbing) equity capital.

\section{Equity capital requirements far too low to significantly enhance resilience}

It is disappointing that the European recapitalization exercise did not specify a threshold for minimum equity capital funding, and that the level of equity capital implied (through the CT1 requirement) was lower than the recently agreed international standard of at least 3 percent of total assets. But the problem is a much deeper one than merely "undercutting" Basel III. For a healthy and resilient banking sector, Basel III is a poor benchmark. Although the Basel Committee sees its minimum capital requirements as an essential means "to transform the global regulatory framework and promote a more resilient banking sector" (BCBS 2010, 2), it is unlikely that capital requirements as low as those of Basel III will contribute to increasing the resilience of the banking sector.

Although Andrew Haldane noted that Basel III, if fully adopted, would cause the minimum equity capital ratio to "quintuple over the next decade, rising from $2 \%$ to close to $10 \%$ of RWA for the largest global banks," he nevertheless stressed that even a loss in the value of a bank's assets of only 4 percent "will be enough to render it insolvent" (Haldane 2011, 14). This observation is of course particularly troubling when one recalls that many banks experienced losses well above this 4 percent threshold during the global financial crisis. ${ }^{9}$

In late 2010, a group of 20 finance professors published a joint letter in the Financial Times, noting that 'banks' high leverage and the resulting fragility and systemic risk 
Table 5.4. The scale of Basel III inadequacy (for large international banks)

\begin{tabular}{lccccc}
\hline Equity capital & Basel II & Basel III, 2013 & Basel III, 2019* & Basel III, 2019 ** & $\begin{array}{l}\text { Optimal } \\
\text { equity } \\
\text { capital }\end{array}$ \\
\hline $\begin{array}{l}\text { In \% of risk- } \\
\text { weighted assets }\end{array}$ & 2 & 4.5 & 9 & 12 & 45 \\
\begin{tabular}{l} 
In \% of total assets \\
\hline
\end{tabular} & 0.67 & 1.5 & 3 & 4 & 15 \\
\hline
\end{tabular}

Source: Authors' calculations based on BCBS (2010).

contributed to the near collapse of the financial system" and pointing out that Basel III was "far from sufficient to protect the system from recurring crises" (Admati et al. 2010). "If a much larger fraction, at least 15 percent, of banks' total, non-risk-weighted assets were funded by equity," they argued, "the social benefits would be substantial" (ibid.).

The Basel III ratios for equity capital thus may seem large at first, at least when judged by the almost five-fold increase of this ratio that will result when fully implemented in 2019, as noted by Haldane. But rather than be impressed with this increase, we should be astonished that the requirements have previously been so low that even a quintupling can be so far from adequate.

Table 5.4 illustrates the scale of the inadequacy of Basel III capital requirements, focusing on large international banks (assumed to have total assets three times larger than RWA, as the empirical evidence suggests). For such banks, the recommendation of 15 percent equity capital to total assets translates into a Tier 1 capital ratio to RWA of 45 percent. Similarly, the current requirement of Basel III that banks have 4.5 percent equity capital relative to their RWA corresponds to a requirement to have 1.5 percent equity capital relative to their total assets. Even if we consider two hypothetical scenarios of fully phased-in Basel III equity capital requirements, where both the countercyclical buffer and the G-SIBS surcharges are applied close to their maximum levels, the results are far below the levels recommended by scholars: 3 and 4 percent equity capital to total assets, respectively. ${ }^{10}$

What emerges from these considerations is that equity capital requirements would have to be quintupled to reach levels recommended by scholars, whether calculated relative to total assets (from 3 to 15 percent equity capital) or relative to RWA (from 9 to 45 percent). Thus, although Basel III, when fully implemented in 2019, will have effectively quintupled equity capital requirements (from their current level at 2 percent of RWA to almost 10 percent), a further quintupling will be needed: if equity capital requirements are to be adequate by criteria identified across a range of studies, they should be increased not almost five-fold, but more than twenty-fold (from 2 to 45 percent of RWA) to reach the 15 percent of total assets threshold.

\section{The GRD4: Institutionalizing the Reluctance to Recapitalize?}

The Basel III agreement is currently being implemented in Europe in the form of a regulation and a directive: a Capital Requirement Regulation (CRR) and a Capital 
Requirement Directive (CRD), together known as CRD4. The European Commission presented its first proposal for the CRD4 in July 2011 and originally all member states were expected to have transposed the directive into national law by the end of 2012 . However, meeting this deadline soon looked unlikely. At an Economic and Financial Affairs Council (ECOFIN) meeting in early March 2013, the Council of the European Union officially endorsed a compromise reached in negotiations between the European Parliament and the European Commission. The council mandated the Permanent Representatives Committee to finalize negotiations with the European Parliament on outstanding technical issues. This means that a final deal is expected later in March, and the CRD4 likely will take full effect later in 2013 or by January 1, 2014.

\section{Controversies}

Over the past year, the proposed legislation has been subject to debate and negotiation, both in the European Parliament and in ECOFIN. This reflects that although the Basel III Accord is finalized, its transposition into EU law is not set in stone. Much of Basel III is formulated as minimum requirements and hence the EU may - at least in principledecide to adopt stricter rules if it so wishes.

A key controversy has been whether some countries should be allowed to set higher capital requirements than others - in line with the notion that Basel standards are minimum capital requirements - or should be explicitly disallowed from doing so, with reference to the principle of having a single European market in financial services. Another important debate has focused on whether the EU legislation should "give the leverage ratio a much more central role" than proposed in the Basel III agreement and in the original European Commission proposal (Lannoo 2012; Masters 2012). Thirdly, there has been considerable controversy on the issue of whether Basel III restrictions on what can be counted as "high-quality capital" should be adopted rigorously in the CRD4 or whether certain exemptions could be made. Finally, some have argued that the CRD4 should discontinue the practice of allowing government bonds to be classified as "risk free" in calculations of banks' total RWA.

\section{The CRD4 is a major setback compared to Basel III}

Overall, the CRD4 was expected to substantially replicate the Basel III agreement; the minimum capital requirement would be the same, and the new capital buffers and the leverage ratio would be adopted more or less as outlined in Basel III. However, there are substantial digressions from Basel III, most of which go in the wrong direction, and hence, render the CRD4 a most unfortunate setback relative to Basel III.

\section{Diluting the capital definitions of Basel III}

First, the stricter definitions of capital agreed in Basel III will most likely be softened in the CRD4, as a result of pressure from German and French banks. More specifically, exceptions have been made for the so-called silent participation of German banks and 
minority stakes of French banks in insurance companies, both of which have somewhat questionable loss-absorbency qualities (Goldstein 2012). It will be difficult to assess this fully before all technical deals are negotiated and released.

\section{Watering down the leverage ratio}

Whereas Basel III stipulates the leverage ratio in terms of the highest quality of capital, namely equity capital, relative to total assets, the CRD4 waters it down by defining it in terms of Tier 1 capital relative to total assets (Council of the EU 2013, 3). This most probably means that the above-mentioned exceptions made for German and French banks will count toward meeting the leverage ratio requirement. Note that in specifying its leverage ratio, the CRD4 adopts a capital category that is not only weaker than that of Basel III, but also weaker than the capital category it used for its 2011 stress test and the recapitalization exercise - namely, the CT1 ratio.

\section{New systemic risk buffers}

The CRD4 adopts the capital conservation buffer and the countercyclical buffers as specified in Basel III, but replaces the capital surcharge for global systemically important financial institutions (G-SIFIs) with a broader "systemic risk buffer." The systemic risk buffer will be mandatory for G-SIFIs but voluntary for other systemically important financial institutions. Member states will be able to apply this systemic risk buffer in the range from 1 to 3 percent of all exposures, and up to 5 percent for domestic and third-country exposures. This corresponds roughly to the range defined in the FSB capital surcharge for G-SIFIs (1-3.5 percent), but opens up for some further capital tightening with respect to domestic exposures.

\section{Introducing maximum capital requirements?}

Fourth, and finally, the CRD4 effectively entails a de facto ceiling on capital requirements in the Eurozone. The CRD4 will "enable members to impose, for up to two years (extendable), stricter macroprudential requirements for domestically authorized financial institutions in order to address increased risks to financial stability"- but such measures, including the capital requirements above the levels stipulated in the CRD4, will be subject to approval by the Council of the European Union. ${ }^{11}$ It will be difficult for any member state to transgress this line, not least because of the signal this would send to markets, and the heavy costs that would be associated with it, both politically in the EU, and through higher funding costs in the market. Whereas the capital requirements of Basel III were always minimum requirements - allowing all countries to set their capital requirements at whatever higher levels they wanted - now, in the Eurozone, they seem to have become de facto maximum capital requirements instead.

\section{Discussion}

A European-wide de facto ceiling on capital ratios is bad news in itself, but all the more so given that it is set far too low, relative to what is needed to ensure the resilience of 
European banking. In more concrete terms, the implications of the new rules are as follows:

The systemic risk buffer can be imposed at different levels for different exposures, but assume for simplicity that banks have significantly higher domestic and thirdparty exposures than EU exposures, such that the regulator can set the systemic risk buffer close to its maximum level - say, at 4.5 percent. In this case, an EU member state may impose a systemic risk buffer of 4.5 percent equity capital relative to RWA. This will be in addition to the standard minimum capital requirement of 4.5 percent equity capital relative to RWA, which was stipulated in Basel III and adopted in CRD4. In other words, the systemic risk buffer allows a member state to raise requirements for equity capital relative to RWA from 4.5 to 9 percent. This corresponds, roughly, to a ratio of equity capital to total assets of 3 percent.

Obviously, the calculation changes if we add to the capital requirement the two additional capital buffers, which are to be gradually phased in from 2016 to 2019 - namely, the capital conversion buffer (2.5 percent) and the countercyclical buffer (0-2.5 percent). At their maximum levels, these buffers allow an additional 5 percent capital to RWA, such that the total is 14 percent. This, in turn, corresponds to a maximum ratio of equity capital to total assets of less than 5 percent, far below the 15 percent ratio recommended in the bank capital regulation literature.

If the CRD4 is adopted in EU legislation along the lines currently discussed, it will make it difficult for any EU member country to recapitalize its banks in a substantive and serious way. By making recapitalization above the levels discussed above contingent on the approval of other member countries, these new rules will limit the ability of individual member countries to insist that their banks recapitalize at such a scale that capital buffers large enough to ensure solvency even in adverse scenarios may be built. In so doing, it will further institutionalize the European reluctance to seriously recapitalize its banks.

\section{Concluding Remarks}

Since spring 2011, the EBA has conducted three capitalization assessments: a stress test exercise to test a bank's resilience to an adverse macroeconomic shock, a monitoring exercise to assess a bank's capitalization in terms of the recently agreed international standards (Basel III), and a recapitalization exercise undertaken in collaboration with banks and in consultation with national regulators. The culmination of this process was the singling out of 27 banks that were to raise a total of $€ 76$ billion between September 2011 and June 2012. When publishing the results of the recapitalization exercise in October 2012, the EBA reported that European banking had been successfully recapitalized and now was in a much stronger position, with a much strengthened capital base and overall resilience.

Our analysis gives occasion to considerable skepticism with regard to this conclusion. From the stress tests in 2011 to the recapitalization in 2012, the EBA relied more or 
less exclusively on capital data relative to RWA, and did not specify requirements for minimum levels of equity capital funding. The literature on bank capital regulation regards the leverage ratio - equity capital to total assets - as a much more reliable indicator of banks' soundness and resilience than ratios based on broader measures of capital measured relative to RWA. Therefore, throughout the paper, we compare the results of the various assessments reported by the EBA with data for leverage ratios.

In terms of bank-by-bank data, we find that the recapitalization exercise in many instances in fact did not recapitalize a given bank when measured by equity capital to total assets. Only 7 out of 24 banks involved improved their leverage ratios, whereas 16 banks worsened their capital positions. In opposition to the EBA's positive assessment of the results of the recapitalization exercise, we find strong reasons for concern about the resilience of European banking.

Our finding that equity capital levels in European banking are far below the 15 percent of total assets recommended by scholars (Admati et al. 2010) is troubling but not surprising. What is surprising, however, is that large parts of European banking are undercapitalized, even when the Basel III minimum requirement of 3 percent equity capital to total assets is used as a benchmark, despite the fact that this threshold is widely considered to be far too low.

This leads to the next key finding of the report: the least well-capitalized banking sector among the larger Eurozone countries is not Spain or Italy, but Germany, closely trailed by France. The banking sectors of Spain and Italy have equity to total assets roughly double the size of those of Germany and France.

All in all, our results reveal that the devil really is in the detail, and that by using ratios based on broader measures of capital than equity, and measuring it relative to RWA instead of relative to total assets, the EBA has obscured rather than illuminated the capitalization of European banks. The continued reliance on ratios of Core Tier capital relative to RWA allows banks characterized by low and precarious levels of capital to appear healthy and strong. Little is achieved by this, other than keeping a game going, which will eventually come to an end-namely, the game of avoiding a serious recapitalization of Europe's banks.

Unfortunately, this "recapitalization reluctance" has also shaped the European adoption of Basel III. The flawed and reluctant European approach to bank capital regulation is now resulting in a European ceiling on bank capital requirements, as part of a larger compromise on the fourth European CRD, which is currently in the final stages of being adopted in EU legislation. If a ceiling on bank capital is indeed adopted in EU legislation, at roughly the levels reported from the negotiations, it will make it more than difficult for any EU country to require its banks to have equity capital in excess of 6 percent of total assets. In this way, Europe is about to turn its reluctance to recapitalize its banks into an institutionalized commitment to undercapitalized banking in a most unfortunate manner.

The European reluctance to restructure and recapitalize will be costly in many ways. Above all, the absence of substantial recapitalization of Europe's banks poses a significant systemic risk: a full-blown European banking crisis will have enormous private and social costs for all European countries, not to mention global repercussions. 


\section{Notes}

1 Admati et al. (2011), Admati and Hellwig (2013), Blundell-Wignall and Atkinson (2010), BlundellWignall and Roulet (2012), Brealey (2006), Goodhart (2010), Haldane (2011, 2012), Harrison (2004), Hellwig (2010), Hanson et al. (2010), Miles et al. (2012), Slovik (2011), and Turner (2010).

2 More specifically, the total effect of the envisaged shock was a fall in EU real GDP by 0.4 percent in 2011 and zero growth in 2012. Average unemployment in the EU was projected to reach 10 percent in 2011 and 10.5 percent in 2012. Further assumptions included that yields on German 10-year bonds were to remain at the baseline level, whereas EU long-term interest rates would go up by 66 basis points (on average); and that short-term, interbank interest rates in the European money markets would increase by 125 basis points and that stock prices in the EU would suffer a negative shock of 14 percent on average.

3 However, the composition of the recapitalization is interesting. Only $€ 43.6$ billion of the $€ 115.7$ billion total recapitalization amount was due to an increase in the core capital position of the banks (EBA 2012a, 10), corresponding to just 38 percent of the total recapitalization reported. The capital impact of so-called RWA measures corresponded to 28 percent of the total recapitalization amount.

4 BNP Paribas passes on the 9 percent Tier 1 ratio but fails the other two, while Deutsche Bank, Commerzbank, and Societé Generale fail on all three. For a full list of the banks that would have failed the stress test according to the four different criteria, see Vestergaard and Retana (2013, Annex B).

5 In general, small banks are unlikely to have lower capital levels than large banks for a number of reasons, including lower competitive pressure on this particular parameter, and less reliance on "risk-weighted asset optimization" strategies.

6 In terms of quantitative analysis, a means difference test leads us to reject the null hypothesis that the difference in the mean leverage ratio of German and French banks on the one hand and Spanish and Italian banks on the other is equal to zero.

7 On average, the levels of leverage of German banks are not much higher than that of Dexia just before it collapsed.

8 For an examination of these problems in the context of the European recapitalization exercise, see Vestergaard and Retana (2013, 27-38).

9 The IMF estimated, for instance, that the cumulative credit losses of US banks in the period from 2007 to 2010 were in the order of 7 percent of assets (IMF 2010).

10 The 2019* scenario assumes the imposition of a 2 percent countercyclical buffer on top of the minimum equity capital requirement (4.5) and the capital conservation buffer (2.5), which result in a ratio of 9 percent equity capital to RWA. This translates into a 3 percent equity capital to total assets ratio. The 2019** scenario assumes the imposition of a G-SIB capital surcharge of 2.5 percent and the countercyclical capital buffer is raised from 2 to 2.5 percent, so that a total level of 12 percent of RWA is reached, corresponding roughly to 4 percent of total assets.

11 More specifically, the "Council can reject, by qualified majority, stricter national measures proposed by a member state" (Council of the EU 2013, 3).

\section{References}

Acharya, V., H. Mehran, T. Schuermann, and A. Thakor. 2012. "Robust Capital Regulation." CEPR Discussion Paper, no. 8792. London: Centre for Economic Policy Research.

Admati, A. R., and M. Hellwig. 2013. The Bankers'New Clothes: What's Wrong with Banking and What to Do about It. Princeton, NJ: Princeton University Press.

Admati, A. R., P. DeMarzo, M. F. Hellwig, and P. Pfleiderer. 2011. "Fallacies, Irrelevant Facts, and Myths in the Discussion of Capital Regulation: Why Bank Equity Is Not Expensive." Stanford GSB Research Paper, no. 2063. Stanford: Stanford Graduate School of Business. 
2012. "Debt Overhang and Capital Regulation." INET in Berlin: Rethinking Economics and Politics, April 13. Online: http://www.gsb.stanford.edu/news/packages/PDF/ AdmatiDebt032612.pdf (accessed August 12, 2014).

Admati, A., et al. 2010. "Healthy Banking System Is the Goal, not Profitable Banks." Letter published in Financial Times, November 9.

Alexander, K., R. Dhumale, and J. Eatwell. 2005. Global Governance of Financial Systems: The International Regulation of Systemic Risk. New York: Oxford University Press.

Bain \& Co. 2012. A World Awash in Money: Capital Trends through 2020. Online: http://www.bain. com/Images/BAIN_REPORT_A_world_awash_in_money.pdf (accessed August 12, 2014).

Basel Committee on Banking Supervision (BCBS). 2010. Basel III: A Global Regulatory Framework for More Resilient Banks and Banking Systems. Original version, December 2010. Basel: BIS.

201 1. Global Systemically Important Banks: Assessment Methodology and the Additional Loss Absorbency Requirement. Basel: Bank of International Settlements.

BCBS. 2012. Results of the Basel III Monitoring Exercise Based on Data as of 31 December 2011. September. Basel: BIS. Online: http://www.bis.org/publ/bcbs231.pdf (accessed September 18, 2014).

2013. Regulatory Consistency Assessment Programme (RCAP): Analysis of Risk-Weighted Assets for Market Risk. January. Basel: Bank of International Settlements.

Bisio, P., D. Jurcevic, and M. Quagliriello. 2011. "A Short Guide to the EBA's Recapitalization Results." VOX, December 21. Online: http://www.voxeu.org/article/short-guide-eba-srecapitalisation-results (accessed September 18, 2014).

Blundell-Wignall, A., and P. Atkinson. 2010. "Thinking beyond Basel III: Necessary Solutions for Capital and Liquidity." OECD Fournal: Financial Market Trends 2010 (1): 5-6.

Blundell-Wignall, A., and C. Roulet. 2012. "Business Models of Banks, Leverage and the Distanceto-Default." Financial Market Trends 2012 (2).

Brealey, R. 2006. "Basel II: The Route Ahead or Cul-de-Sac?" Fournal of Applied Corporate Finance 18 (4): $34-43$.

Council of the European Union. 2013. "Bank Capital Rules: Council Endorses Agreement with EP.” Press Release. March 5.

Dailami, M. 2012. "Looking beyond the Euro Area Sovereign Debt Crisis." Economic Premise, no. 76. Washington, DC: The World Bank.

Dailami, M., and J. Adams-Kane. 2012. "What Does the Future Hold for the International Banking System." Economic Premise, no. 94. Washington, DC: The World Bank.

Das, S., and A. N. R. Sy. 2012. "How Risky Are Banks' Risk Weighted Assets? Evidence from the Financial Crisis.” IMF Working Papers, no. 12/36, January.

Demirgüç-Kunt, A., E. Detragiache, and O. Merrouche. 2010. "Bank Capital: Lessons from the Financial Crisis." IMF Working Papers, nos 1-35, December.

ECOFIN Presidency and EBA. 2011. "Joint Statement by the Presidency of the ECOFIN Council and the EBA." Online: http://www.eba.europa.eu/documents/10180/26923/2011+12+08EGOFIN-EBA-Statement+FINALv2.pdf/434c8acd-4ceb-48ee-9755-2d69e 1 le6 1 a 7 (accessed August 12, 2014).

Engelen, E., I. Ertürk, J. Froud, S. Johal, A. Leaver, M. Moran, et al. 2011. After the Great Complacence: Financial Crisis and the Politics of Reform. Oxford: Oxford University Press.

European Banking Authority (EBA). 2011 a. 2011 EU-Wide Stress Test: Methodological Note; Additional Guidance.June 9. London:EBA. Online: http://www.eba.europa.eu/documents/10180/15935/ Additional+guidance + to + the + methodological+note.pdf/db lda 102-7669-41 eb-a9e93f44c23610ef (accessed September 18, 2014).

201 1b. 2011 EU-Wide Stress Test: Aggregate Report. July 15. London: EBA. http://www.eba. europa.eu/documents/10180/15935/EBA_ST_2011_Summary_Report_v6.pdf/54a9ec8e3a44-449f-9a5f-e820cc2c2f0a (accessed September 18, 2014).

2011 c. Capital Buffers for Addressing Market Concerns over Sovereign Exposures. Methodological Note. December 8. London: EBA. https://www.eba.europa.eu/documents/10180/26923/ 
Methodology+FINAL.pdf/b4525778-7375-4dae-b821-2ef3bd9af02e (accessed September 18, 2014).

.2012a. Final Report on the Implementation of Capital Plans Following the EBA's 2011 Recommendation on the Creation of Temporary Capital Buffers to Restore Market Confidence. October. London: EBA. Online: https://www.eba.europa.eu/documents/10180/15956/Finalreportrecapitalisationexercise. pdf/87602d3f-ec8d-4788-9aa8-fae0f28f4c23 (accessed September 18, 2014).

2012b. "EBA Publishes Final Report on the Recapitalisation of European Banks and Paves the Way for the Transition to the CRDIV Framework." Press Release. October 3.

European Central Bank. 2011. Macroeconomic Adverse Scenario for the 2011 EU-wide Stress-test: Specification and Results. March 18. London: EBA. Online: https://www.eba.europa.eu/ documents/10180/15932/EBA-ST-2011-004-Annex-2-_General-features-of-the-adversescenario.pdf (accessed September 18, 2014).

Financial Times. 2011. "Lagarde Calls for Urgent Action on Banks." Financial Times, August 27. 2013. "Basel Eyes Set Periods for Banks' Risk Models." Financial Times, February 17.

Gapper, J. 2013. "Wave of Money Eludes the Real Economy." Financial Times, February 8.

Goldstein, M. 2012. "Stop Coddling Europe's Banks." VOX, January 11.

Goodhart, C. 2010. "How Should We Regulate the Financial Sector?" In The Future of Finance, 165-86. London: LSE.

Haldane, A. 2009. "Small Lessons from a Big Crisis." Remarks made at the Federal Reserve Bank of Chicago 45th Annual Conference on "Reforming Financial Regulation," May 8.

2011. "Control Rights (and Wrongs)." Wincott Annual Memorial Lecture, October 24, Westminster, London.

Haldane, A. G. 2012, August. "The Dog and the Frisbee." In Federal Reserve Bank of Kansas City's 36th Economic Policy Symposium, "The Changing Policy Landscape,” Jackson Hole, WY (vol. 31).

Hanson, S. G., A. K. Kashyap, and J. C. Stein. 2011. "A Macroprudential Approach to Financial Regulation." Fournal of Economic Perspectives 25 (1): 3-28.

Harrison, I. 2004. "Banks, Capital and Regulation: Towards an Optimal Capital Regime for a Small Open Economy." Working Paper. New Zealand: Reserve Bank of New Zealand.

Hellwig, M. 2010. Capital Regulation after the Crisis: Business as Usual? Bonn: Max Planck Inst. for Research on Collective Goods.

International Monetary Fund (IMF). 2010. Global Financial Stability Report, April 2010. Washington, DC: IMF.

2012. Global Financial Stability Report, April 2012: The Quest for Lasting Stability. Washington, DC: IMF.

Jenkins, P. 2011. "Europe Stress Tests Undermined by Indecision.” Financial Times, July 18.

Lagarde, C. 2011. "Global Risks Are Rising, But There Is a Path to Recovery." Remarks made at Jackson Hole, WY, August 27. Online: http://www.imf.org/external/np/ speeches/2011/082711.htm (accessed August 12, 2014).

Lannoo, K. 2012. "Europe Needs to Flex Its Muscles with Banks.” Financial Times, January 30.

Linklaters. 2011. CRD IV: The European Response to Basel III and the Impact on Tier 1 and Tier 2 Bank Capital. London: Linklaters.

Mariathasan, M., and O. Merrouche. 2012. "The Manipulation of Basel Risk-Weights. Evidence from 2007-10." Department of Economics Discussion Paper Series, no. 621. Oxford University.

Masters, B. 2012. "Leverage Cap Has the Power to Reshape Banking.” Financial Times, February 13.

Miles, D., J. Yang, and G. Marcheggiano. 2012. "Optimal Bank Capital.” Economic Fournal 123 (567): 1-37.

Onado, M. 2011. "European Stress Tests: Good or Bad News?" VOX EU, August 16.

Ozgercin, K. 2012. "Seeing Like the BIS on Capital Rules: Institutionalising Self-regulation in Global Finance." New Political Economy 17 (1): 97-116. 
Pollack, L. 2012. "Basel 3 Study Demonstrates Impact of Getting Rid of BS Capital." Financial Times Alphaville, April 17.

Power, M. 2005. "The Invention of Operational Risk." Review of International Political Economy 12 (4): 577-99.

Slovik, P. 2011. "Systemically Important Banks and Capital Regulations Challenges." OECD Economics Department Working Papers, no. 916. Paris: Organization of Economic Corporation and Development.

Tarullo, D. K. 2008. Banking on Basel: The Future of International Financial Regulation. Washington, DC: Peterson Institute for International Economics.

Turner, A. 2010. "What Do Banks Do? Why Do Credit Booms and Busts Occur and What Can Public Policy Do About It?” In The Future of Finance: The LDE Report, 5-86. London: LSE.

Young, K. L. 2012. "Transnational Regulatory Capture? An Empirical Examination of the Transnational Lobbying of the Basel Committee on Banking Supervision." Review of International Political Economy 19 (4): 663-88. 


$$
\text { Part } 2
$$

\section{BANK RESOLUTION}





\title{
Chapter 6
}

\section{BANK RESOLUTION IN COMPARATIVE PERSPECTIVE: WHAT LESSONS FOR EUROPE?}

\author{
Charles Goodhart
}

\section{Introduction}

Prior to the recent financial crisis, the failure of a bank would in most countries be treated under the standard law of bankruptcy applicable to all institutions. Standard bankruptcy law is, however, best suited to those instances where the bulk of the assets are fixed, real assets, property, land and buildings, or equipment, such as railroad lines, steel furnaces, or airplanes - assets whose nature and value are not affected by the process of bankruptcy itself. Then the bankruptcy can, and does, involve a process of finding a (highest bidding) buyer for the unchanged real assets who can take them over and use them again productively. The more a business is built on such real assets, with a relatively assured and stable secondhand resale price, the more appropriate is debt finance, limited liability equity finance, and a continuing market, via takeovers, for ownership in that equity market.

Bankruptcy procedures and governance structures may need to become more complicated when the institution is primarily based on intangible capital - intellectual know-how - rather than on real tangible assets. Examples are legal and accountancy firms, advertising agencies, medical practices, universities, etc. In such cases, with no or little ability to constrain and to pre-commit the staff, who possess the human capital, by indenture or by slavery, the gone-concern value of such an institution is often a tiny fraction of its potential going-concern value. In such a condition, debt is, in general, not such an appropriate financing vehicle (on what would it be based?), a market for ownership of the institution is more problematical, and partnerships, of some form, are more suitable than a (limited liability) equity base. Normally, however, the failure of one such service provider strengthens its competitors in the market. Not only is competition for their output reduced, but they may also be able to pick up displaced and unemployed skilled staff more easily from the failing firm(s). As a generality, the failure of a service provider does not lead to contagion in that sector, whereby the failure of one firm drags others down with it.

Much of the value of a bank lies in the intangible value of being able to allocate funds wisely to good investments. It provides financial services, mainly based on the utilization of 
human rather than fixed capital. Moreover, should the bank be forced to realize its assets (or to call in its loans) in order to meet withdrawals, such pressurized sales will worsen the position of other similar banks in a variety of ways - for example, via the interbank market, by causing fear among depositors, by reducing the market value of their assets, and by damaging the general economy. Thus, the failure of one bank can have a contagious impact on other banks, the more so the greater the perceived similarity between the failing bank and others like it, which may often be aggravated by microprudential policies that encourage self-similarity among banks. With banks undertaking maturity mismatch, they are bound to depend, more or less, on confidence in their continued operation. The standard bankruptcy procedure will damage such confidence not only in the bank being liquidated, but also in other banks that are perceived as similar.

The potentiality for contagion as banks began to fail during the recent crisis soon became obvious (Northern Rock, Lehman), and led to a variety of crisis measures, such as guarantees of bank creditors, both depositors and bondholders, and to forced state recapitalization of banks. But such measures were expensive to taxpayers, at least initially, and remained so in some cases, and were resented as they represented a transfer from poorer taxpayers to wealthier bankers, and to bank bondholders. The cry has gone up: "This must never happen again."

To some degree, an institution, such as a bank, dependent on both intangible human capital and subject to contagion when confidence goes, might seem better suited to a partnership, with or without some limit to liability. The problem with partnerships is that they restrict the equity capital that can be deployed and, hence, the size of the institutions. Where there appear to be economies of scale, though their extent in banking is a contentious issue, there will be pressure to transform into a publicly listed limited company in order to become larger. In any case, contagious failure was rife in systems with large numbers of poorly capitalized small banks, whether partnerships or limited liability entities, such as the country banks in the UK in the first half of the nineteenth century or the unit banks in the USA in the interwar period. Moreover, there is always a temptation with a partnership or a mutual company to cash in one's chips by going public.

Be that as it may (and on this view, there are grounds for reviewing the extent of the potential liability of some or all equity holders of a bank), one lesson of the recent financial crisis has been that standard bankruptcy procedures are inappropriate in the case of a bank. Instead, we need a special resolution regime (SRR) for banks, enabling the financial authorities, in the guise of an institution set up for that particular purpose (whether or not it is part of the central bank), to intervene in a failing bank to handle its demise in a variety of ways as might seem best - for example, to divide the existing bank into good/bad bank segments, to sell the (good) bank to another bank, to run the bank itself (effectively to nationalize it, though only as a temporary expedient), or, at least as a last resort, to liquidate it.

The establishment of an SRR is to be buttressed with two further reforms. The first is that the ratio of potentially loss-absorbing capital to (risk-weighted) assets should be greatly increased. There are various potential ways of doing so, either by requiring a higher equity ratio, by increasing the potential liability of (some or all) equity holders, or by forcing certain (non-equity) creditors to transform their claims into equity when 
failure looms (or possibly well beforehand in the case of high-trigger CoCos). Largely because of the tax advantage of debt (relative to equity) and the difficulties banks face in raising new equity, not least because of the continuing uncertainty about the form of the regulatory framework, most attention has been paid to proposals that require banks to augment their loss-absorbing capital by issuing bail-inable bonds that transform into equity when a bank approaches failure.

The second reform involves making advance plans for periods of extreme difficulties for large and systemic banks in the shape of recovery and resolution plans (RRPs). The first part, the "recovery" segment, requires the bank to think how it might be able to survive periods of extreme pressure (e.g. by selling assets or by borrowing, perhaps by establishing some kind of contingent put option). The second part, the "resolution" plan, requires the bank to organize its affairs in such a way as to facilitate and expedite intervention by the official agency established under the SRR for the purpose of resolving failed banks (should the recovery part of the RRP prove insufficient).

\section{What Should Happen?}

- Stage 1: A bank gets into trouble. The prearranged recovery plan kicks in. The bank involved sells assets, or borrows as contingently arranged. Liquidity support from central bank may be needed.

- Stage 2: Assuming that Stage 1 does not suffice, and the bank continues its downward spiral toward failure. If the bank has previously established low-trigger CoCos or bailinable bonds that are triggered when equity values fall far enough, then these would be activated so that the bank obtains sufficient equity to absorb the losses. Liquidity support from the central bank will, almost certainly, also be needed.

- Stage 3: Otherwise, the bank will enter formal resolution under the aegis of the SRR. Then the authorities bail in the unsecured creditors with the aim of recapitalizing and refloating the bank using such funds.

- Stage 4: If the forced recapitalization from bail-ins by the SRR proves to be inadequate, then there may have to be recourse to taxpayer funds in the short run-for example, to recapitalize the bank - but the intention is that such funding should be recouped by a tax/levy on the banks, either from a fund established ex ante or a levy imposed on surviving banks ex post. The idea is that any taxpayer assistance should be strictly temporary. Again, if any such failing bank is to be reconstituted, central bank liquidity support will, almost certainly, be required.

So far, perhaps so good. What can now go wrong?

\section{What May Go Wrong and What to Do About It}

\section{Cross-border, universal banks and the point of entry}

Thus far, we have been implicitly assuming that a bank is a simple institution operating within a single jurisdiction and undertaking only one version of financial intermediation 
described as "banking." What happens instead if the bank has subsidiaries, operating as separately capitalized entities in multiple jurisdictions? Alternatively, what happens if the bank has several subsidiaries, or associated companies, undertaking several different kinds of financial intermediation, again either in one or multiple jurisdictions, such as insurance, investment banking, broker/dealer, retail banking, etc.?

Currently we see two potentially conflicting directions of travel. First, there is the provisional agreement on "Resolving Globally Active, Systemically Important, Financial Institutions" between the Bank of England and the Federal Deposit Insurance Corporation (FDIC) (December 10, 2012), which proposes that above any bank - which may have subsidiaries and/or associated companies in other jurisdictions, and may also be doing other kinds of (financial intermediation) business - there should be one overall controlling holding company. This superior holding company should be the single point of entry for the purpose of bank resolution. The holding company should, in turn, be the level at which sufficient loss-absorbing capital (equity plus bail-inable bonds) be held in order to prevent or to limit taxpayer liability.

The second trend is to divide a banking business into different kinds of activities with differing contingent liabilities for taxpayers in the various cases. Thus, the (Vickers) Independent Commission on Banking would seek to ring fence a specified retail banking business operating in the $\mathrm{UK}$ and the rest of the EU, which the British government would be pre-committed to supporting and to maintaining. The remainder of any associated banking business, whether banking (of any kind) outside of the EU, or non-retail financial intermediation within the EU-for example, investment banking - should then not rely on any financial support from UK taxpayers. As a corollary, the differing parts of the bank would need to be separately capitalized with, for example, strict controls over the transfer of funds out of the (protected) UK retail banking entity into any other part of that business. The implication would then seem to be that Vickers, and the somewhat similar Liikanen Report, would require resolution of a banking business to be done via multiple points of entry with each segment - that is, EU retail banks, EU investment banks, and rest-of-the-world (RoW) banks going through separate bankruptcy procedures.

The single point of entry (BoE/FDIC) approach is far better suited to a globalized, cross-border, worldwide financial system. It clarifies responsibility within the authority in which the holding company is registered. Presumably, a host country could refuse to authorize a banking subsidiary headquartered in a country whose legal system or resolution mechanisms were considered unsatisfactory by the host country. Such a system should minimize disputes between the authorities in which the (failing) bank operated, since the actions would necessarily fall on the home country.

The problem, of course, has been that with insufficiently capitalized banks, the resultant contingent liability on the home country has been greater than their taxpayers could bear. The imposition of losses on what would probably be primarily domestic stakeholders through top-down bail-in would probably transfer value from domestic stakeholders to foreign creditors, and would be politically difficult. This might be acceptable if all countries were clearly committed to playing by the same rules, but there is no certainty, or perhaps even likelihood, of this. With competitive pressures, current constraints on raising equity in a recession, and the banking lobby, all limiting any (rapid) 
rise in the ratio of loss-absorbing capital, the best way to limit taxpayers' contingent liability appeared to be to distinguish between those parts of the bank that the home authority would support, if the worst came to the worst, and those that it would not.

While the incentive for such a division into multiple points of entry on resolution is clear enough, the results are likely to be untidy, and to lead, perhaps intentionally, toward greater national fragmentation and protectionism in financial intermediation. If the home authority is to wash its hands of responsibility for the subsidiaries of one of its banks outside its own country or region, then one would expect each host country not only to require the maintenance at all times of specific local (trapped) capital and liquidity, but also to limit transfers of funds from the local subsidiary to the rest of the bank.

Meanwhile, the interconnectedness of investment banks, and hence the likelihood of contagion, is, in general, considerably greater than that of retail banks. Apart from IT and administrative problems, retail banks are relatively easy to divide into good and bad parts, thus enabling the refloating or selling off of the good parts. In contrast, the manifold market and other interconnections of investment banks make them a nightmare to liquidate, as in the case of Lehman Bros. From a macroeconomic viewpoint, the externalities and potential contagion arising from the closure and liquidation of an investment bank could be much worse than that arising from the same fate befalling an equal-sized retail bank. Thus, the economic advantages of recapitalizing an investment bank as a going concern, whether by taxpayer funds or otherwise, could well be greater than doing so for a retail bank. But the political calculus dominates the economic calculus.

Whether the single-point-of-entry (SPE) approach to resolution can survive in a financial system in which different parts of cross-border, universal banks are regulated and treated in different ways has yet to be discovered. Of course, if the SPE approach worked, and was credibly expected to work, always and everywhere, then ring fencing would be irrelevant. The fact that ring fencing is up front and central to the structural debate on the future of banking in the EU implies that there is a lack of confidence about the efficacy of the SPE approach. In what circumstances - for example, when the business of the group and its assets are so rotten throughout that it is impossible to value the size of the hole up front, which is important for determining how far to write down debt claims to cover the losses - might SPE not work?

If, in such particular circumstances SPE does not work, then the fall back to multiple points of entry (MPE) and ring fencing might help some of the subsidiaries providing "elemental" services - that is, payments. Seen this way, ring fencing is about making an entity super-resolvable, if a group-wide SPE resolution does not work. To an outsider, the regulatory authorities appear to be trying to ride two differing horses (SPE and MPE) simultaneously. Such twin-horse riding may be doable, but it is hard for a cynical commentator to see how they can be compatible.

More or less identical issues are at stake in the continuing discussions on bank resolution within the Banking Union. If responsibility for meeting losses, beyond those that can be absorbed by bank creditors, stays primarily with the nation-state of that bank, then each state will try to limit contingent conditional liability by adopting MPE. If, on the other hand, losses in the course of resolution are met through a European-wide 
SPE mechanism - say, via the European stability mechanism (ESM) - then there will be political difficulties in achieving transfers of funds from some countries (who regard themselves as innocent bystanders) to others (who may or may not have some closer responsibility for such failings).

Be that as it may, the earlier the intervention into a failing bank occurs, the more likely it would be that the available capital could absorb the losses accrued to that date.

\section{The timing of intervention}

While early intervention may lower the cost of remedying bank failure, it may also prematurely interfere with the ownership, property, and rights of bank shareholders. So there is a need to balance the advantages both to other bank creditors and to society as a whole, against the (property) rights of bank owners (shareholders).

In the Financial Stability Board's (FSB's) pamphlet Key Attributes of Effective Resolution for Financial Institutions (October 2011), there is a short, three-sentence section on the timing of such intervention. It reads:

Resolution should be initiated when a firm is no longer viable or likely to be no longer viable, and has no reasonable prospect of becoming so. The resolution regime should provide for timely and early entry into resolution before a firm is balance-sheet insolvent and before all equity has been fully wiped out. There should be clear standards or suitable indicators of non-viability to help guide decisions on whether firms meet the conditions for entry into resolution. (FSB 2011, 3.1)

At first sight, the first two sentences seem inconsistent, with the first sentence emphasizing the rights of shareholders to remain in control until all reasonable hope of recovery has vanished, and the second outlining the advantages within the resolution process of quick intervention. I have, however, been led to believe that the first sentence is key, with the second sentence simply acting as a qualifier. Thus, the authorities should wait until all practicable hope of recovery has gone, but, once that has happened, they should intervene immediately to resolve the failing bank. One issue is who calls the shots. Prudential supervisors are prone to delay, whereas resolution agencies would prefer to act sooner. The forthcoming role of the European Central Bank (ECB) as a supervisor may serve to expedite the process of entering resolution.

In my view, the balance has been tilted too far toward respect for shareholders' rights, and away from the wider interests of other creditors, and of society. Hope springs eternal in the human breast and also in that of accountants. It is extremely rare for a bank to close because the auditor has stated that liabilities exceed assets. Instead, creditors in repo, bond, and deposit markets flee, and the bank fails because it cannot find cash with which to pay its bills. Banks fail because they run out of money, not because the auditor finds their capital deficient. By the time that effective liquidity constraints force intervention, the true mark-to-market value of a bank, in such distressed fire sale conditions, may be severely under water. Thus, present proposals for the timing of intervention may be excessively careful regarding shareholder property rights. 
Under the Federal Deposit Insurance Corporate Improvement Act (FDICIA) of 1991, Congress tried to square this circle by requiring that banks either be closed or recapitalized by their shareholders once the (accounting) value of equity fell below 2 percent of total assets (a simple leverage ratio). The idea was that the ability of shareholders to recapitalize the bank, rather than lose it when in difficulties, gave them sufficient protection if the bank really did have upside value. The problem, however, lay in the reliance on accounting figures for capital. As has been shown, for example by the IMF (2009) and by Calomiris and Herring (2011), banks that failed more often than not had higher audited capital ratios than those that survived.

The idea was good, but the metric intended to discriminate between banks that were likely to fail and those that were likely to survive was badly chosen. Accounting valuations have little predictive capacities. As Calomiris has shown, the market value of equity has much greater predictive content for success or failure. The need is to find a better, market-based metric that appears to have greater discriminant powers. Such an exercise is one facet of my continuing research agenda. Even if such a discriminating metric can be found, its subsequent new use as a trigger for intervention could lead to changes in behavior, via manipulation or otherwise, that would lead to shifts in the relationship that could negate or damage the purpose of the exercise (the Lucas critique; Goodhart's Law). So caution is required.

Nevertheless, present arrangements for the timing of intervention are unsatisfactory. The FSB proposals are likely to delay the event of such intervention for too long. But there is no improved, better, earlier trigger for intervention yet discovered, let alone one that is generally agreed upon and accepted.

\section{The coverage of deposit insurance}

During the course of the recent financial crisis, the top limit for deposit insurance was raised to $€ 100,000$ throughout the EU. Although this is well in excess of what any individual would normally keep in a bank account, there are occasions when such a sum is temporarily held in an individual's accounts - for example, after or just before the sale of a home, a divorce settlement, the completion of a will, etc. Sir Mervyn King has several times expressed his concern that the apparent unfairness of potentially penalizing such temporary deposits could force a government, ex post facto, to guarantee all deposits at banks, whether investment or retail banks. Then, if bondholders are to be treated pari passu with depositors, this would seemingly mean that only subordinate bondholders, or those bondholders where a bailinable clause was written into the contract, would be available to absorb losses.

But it might be easy enough to draft a get-out clause for individuals with a temporary accumulation. For example, any bank account holder could be covered, say, by up to $€ 5$ million, for a period of, say, one month from the date that that account broached the normal upper deposit level, so long as that account holder had not held a sum greater than the normal upper limit in that or any other bank account for the previous, say, twelve months. ${ }^{1}$ This would deal with windfalls, while the conditionality would prevent institutions with regular, perhaps occasionally large, holdings of money from being automatically protected. 
In fact, concern about the coverage of deposit insurance should probably relate more to institutions than to individuals. What should be done about those institutions caught with large deposits just in advance of major payouts for wages, dividends, takeovers, etc.? What about charities just completing their fundraising? While the plight of individuals caught unawares with temporary accumulations of money may be more newsworthy and politically potent, the loss of wealth by institutions could be much more economically damaging.

This latter consideration suggests that there may be a case for depositor preference in the process of bank liquidation; the bank depositor, whether formally insured or not, gets paid out by the liquidator before any unsecured bondholder - the doctrine of pari passu would be abrogated in this respect. But in that case, why would any investor want to buy a bond junior to a deposit (except at a significantly higher interest rate), when they could put their funds with the bank - for example, in a certificate of deposit form that would count as a deposit (for protected status) but would otherwise mimic the characteristics of a bond? Would depositor preference totally distort the funding practices of banks? ${ }^{2}$

\section{Bail-inable bond and contagion}

Many regulators (e.g. Haldane and Hoenig) call for more simplicity in the regulatory framework. Yet, at the same time, the authorities are pressing banks to issue more lossabsorbing bail-inable bonds, or CoCos. Such instruments that can transform under certain conditions into equity are by nature far more complex than straight equity or simple bonds. Both the uncertainty about whether the trigger may get pulled (and when, and how, and by whom) and the complex details of the trigger and of the transformation are likely to make the instrument less attractive to investors, and thus only saleable at a higher yield. So why would any bank want to issue such an instrument? The answer is because the authorities are pressing banks to increase their holdings of loss-absorbing capital, and, even at much higher yields, their issue may be preferable to existing shareholders, given present market conditions, to an attempt to issue new equity, if the latter is effectively feasible at all.

When the first bank to fail goes under, then, barring delays, perhaps due to legal wrangling over their treatment, such bail-inable bonds are likely to do their job in meeting the accrued loss, and allowing this bank to continue as a going concern. But it will take time to ascertain with any clarity what loss of value, if any, has been suffered by such bondholders. Meanwhile, the failure of this first bank will in most cases have raised the probability of default in other similar banks, but to an extent that will be difficult to judge. Bail-inable bonds will become more difficult to price, conditional on the failure of the first bank. Under these circumstances, the market for new issues of such bonds will become more difficult and perhaps dry up altogether.

Assume that the capital adequacy requirement sets a desired level of 10 percent (of risk-weighted assets [RWA]) for equity and another 8 percent for bail-inable bonds. By definition, the first failing bank, rescued by triggering those bonds, will now be below the joint ratio; the equity ratio may have been restored, but bail-inable bonds have been triggered and so will now be zero. As the market for new bail-inable bonds then gets more 
difficult, banks with such bonds maturing will become unable or unwilling to roll them over, and their ratio will start to fall below the desired level. What happens then? What (ladder of) sanctions will be imposed on those banks which allow their holdings of lossabsorbing capital to fall below the desired level?

It sometimes feels as if regulators concentrate on each single bank (microprudential regulation) and ask themselves how best to handle that single bank should it fall into serious difficulties. In contrast, the task of macroprudential regulators is to ask themselves how to protect the system of banks, conditional on another bank, perhaps one of the biggest and most interconnected, having already failed. It was clear in the aftermath of the Lehman failure that that exercise had not been done. The manner in which the proposals for bail-inable bonds has been put forward - for example, with no attention to (potentially time-varying) ladders of sanctions - makes me wonder whether the focus has remained on the single bank rather than the system as a whole.

\section{The banking resolution fund}

The focus of the exercise to reform bank resolution has been to shift the burden of repairing banking losses from the taxpayer to the bank creditor. Particularly since the regulators have not seized the chance to enforce early intervention, it remains possible that the resultant loss could in some cases exceed the available amount of loss-absorbing capital, even when this has been greatly augmented, as planned. In the immediate short run, the only alternatives would be recapitalization by the taxpayer or by a prearranged bank fund (nota bene: the bank fund should not be invested in the sovereign debt of the home country, since this would reinforce the bank/sovereign doom loop). Given the uncertainty about the future occasion and severity of a financial crisis, such an ex ante fund would probably be insufficient to meet the losses occasioned by a major financial crisis. While, in principle, such an ex ante fund could be risk based, in practice, the difficulties of defining risk in a generally acceptable way mean that it is levied on a pro rata basis.

But even if the taxpayer should still be called upon to meet a severe crisis in the short run, the general idea is that the taxpayer should be recompensed by a levy to be imposed on surviving banks. But while such a tax is, not surprisingly, politically popular, it is structurally unsound. It hits the better-behaved surviving banks, generally in a way that does not make them more risk averse at a time (i.e. after the crisis) when they feel financially weakest. Moreover, the parameters of the tax (e.g. how long the banks should have to pay back for the cost of rescue; what the final cost of the rescue should turn out to be; what the relative interest rate to discount future tax flows to the present value should be - whatever it may be regarding the cost of rescue) are all likely to be quite arbitrary and subjective at the time of imposition. So such a bank tax will, once again, be determined more by the political rather than by any economic calculus.

\section{Conclusions}

The return on equity (ROE) in banking, including the remuneration of senior staff, was greatly raised by leverage. As a consequence, when asset prices (of MBS) fell, there was 
not enough loss-absorbing capital to meet that loss. The alternatives were financial chaos or taxpayer recapitalization. Although the correct choice between these two was made post-Lehman, there was much resentment that such a choice had been forced on us all by the preferences of bankers and bank shareholders.

In the field to which this paper relates (i.e. bank resolution), the attempt is being made to shift the burden of any loss from the taxpayer to bank creditors, first by requiring banks to hold a much higher ratio of loss-absorbing capital to assets, whether measured in risk-weighted or in simple leverage format, and, second, by imposing an ex post levy on banks to recoup (part of) the earlier cost of taxpayer recapitalization. The main problem is that present market conditions make the issue either of new equity or of specifically bail-inable bonds more than a little unattractive. The result is that banks are seeking to enhance their (required) ratios by a massive process of deleveraging.

Many have argued that financial intermediation has been excessive. Some reduction in balance sheets may, therefore, be welcome. But the full extent of deleveraging, not only in the past but that still in prospect, at a time of continuing economic stagnation is surely disadvantageous. The ultimate achievement of an equilibrium in which banks hold much more equity (as a ratio to assets) is considerably safer and has a much lower ROE, and remains highly desirable, yet the dynamic process of moving toward such an equilibrium has been badly handled. It has resulted in massive inconsistencies in policy, with banks being urged to increase credit expansion (to domestic borrowers) at the same time as they are being required to raise the capital to be held against such lending; the UK Funding for Lending Scheme at least attempts to resolve such an inconsistency.

The same desire to protect taxpayers has led to proposals (e.g. the Vickers Report) to limit their contingent liability to the support and recapitalization of domestic retail banking. This will lead to further fragmentation and balkanization of the previous globalized financial system. It is hard for me to see how such national preference would be compatible with the more global SPE proposal emanating from the Bank of England/ FDIC for the resolution of cross-border, universal banks. Indeed, recent US proposals for mandatory incorporation of US-based foreign banking activities into a US subsidiary (Federal Reserve 2012) hardly represents a note of resounding confidence in the efficacy of an SPE approach. No doubt both the US regulatory authorities and the Bank of England are subject to internal conflicts and split personalities.

The future not only of the process for bank resolution, but also of the structure of the wider financial system, remains in doubt. We may know what kind of ultimate equilibrium state for the financial system we might like to attain, but the empirical evidence clearly suggests that we do not have a very clear idea about how best to get from here to there.

\section{Notes}

1 Colleagues who know better than me have, however, warned that temporarily higher deposit limits for certain groups for certain reasons are legally almost impossible to draft (o.a. principle of equity).

2 The majority of large global banks are predominantly depositor funded. At the moment, on a bank failure, depositors rank pari passu with ordinary creditors - the difference is that (for insured depositors) the loss to the depositors flows from the bank to the protection scheme, and thus onto 
the other banks in the system concerned. This is one of the most important points about the impact of bank failure - the loss to senior creditors falls (in theory anyway) outside the system; the loss to insured depositors falls (by definition) on other banks in the system. Thus, if you have a bank whose funding is 80 percent deposits and 20 percent from other creditors, if the bank fails, 80 percent of the total loss will be recycled within the banking system concerned. This is potentially a trigger for domino default within that system. Depositor preference looks like an answer to this, but it is not. This is because in a system with depositor preference, no sane person becomes an unsecured creditor of a bank. This is why the smaller FDIC banks have "dumbbell" financing - deposits and secured financings, but no unsecured senior. After a while, this becomes a self-fulfilling prophecy; as the FDIC say on their website (FDIC 1988), in a normal FDIC resolution, unsecured creditors get 0 percent on their claims. For these banks, once you have satisfied secured creditors, 100 percent of the loss therefore flows back into the national banking system through the deposit protection scheme. This can make government intervention inevitable.

\section{References}

Calomiris, C. W., and R. Herring. 2011. "Why and How to Design an Effective Contingent Capital Requirement." Columbia Business School Working Paper. February.

Federal Deposit Insurance Corporation (FDIC). 1988. Managing the Crisis: The FDIC and RTC Experience. Washington, DC: FDIC. Online: http://www.fdic.gov/bank/historical/managing/ history1-10.pdf (accessed August 14, 2014).

Federal Deposit Insurance Corporation (FDIC) and the Bank of England. 2012. Resolving Globally Active, Systemically Important, Financial Institutions. December 10. Online: http:/ / www.bankofengland. co.uk/publications/documents/news/2012/nr156.pdf (accessed August 14, 2014).

Federal Reserve. 2012. "Press Release." Online: http://www.federalreserve.gov/newsevents/ press/bcreg/20121214a.htm (accessed August 14, 2014).

Financial Stability Board (FSB). 2011. Key Attributes of Effective Resolution Regimes for Financial Institutions. Pamphlet, October. Online: http://www.financialstabilityboard.org/publications/ r_111104cc.pdf (accessed August 14, 2014).

International Monetary Fund (IMF). 2009. "Responding to the Financial Crisis and Measuring Systemic Risks." Global Financial Stability Report. April. Washington, DC: IMF. 



\title{
Chapter 7
}

\section{RESOLVING PROBLEM BANKS: A REVIEW OF THE GLOBAL EVIDENCE}

\author{
Martin Čihák and Erlend Nier
}

\section{Introduction}

Responding to the global financial crisis, many country authorities are considering or have made changes in regimes for resolving problem banks. In most cases, this has involved carving bank resolution out of general bankruptcy regimes, and moving toward early intervention and resolution regimes specifically designed for banks. Such special regimes typically give more powers to central banks and other financial authorities, and reduce the involvement of the judicial system. This chapter provides a brief review of the reforms in bank resolution regimes around the globe, building on updated information from recent global surveys, including the World Bank's (2013) latest "Bank Regulation and Supervision Survey."

\section{The Case for Special Resolution Regimes}

There is a strong case for financial institutions to be subject to a special resolution regime (SRR). Banks and other financial institutions play a special role, performing financial services fundamental to the functioning of the economy, and contributing to the transmission of monetary policy. The failure of financial institutions can cause disruption and major negative externalities, such as a liquidity crunch, a fire sale of assets, and spillovers via the interbank market. For example, during Japan's so-called lost decade in the 1990s, the effectiveness of monetary policy was hampered by insufficient restructuring of the banking system (IMF 2009). Introduction of a sound legal framework for the resolution of financial institutions is likely to increase the speed and decisiveness of efforts to restructure national banking systems, which may come to increase the effectiveness of monetary policy, and the speed of recovery of the economy.

The absence or inadequate scope of resolution tools to deal with failing financial institutions was highlighted globally during the financial crisis that started in 2007 and intensified in the second half of 2008. Authorities were often confronted with two unappealing options: corporate bankruptcy - as chosen, for instance, by the US authorities on September 15, 2008 in the case of Lehman Brothers, a global financialservices firm - or an injection of public funds - as chosen by the US authorities in the 
case of the American International Group two days later (see e.g. Sorkin 2008; Andrews 2008). Both of these alternatives can be very costly. A disorderly bankruptcy can magnify the systemic impacts of the failure of a financial institution, leading, for example, to a loss of access to key financial services. When the authorities aim to avoid these impacts by injecting capital to support the institution, the fiscal outlays incurred in the course of an open-ended injection of capital can also be large (Ayotte and Skeel 2010).

Figure 7.1 illustrates the cases of "disorderly bankruptcy" and "injection of public funds" under an ordinary bankruptcy regime. An SRR can lead to a net efficiency improvement in terms of the tradeoff between fiscal costs and containment of systemic (financial stability) impact. It can do so by imposing on shareholders (and potentially debt holders) some or all of the losses that would otherwise be borne by taxpayers. The SRR also gives the country authorities more flexibility to explore the tradeoff between fiscal costs and systemic risk containment.

When ordinary bankruptcy is too costly, bankruptcy ceases to be a credible threat. If, in the absence of other options, public infusion of capital becomes the only alternative, this creates moral hazard and reduces market discipline. Empirical research documents how institutions expecting to receive public support hold smaller amounts of tangible common equity relative to total assets, on average, thus increasing the likelihood of failure (Nier and Baumann 2006). This research also shows that expectations of public support reduce the force of market discipline that may go along with enhanced disclosure of information.

Recent evidence also suggests a strong correlation between the weaknesses of supervisory and resolution powers at the national level and the buildup of financial imbalances across the OECD ahead of the global financial crisis. Using an index of supervisory and resolution powers, constructed from information contained in a World Bank database, Merrouche and Nier (2010) show that the buildup of financial

Figure 7.1. Fiscal cost and systemic impact in resolution regimes

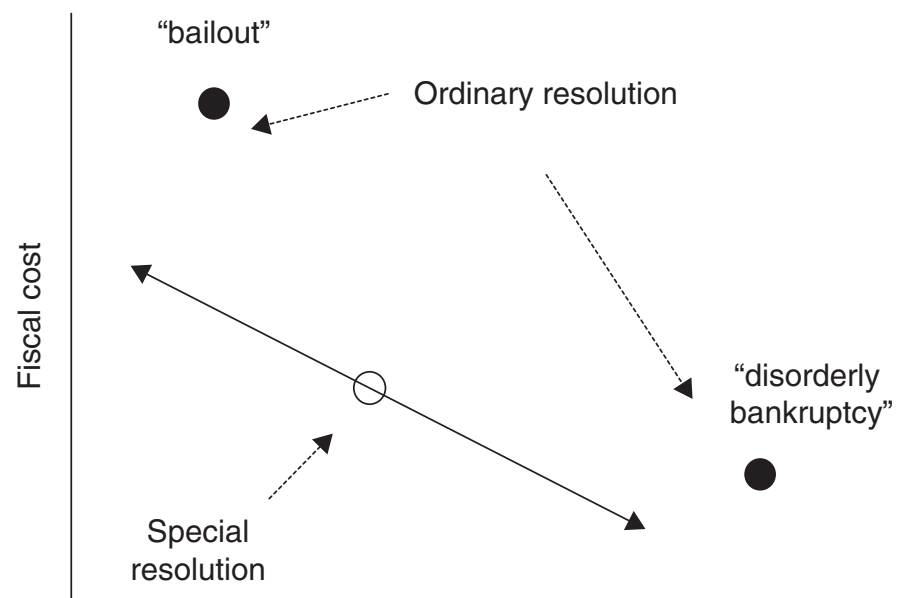

Systemic (financial stability) impact

Source: Čihák and Nier (2012). 
imbalances, as measured by increases in the size of banking sector balance sheets relative to core deposits, was stronger where national early remedial and resolution powers were relatively weak (Merrouche and Nier 2010).

\section{Changes in Resolution Regimes during the Global Financial Grisis}

There is clearly a recent trend toward introducing specialized bank resolution regimes. A prominent example is the regime introduced in the UK in 2009, which gives the banking authorities special resolution powers, enabling far-reaching and rapid action without the need to seek prior agreement of shareholders or creditors (Brierley 2009). Similar powers exist in Canada, Mexico, Japan, South Korea, and the USA, where the law provides special rules for bank insolvency, administered by the supervisor or the deposit protection agency; in many European countries, by contrast, the general insolvency law applies to financial institutions, with the extent of bank-specific modifications to the general law and the range of authority granted to official administrators varying across countries (Hüpkes 2000). For example, in some European countries, the banking authorities have the right to initiate proceedings, but the process is otherwise in the hands of the bankruptcy court; in other cases, the authorities play a stronger role in reorganization, but their powers are limited or less clearly defined (Marinč and Vlahu 2011). In particular, shareholders often retain the right of final approval of any reorganization measures.

Other countries that have recently introduced an SRR or have substantially strengthened an existing regime, in addition to the UK, include Denmark, Germany, and Ireland (Čihák and Nier 2012). Austria recently strengthened its resolution regime, as did several other

Figure 7.2. Revisions in countries' bank resolution frameworks, 2008-11

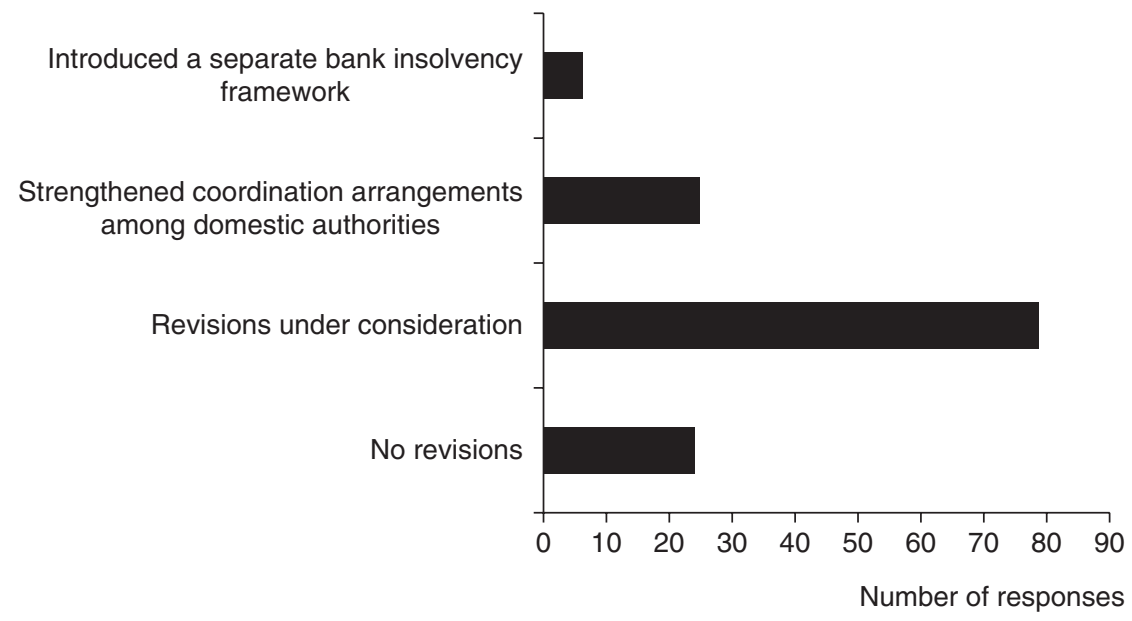

Source: Calculations based on the World Bank's 2011 Banking Regulation and Supervision Survey (http://worldbank.org/financialdevelopment).

Note: The survey is based on responses from senior banking supervisors in 142 countries. This figure is based on survey question 11.12 ("Have you introduced significant changes to the bank resolution framework in your country as a result of the global financial crisis?"). 
Table 7.1. Changes in resolution regime introduced in response to the global crisis

Have you introduced significant changes to the bank resolution Crisis

Non-crisis p-value framework in your country as a result of the global financial crisis?

\begin{tabular}{llrl}
\hline a. Introduced a separate bank insolvency framework (\% Yes) & 11 & 8 & 0.77 \\
$\begin{array}{l}\text { b. Implemented coordination arrangements among domestic } \\
\text { authorities (\% Yes) }\end{array}$ & 32 & 42 & 0.43 \\
\begin{tabular}{l} 
c. Other (\% Yes) \\
\hline
\end{tabular}
\end{tabular}

Source: Calculations based on World Bank's 2011 Banking Regulation and Supervision Survey (http:// worldbank.org/financialdevelopment). The survey is based on responses from senior banking supervisors in 142 countries. See also Čihák et al. (2012).

Note: Following Laeven and Valencia (2012), the "crisis" countries are Austria, Belgium, Denmark, Germany, Greece, Iceland, Ireland, Kazakhstan, Latvia, Luxembourg, Netherlands, Nigeria, Spain, Ukraine, UK, and USA (cases of systemic banking crises); France, Hungary, Italy, Portugal, the Russian Federation, Slovenia, Sweden, and Switzerland (borderline cases). T-tests are used to test for the equality of the means (percentage of "Yes" responses) between crisis and non-crisis samples.

countries, and virtually all the other EU member countries are considering changes or are in the process of revising the relevant legislation (Overhofer and Rath 2012). On a global scale, calculations based on the World Bank's recently updated Banking Regulation and Supervision Survey reveal a similar picture (Figure 7.2).

Interestingly, the changes in the resolution regime during the global financial crisis do not seem to differ significantly between countries that were directly hit during the global financial crisis and those that avoided the direct impact of the crisis. This is illustrated in Table 7.1, which shows country authorities' responses to questions about banking resolution regimes in the World Bank's latest Bank Regulation and Supervision Survey. The table includes p-values from tests of the null hypothesis that the changes observed across countries are not significant. The table suggests that while bank resolution was an important area of reform after the crisis, countries implemented changes across the board, whether they were affected by the crisis or not. This is in line with the findings in Čihák et al. (2012).

\section{Principles and Design of the Framework}

\section{Principles}

Based on the review of crisis and pre-crisis experience, a consensus has begun to emerge that a resolution framework should satisfy five basic principles (Čihák and Nier 2013). First, it should allow the country authorities to take control of the financial institution at an early stage of its financial difficulties, through "official administration." Second, it should empower the authorities to use a wide range of tools to deal with a failing financial institution, without the consent of shareholders or creditors. Third, it should establish an effective and specialized framework for liquidation of the institution that assigns a central role to the authorities. Fourth, it should ensure clarity as to the objectives of the regime and define clearly the scope of judicial review. And fifth, it should promote information sharing and coordination among all authorities involved in supervision and resolution. 


\section{Scope}

Scope, or coverage, is a key aspect of the SRR. For example, the regime operated in the USA during the financial crisis applied only to commercial banks, and did not include bank holding companies and other financial institutions, which did not take deposits, but may still warrant inclusion in a regime that aims to reduce the impact of failure of systemically important institutions and financial groups. Investment banks - such as Bear Stearns and Lehman - are important examples of such institutions. Other examples include Northern Rock and HRE, which relied on wholesale funding to a significant extent, but turned out to have systemically relevant implications.

One approach to defining the scope is for the law to enumerate the types of institutions falling within its scope, or to set out criteria and quantitative thresholds that determine unequivocally whether a particular institution or group falls within the scope. An alternative approach is for the law to set out the scope in more operational terms. This can be achieved by giving the resolution authority the power to "designate" particular non-bank institutions to fall under the scope of the regime. Such a designation could be made on the basis of a rigorous but more qualitative assessment of the systemic risk posed by a given individual institution against a suitable set of criteria. When such an assessment is conducted periodically and across all potentially relevant institutions, this permits a more dynamic framework that is able to respond flexibly to developments in financial markets and changes to the business models of any particular institution. ${ }^{1}$ One example is the approach taken in the USA, where the law enables the authorities to designate financial companies, including bank holding companies and their non-bank subsidiaries, as well as systemically important non-bank companies, such as insurance companies and securities brokers, as covered by an expanded SRR operated by the Federal Deposit Insurance Corporation (FDIG). ${ }^{2}$

\section{Thresholds}

The resolution regime needs to specify a regulatory threshold, such that when the threshold is crossed, the resolution authority is entitled to take control of the financial institution and start the restructuring. The threshold reflects the essence of special resolution proceedings - to permit the financial stability authorities to intervene in a financial institution at an early stage of difficulty when, while the position of the financial institution has weakened substantially, it may still have positive net worth (IMF and World Bank 2009). This contrasts with the "balance sheet threshold" often applied in ordinary bankruptcy proceedings, which permits proceedings to be initiated only after net worth is close to exhausted. Taking control at an early stage permits the authorities to explore the most appropriate resolution option prior to a full deterioration of capital, while seeking to prevent further weakening of the institution's condition.

There are many ways in which a threshold can be defined. In the USA, the Federal Deposit Insurance Act specifies a mandatory threshold of a bank being "critically undercapitalized," defined as a leverage ratio - tangible equity to total assets - below 2 percent. ${ }^{3}$ The threshold is mandatory in the sense that the authorities are not only 
entitled but required by law to take action if the threshold is breached. Other countries apply softer thresholds. The resolution regime introduced through the 2009 Banking Act in the UK (discussed earlier) applies a soft threshold, which amounts to a test of whether the bank in question is "likely to fail" the requirements for it to be licensed as a deposit taker. The relevant criteria include the "adequacy of the firm's resources."

The choice between a soft and a hard threshold can draw on the familiar debate on "rules" versus "discretion." A rule can increase commitment to take resolution action and therefore reduce the scope for forbearance. Indeed, a hard threshold was introduced in the USA to limit what was deemed excessive forbearance on the part of the authorities during the so-called savings and loans crisis in the 1980s and early 1990s (Mayes 2009).

The limitation of rules is that they cannot fully capture all considerations about appropriate actions taken at a given point in time. Having some discretion can allow for a fuller appraisal of the situation and make it easier to incorporate judgment. Indeed, discretion may sometimes favor more rapid action - for example, when an institution is rapidly deteriorating due to lack of access to key funding markets, but such deterioration is not well captured by the regulatory threshold.

Discretion may increase ex post efficiency by ensuring that the action taken is fully appropriate in light of the situation. A rule can increase ex ante efficiency by limiting forbearance and the resulting moral hazard. In practice, an appropriate solution may trade off the two. For example, in Canada, the institution needs to be deemed no longer "viable." Excessive dependence on financial assistance, lack of depositor confidence, and capital deficiencies are introduced as indicative criteria of this threshold having been breached.

\section{Early intervention}

It is important for actions in the resolution stage to be complemented by "early remedial action" by the relevant supervisory agency - that is, a phase of heightened supervisory involvement, aiming to reduce the chance that the resolution stage will need to be invoked. This may involve supervisory "assistance" in the design of a "recovery plan" to address incipient financial weakness and the monitoring of the plan's execution by the supervisory authority. The plan might involve raising private capital, modifications to particular lines of business, and the divestiture of particular assets. To ensure the success of the early intervention phase, it is important for supervisory authorities to have appropriate enforcement actions at their disposal.

It is equally important for the early intervention and resolution phases to be well integrated operationally. Operational integration of the early intervention and resolution phases can be facilitated when both the prudential regulation of systemically important institutions and the resolution of such institutions are assigned to the same agency. Where more than one agency is involved in supervision and resolution, this integration requires rules governing the exchange of information between agencies. It also requires a high degree of coordination between all authorities involved. Such coordination should involve clear and detailed processes to reach the appropriate degree of consultation and to achieve the aggregation of views held by different authorities. An example are the 
rules that govern cooperation between the Canadian banking regulator (OSFI) and the Canadian deposit insurance agency (CDIC) along four stages of an integrated early intervention and resolution process. OSFI (2010) describes the four stages of intensifying intervention, the actions that may be taken by both authorities in each stage, and the means of coordination between both authorities.

\section{Tools}

Effective resolution requires expanding the set of tools beyond liquidation and capital support. This section discusses tools that should be considered when existing regimes are reviewed. Most of these are available under the existing regimes in the USA, the UK, Mexico, South Korea, Canada, and Japan (Brierley 2009).

Acquisition of the failing institution as a whole is often the most desirable outcome when a financial institution is in distress. This solution can provide continuity of services, protect the public purse, and, at the same time, protect the interests of creditors and counterparties, whose exposures to the failing institution are replaced by claims on a stronger institution. Importantly, the resolution authority needs to be able to reach a private sector sale, even if the terms of the sale impose losses on existing shareholders. As illustrated, for example, in the case of the resolution of the US bank Washington Mutual, this can be achieved by assigning the power to effect the transfer of the institution on terms that do not require the consent of existing shareholders.

Bridge banks are temporary institutions created by the resolution authority to take over the operation of the failing institution and preserve its going-concern value, while the resolution authority seeks to arrange a permanent resolution of the failure. The bridge bank tool allows the resolution authority to "bridge" the gap between an institution's failure and the time when a suitable purchaser has been found. This tool may be attractive in particular for large and complex organizations, where due diligence examinations of assets and liabilities by a potential purchaser can take time, and where it is important to keep up critical services, such as payment and infrastructure, provided by the bank (Hüpkes 2000). Importantly, under the bridge bank tool, the incumbent management is replaced and new management services are contracted for by the resolution authority.

Where some of the institution's assets are doubtful, non-performing, or difficult to value, it may be challenging to find an acquirer willing to take over the institution as a whole. In such cases, the resolution authority needs to have the powers to sell some of the assets and liabilities. In a "good bank" solution, only easy-to-value or "clean" assets are transferred, in addition to deposits and (a fraction of) the bank's other liabilities. The residual institution is left with the difficult-to-value ("toxic") assets and the cash raised by the transfer. Having been turned into a "bad bank," the residual institution is owned by existing shareholders, whose capital continues to be at risk from a loss in value of the toxic assets.

Alternatively, the resolution authority may want to set up a new entity, such as an asset management company under government control, and force the transfer of doubtful or toxic assets to that company, which may be in a position to hold on to the doubtful assets or have special skills in collecting on or selling these assets into the market. ${ }^{6}$ 
Care needs to be taken to ensure that the transfer occurs at a fair price, which may be difficult to determine in stressed market conditions. It is important also to ensure that, while the original entity can participate in any upside, it is not left with any residual uncertainty on the downside, which could weigh on its cost of funding, and compromise the success of resolution.

If some assets are hard to value, a further alternative is for authorities to sell the institution as a whole, but provide some form of financing or a guarantee to the acquirer. Such a guarantee is provided to the acquiring institution, rather than to the existing institution and its shareholders, reducing moral hazard, and preserving incentives for private risk management. $^{7}$

As a last resort, the government needs to be able to take temporary public ownership of the failing institution. This may be appropriate where a large amount of public funds need to be made available to stabilize the institution. Temporary public control (nationalization) was the main tool used under the Swedish "triage" approach for those banking institutions deemed neither "clearly non-viable" nor "clearly viable" during the 1990s (Čihák and Nier 2012). Temporary public control may be useful if the banking system is highly concentrated and there are limited options for a sale to private bidders. However, it is important to ensure that former shareholders take the first loss and do not benefit from the assistance provided by the public, that new management is contracted, and that the institution is restructured in a way that can restore viability.

Common across these tools is the absence of a subsidy to existing shareholders. Instead, each of the resolution paths will typically impose losses on shareholders, relative to a situation where the bank is bailed out. As argued above, this is useful both to reduce public outlays in bank resolution and to increase longer-run financial stability by strengthening private incentives for risk management. Moreover, as long as shares in the failing institution are widely held, imposing losses on shareholders should not be a greater concern from the point of view of the stability of the system than when losses are imposed on the sovereign. Finally, relative to ordinary liquidation - the tool commonly used in corporate insolvency of non-financial firms - shareholders would not tend to be worse off under the resolution tools described. In liquidation, shareholders hold the most junior claim and typically lose their entire investment. Under the resolution tools described here, the losses to shareholders are likewise capped by the amount of their investment. The liquidation value is also a relevant yardstick to compare the shareholder's position under the use of special resolution tools. This is because if these tools were not used-and in the absence of public support - liquidation of the bank is the most likely eventual outcome.

Relative to ordinary bankruptcy and liquidation, all resolution tools tend to reduce losses borne by creditors, including both senior and junior classes. In a liquidation of financial institutions, the recovery on assets is typically low, and low recovery is felt most acutely by creditors, while shareholders' losses are capped by limited liability. Since the resolution paths opened up through reorganization are more efficient, such resolution will therefore, in the normal course, tend to protect the interests of creditors.

Losses for creditors may be most likely under the "good bank" approach, where there is a partial sale of "clean" assets to a good bank and this bank also assumes the liabilitiesup to the value of the clean assets - from the residual bank. In this case, whenever the book value of the difficult-to-value assets exceeds shareholder funds, some (classes of) 
creditors will, by a simple balance sheet identity, need to remain exposed to the valuation risk associated with the remaining assets. From the point of view of market discipline and longer-term financial stability, letting losses be borne by debt holders is useful. However, when other financial institutions hold sizable exposures, uncertainty about future losses will increase the vulnerability of these institutions, potentially contributing to systemic risk. One approach to resolving this dilemma is for the resolution authority to buy out financial institutions with sizable exposures as part of the resolution process. Another is for the law to prohibit banks from holding each other's subordinated or senior debt, or otherwise to discourage such exposures, through higher capital requirements on exposures to other financial institutions, and regulations imposing limits on the size of individual exposures, so as to keep knock-on effects at a manageable level.

The above tools differ in the degree to which the public sector assumes valuation risks associated with "toxic" assets. The public sector risks are lowest under the "good bank" approach and highest under the "temporary public control" approach. However, they each avoid the difficulties inherent in solutions that envisage a voluntary sale of difficult-to-value assets by the troubled bank to a private bidder. A voluntary sale is difficult to achieve because the troubled institution may have better information on its portfolio, leading it to place a higher value on the assets than an outside bidder would, or because a complex portfolio can be worth more at the margin to the troubled institution than to a potential buyer. Moreover, none of these tools involve a subsidy to the existing shareholders of the failing institution and each therefore preserves incentives for private risk management. This contrasts with some of the asset resolution schemes that have been devised to cleanse the financial system of its legacy assets, which often envisaged voluntary sales and sought to incentivize such sales through attractive pricing. ${ }^{8}$

\section{Beyond the Special Resolution Regime}

A central point of this chapter is that SRRs, while helpful, are far from a panacea. Even where country authorities have special resolution powers, as described above, large and complex financial institutions may still prove difficult to resolve in an orderly manner. This has sparked intensive debate on additional measures that can be taken to address the risk of failure of institutions that are "too important to fail." There is an emerging consensus that a multipronged and integrated set of policies is required (Ötker-Robe et al. 2011). In other words, the resolution regime is a key, but not the only part of the broader financial stability framework. Prudential supervision has particularly close links to the resolution regime: an effective resolution regime helps to make supervision more effective, and effective supervision helps to identify and prevent problems in financial institutions even before a resolution may be needed.

An important element of the broader approach is a regulatory requirement for systemically important institutions to hold additional capital that can ensure a greater capacity to absorb losses and reduce the likelihood of failure of such institutions. For

globally systemically important institutions, the size of these additional requirements, agreed to by the Financial Stability Board (FSB), will amount to up to 2.5 percent of riskweighted assets, to be met with common equity (Fontevecchia 2011). 
A number of studies have called for additional capital requirements that banks could meet with debt instruments that convert into equity when the bank is under stress. These instruments, known as contingent convertible capital (CoCos), may be less burdensome than common equity, since interest payments on debt instruments are usually treated as an expense and are therefore tax deductible. Moreover, CoCo requirements can have beneficial incentive effects. For example, Calomiris and Herring (2011) argue that when conversion is triggered by falls in the market value of equity relative to assets, shareholders have incentives to issue new equity so as to avoid conversion of convertible debt, since conversion is designed to result in a substantial dilution of shareholders. Properly constructed, a contingent capital requirement can thus complement early intervention by supervisors.

The FSB (2011) has recommended that supervisors regularly assess the feasibility of resolution strategies and be given the power to require appropriate measures to remove obstacles to resolvability. This could include powers to require changes to the institution's business structure, systems, and organization to reduce the complexity and costliness of resolution. For example, to enable the continued operations of systemically important functions, authorities may need to be in a position to require that these functions be segregated in legally and operationally independent entities, so that they can be easily separated and shielded from problems of the group. However, while in the USA, the Dodd-Frank Act has given the Federal Reserve fairly broad powers to improve resolvability, very few supervisory authorities in Europe (or elsewhere) currently dispose of these powers (Basel Committee 2011).

A number of countries, including Germany and Sweden, have recently established dedicated resolution funds that can contribute to the funding of costs incurred in resolving financial institutions (Tait et al. 2010). The IMF (2010) has proposed for such resolution funds to be prefunded by a levy on the non-deposit (wholesale) liabilities of financial institutions. These liabilities are not covered by traditional deposit insurance schemes, but have proven to be vulnerable to runs. The proposed levies can therefore reduce incentives for financial institutions to over-rely on such volatile funding. A further advantage of industry-funded schemes is that they reduce the need for taxpayer support of resolution actions. However, a disadvantage of resolution funds is that, unlike capital requirements, they do not by themselves reduce the likelihood of failure of individual institutions, and may increase the likelihood of failure in a pro-cyclical fashion when contributions are increased at a time of systemic stress. Care also needs to be taken that resolution funds are used only to support resolution action that wipes out shareholders and replaces management, since the availability of a dedicated fund may otherwise contribute to bailout expectations, creating moral hazard.

There is ongoing debate on the merits of expanding the resolution toolbox beyond the tools discussed in the previous section to include bail-in powers - that is, the power to write down the claims of senior unsecured creditors, or to force a conversion to equity of such claims. Such powers were established in Denmark in October 2010 and used in the resolution of Amagerbanken in February 2011 (Schwartzkopff 2011). The benefit is that the write-down of claims can help re-establish the bank as a going concern by boosting its equity capital, while shielding taxpayers from losses. These powers also 
address an anomaly where holders of senior corporate debt are at risk in insolvency proceedings, while the early resolution of banks often largely preserves the value of senior debt. However, the use of bail-in powers can put strains on both the stricken bank's funding and other banks' funding, increasing the cost of replacing maturing debt, in particular in stress times when investor confidence is fragile. Moreover, if senior debt instruments are held by other leveraged financial institutions (such as other banks or money-market mutual funds), a write-down of senior debt can trigger the very systemic repercussions that the introduction of special resolution powers are meant to avoid. To prevent this, it is possible to exempt certain classes of claims, such as shortterm debt and interbank liabilities, but such exemptions may lead banks to increase the share of exempt liabilities in their funding, requiring mandatory levels of issuance of bail-in debt.

\section{Cross-Border Issues}

Handling failures in cross-border financial groups involves additional layers of complexity. It can cause significant tensions between home and host countries that may stand in the way of cost-minimizing solutions. Particularly complicated have been cases when problems in financial institutions exceeded their home country's capacity to offer support (the Icelandic banks) and the resolution of truly multinational banks, such as Fortis (Fonteyne et al. 2010; Čihák and Nier 2012). In those cases, holding up the letter and spirit of existing cooperation and "burden sharing" arrangements has proven hard. Moreover, the crisis illustrated an important challenge for small countries with banking sectors that are dominated by foreign-owned financial institutions, where it may be difficult to determine the extent to which foreign financial institutions will benefit from support put in place by their home countries.

In the European Union, a particular tension arises since cross-border activity has been encouraged as a way of achieving a common market for financial services, while the pan-European legal and administrative framework for bank resolution and insolvency has been lagging. Moreover, in the absence of a strong EU-level fiscal authority, the resolution of failing institutions remains the domain of national authorities. A number of past and present initiatives aim to resolve this tension. Čihák and Decressin (2007) pointed out that a resolution regime at the fully consolidated level would have to be an element of a dedicated European regime for cross-border financial institutions, which would also need to include (i) a European banking license; (ii) a European resolution authority and European resolution fund; (iii) a European deposit insurance scheme, covering deposits issued by branches and subsidiaries; and (iv) strong supervision under the auspices of the new European Banking Authority, also involving colleges of supervisors that include both home and host country authorities.

Čihák and Nier (2012) provide a further analysis on the subject, noting that while national SRRs are only partial and unable to fully address all cross-border issues, they do increase the chance of a successful resolution of the group as a whole. While there is an active international debate on frameworks for the resolution of financial 
institutions that operate across national borders, no formal international agreement is likely in the foreseeable future. Stricter regulation of cross-border institutions will need to be considered as part of the answer.

\section{Conclusion}

There is a strong conceptual case for banks and other systemically important institutions to be subject to a special insolvency regime. Standard judicial insolvency regimes do not necessarily take into account financial-stability considerations, and are typically cumbersome and slow, while in financial crises, speedy and decisive action is necessary.

SRRs can contribute to overall financial stability, and improve the tradeoff between the need to stabilize the financial system and to minimize fiscal costs and longer-run costs of moral hazard. More specifically, by expanding the toolset at the disposal of authorities, a special regime may come to facilitate a decisive restructuring of weakened financial institutions, should such an effort be needed as part of an overall strategy to restore confidence in the financial system.

The chapter reviews the international evidence, and identifies features of a welldesigned and well-implemented bank resolution regime that can be helpful in containing the fiscal costs and limiting the impact of a bank failure on financial stability, both in the home country and in foreign jurisdictions. It highlights the issue of rules versus discretion: these regimes provide wide discretion to financial authorities to act in resolving the problem bank, but they also need to contain clear rules to ensure that timely action occurs, and that it withstands subsequent legal challenges.

The chapter notes that while the conceptual reasons for SRRs for banks are strong, such regimes are not a panacea, and need to be complemented by other measures. Also, real-life resolution regimes have important limitations and shortcomings that reduce their effectiveness. Indeed, reviews of the post-crisis reforms (e.g. Čihák et al. 2012) suggest that the legal and regulatory changes have not yet fully addressed the underlying incentive breakdowns highlighted by the global financial crisis.

\section{Notes}

1 The IMF, FSB, and BIS (2009) provide guidance on an assessment of the systemic importance of financial institutions, as presented to the G20 in November 2009.

2 Dodd-Frank Wall Street Reform and Consumer Protection Act, Pub. L. 111-203. 124 Stat. $1376(2010)$.

3 Federal Deposit Insurance Act § 38, 12 USG, § 18310 (2006).

4 UK Financial Services and Markets Act c. 8, § 296 (2000).

5 Canada Deposit Insurance Act, RSC c. C-3 (1985).

6 This was used when the Swedish government established Securum, a bank founded to take on bad assets during the Swedish banking rescue of 1991-92. In 2009, the Irish government established the National Asset Management Agency, a bad bank.

7 This tool was used in the resolution of Wachovia, a large US bank-holding company.

8 Examples are the US Troubled Asset Relief Program that was originally conceived to relieve banks of their toxic assets through voluntary sales, as well as the German asset relief scheme, approved by the European Commission in July 2009 (http://europa.eu/rapid/pressReleasesAction. 
do? reference $=\mathrm{IP} / 09 / 1216$, accessed August 14, 2014). Neither scheme was taken up, illustrating the difficulties of cleansing bank balance sheets through voluntary sales.

\section{References}

Andrews, Edmond. 2008. “Fed’s \$85 Billion Loan Rescues Insurer.” New York Times, September 17, A1. Ayotte, Kenneth, and David Skeel. 2010. "Bankruptcy or Bailouts?" Fournal of Corporation Law 35: 469, 488-90.

Basel Committee on Banking Supervision (BCBS). 2011. Bank for International Settlements, Resolution Policies and Frameworks: Progress So Far. Basel: BIS. Online: http://www.bis.org/publ/bcbs200. pdf (accessed August 14, 2014).

Brierley, Peter. 2009. "The UK Special Resolution Regime for Failing Banks in an International Context." Financial Stability Paper, no. 5. London: Bank of England.

Calomiris, Charles, and Richard Herring. 2011. "A Contingent Capital Requirement for Banks." E21 Commentary Series. Online: http://economics21.org/files/pdfs/commentary/04_21_2011_ ContingentCapital.pdf (accessed August 14, 2014).

Čihák, Martin, and Erlend Nier. 2012. "The Need for Special Resolution Regimes for Financial Institutions: The Case of the European Union.” Harvard Business Law Review 2: 396-433.

Čihák, Martin, and Jörg Decressin. 2007. "The Case for a European Banking Charter." International Monetary Fund Working Paper, no. 07/173. Washington, DC: IMF.

Čihák, Martin, Aslı Demirgüç-Kunt, Maria Soledad Martínez Pería, and Amin Mohseni. 2012. "Banking Regulation and Supervision around the World: A Crisis Update." Policy Research Working Paper, no. 6308. Washington, DC: World Bank. Forthcoming in fournal of Financial Stability.

Condon, Christopher, and Bryan Keogh. 2008. "Funds' Flight from Commercial Paper Forced Fed Move." Blooomberg, October 7. Online: http://www.bloomberg.com/apps/news?pid=newsarc hiveandsid=a5hvnKFCG_pQ (accessed August 14, 2014).

Financial Stability Board (FSB). 2011. Key Attributes of Effective Resolution Regimes for Financial Institutions. Online: http://www.financialstabilityboard.org/publications/r_111104cc.pdf (accessed August 14, 2014).

Fontevecchia, Agustino. 2011. "The 29 Global Banks That Are Too Big to Fail." Forbes, November 4. Online: http://www.forbes.com/sites/afontevecchia/2011/11/04/the-worlds-29-mostsystemically-important-banks (accessed August 14, 2014).

Fonteyne, Wim, et al. 2010. "Crisis Management and Resolution for a European Banking System 60.” International Monetary Fund Working Paper, no. 10/70. Washington, DC: IMF.

Hüpkes, Eva. 2000. The Legal Aspects of Bank Insolvency: A Comparative Analysis of Western Europe, the United States, and Canada. The Hague: Kluwer Law International.

International Monetary Fund (IMF). 2009. Regional Economic Outlook, Asia and Pacific. Washington, DC: IMF. Online: http://www.imf.org/external/pubs/ft/reo/2009/apd/eng/areo 1009.pdf (accessed September 18, 2014).

2010. A Fair and Substantial Contribution by the Financial Sector. Final Report for the G-20. Washington, DC: IMF. Online: http://www.imf.org/external/np/g20/pdf/062710b.pdf (accessed August 14, 2014).

International Monetary Fund, Financial Stability Board, and Bank for International Settlement. 2009. Guidance to Assess the Systemic Importance of Financial Institutions, Markets and Instruments: Initial Considerations, Report to the G-20 Finance Ministers and Central Bank Governors. Washington, DC: IMF Online: http://www.imf.org/external/np/g20/pdf/100109a.pdf (accessed September 18, 2014).

International Monetary Fund and World Bank. 2009. An Overview of the Legal, Institutional, and Regulatory Framework for Bank Insolvency. Washington, DC: IMF/World Bank. Online: http:// www.imf.org/external/np/pp/eng/2009/041709.pdf (accessed August 14, 2014).

Laeven, Luc, and Fabian Valencia. 2012. "Systemic Banking Grisis Database: An Update." IMF Working Paper, 08/224. Washington, DC: IMF. 
Marinč, Matej, and Razvan Vlahu, 2011. The Economics of Bank Bankruptcy Law. 103-109. Online: http://www.amazon.com/The-Economics-Bank-Bankruptcy-Law/dp/3642218067 (accessed September 18, 2014).

Mayes, David. 2009. "Banking Crisis Resolution Policy: Lessons from Recent Experience 10." CESifo, Working Paper, no. 2823. Online: http://wrerr.cesifo-economic-studies.de/DocDL/cesifo1_ wp2823.pdf (accessed August 14, 2014).

Merrouche, Ouarda, and Erlend Nier. 2010. "What Caused the Global Financial Crisis? Evidence on the Drivers of Financial Imbalances 1999-2007." International Monetary Fund Working Paper, no. WP/10/265. Washington, DC: IMF.

Nier, Erlend, and Ursel Baumann. 2006. "Market Discipline, Disclosure and Moral Hazard in Banking." Fournal of Financial Intermediation 15: 332-5.

Office of the Superintendent of Financial Institutions (OSFI) Canada. 2010. Guide to Intervention for Federally Regulated Deposit-Taking Institutions. Ottawa: OSFI. Online: http://www.osfi-bsif.gc.ca/ Eng/fi-if/rai-eri/sp-ps/Pages/gid.aspx (accessed August 14, 2014).

Ötker-Robe, İnci, et al. 2011. "The Too-Important-to-Fail Conundrum: Impossible to Ignore and Difficult to Resolve." International Monetary Fund Staff, Discussion Note no. SDN/11/12. Online: http://www.imf.org/external/pubs/ft/sdn/2011/sdn1112.pdf (accessed August 14, 2014).

Oberhofer, Katharina, and Ursula Rath, 2012. "Austria: Financial Market Authority Tightens Insider Rules In New Compliance Regulation.” Schonherr, January 31. Online: http://www. schoenherr.eu/news-publications/legal-insights/austria-financial-market-authority-tightensinsider-rules-in-new-compliance-regulation (accessed August 14, 2014).

Schwartzkopff, Frances. 2011. "Denmark Tells Banks Facing Insolvency to Prepare Auction Plans." Bloomberg BusinessWeek, October 12. Online: http://www.businessweek.com/news/2011-10-12/ denmark-tells-banks-facing-insolvency-to-prepare-auction-plans.html (accessed August 14, 2014).

Sorkin, Andrew Ross. 2008. "Lehman Files for Bankruptcy; Merrill Is Sold." New York Times, September 15, A1.

Tait, Nikki, et al. 2010. "Europe Faces Bank Resolution Fund Debate." Financial Times, May 26. Online: http://www.ft.com/intl/cms/s/0/03f66b8e-6908-11df-910b-00144feab49a. html\#axzzlqqDxbVRG (accessed August 14, 2014).

Thomas, Landon, Jr. 2008. "Funds Try to Lose Ties to Lehman." New York Times, October 1, C1 1. World Bank. 2013. "Bank Regulation and Supervision Survey." Global Financial Development Report. Online: http://go.worldbank.org/WFIEF81AP0 (accessed August 29, 2014). Washington, DC: World Bank. 


\title{
Chapter 8
}

\section{BANK RESOLUTION IN NEW ZEALAND AND ITS IMPLICATIONS FOR EUROPE}

\author{
David G. Mayes
}

Although New Zealand is a small country and has a somewhat unusual banking system - in that the four largest banks, which form well over 80 percent of the market, are Australian owned, and the next largest, Kiwibank, is effectively owned by the government - it has taken some striking steps in bank resolution that make it an interesting example for European countries to consider. The overriding precepts of the system are that the taxpayer should not have to pay for bank failure however large the bank and that the vital functions of the large banks have to continue uninterrupted despite the failure. Furthermore, since all the systemically important financial institutions (SIFIs) are foreign owned, the way in which they are structured must be such that the New Zealand authorities can resolve the parts in their jurisdiction satisfactorily, irrespective of what their owners and the Australian authorities decide to do.

For small banks whose individual closure would have no implications for the stability of the financial system, the regime is simple. Such banks will simply be closed and the normal rules of insolvency as applied to any other company will be applied. The only difference is that the central bank is able to step in and have the bank placed in statutory management (an equivalent of receivership) so that it can control the insolvency process if necessary. While no banks failed in the global financial crisis (GFG) in New Zealand, this form of statutory management was applied to the largest of the finance companies that failed (South Canterbury Finance), so the possible process is clear. Other than Kiwibank, none of the other retail banks except the four largest, either jointly or separately, has a significant market share. (Kiwibank will presumably be recapitalized by its owner and, as a narrow bank, it should not be exposed to high risks, except possibly through its mortgage portfolio.)

For the large banks, the regime is a little more complicated. First of all, each bank must be locally incorporated, separately capitalized, and locally managed. In this way, the New Zealand authorities will have the legal authority to resolve it. Secondly, it must be capable of operating on its own within the trading day, independent of its parent or any other significant external supplier. In that way, the New Zealand authorities will have the practical ability to resolve it. Thirdly, the process of resolution that is likely to be applied is that the Reserve Bank (the prudential banking regulator and resolution authority) will apply for the bank to be placed in statutory management. The statutory manager will then, 
on a summary valuation of the bank, apply a conservative write-down to all of the claims, in the order of priority that would apply in an insolvency, and ensure that the bank can continue trading on the next day, without a material break in its operations, and without triggering any close-out clauses or other actions that would stop it trading normally. The regime has been labeled "open bank resolution" (OBR; see Hoskin and Woolford 2011 for an exposition) although its previous name "bank creditor recapitalization"1 also explains the process. The statutory manager would not necessarily treat all of the bank's operations in the same way, as some may not be of systemic importance, and could form part of a normal insolvency or separate sale, whichever is in the best interests of the creditors.

Clearly, there are plenty of practical problems in implementing this form of resolution and these are being addressed at present. In imposing statutory management, the procedure is akin to forming a bridge bank, in that the authorities take over the running of the bank until such time as it can be sold to another authorized provider and recapitalized. In the meantime, it will probably operate under government guarantee against subsequent loss. The taxpayer will hence only be exposed in so far as the write-down of creditors was insufficient or continuing operations results in further losses that were not anticipated. The writingdown process will start with the shareholders, who are likely to be wiped out entirely unless intervention is remarkably quick, and will then move onto the subordinated debt holders, the unsecured creditors, and on upwards through the bondholders if necessary to the point that the losses are clearly accounted for. All those written down will receive a residual claim on the net assets of the bank (which will probably be tradable, if they have any value).

Although somewhat unusual, this all seems straightforward, until one considers the depositors. New Zealand has no deposit insurance. Depositors, therefore, are junior creditors whose claims will be written down in proportion along with other creditors in the same class. Hence, all deposits will be divided into a frozen portion and a continuing portion that can be used in normal transactions immediately. This has some heavy IT and "prepositioning" requirements on the banks, as they will have to be able to identify the balances in all accounts on any given day and perform the separation into the two parts overnight. ${ }^{2}$

Clearly, these proposed arrangements present a number of major problems, and the rest of this chapter deals with them. As there have been no bank failures in recent years and no experience of problems in large institutions, these arrangements are untried - fortunately.

The chapter therefore considers just five issues in consecutive sections before concluding:

- The division of the bank along jurisdictional boundaries for systemic activities

- Whether one can have a resolution arrangement that will work without explicit cooperation of the different jurisdictions involved

- Whether writing down the creditors' claims works better than other forms of bailing in

- Whether the resolution can take place fast enough that it can actually be done while the bank remains "open"

- Whether OBR can operate without provoking a bank run because of the lack of deposit insurance

OBR should reduce the cost of bank resolution in two respects: it should reduce the costs to creditors, and in favorable cases to shareholders, as the deadweight cost of the loss of 
franchise and the costs of working out the resolution through insolvency are reduced; and it should reduce the systemic impact on the rest of the economy by limiting the extent of any direct contagion through failed transactions and indirect contagion through loss of confidence in the banking system as a whole, and uncertainty about where the losses will fall. However, by concentrating the cost in the present by bailing in, it may have a larger, adverse short-run impact on the real economy than would spreading it over time through a tax-financed bailout. ${ }^{3}$

\section{Splitting the Bank}

One of the keys to the New Zealand approach is the ability of the authorities to take control of a free-standing entity and resolve it without recourse to other authorities or the parent. The EU, with its plans for a banking union, is going in a different direction of trying to get "federal level" authorities that can supervise the banking group as a whole, take decisions, and coordinate the different authorities involved in the resolution. ${ }^{4}$ Previously in the GFC, it became clear that the only cross-border arrangement that works well is where the home country authorities take on the job and allow the whole group to continue. Then none of the conflicts of interest about what is best for one country, particularly from the point of view of systemic stability, need to be addressed. In practice of course, this was the bailout route, although, as in the case of the Royal Bank of Scotland, for example, this can enable the authorities to have quite a considerable say over how the group is run since they are the large majority owner. European-level constraints, such as the commission's requirements as the relevant competition authority for Lloyds Group to sell off some of the branches as a condition of their acquisition of HBOS, do not appear to offer any constraint on the essential feature of the resolution, which is to keep the bank operating in all countries without a break. It is noticeable that the UK and the USA, in the joint statement by the Federal Deposit Insurance Corporation (FDIC) and the Bank of England, have continued with this view that the practical route to resolving a SIFI is for the authorities responsible for the parent organization to tackle it at the group level, including any bail-in (FDIC and Bank of England 2012).

How the new EU ideas will pan out depends very much on the detail - not just in the relevant regulations and directives, but in how they are applied. The initial concern is that the group should be properly supervised as a single entity, although this will only apply to groups that are headquartered in the EU/EEA. It does not necessarily mean that there will be a single resolution agency, and the problem may still be how to coordinate all the individual jurisdictions. ${ }^{5}$ If the intention is to organize a bailout, then this may still be straightforward, but as soon as the resolution involves closing or severely restricting some parts of the group, then conflicts of interest among the countries involved may surface. For example, closing a loss-making operation may be in the best interests of the creditors as a whole but cause a systemic problem in one country. Conflicts can also occur in bailout, as some countries may regard the source of the difficulties as being the fault of other regulatory authorities or the result of events that are completely extraneous to them, and hence the concern solely of other regulators/bailout funds. Once the 
Single Supervisory Mechanism is in place and the problems from the past have been satisfactorily dealt with, including adequate recapitalization, then the chance of such blame should be much smaller when supervision is a joint activity led by the European Central Bank (ECB).

Conflicts may also be avoided if bail-in arrangements are sufficiently extensive that the entire banking group can continue to operate. In that way, it might be possible to avoid the use of taxpayer funds, especially if deposit insurance and resolution funds are provided by the industry and not by the state, as intended in the Recovery and Resolution Directive (RRD). However, such bail-in arrangements would have to be carefully specified in the design of bonds and subordinated debt. In particular, that it could be triggered before the bank reaches insolvency. ${ }^{6}$ Managing a cross-border insolvency would still be very difficult. Almost any halfway house between legal and practical separation and a single jurisdiction for the whole group looks fraught with difficulty.

Separability, at face value, sounds as if it runs counter to all of the ideas of the European single market, but in practice the strict separability required between Australia and New Zealand seems to have been of little consequence for the banks. Staff move between the two jurisdictions - the current and previous CEOs of one of the main four banks, Commonwealth, are New Zealanders - and many of the managerial practices and products are common. However, the New Zealand banks have by and large maintained their own trading names when they have been acquired, and the fact that the absorbing of the National Bank of New Zealand into the ANZ in early 2013, having been owned by it for a number of years, seems to have lost them some customers, tends to confirm this. ${ }^{7}$ Thus, although the literature suggests that economies of scale are possible until banks are very large, there does not appear to be much loss from these sources of separation. The parent will still access capital markets on behalf of the group, many investment services will be sourced from Australia, and hence many of the spillovers will still take place.

For large groups, a different dimension of separability needs to be considered relating to non-bank arms, such as insurance, and retail and investment banking activities, but here, the New Zealand example has little to offer in the way of lessons. The stability of the main four banks in the GFC relates mainly to their not having participated in risky activities and having little exposure to the USA. Many argue this was simply because they had no shortage of profitable opportunities remaining at home and so did not face the same "search for yield."

The high-level group behind the Liikanen Report (2012) were clearly of the opinion that current and indeed proposed requirements for separability in EU banking groups was going to be insufficient: "In the Group's view, producing an effective and credible RRP [Recovery and Resolution Plan] may require the scope of the separable activities to be wider than under the mandatory separation" (103; emphasis in original).

\section{Can One Ignore the Australians?}

OBR is in part predicated on the idea that what the Australians wish to do, while relevant, is not going to constrain New Zealand in its resolution procedures. This seems unlikely. While New Zealand operations may only be around 15 percent or so of the banking 
group's activities, they are large enough to have an implication for the whole group, even if only on grounds of reputation risk. If an Australian bank has been prepared to let its New Zealand subsidiary fold, what does that imply for its overall viability? Thus, the Australian authorities are likely to be intervening at the same time. No doubt what they would like to do is resolve the group and send New Zealand the bill for its share, based perhaps on the share of assets, much along the lines suggested for European banks by Goodhart and Schoenmaker (2009).

It is therefore important to understand how Australia will probably go about a resolution. They have made it clear that the four main banks are pillars of the system and will not be allowed to fail. However, they would follow a similar statutory management route to New Zealand but without the writing down of depositors in the same way. Australia operates a deposit guarantee scheme. This is unfunded, and losses would be met by a government loan in the short run before levies could be raised to claw back the losses. ${ }^{8}$ However, (domestic) depositors are preferred creditors in Australia, so the chances of them making losses eventually are small. Hence, the guarantee scheme is only likely to act as a temporary financer of depositors. Indeed, if there is no run, it is not clear that it will have much of a job to do until the losses are very large. The Australian authorities have not made it clear what they will do, except that once in statutory management, the bank will need to be recapitalized (Australian Prudential Regulation Authority 2012). This can come from taxpayers, levies on the industry or creditors, or of course capital injections by a purchaser. Since a bank in statutory management can continue to trade with a government guarantee even though its liabilities exceed its assets, this can be a viable way forward. Assuming, that is, that people find the guarantee credible. If a bank has a "living will," the route to recapitalization will be rather clearer.

The implications for New Zealand are then interesting. It depends which route to recapitalization is going to dominate. A cynical view of the position would argue that because of reputation risk and the systemic importance of the financial institutions to Australia there is little need for the New Zealand authorities to take much action. A problem with one of the big four banks, even if it occurred primarily in New Zealand, would be handled by Australia with little, if any, implications for either the New Zealand taxpayer or for financial stability in New Zealand as the bank would be kept open. Indeed, if the problem occurred primarily in Australia, the New Zealand authorities would have a reasonable case for feeling that they should not have to make any financial contribution to the resolution.

The drawback of any such assessment is that it is a guess, and if it were to be incorrect, the New Zealand authorities would face a crisis if they were not prepared. Going carefully through all the steps in preparing for OBR therefore makes sense even if the underlying guess is that it will never be used. Its mere existence will help in resolution and, more importantly, its existence will help in reducing any moral hazard that is currently present. If the banks know that the New Zealand authorities have in place a workable resolution scheme that will result in the wiping out of shareholders and the probable loss to the senior managers of their jobs, then they will be that much more reluctant to take on excessive risk. 
Given that this is a bilateral relationship rather than one with the multilateral complexity in Europe, one might expect that the two countries would try to produce a highly coordinated system even though they are preparing for a contingency that they think highly unlikely. Routes to achieve this exist through the Trans-Tasman Council on Banking Supervision, ${ }^{9}$ for example, through which the memorandum of cooperation was signed in $2010 .{ }^{10}$ While harmonization of procedures might seem desirable, even if this cannot be achieved, some clear form of understanding of what the two countries expect of each other would be normal, even though memoranda of understanding have been shown to have limited value by the GFC. At a minimum, regular testing of the resolution procedures on a cross-country basis would seem a wise precaution.

The first principle of the Memorandum of Cooperation on Trans-Tasman Bank Distress Management is as follows: "Consistent with the legislation in both countries, the participants in responding to bank distress or failure situations, will to the extent reasonably practicable, avoid any actions that are likely to have a detrimental effect on the other country's financial system" (2010, 3). But the second principle acknowledges the advantages of cooperation: "A coordinated, cooperative approach involving the participants is likely to lead to a more cost effective financial crisis resolution and a more effective means of maintaining financial system stability in both countries than one in which the respective participants pursue separate agendas" (4). While the rest of that principle says they will "cooperate, where practicable, in respect of all stages of resolving a crisis situation, including problem identification; information sharing; systemic impact analysis; assessment of response options; implementation of resolution; public communication; and exit strategy" (4), there is little practical detail, except to make it clear that New Zealand will be responsible for what lies within its jurisdiction, and Australia will be responsible for the parent and its jurisdiction.

Thus, while the potential for a less costly cooperation exists, it does not seem likely that the two countries will move toward it any time soon.

\section{Bailing In}

If there are losses, someone has to bear them. Furthermore, it is generally thought that recognizing the losses early and assigning them is much more beneficial to the recovery than trying to cover them up and obscure who the holders of the losses are. Japan is the major case in point. However, the conclusions are not that clear, as there is considerable debate about whether it is better to try to recapitalize the business as a whole or separate it into a good bank and a bad bank (or in the Icelandic case, into a domestic bank and a foreign residual). ${ }^{11}$

The New Zealand arrangements cut through this. First of all, the statutory manager can, if he thinks that it is in the best interests of the creditors and of financial stability, place some of the bank in insolvency, and only resolve part by the write-down of claims. Those written down have a claim on the insolvency estate. Furthermore, the process buys time. It returns the bank to operating viability but it does not solve the question of recapitalization. In Mayes et al. (2001), we suggest that a write-down could go all the way to recapitalization, with those who are written down becoming the new owners of 
the bank (this appears to be the provision in the RRD as well). The drawback of this arrangement is that there is no reason to expect that the new owners will be "fit and proper persons" to run a bank, and hence, there would have to be a transition before the statutory manager or his equivalent was prepared to step back from running the bank. In the New Zealand arrangements, there is a period after resolution where the statutory manager looks for the new owners. Presumably this would be some form of auctioning process such as that which the FDIC performs when it wishes to find new owners for a failed institution, but with it being held in an equivalent to a bridge bank in the meantime.

With CoCos or other contracted bail-in arrangements, such as subordinated debt in Denmark, it is clear how much debt is available to be turned into equity. With the New Zealand arrangements, there is no legal provision in the debt instruments, but their status is overruled by the resolution arrangements. (One can readily envisage foreign bondholders contesting that through the courts.) There is also no limit to how much might be written down except for the size of the eligible debt. Thus, covered bonds, repos, and all the other collateralized transactions would be excluded (again as is proposed in the RRD). It is not surprising, therefore, that deposits have to form part of this pool or one might run out of suitable cover for a major loss - of the proportion of Landsbanki or the Anglo-Irish Bank, for example. Bertram and Tripe (2012) show, for example, that in the New Zealand environment, all wholesale lending might well be covered, so that once the shareholders and the subordinated debt holders are wiped out, the depositors will bear the rest of the exposure. ${ }^{12}$ If smaller depositors were excluded by the de minimis clause, then the burden on the remainder could be quite substantial ${ }^{13}$ — certainly substantial enough that the political fallout from those being written down would be considerable. ${ }^{14}$

There is thus a strong incentive to try to make the bail-in arrangements as explicit as possible. Clearly, one argument against this might be that this would increase the cost of debt. But with large, strong banks, the cost from existing CoCos appears to be quite small. The alternative is to place limits on covered bonds and other secured debt. If depositors are going to be in the frontline in most resolutions, this will heighten the risk of a run should the banking system start looking at all weak.

The identity of those who have to bail in is important, as in periods of difficulty it is important that those who provide capital are not simultaneously weakening the position of other financial institutions. Thus, on the whole, the funds should come from outside the banking system unless they come in the form of a merger or acquisition which is acceptable to the authorities. A well-known problem is the merger of a weak bank with a strong bank creating a large weak bank rather than resolving the issue.

Where ownership structures in Europe are more complex, with cross-holdings, clearly, formal ex ante agreed bail-in and, indeed, bailout arrangements will become more difficult to apply. Knowing that bail-in clauses are likely to activate will alter the value of debt shortly before that activation. Whereas depositors can exit, bond holders can only sell to another willing purchaser. In this case, a fall in the market value of the debt will not provide too much of a problem in the way that the decline in share prices does, although it might affect its repo usefulness.

The New Zealand scheme therefore faces one problem in this regard. If the claims have been written down but the bad loans are still left on the balance sheet (but at 
written-down values), a potential purchaser/provider of the recapitalization may still have worries about the likely outcome when the loans are eventually worked out. This would therefore make exit from statutory management difficult. However, the problem is no different from any other resolution, except possibly for the size, as transferring the impaired loans to an asset management company does get rid of the difficulty. OBR thus does not get round this, but then neither does any of the other plausible routes to resolution.

The Liikanen Report (2012) also puts an emphasis on bail-in facilities: "The power to write down claims of unsecured creditors or convert debt claims to equity in a bank resolution process is crucial" (viii). One aspect that they draw attention to, given the focus of the report on structure, is where the bail-in occurs. Is it to the parent or to the subsidiary? Their concern is that the bail-in goes to the retail bank, as for them that is the part that needs to continue. In the present context, it is the retail banking operations in each jurisdiction plus any other activities of the group that are of systemic importance in any jurisdiction that matters. The New Zealand scheme gives the appropriate distribution automatically, whereas there are no such guarantees in the EU, which makes the idea of wanting to handle the problem at the EU level all the more understandable. ${ }^{15}$

The Liikanen Report also agrees that bailing-in options should be explicit:

The Group has come to the conclusion that there is a need to further develop the framework, so as to improve the predictability of the use of the bail-in instrument. Specifically, the Group is of the opinion that the bail-in requirement ought to be applied explicitly to a certain category of debt instruments, the requirement for which should be phased in over an extended period of time. This avoids congestion in the new issues market and allows the primary and the secondary market to grow smoothly. (2012, 103; emphasis added)

This last aspect of the impact of introduction has not been considered in the New Zealand scheme. On the other hand, the ideas behind OBR have been revealed steadily over a decade and the explicit formulation of the plans does not appear to have had any noticeable effect on markets. It is perhaps not so much the cost of the potential bail-in which affects the debt when it is sold as the impact on liquidity when the bail-in takes place. Here, the nature of the bail-in is important. A write-down leaves the bondholder with little value in the written-down part. If, on the other hand, this is a debt for equity swap, the bondholder will have a stake in the future of the bank. In both the Nordic crises and in a number of cases in the GFC, investments by governments in failing banks and other institutions have paid off, and resale to the private sector has not merely repaid the money but offered a rate of return higher than the cost of government debt. ${ }^{16}$

One thing that the Reserve Bank of New Zealand (RBNZ) has done, which is a helpful pointer to others intending to implement bail-in schemes, is to conduct an impact assessment (RBNZ 2012). Using an undisclosed model, the RBNZ (2012) assumes that the cost of a banking crisis is 20 percent of gross domestic product (GDP) for the typical case of a bailout, although a "good" bailout could reduce this a little. Recapitalization through the market works best at 12.5 percent, and falling into statutory management, and hence into a disorderly failure, is worst at 25 percent of GDP. While one might 
dispute all of these magnitudes, the RBNZ's view is that a good use of OBR would also deliver a cost of 20 percent of GDP, and if it does not go well it could be similar to the worst-case 25 percent cost.

Thus, there is no claim that using OBR (bailing in) per se reduces the cost of failure. What they do claim is that because bailing in offers a plausible route forward that puts the loss on the shareholders, management, and creditors, there will be much more effort to ensure that market-based recapitalizations take place. Hence, the probability of lowcost resolutions goes up and the expected costs of resolutions under an OBR regime as opposed to actually having to implement OBR for a specific failure are considerably reduced.

Taking this change in probabilities into account, RBNZ (2012) then estimates that the overall reduction in cost is likely to be of the order of 16.5 percent. Table 8.1 reproduces the calculations. No doubt the individual numbers are very soft, but they have several noteworthy features. First of all, the banks will have to pay more for their funding and this cost will accrue irrespective of a failure. The costs of implementing and maintaining the capacity within banks for undergoing OBR is trivial by comparison. The largest gain comes from OBR being cheaper to apply than a bailout and, of course, from the lower economic cost as a result of the greater likelihood of more efficient methods being used. It is worth noting that they do not forecast the chance of requiring a bailout to be zero and hence there may still be ongoing costs from increased government debt.

It is not clear that the putative cost of the RRD or the hoped-for reductions in impact are assessed as still being so substantial. If a SIFI fails, it is likely to be as part of a more general crisis and the impact on the economy is likely to be substantial. What bailing in does is shift the incidence across the economy considerably. It is not immediately apparent that such a shift is necessarily beneficial for the economy as a whole, nor indeed for ordinary people, who are thought to be the victims as taxpayers when a bailout is used. A bail-in concentrates the cost as well on a relatively narrow group of creditors, primarily depositors in the New Zealand case. With deposit insurance, that cost is not only substantially met in advance through the deposit insurance fund, which is then slowly replenished after the event, but it is spread across all depositors, and not just those in the failing bank. It is not intuitively obvious whether the impact on people as

Table 8.1. Estimated impact of implementing OBR (\$mn)

\begin{tabular}{lccc}
\hline Factor & Status Quo & OBR available & Difference \\
\hline Economic cost & 5492 & 4764 & 728 \\
Bailout cost & 1703 & 693 & 1010 \\
Government debt service cost & 413 & 172 & 241 \\
Bank funding cost & 282 & 936 & -653 \\
Maintenance cost & 0 & 10 & -10 \\
Build cost & 0 & 20 & -20 \\
Overall NPV & & & $\mathbf{1 2 9 4 . 5}$ \\
\hline
\end{tabular}

Source: RBNZ (2012). 
depositors or as taxpayers is more or less equitable. The richer in society may have more difficulty avoiding tax than they do in finding non-bank deposit vehicles for their savings. However, uninsured depositors are hit much harder under a bail-in as they incur all the loss upfront, and indeed, with a conservative valuation, face more than 100 percent of it in the short run until the true value is established. As taxpayers they have the cost spread over a generation. The same problem applies to other bailed-in creditors. If these happen to be pension funds, then they are likely to have an extended period over which to repair the damage, either through increased premiums or through lower benefit rates.

Similarly, hedge funds may be good loss absorbers, but a proper analysis of the impact of these measures needs to consider on whom the direct cost falls, and what consequences this will have on their subsequent behavior. Imposing losses directly on ordinary depositors will reduce consumption. While pension funds or taxpayers/the government may have to increase their savings rates over the longer term to compensate for the loss, the initial impact may be much smaller. Simple net present values will not cover this, as trying to limit the downturn in the economy and get back into rapid recovery as soon as possible are key policy imperatives.

\section{Swift Action}

One of the great problems in any resolution framework is that it needs to cut in early. The role of all the parties involved (central bank, resolution agency, ministry of finance, and supervisor) needs to be clear and regularly tested. Here, the position of the New Zealand authorities, while not unusual, does have some clear advantages in that a statutory manager can be appointed before a bank reaches the point of insolvency. The terms under which it can intervene are not precise, but severe undercapitalization or inappropriate responses in the face of coming failure could trigger it. However, there are checks in the system of appointment. The Reserve Bank makes the recommendation to the minister of finance, who then requests the governor-general to implement it. Similarly, while there are abilities to claim compensation should the actions of a statutory manager lead to losses, the decisions of the manager in imposing the resolution cannot be reversed, therefore giving certainty to those involved.

What the New Zealand system does not include is any set of mandatory prompt corrective action (PCA) along the lines laid down for the FDIC. Indeed, RBNZ (2012) casts some doubt over the plausibility of such early intervention regimes (including implicitly the "recovery" part of the RRD). One of the main problems revealed (again) in the GFC is the extent to which authorities have put off reacting - even where there was a mandatory requirement in the USA (Garcia 2012; Bair 2012). However, the position is similar in most European countries, so one can be reasonably confident that intervention is unlikely to take place before the point that the bank is insolvent. However, the important question in the present context is the amount of time the authorities will have had to try to put an orderly resolution together.

While the requirements in New Zealand for being able to separate the claims of the creditors into frozen and continuing parts can be put in place overnight and tested on a regular basis, if there has been no serious preparation, the summary assessment of the 
financial position of the bank will be very difficult to do. Even if claims are being marked to market, one can be reasonably confident that the bank's own assessment of the value of its assets is likely to be optimistic. One need only observe the enormous inaccuracy of the initial assessment of the value of the assets of Anglo-Irish Bank in 2008 to realize how severe the problem might be (Honohan 2010). If the supervisor/resolution agency is not doing preparatory work inside the bank for several weeks before the resolution, there is a strong opportunity for difficulty, and possible exposure to taxpayer losses if the write-down of the creditors' claims turns out to be insufficient.

It is not clear whether other jurisdictions are putting in place adequate prepositioning to be able to handle the resolution of their largest banks, although the USA has got as far as drawing up the specification of what would need to be in place for this to work. Leaving this undone must mean that only a bailout is likely to work in practice unless a consolidation is possible, as with the purchase of Wachovia by Wells Fargo in 2008. In this case, Wells Fargo was prepared to take the risk that it was paying too much. It could then spend nearly three years absorbing the new organization, with the last branches of Wachovia becoming Wells Fargo in October 2011. The alternative available at the time was an assisted purchase by Citi. Again this would have allowed Wachovia to be absorbed steadily, but the authorities would not have been able to exit their own expenditure rapidly. Of course in the traditional resolution of small banks in a closed bank resolution, it is still the case that the deposit insurer will not get closure until all of the assets have been sold, and issues relating to all of the contested claims have been worked out through agreement or through the courts.

If everything is ready and the systems are tried and tested, then it seems likely that the necessary computer-based separation of creditors' claims into frozen and accessible components could be achieved overnight, as well as allowing all transactions in progress to be completed on time so there is no disruption to the normal business and no possibility of claiming that a default event had occurred. Division into insured and uninsured deposits has been practised elsewhere, particularly in the USA, within the necessary timeframe. While the USA has handled bigger banks, they have had a larger staff to do this. The size of team that the RBNZ could put together from its own staff in a crisis would be quite small and they would have no experience of handling such an event. They could perhaps organize a pool of contingent trained staff on whom they could call in a crisis. While some of these could be retirees, others might well have other employment. Clearly, the idea of getting any help from Australia is unlikely, as they will be flat out handling the problem in the parent bank simultaneously. Getting help from anywhere else would take longer to organize.

\section{An Error over Deposit Insurance}

There is a serious flaw in the New Zealand arrangements for OBR. New Zealand does not have deposit insurance, and hence, as junior creditors, depositors will incur losses in the resolution. It is yet to be decided how many depositors may be excluded from this threat through the imposition of a de minimis clause that exempts small deposits from any write-down. (Such a de minimis clause makes sense anyway as it would avoid a lot of 
administrative expense for small sums of money.) Where any de minimis line is to be drawn is not to be disclosed in advance. Even if it is drawn as high as NZ\$20,000 there will still be a large number of depositors affected.

The appropriate strategy for depositors if there was any sniff of doubt about the viability of a bank would be to remove their deposits or at least reduce them to below any expected de minimis level. Thus, whereas elsewhere deposits are a stabilizing force for troubled banks, this would not be the case in New Zealand. Funding problems for troubled banks occur in wholesale markets as informed counterparties first of all demand a premium and then refuse to lend at all as difficulties mount. This inability to borrow in wholesale markets then causes banks to approach the central bank as lender of last resort. If they are thought solvent, the central bank will step into the place of the market, or if they are thought likely to be insolvent, the process of resolution will start. To organize resolution well, the authorities require quite a long lead time, perhaps as much as two to three months if USA and UK experience is anything to go by. Depositors help provide that time period because, since their credit to the bank is not under threat, they continue to maintain their loans and the bank can make its cash flow demands. If the depositors follow on the wholesale funders quite quickly, this grace period will not be possible, and the resolution will be messier and more inequitable as some will have been able to withdraw their deposits and others not.

Since OBR relates to the large banks, unless there is very clear evidence that problems are related to a specific bank, the chances are that there will be a general loss of confidence, and larger depositors will start removing the money from all banks as a precaution. Thus, a manageable problem is turned into a full-blown financial crisis. Almost certainly, the government would need to renege on its commitment not to use taxpayer funding.

Thus, not only is OBR likely to be destabilizing, but it is simply unlikely ever to be exercised, as the authorities are likely to have to offer a blanket guarantee to depositors to prevent a general crisis. Simply having deposit insurance with a fairly high coverage ratio would address this problem, although in the event of a large bank failing, the resources required may exceed those held by the deposit insurer. In that case, temporary government funding would be required if the fund is not to default.

The New Zealand authorities seem to have a well-entrenched objection to deposit insurance, which will have been reinforced by the rather disastrous introduction of temporary deposit guarantees in 2008 (the Crown Retail Deposit Guarantee Scheme). ${ }^{17}$ The government ended up paying out not just the depositors, but all creditors of South Canterbury Finance, owing to a series of design failures in the scheme. Nevertheless, in the face of a run on the main banks, especially where most are thought to be solvent, the authorities would have no alternative but to introduce a new guarantee scheme. No doubt the previous drawbacks will be avoided, but we could expect in practice that individual deposits end up being insured up to some quite high value - say, $\$ 250,000$, where the scheme ended up, or $\$ 1,000,000$, where it started. In this case, there would be a serious problem with the exposure of the taxpayer when the first bank needs to be resolved.

The government will then face the normal dilemma. If the bank is bailed out, there will be no call on the guarantee fund. If the bank is not bailed out and OBR is applied, then the Crown will become liable for the whole write-down of insured depositors' funds. 
Neither sounds attractive. The simplest solution is presumably to introduce the same guarantee scheme as Australia or even just introduce depositor preference. Providing there are enough available funds, the other creditors will have to meet the banks' losses under OBR ahead of the depositors. The high size of such a non-depositor write-down may threaten the viability of the scheme. The Australian arrangements will also be unrealistic in that regard if there are insufficient non-depositor creditor funds after taking account of all the carve-outs from repos, collateralized bonds, and other protected financial market contracts. The position in Europe depends upon not just whether there is depositor preference, but on how deposit insurance is financed. ${ }^{18}$ If it is prefunded by the industry, the taxpayer will not be called on unless that funding is insufficient and the fund has to borrow - temporarily - from the government. If it is ex post funded by the industry, then the temporary government funding is certain. If it is funded by the government, then obviously the taxpayer pays. The addition of resolution funds as planned in the EU/EEA, will increase the chance of being able to organize the resolution, as it will not be necessary to raise that funding either from the deposit insurer or from the other creditors.

\section{Concluding Remarks}

While New Zealand's new OBR proposals are untried, they sound a plausible way of organizing the resolution of systemically important subsidiaries of foreign-owned banks - provided that the increased threat to financial stability posed by the lack of deposit insurance is addressed. The arrangement not only offers a practical solution that can be implemented swiftly without the need for taxpayer funding, but it appears to be one that does not place large continuing costs on the banking system. Four ingredients are necessary for the scheme to work:

- A clear legal and practical ability for the authorities to take over the subsidiary and get it operating again within the same value day

- Adequate prior preparation to ensure all the necessary IT and other procedures required are in place and regularly tested

- The ability to write down creditors' claims and thereby organize a bail-in to keep the vital functions of the bank operating without material interruption

- The legal rules necessary to ensure that contracts are not closed by the operation of the resolution - since some contracts will be written down to zero and others substantially, this may pose a problem with other jurisdictions

Rather than ensuring a clear separation so that all authorities can look after their own systemic requirements, the EU has decided to pursue the idea of a "banking union," which would enable a new European-level supervisor, the ECB, to coordinate supervision so it can be undertaken for the entire banking group in a single operation. However, resolution is not being concentrated in the same way, although the commission has suggested itself for much of the role (see Endnote 4). However, this only relates to the European area plus others who choose to join and to banking not all financial operations of the group (see Endnote 4). Resolution is to be coordinated separately under a Single 
Resolution Board, based in Brussels, also only covering the European area plus those who choose to join. This Board will have access to a Single Resolution Fund contributed by the banks themselves in advance. How this will work remains to be clarified and its detail will determine its feasibility. Most awkwardly, not all countries are participating, and the $\mathrm{UK}$, with the most important banking system in the area, is staying out. Hence, only some cross-border SIFIs will be fully covered. New Zealand's straightforward approach may be difficult to apply in this framework.

A plausible scheme that enables systemically important banks to be resolved without a material break in their vital operations and without the use of taxpayer funds is an important contribution to financial stability - not simply because of what it will achieve in a crisis, but because it encourages prudence, and makes the chance of its being called upon smaller. Traditional OBR methods applied in the GFC involved injections of taxpayer capital, no losses to creditors, and many of those responsible for the running of the companies kept their jobs. With a much more limited chance of a bailout, those running banks and lending to them, particularly shareholders who are first in line for the losses, will be keen to see banks manage their risk better and not encounter the fragility of recent years. Better supervision and the increase in capital and liquidity buffers will also contribute to a lower chance of ever needing the resolution arrangements. That does not mean that they should not rapidly now be put in place while the political will lasts. As Tucker (2012) puts it, they provide the two "bookends" to a successful treatment: reducing the probability of occurrence at the one end and having a viable means of handling any problems that do nevertheless occur at the other.

Perhaps the most important lesson New Zealand can offer is over how to handle the long interim period before the ideal of the banking union across the whole of the EU comes into being. The UK has stressed the importance of the authorities in the parent country being able to handle the entire problem with a single point of entry to the insolvency proceedings (FDIC and Bank of England 2012; Tucker 2012) and this would work for most EU SIFIs. The problem area is where the banks are large compared to their parent countries. There, multiple points of entry to the resolution process are inevitable, with each jurisdiction having to handle its own subsidiaries and manage the costs. Following the New Zealand route of each being able to handle the problems for their own stability until the full system comes online would make the transition much more robust, and from the estimates of the costs in RBNZ (2012), it would not add much to the total for a potentially important benefit, as it seems so difficult to exit firmly from the problems of the GFC.

\section{Notes}

1 Harrison et al. (2007) provide a clear statement of what is required and the main features needed for it to work well.

2 The prepositioning requirements in New Zealand are set out in a 25-page document by the RBNZ: "Open Bank Resolution (OBR) Pre-positioning Requirements Policy." Document BS17, September 2013. Online: http://www.rbnz.govt.nz/regulation_and_supervision/ banks/banking_supervision_handbook/5341478.pdf (accessed August 14, 2014).

3 OBR actually imposes more than a 100 percent initial impact in the present, as the writedown will be conservative and it will not be until later that those written down get a further 
release of funds as the proceeds of the insolvency or valuation of transferred assets are revealed. Thus, while the impact of OBR on creditors, and hence on the real economy, will be a clear improvement over a traditional insolvency where payouts depend on the actual and potential sale of assets, it is not so clear how it will rank compared with a bailout as the resolution method.

4 As of September 2014, the EU has got as far as agreeing that the ECB should be the overall supervisor for banks in the euro area and for other countries who decide to join the Single Supervisory Mechanism. It is envisaged that the ECB would supervise the banks of systemic importance directly, which would cover 80 percent of assets, but only one hundred and fifty or so banks. (This is embodied in two regulations, one to give the necessary powers to the ECB ["Proposal for a Council Regulation Conferring Specific Tasks on the European Central Bank Concerning Policies Relating to the Prudential Supervision of Credit Institutions," 2012/0242 (CNS), April 16, 2013. Online: http://register.consilium.europa.eu/pdf/en/13/st07/ st07776-re01.en13.pdf, accessed August 15, 2014] and the other [http://register.consilium. europa.eu/doc/srv?l=EN\&f=PE\%2022\%202013\%20INIT], which amends the Regulation on the European Banking Authority to establish its relationship with the ECB and to amend the voting rules in the Board of Supervisors.) The resolution authority would, however, be different, and this is laid out in the Recovery and Resolution Directive (2014/58/EU) (http:// eur-lex.europa.eu/legal-content/EN/TXT/?uri=CELEX:32014L0059, accessed August 15, 2014) and a separate Single Resolution Regulation (SRR) (http://eur-lex.europa.eu/legalcontent/EN/TXT/?uri=CELEX:32014R0806, accessed August 15, 2014). The SRR creates a Single Resolution Board independent of the ECB and a Single Resolution Fund that will be built up over 8 years. This board and all the national resolution authorities will have access to the full range of instruments necessary for a resolution including bailing in. Public money is only to be used as a last resort and instead resolution funds, contributed by the banks, will be available after 8 per cent of liabilities have been bailed in to cover costs that would not normally have been borne by creditors so that nobody is worse off than they would have been in traditional insolvency. Again the SRB would only cover participating countries. Proposals for how banking groups might be required to restructure following the Liikanen Report have been delayed by the European Parliament elections and the appointment of a new commission. Thus, at this stage, the EU proposals are complex and incomplete.

5 The European Commission has proposed itself as the appropriate authority for taking the lead in cross-border resolutions, but the Recovery and Resolution Directive does not create such a resolution authority as such, as proposed by Mayes (2006) and Schoenmaker and Gros (2012).

6 The Recovery and Resolution Directive (RRD), as its name implies, addresses this concern upfront by seeking to have not just resolution plans for each systemic bank, which would enable orderly resolution should they fail, but also recovery plans that give a plausible path for the bank to restore capital adequacy and a return to profitability without failing should it experience a severe shock.

7 There were substantial customer losses when Danske Bank (Denmark) decided to integrate Sampo Bank (Finland) rapidly into its systems shortly after acquisition in 2007, although the name did not change until 2012.

8 The Australian authorities have recently announced that they intend to create a resolution fund by imposing a levy on the banks in proportion to their asset base. See Chris Bowen, press conference, Canberra, August 2, 2013. Online: http://ministers.treasury.gov.au/ DisplayDocs.aspx?doc $=$ transcripts $/ 2013 / 022 . \mathrm{htm} \&$ pageID $=004 \& \mathrm{~min}=$ cebb $\&$ Year $=\&$ Doc Type $=($ accessed August 15, 2014).

9 The council and its terms of reference are described in http://www.cfr.gov.au/about-cfr/ financial-distress-planning-management/trans-tasman-council-on-banking-supervision.html and http://www.rbnz.govt.nz/regulation_and_supervision/banks/relationships/4674137. html (accessed August 15, 2014).

10 The memorandum is available at http://www.cfr.gov.au/about-cfr/financial-distress-planningmanagement/pdf/ttbc-memorandum-of-cooperation.pdf (accessed August 15, 2014). 
11 See, for example, the debate between Norway and Sweden and Finland discussed in Moe et al. (2004).

12 It is clear from Figure 2 in Hoskin and Woolford (2011) that the RBNZ has a very different view about the proportion of claims that are likely to be secured or otherwise collateralized, as these are shown as a small minority. They envisage "wholesale financing" as being able to contribute substantially to the write-down. Given that the exit of wholesale financing in what Kane (1999) describes as a silent run is usually the direct cause of the bank failure, this may be rather optimistic.

13 The illustration of the de minimis clause used in the consultative paper is only for $\$ 500$, which would eliminate quite a large number of small or dormant accounts but would not reduce the overall value of claims substantially. See RBNZ, "Consultation Document: Pre-positioning for Open Bank Resolution (OBR)," consultation paper, March 2011. Online: http://www.rbnz. govt.nz/regulation_and_supervision/banks/policy/4335146.pdf (accessed August 15, 2014).

14 Denmark is one of the few countries that have employed a similar technique to OBR. Poulsen and Andreasen (2011) show that in the best-known example of its use, for Amagerbanken, unsecured creditors were initially written down by as much 41.2 percent, although the writedown was later reduced to 33.9 percent and then lower. Such a write-down on depositors would cause an outcry.

15 Unless the parent company's authorities are prepared to undertake the resolution for the whole banking group.

16 The Liikanen Report offers one comment on bailing in which is very attractive; namely, that it should apply to some of the remuneration of the senior executives: "Bail-in instruments should also be used in remuneration schemes for top management so as best to align decision-making with longer-term performance in banks. The Group suggests that this issue should be studied further" $(2012,104)$. The narrow New Zealand approach does not address this attempt to try to align management incentives more with systemic prudence.

17 The auditor-general's (2011) highly critical review of the handling of the scheme covers the main concerns.

18 The RRD appears to favour depositor preference.

\section{References}

Australian Prudential Regulation Authority. 2012. "The Financial Claims Scheme for Authorised Deposit-Taking Institutions.” February 1. Online: http://www.apra.gov.au/CrossIndustry/ Documents/ADI\%20Financial\%20Claims\%20Scheme\%20FAQ\%2001\%2002\%2012.pdf (accessed August 15, 2014).

Bair, S. 2012. Bull by the Horns: Fighting to Save Main Street from Wall Street and Wall Street from Itself. New York: Free Press.

Bertram, G., and D. Tripe. 2012. "Covered Bonds and Bank Failure Management in New Zealand." Policy Quarterly 8 (4): 38-43.

Federal Deposit Insurance Corporation (FDIC) and the Bank of England. 2012. Resolving Globally Active, Systemically Important, Financial Institutions. December 10. Online: http://www.bankofengland. co.uk/publications/Documents/news/2012/nr156.pdf (accessed August 15, 2014).

Garcia, G. 2012. "Missing the Red Flag." In Reforming the Governance of the Financial Sector, edited by D. G. Mayes and G. E. Wood, 230-247. Abingdon: Routledge.

Goodhart, C. A. E., and D. Schoenmaker. 2009. "Fiscal Burden Sharing in Cross-border Banking Crises." International Fournal of Central Banking 5 (1): 141-65.

Harrison, I., S. Anderson, and J. Twaddle. 2007. "Pre-positioning for Effective Resolution of Bank Failures." Journal of Financial Stability 3 (4) (December): $324-41$.

Honohan, P. 2010. The Irish Banking Crisis: Regulatory and Financial Stability Policy 2003-2008. A report for the minister of finance by the governor of the Central Bank, May 31. Online: http:// 
www.bankinginquiry.gov.ie/The_Irish_Banking_Crisis_Regulatory_and_Financial_Stability_ Policy_2003-2008.pdf (accessed August 15, 2014).

Hoskin, K., and I. Woolford. 2011. "A Primer on Open Bank Resolution." Reserve Bank of Nerw Zealand Bulletin 74 (3): 5-10.

Kane, E. J. 1999. "Capital Movements, Banking Insolvency, and Silent Runs in the Asian Financial Crisis." Pacific Basin Finance Fournal 8 (May): 153-75.

Liikanen, E. (chair). 2012. High-Level Expert Group on Reforming the Structure of the EU Banking Sector: Final Report. October 2, Brussels.

Mayes, D. G. 2006. "Cross-Border Financial Supervision in Europe: Goals and Transition Paths." Sveriges Riksbank Economic Review 2: 58-89.

Mayes, D. G., L. Halme, and A. Liuksila. 2001. Improving Banking Supervision. Basingstoke: PalgraveMacmillan.

Moe, T. G., A. Solheim, and B. Vale. 2004. The Norwegian Banking Crisis. Oslo: Norges Bank.

Office of the Auditor-General. 2011. "The Treasury: Implementing the Crown Retail Deposit Guarantee Scheme.” Performance audit report. Wellington, NZ. Online: http://www.oag. govt.nz/2011/treasury (accessed August 15, 2014).

Poulsen, U. L., and B. L. Andreasen. 2011. "Handling Distressed Banks in Denmark." Nationalbankens Kvartalsoversigt (3rd quarter 2011): 81-96. Danmarks Nationalbank.

Reserve Bank of New Zealand (RBNZ). 2012. Regulatory Impact Assessment of Pre-positioning for Open Bank Resolution. November. Wellington, NZ. Online: http://www.rbnz.govt.nz/regulation_ and_supervision/banks/policy/5014272.pdf (accessed August 15, 2014).

Schoenmaker, D., and D. Gros. 2012. "A European Deposit and Resolution Fund: An Update." Duisenberg School of Finance Policy Paper, no. 26.

Tucker, P. 2013. "Resolution and Future of Finance." Speech given at the INSOL International World Congress, The Hague, May 20. Online: http://www.bankofengland.co.uk/publications/ Pages/speeches/default.aspx (accessed August 15, 2014). 



$$
\text { Part } 3
$$

\section{GENTRAL BANKING WITH COLLATERAL-BASED FINANCE}





\title{
Chapter 9
}

\section{GOLLATERAL AND MONETARY POLICY}

\author{
Manmohan Singh
}

The relative price(s) of money and collateral matter for financial lubrication in the markets. Some central banks are now a major player in the collateral markets. Analogous to a coiled spring, the larger the quantitative easing efforts, the longer the central banks will impact the collateral market and associated repo rate. This may have monetary policy and financial-stability implications since the repo rates maps the financial landscape that straddles the bank/non-bank nexus.

\section{Introduction}

The importance of collateral has been investigated in several strands in the theoretical literature. One strand is the literature on collateral and default, which has focused primarily on the role of margin and "haircuts" and "fire sales" (Geanakoplos 2003; Krishnamurthy, Nagel, and Orlov 2010). Another strand is on securitization, where collateral serves to support specific asset values (Shleifer and Vishny 2011).

This chapter echoes discussions on the supply and demand of safe assets. Empirical evidence that the (demand for) safe-asset share has been relatively stable was postulated by Gorton et al. (2012) using flow-of-funds data only. Goncerns have been raised about the supply of safe assets. The IMF’s Global Financial Stability Report estimated a US\$74 trillion figure for safe assets (April 2012), which would appear to be ample. However, a large fraction of such safe assets is held by buy-and-hold investors and is not available for reuse in financial markets. Some market sources conclude that there is little evidence to support that good collateral will be in short supply (J. P. Morgan). Others argue that there could be such a shortage and that safe assets should be provided as a public good to avoid financial instability associated with the private supply of safe assets. This thinking is now being reflected in the US Federal Reserve's recent reverse repo program.

This contribution has three aims. It first clarifies the distinction between the price of money and the price of collateral. It then discusses the factors driving the demand and supply of collateral. Finally, it highlights the importance of collateral for monetary policy through an updated IS/LM framework. With this, the contribution reflects on the prospects for unwinding extraordinary monetary policy interventions. 


\section{Price of Money and Price of Collateral}

The price of money and the price of collateral are set through distinctive practices during "normal" times. Central banks use open-market operations - that, when conducted through repos, involve collateral - to target a money market interest rate that is consistent with their desired path for consumer prices. Now consider collateral or repo rates. Recall that collateral rate (or repo rate) is the rate at which cash is lent against collateral for an agreed tenor. It is agreed upon by the two parties at $t_{0}$ or start of repo. Typically, collateral shortage lowers repo rates; collateral abundance increases repo rates. This rate is a proxy for collateralized transactions that underpin the financial plumbing between the dealer banks/non-banks.

Unconventional monetary policies may sharpen the distinction between the price of money and the price of collateral during crisis. In some countries like the USA and the UK, the price of money and money market rates are not market-determined if central banks decide to pay interest on excess reserves (IOER) to depository institutions. Following the Lehman failure, the Fed introduced interest on excess reserves for depository institutions. This was intended to place a "floor" (minimum bid) on shortterm liquidity in the corridor system. This creates a wedge between banks and nonbanks, and thus impacts other short-end rates. For example, in the USA, Freddie, Fannie and other non-depository institutions are not eligible to deposit excess reserves at the Fed and thus do not have access to IOER. However, Fannie and Freddie cannot access IOER (25 basis points) that banks can only receive, and, therefore, GSE cash positions (and cash positions of other home loan banks) have largely determined the federal funds rate, which trades below the IOER "floor." This wedge between IOER and the federal fund rate is important; the rate on July 29, 2013 was 9 bps, quite far from the likely first step in tightening rates.

The IOER in the USA has also been instrumental in keeping a wedge between comparable repo rates in the USA and those in the Eurozone (see Figure 9.2). Recently

Figure 9.1. Collateral rates in selected Eurozone countries (left) and the USA (right)
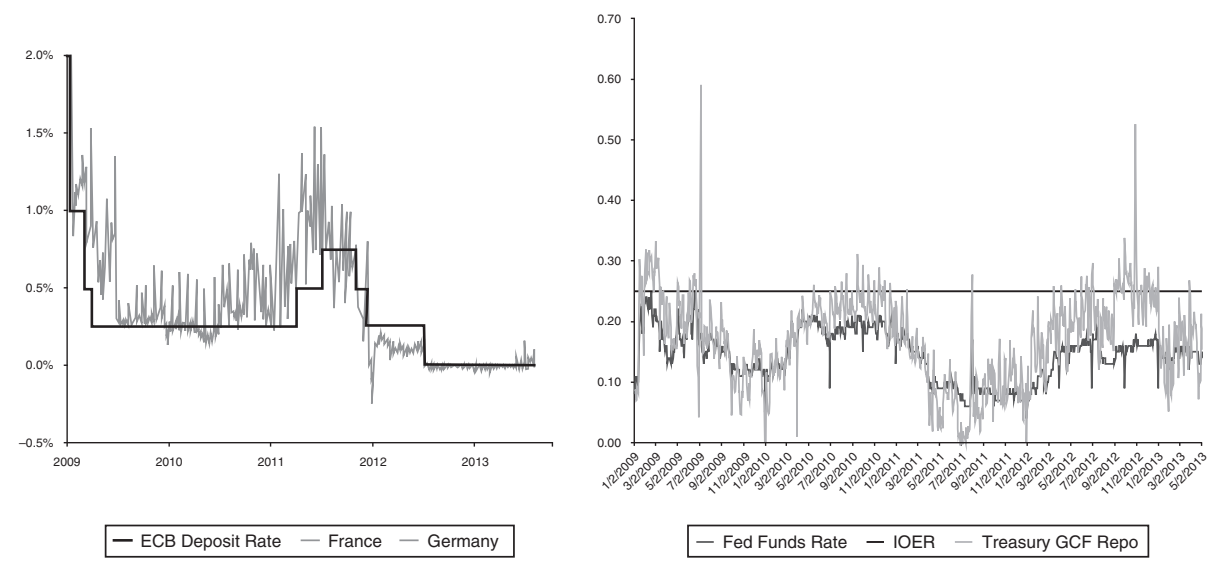

Sources: ICAP, Bloomberg, DTCG, and staff estimates. 
in the Eurozone, collateral/repo rates have dipped below zero; these include German/ French/Dutch and also Danish/Swiss repo rates. ${ }^{1}$ However, this is not the case with collateral/repo rates in the USA. In theory, the price of "good collateral" should not vary across assets except due to technical factors, including "home" bias, the liquidity/depth/ size of good European collateral relative to the US T-bill market, different types of QEs (Fed vs ECB), the cheapest to deliver collateral, etc. Operation Twist also provided an extra dose of T-bills in 2012 to provide some lift to the GC rates. Thus good collateral like US GC rates are still in positive territory relative to good collateral in the Eurozone that has been in negative territory. In the USA, it remains to be seen if cash shifts from repo to bank deposits when overnight GC goes negative in. There's a big psychological barrier between explicitly paying for protection and "accepting a lower return" to get protection.

\section{The Changing Collateral Space}

A great deal of short-term financing is generally extended by private agents against financial collateral. In the "old" global financial system, non-banks were the primary actors that allowed reuse of their collateral in lieu of other considerations. Earlier work has highlighted that the key providers of pledged collateral to the "street" (or large banks/dealers) are hedge funds and custodians on behalf of pensions, insurers, and official sector accounts, etc. (Figure 9.2). ${ }^{2}$ In this nexus of non-banks/banks, "supply" of pledged collateral is typically received by the central collateral desk of the large banks/dealers that reuse the collateral to meet the "demand" from the financial system.

When mapping the changing collateral space in Figure 9.2, we assume that the debt/GDP of developed countries will not increase significantly (otherwise the topic of collateral shortage is moot). Also we assume that regulation and collateral standards will not become so lax that junk will be deemed as "good collateral" with only a token haircut. We also acknowledge a new supply source - the recent reverse repo by the Fed that has started to provide collateral to banks and non-banks. We focus on collateral "flows," since whatever the stock of good collateral, only a fraction flows to markets to seek economic rent.

The rectangle in the center of Figure 9.2 depicts the volume in the old collateral space (in the orange area) and illustrates the reduction in collateral volumes as of end-2012, relative to end-2007. The recent crisis has resulted in elevated counterparty risk leading to incomplete markets and idle, and thus stranded, collateral pools. Also, some central bank purchases of good collateral have contributed to shrinkage in the pledged collateral market from US\$10 trillion prior to the Lehman crisis (end-2007) to about US\$6 trillion (end-2012).

Pledged collateral market (in the old collateral space) is different from some "restricted" collateral markets. For example, securitization-based structures (SIVs) that have lien against specific pieces of collateral are impossible to re-pledge. Also the triparty repo (TPR) market is a primary source of funding for banks in the USA, standing at US $\$ 1.7$ trillion (end-2012). It provides banks with cash on a secured basis, with the collateral 
Figure 9.2. The changing collateral space

OTC Derivatives Regulators

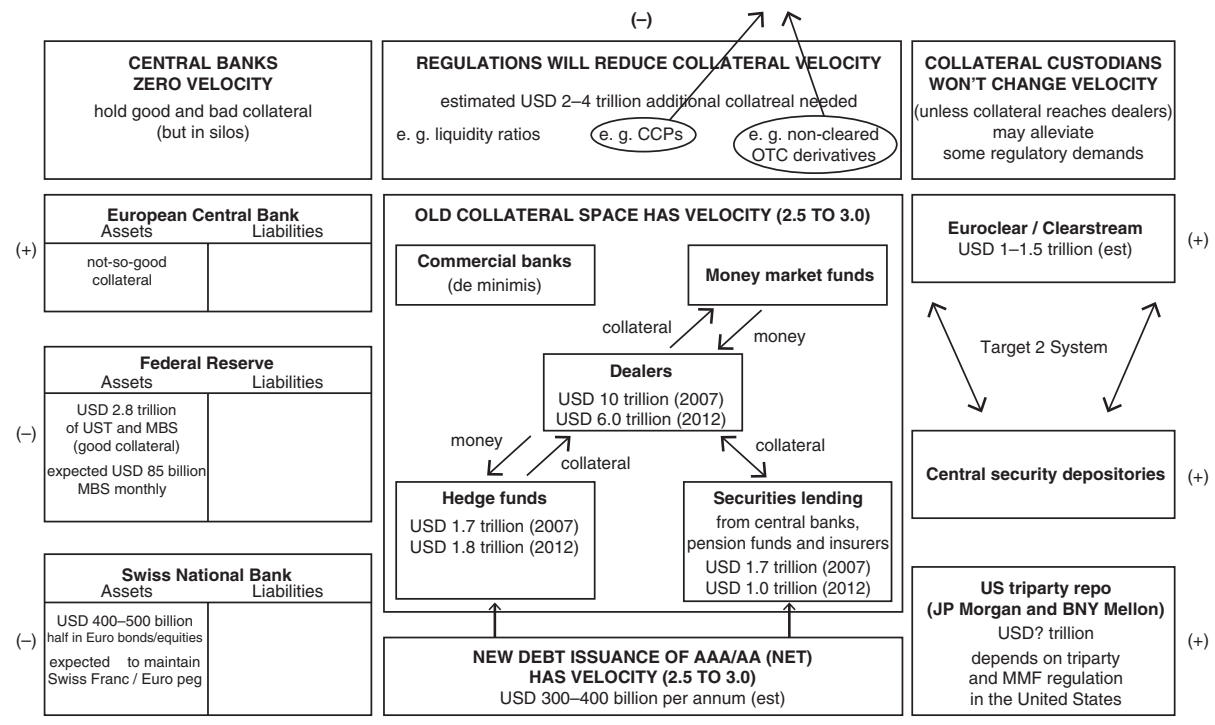

$(+)$

$(-) /(+)$ refers to the impact on both the amount and velocity of collateral

$(-)$ negative for global liquidity

$(+)$ positive for global liquidity

being posted to lenders - like money-market funds - through one of two clearing banks: BNY Mellon and J. P. Morgan. However, such pledged collateral sits with custodians and is not rehypothecable to the street. We ignored such restricted markets in the old collateral space, since collateral was not reusable, nor did it have restricted velocity.

The "new" collateral space straddles not only the bank/non-bank nexus (where collateral generates a velocity), but other participants who are now significantly impacting collateral availability. The increasing role of central banks, regulations, and collateral custodians is significantly changing the collateral landscape. These new dimensions involve (i) some aspects of unconventional monetary policies pursued by advanced-economy central banks that remove good collateral from markets to their balance sheet, where it is siloed; (ii) regulatory demands stemming from Basel III, Dodd-Frank, the EMIR, etc. that will entail building collateral buffers at banks, CCPs, etc.; (iii) collateral custodians who are striving to connect with the central security depositories (CSDs) to release collateral from silos; and (iv) net debt issuance from $\mathrm{AAA} / \mathrm{AA}$ rated issuers.

\section{Central banks (Figure 9.2, area on left)}

Despite the ECB's efforts to keep the ratio of good/bad collateral high in the EU financial markets, the actions of the SNB (and other central banks) are at odds with this objective. Since the Swiss franc/euro peg in September 2011, the SNB balance sheet has grown sizably to about US $\$ 500$ billion. About half of assets now comprise short-tenor "core" 
euro bonds and equities. This reflects prudent asset-liability management at the SNB. ${ }^{3}$ However, the SNB's bond purchases withdraw the best and most liquid collateral from the Eurozone; this reduces the collateral reuse rate, since these bonds are siloed at the $\mathrm{SNB}$, and are not pledged in the financial markets. Siloed collateral has zero velocity by definition. The ECB has expanded collateral eligibility, which includes lowering the assetbased securities' threshold, and relaxing the foreign-exchange collateral requirement (i.e. non-euro collateral is eligible).

The Federal Reserve in the USA continues QE3 until labor markets turn around. Since the Lehman crisis and since continuing with the QE efforts, the Fed is housing about US\$2.8 trillion of "good collateral" (largely US Treasuries and MBS). Under Operation Twist (which ended last year), the Fed used to take in long-tenor debt of about US $\$ 45$ billion per month and release short-term treasuries. That program kept the total size of the balance sheet unchanged. Then QE3 expanded the Fed's holdings by another US $\$ 45$ billion per month of long-term US Treasuries (without a parallel sale of short-term debt). Thus, along with QE3 buying of US $\$ 40$ billion MBS per month, the Fed's balance sheet is expanding by US\$85 billion per month. At this rate, the Fed could silo over US\$1 trillion additional good collateral in 2013 (and beyond, if there is no tapering). This is likely to have first-order implications for collateral velocity and global demand/supply of collateral. However, the Fed's very recent reverse repo could be a game changer on the collateral front.

Other central banks, such as the Bank of England's (BoE) QE efforts, have taken about $£ 375$ billion gilts onto its balance sheet; however, looking forward, the BoE is attempting to keep good collateral in the market domain with no more envisaged QE. Also, the Bank of Japan is expected to buy about $¥ 15$ trillion (US\$180 billion) of JGBs, between its Asset Purchase Programme and rinban operations; however, JGBs have very low velocity since they are not used in "upgrade" trades, and are generally held by domestic investors.

\section{New regulations: (Figure 9.2, area on the top)}

Regulatory demands stemming from Basel III and Dodd-Frank are expected to demand US\$2-4 trillion of collateral. Higher liquidity ratio(s) at banks, along with collateral needs for CCPs (and non-cleared OTC derivatives) are some of the other key regulatory changes that will impact collateral markets. These safety buffers will silo the associated collateral and significantly drain collateral in the financial markets (see Figure 9.4, top, yellow area).

\section{Custodians (Figure 9.2, area on the right side)}

The ECB mentions that the Eurozone has $€ 14$ trillion in collateral, much of it locked in "depositories" and thus not easily accessible for cross-border use (Figure 9.4, right side, pink area). However, Euroclear and Clearstream (the key hubs for Eurozone collateral) are working with the local/national CSDs to alleviate collateral constraints. The interconnections to the CSDs will be via the Target 2 Securities (T2S) system 
that will provide a single pan-European platform for securities settlement in central bank money. In the USA, J. P. Morgan and the Bank of New York may also improve collateral flows from within the US tri-party system; however, reforms on the tri-party system and money market funds will play a role in this effort. Preliminary estimates suggest that perhaps US $\$ 1-1.5$ trillion of collateral may be "unlocked" via efforts of custodians to optimize collateral and build a "collateral highway." This collateral in unlikely to reach markets, but will enhance accounting debt and credits to "break" the silo.

Preliminary estimates suggest that perhaps up to $€ 1-1.5$ trillion of AAA/AA quality collateral may be unlocked in the medium term via efforts of custodians to optimize collateral and build a collateral highway or global liquidity hub. However, the internal "plumbing" (i.e. operations, workflows, technology, staff, etc.) that is required to process and manage trillions of collateral balances needs to be smooth.

Every institution or market is different; there is a lot of friction in the pipes. Even though collateral is allowed to be reused legally, if a counterparty along the collateral chain has not built the system to do anything with it, the collateral gets "stuck" in the plumbing. The frictions in aggregate can be quite sizeable and may be another reason why the theoretical balances may not add up mathematically.

Even if this collateral does not reach "large banks/markets," it allows the collateral to leave "CSD silos," improve efficiency, and enhance accounting debt and credits, and reduce the burden on markets to provide collateral for LCR or CCP related regulatory buffers. The tri-party elements in Europe (i.e. Euroclear Bank and Clearstream Banking SA) also have about $€ 900$ billion of client collateral, but unlike in the USA, there is generally no intra-day credit to clients.

In the USA, J. P. Morgan and Bank of New York (BNY) may also improve collateral flows from within the US tri-party repo (TPR) system; however, regulatory reforms on the tri-party and money market funds may limit the size of the collateral market. Money market mutual funds (MMMFs) are an important money artery to the US financial plumbing system and support about one-third of the TPR market. If US regulations move this industry toward variable net asset value, then the money artery may shrink. Lately, US MMMFs have had increasing difficulty finding balance sheets willing to provide investments. That implies that custodial banks such as State Street and BNY will likely grow because of their position as "balance sheet of last resort" for the MMMF industry (unless the Fed's reverse repo leads MMMFs to shift en masse from the TPR to the Fed directly).

In general, central banks, SWFs, and long-term asset managers (life insurance and pension funds) desire collateral that has low volatility, but is not necessarily highly liquid. These entities should be net providers of liquidity, either in the form of cash or liquid collateral. But critically, their "need" for collateral is relatively static (or, as providers of liquidity, they can dictate that counterparties take a fixed amount). On the other side the hedge funds, money market funds (and with the new regulations, the dealer banks too) have a dramatically shifting need for collateral and a large number of counterparties. Their needs are for liquid collateral. So a market for collateral upgrades - in theorycould work. 


\section{New (net) debt issuance: (Figure 9.2, area at the bottom)}

Assuming AAA/AA countries have a GDP of around US\$25 trillion and a deficit of around 4-5 percent, they have supplied (on average) about US $\$ 1$ trillion of new (net) debt - sovereign and corporate - every year, with the latest data on the lower side. ${ }^{4}$ Database and market contacts suggest that on average about 30-40 percent of AAA/ AA collateral inventory reaches markets via custodians for reuse (on behalf of reserve managers, SWF, pensions, insurers, etc.); however, much of the inventory stays with buyand-hold investors. So if debt/GDP remains on trend in developed countries (i.e. the ratio does not increase sizably), new debt stemming from the "numerator" may provide up to US $\$ 300-400$ billion per year to the markets, assuming counterparty risk, especially with European banks, does not elevate. Another 5-10 percent of new inventory (including equities) may come via hedge funds. With a collateral reuse rate of about 2.5 in recent years (and now lower at 2.2 due to the various silo(s) in the "new" collateral space), this may alleviate collateral shortage by about US $\$ 800$ billion to US $\$ 1.2$ trillion per year.

\section{What does all this mean for the nere collateral space?}

The dwindling number of AAA/AA entities, and above all, the potential correlations between borrowers and the collateral they are pledging, creates quite sharp mismatches between what looks like plenty (e.g. Eurozone government bonds), and the extent to which anyone wants to actually take them as collateral from a bank in the same country. Regulations remain in flux; for example, sub-AAA/AA issuance may likely be considered satisfactory collateral. Also, if there is demand, collateral transformation may increase the required supply. On the other hand, debt ceiling issues in the USA may entail a more reduced collateral supply in the form of US Treasuries or bills than was the case in the past.

The ECB still holds good collateral (Bunds, Dutch, French bonds and other AAA/ AA-rated securities). Although the fraction of good collateral has dropped since end2011, the ECB's $€ 3$ trillion balance sheet still holds about 20 percent in good collateral (or $€ 600$ billion). The ECB may want to "rent" the good collateral that they hold, especially if their goal is to keep the good/bad collateral ratio high "in the markets." So far, the ECB has accepted "not-so-good collateral," and thus improved the good/bad collateral ratio in the market by decreasing the denominator. Renting of good collateral does not lower the numerator - the collateral is on loan temporarily. Other EU central banks also hold good collateral. Other central banks (e.g. SNB, UK) do not have the same vested interest as the ECB in propping up collateral markets in the EU. Interestingly, the Fed has started a reverse repo program that will supply collateral to both banks and non-banks.

In summary, the decrease in the "churning" of collateral may be significant, since there is demand from some SIFIs and/or their clients (asset managers, hedge funds, etc.) for "legally segregated/operationally commingled accounts" for the margin that they will post to CCPs. Post MF Global and Peregrine saga(s), there will be a decrease in the "reuse rate" of collateral, as there is increasing demand from several clients (asset managers, hedge funds, etc.) for "legally segregated" accounts. An excellent 
market-based example is from the Reserve Bank of Australia (RBA). Their proposal manages to cope with the upcoming regulatory changes that will warrant significant, additional high-quality liquid assets (or good collateral) without issuing more debt securities, unlike discussions in some policy circles (e.g. Gourinchas/Jeanne, BIS paper). This committed liquidity facility (CLF) is akin to paying a fee to get the guarantee of contingent collateral transformation from the RBA at a penalty rate. Their suggested route is akin to collateral transformation, but this would keep the collateral reuse rate from declining. In other words:

Demand $_{\text {collateral }}=$ Supply $_{\text {collateral }} *$ collateral velocity

The next section straddles collateral and repo rates to monetary policy via the IS/LM framework.

\section{Collateral and Monetary Policy, via the IS/LM Framework}

Collateral was not taught in money or monetary-policy textbooks. To the best of my knowledge, undergraduate macroeconomic text books still use the IS/LM model (investment, saving / liquidity preference, money supply) as a construct to demonstrate the relationship between interest rates and real output in the goods and services market and the money market. In this model, the intersection of the IS and LM curves is where there is simultaneous equilibrium in both markets (Figure 9.3). The horizontal axis represents output or real GDP and is labeled $\Upsilon$. The vertical axis represents the real interest rate, $i$. Since this is a non-dynamic model, there is a one-toone relationship between the nominal interest rate and the real interest rate; therefore, variables such as money demand, which actually depend on the nominal interest rate, can equivalently be expressed as depending on the real interest rate. The point where these schedules intersect represents a short-run equilibrium in the real and monetary sectors. This equilibrium yields a unique combination of the nominal/real interest rate and real GDP.

Figure 9.3. The IS/LM model

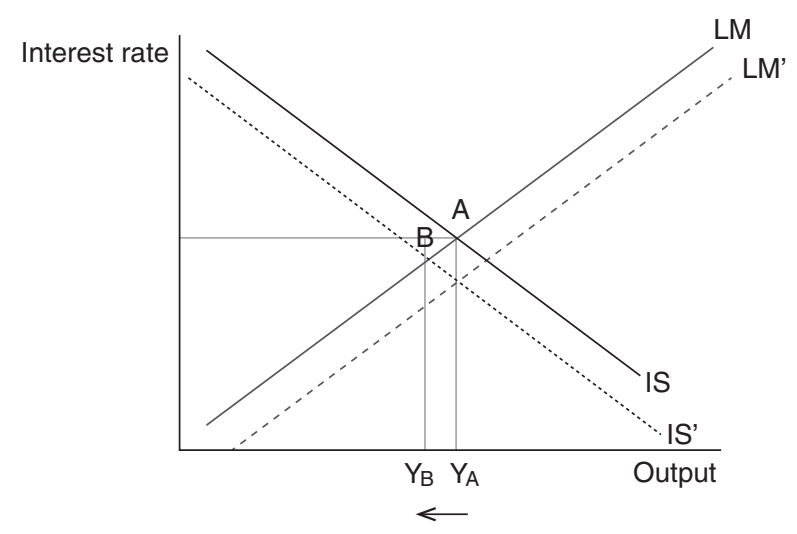


In a simple setting, inward shifts in the IS curve (due to a contraction of the $\mathrm{G}+\mathrm{I}$ + G component that decreases output to $\mathrm{Y}_{\mathrm{B}}$ ) can be neutralized by shifting LM out by lowering (nominal or real) interest rates to attain the initial level of output $\mathrm{Y}_{\mathrm{A}}$. The pioneering works on the financial-accelerator highlights that endogenous shocks to credit markets can initiate cyclical effects to the real economy (Bernanke, Gertler, and Gilchrist, 1996). Specifically, their paper highlights that shocks lead to flight to quality and thus higher cost for risky projects; this shifts "in" the IS curve since households/firms invest less. Subsequently, the authors show, the financial accelerator can amplify shocks stemming from collateral constraints to the economy.

However, financial collateral that substitutes money is different than the general collateral modeled in the original research papers. In volume terms, collateral use has become over the past decade on par with monetary aggregates like M2. When we consider collateral use/reuse in addition to M2 or the monetary base in USA, UK and Eurozone, financial lubrication was over US\$30 trillion before Lehman (and one-third came via pledged collateral). However, post Lehman, the (ongoing) deleveraging in the global financial system along with regulatory measures has constrained the availability of collateral (and its reuse). The subsequent decline in both available collateral and associated reuse of collateral was sizable (an estimated US\$4-5 trillion).

Financial collateral does not have to be rated AAA/AA, but as long as the securities (i.e. debt or equity) are liquid, mark-to-market, and part of a legal cross-border master agreement, they will be used as "cash equivalent." Such pledged financial collateral is difficult to map, but it is a key component of financial plumbing. The collateral intermediation function is likely to become more important over time. In the short term, increased counterparty risks (as during 2007-2008 and in Europe today) make secured funding more attractive. In the longer term, with more arm's length transactions in an increasingly globally integrated financial system, market participants are seeking the security of collateral to underpin a wider range of claims. New regulations are also likely to increase the demand for collateral-based operations (CGFS 2013).

When collateral use drops, financial intermediation slows, with effects similar to the drying up of interbank markets. The stock of collateral can decline as investors become more concerned about counterparty risk, making them less willing to lend securities and meaning collateral sits safely idle in segregated accounts. It can also be affected by central bank measures, such as large-scale asset purchases, which drain good-quality collateral from the system, or a widening of the pool of collateral-eligible assets, which increases the pledge-ability of these assets as collateral to the central banks. Collateral velocitydefined as the volume of secured transactions divided by the stock of source collateralis affected by counterparty concerns and general risk aversion (due to higher haircuts), which then manifest as restrictions on the reuse of collateral.

The recent collapse in financial collateral (by an estimated US\$4-5 trillion) has significantly shifted the IS in (re the IS/LM framework), lowering the output to $\mathrm{Y}_{\mathrm{B}}$ and decreasing the real interest rate. In turn, QE efforts are shifting the LM curve to the right to compensate this decline until the LM curve will intersect with the IS curve at the initial output $\mathrm{Y}_{\mathrm{A}}$. The LM shift due to QE is sizable (and continuing) and along with the IS 
Figure 9.4. Contraction in pledged collateral market and IS/LM shifts

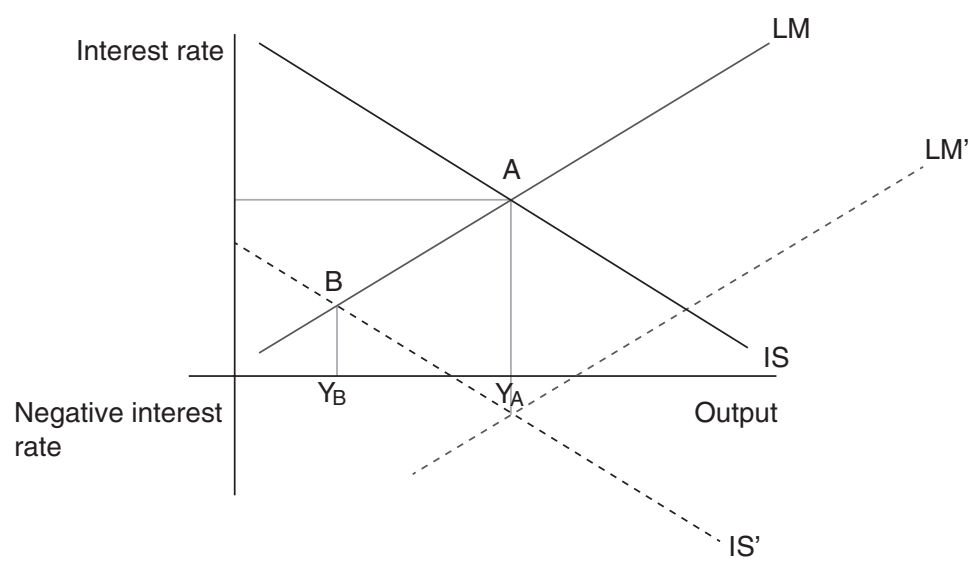

Figure 9.5. Real interest rates via Taylor Rule with/without Fed's balance sheet adjustment

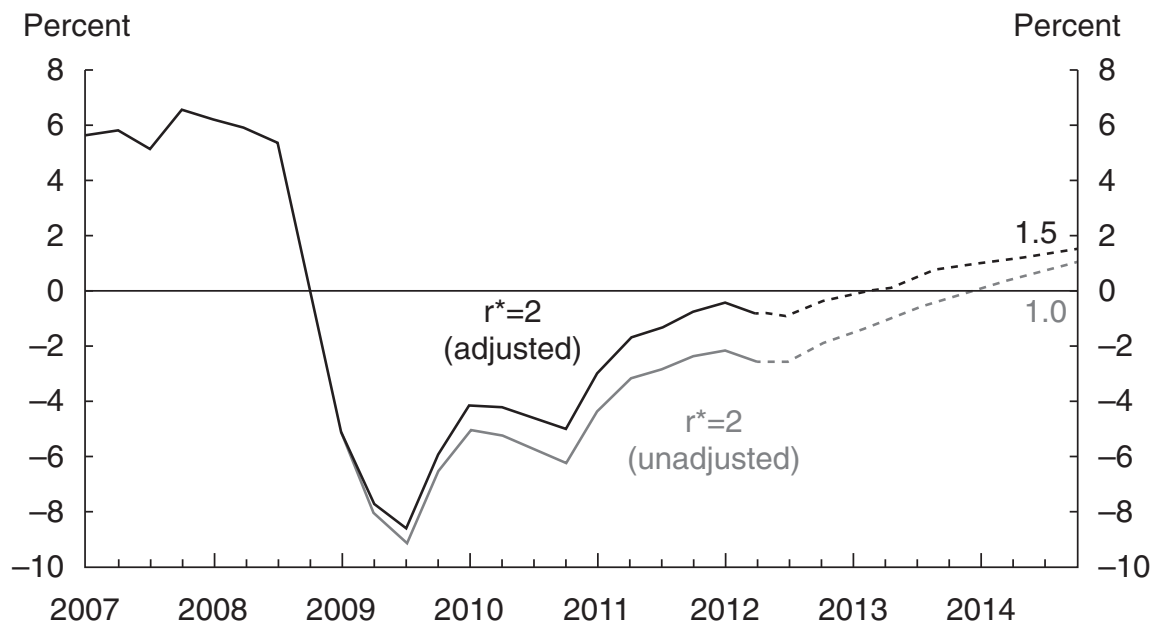

Source: BLS, BEA, FRBNY Staff.

Note: Solid lines are released data; dotted lines are FRBNY Staff projections: output gap is measured by the unemployment gap; inflation is measured by the PCE deflator.

inward shift, real interest rates may be well below zero (but "optically" due to distortions in the money rates that are above zero in nominal terms, we do not see sub-zero real rates).

A recent speech by the New York Fed president suggests that the Fed's QE actions may have lowered the nominal rates by an additional 150-200 basis points (Dudley 2012). So unadjusted real rates (i.e. if the Fed balance sheet had remained the same at US $\$ 800$ billion as of end-2007) may be much lower relative to the adjusted real rates (due to the expanded balance sheet via $\mathrm{QE}$ ) that are officially announced and do not factor the rate cuts imbedded within QE - the blue and green lines respectively (Figure 9.5). Now consider the three most recent tightening cycles in the USA that have averaged close 
to 400 bps; with a 400 basis points tightening cycle, the new policy rate may anchor at 2 percent if it starts from minus 2 percent. Analytically in Figure 9.4, LM shifted out until $\mathrm{Y}_{\mathrm{A}}$ is reached at approximately minus 2 percent, and with a $400 \mathrm{bps}$ tightening, the next policy rate cycle may stop at 2 percent (unless the balance sheet also returns to the 2007 size in tandem).

\section{The Collateral Implications of Exit Strategies}

Although there are many variants and interpretations of "exit," a key aspect is its impact on the part of the market where non-banks, such as hedge funds or money market funds (see Figure 9.6), interact with the large dealer banks to determine the price of collateral (the repo rate). Some central banks that have undertaken QE are now holding sizable amounts of high-quality liquid assets (or good collateral) on their balance sheets. Through long-term refinancing operations, the ECB has printed money but taken in bad collateral. But excess reserves at central banks are not the same thing as good collateral that circulates through the non-bank/bank nexus. As a result of this the non-bank/bank nexus over time has begun to give way to a new central bank/non-bank nexus that has weakened the market's financial plumbing and increased shadow banking "puts" to compensate for the lack of good collateral.

Proposals to unwind that inventory of good collateral come in part to stem any shortage of good collateral. However, such proposals for unwinding will have implications for this part of the market in a way that may cause major adaptations to take place. While it is true that sooner or later these balance sheets will have to unwind - either voluntarily when central banks release collateral and take in money, or involuntarily as the securities held at central banks mature or roll off-unwinding will increase both the (money) interest rate and the (collateral) repo rate.

In the USA, the Fed has bought good collateral from non-banks, not banks (Carpenter et al. 2013); this has increased bank deposits (that belong to non-banks via the QE money they received in lieu of collateral sold to the Fed). So the effect of QE-type efforts is to convert what had been good collateral into additional bank liabilities (i.e. non-banks' deposits at banks). Now, while QE continues, a variant of "QE reversal" may happen simultaneously through the reverse repo program.

The Fed's fixed-allotment reverse repo program, inaugurated on September 23, 2013 , is the first official attempt to unwind part of its balance sheet. The success of this program will be affected by allocation of balance sheet "space" between banks and nonbanks amidst a tighter regulatory environment. Non-banks' "balance sheet space" will be key to any unwinding of collateral. With Basel III regulations at the door (especially the leverage and liquidity coverage ratio), the banking system is likely to have limited appetite for increasing balance sheets. Reverse repos would actually reduce total bank balance sheets by the amount of reverse repo the Fed does with eligible non-banks such as MMMF/asset managers.

If we look at collateral chains as depicted in Figure 9.6 above, at one end there is the MMMF investor - the household and corporate wealth pool (the supplier of money). At the other end, after a couple of loops for transformation and some haircuts and 
Figure 9.6. Collateral and financial plumbing

\section{Non-Bank / Bank / CB Nexus}

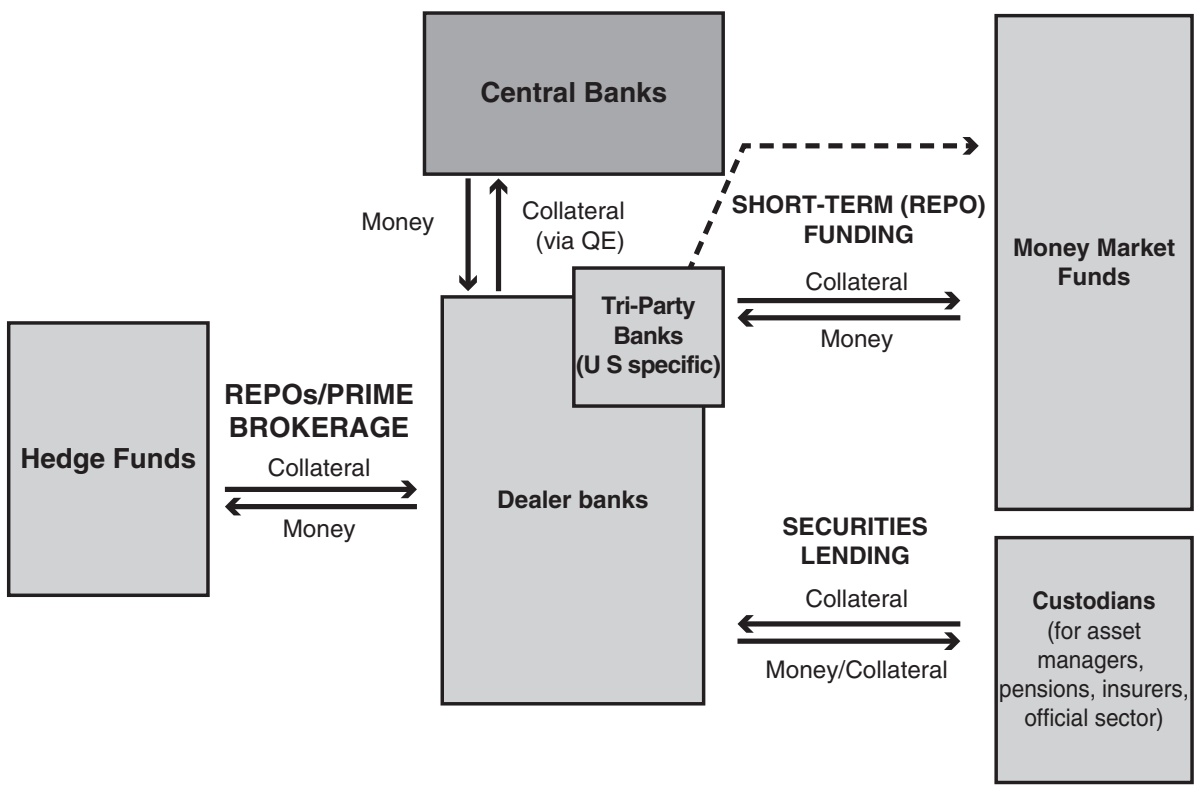

subordination for extra capital, lies the promise to pay made by the borrower - the household (mortgage) or hedge fund. The Fed's reverse repo relieves bank balance sheet constraints but short-circuits the chain. The household and corporate wealth pool is better off; they get a deposit alternative that is superior to anything available now. The borrower pool is worse off as money will go directly to the Fed, and won't be transformed into any lending to them.

The truth is that excess reserves do not simply become "good collateral" as the central bank unwinds its balance sheet. This is primarily because collateral with these non-banks via reverse repos cannot be rehypothecated, or onward re-pledged, and thus will not contribute to financial lubrication. The reasoning for this is that two clearing banks (J. P. Morgan and BNY) can only support rehypothecation of securities in the tri-party process through general collateral finance $(\mathrm{GCF})$, which is an interdealer tri-party service (i.e. banks) for members of the government securities division of the Depository Trust and Clearing Corporation (DTCG). If one is not a GCF participant, then they effectively have "read only" access to their collateral (except in the case of default, for which they have a separate, more manual process to send securities to the customer custodian to facilitate sale).

Only banks are able to rehypothecate collateral received via reverse repo (and increase collateral velocity). Thus, the new non-bank/central bank nexus is good for the non-banks since the collateral counterparty is the central bank. But it also an extension of the Fed's existing "put" to the shadows of the financial system. This has the chance to further weaken the financial plumbing between bank/non-banks. At least prior to QE, 
non-banks like MMMFs had to work hard for a positive return (i.e. higher than bank deposits) by choosing a good counterparty. Going forward, it is likely that the assets of MMMFs will grow, given the guaranteed return from reverse repos (and at odds with proposed regulations - like floating NAV - that try to limit the size of MMMFs).

Central banks that have been taking good collateral out of the market for sound macro reasons will not let the ownership of these securities go back to the private market as it will impact the repo rates (via collateral velocity). However, the market needs the collateral services that these securities can offer, which transfers with possession, not ownership (for example, under the proposed reverse repo, non-banks will gain ownership but not possession to reuse securities). Securities in the market's possession have velocity; those at the central bank do not. There will be a net reduction in overall financial lubrication if nonbanks are the primary conduits for the Fed's reverse repo.

\section{Conclusion}

Just as water finds its own level, collateral in the market domain generally finds its economic rent when it is pledged for reuse. The past few years since Lehman has seen major central banks take out good collateral from markets and replace it with freshly printed money (except for the ECB, which has printed money but taken in bad collateral). Sooner or later, these balance sheets will unwind - either voluntarily when central banks will release collateral and take in money, or involuntarily as the securities held at central banks mature or roll off. Analytically, the rate of absorbing money will move the LM curve left. Simultaneously the rate of release of collateral (in lieu of money) will move the IS curve up. So unwind will increase both the (money) interest rate and the (collateral) repo rate. As both rates move up, policymakers will attempt to keep them close (and not create a wedge between them). This may be another reason why the Fed may want to keep an eye on the repo rate and hence its reverse repo program (while still doing QE).

\section{Notes}

1 Despite the European Central Bank's (ECB) efforts to take in lower-grade collateral, actions of the Swiss National Bank (SNB) (and other central banks) are diluting this objective. After the Swiss franc/euro peg, the SNB balance sheet is now almost $€ 500$ billion with half of the assets comprising of "core" euro bonds and equities. However SNB's bond purchases withdraw the best and most liquid collateral from the Eurozone; this reduces the collateral reuse rate since these bonds are siloed at SNB and not pledged in the financial markets. Siloed collateral has zero velocity by definition.

2 Hedge funds via their prime brokers allow for collateral reuse as a quid pro quo for the leverage/ funding they receive from dealers. The other non-bank providers of collateral generally loan collateral for various tenors to optimize their asset management mandates. Commercial banks are not active in this bank (hence, de minimis).

3 Alternately, the SNB could use foreign exchange or other derivatives to hedge the peg.

4 The Risk Management Association's (RMA's) database summarized the inventory on loan to the market. See Barclays AAA/AA index and http://www.rmahq.org (accessed August 15, 2014), which provides data on securities lending with title transfer. 


\section{References}

Adrian, Tobias, and Hyun Song Shin. 2014. "Collateral Shortage and Debt Capacity." In Manmohan Singh, Collateral and Financial Plumbing, ch. 2, annex 2.1, 30-32. London: Risk Books.

Bernanke, Ben, Mark Gertler, and Simon Gilchrist. 1996. "The Financial Accelerator and the Flight to Quality." Review of Economics and Statistics 78 (1) (February): 1-15.

Carpenter, Seth, Selva Demiralp, Jane Ihrig, and Elizabeth Klee. 2013. "Analyzing Federal Reserve Asset Purchases: From Whom Does the Fed Buy?” Staff paper, no. 2013-32, April.

Committee on the Global Financial System (CGFS). 2013. "Asset Encumbrance, Financial Reform and Demand for Collateral Assets." GCFS Papers, no. 49, May. Basel: BIS.

Copeland, Adam, Antoine Martin, and Michael Walker. 2010. "The Tri-party Repo Market before the 2010 Reforms." FRBNY Staff Report, no. 477. New York: Federal Reserve Bank of New York.

Debelle, Guy. 2012. "On Europe's Effects on Australian Financial Markets." Address to the Bloomberg Seminar, Sydney, February 14.

Duffee, Gregory R. 1996. "Idiosyncratic Variation of Treasury Bill Yields." Fournal of Finance $51(2): 527-52$.

Fegatelli, P. 2010. "The Role of Collateral Requirements in the Crisis: One Tool for Two Objectives." Working Paper, no. 44. Luxembourg: Banque Central du Luxembourg.

Greenwood, Robin, Samuel Hanson, and Jeremy Stein. 2010. "A Comparative-Advantage Approach to Government Debt Maturity." Harvard Business School Working Paper, no. 11-035.

Gourinchas, Pierre-Olivier, and Olivier Jeanne. 2012. "Global Safe Assets.” BIS Working Papers, no. 399. December.

International Monetary Fund (IMF). 2012. "Safe Assets: Financial System Cornerstone?" In Global Financial Stability Report, April, 81-122. Washington, DG: IMF.

Singh, Manmohan. 2011. "Velocity of Pledged Collateral: Analysis and Implications." IMF Working Paper, no. 11/256. Washington, DC: IMF.

2012. "The (Other) Deleveraging.” IMF Working Paper, no. 12/179. Washington, DC: IMF. 2013a. "The Changing Collateral Space." IMF Working Paper, no. 13/25. Washington,

DC: IMF.

2013b. "Collateral and Monetary Policy." IMF Working Paper, no. 13/186. Washington, DC: IMF.

Singh, Manmohan, and Peter Stella. 2012. "Money and Collateral." IMF Working Paper, no. 12/95. Washington, DC: IMF.

Tarullo, Daniel. 2013. "Testimony on the Dodd-Frank Implementation." Before the Committee on Banking, Housing, and Urban Affairs, US Senate, Washington, DC, July 11. 


\title{
Chapter 10
}

\section{THE EGB AND THE POLITICAL ECONOMY OF GOLLATERAL}

\author{
Daniela Gabor
}

\section{Introduction}

Anxieties about central banks' interventions in financial markets often arise during periods of crisis. Extraordinary measures may trigger controversies when existing policy solutions are difficult to translate across institutional landscapes. The European Central Bank's (ECB's) decision to initiate the Securities Market Programme in May 2010, as governments in the Eurozone's peripheries faced increasing borrowing costs, offers an interesting example. The strongest opposition, mostly although not exclusively voiced by German policymakers (including the German representatives on the ECB Governing Council), warned that purchases of government bonds are ill-advised on legal, political, and economic grounds, contravening the Maastricht Treaty prohibition of public debt monetization, reducing the urgency for fiscal adjustments and distorting financial markets (Belke 2010; Weidmann 2012). According to this account, interventions in sovereign bond markets cement the view that the ECB is the only institution that can effectively contain a crisis, turning the central bank into a "whipping boy" for political elites hesitant to engage with the structural problems underpinning the euro crisis. In turn, the ECB attributed its interventions to legitimate concerns with stabilizing disrupted markets segments crucial to the transmission of monetary policy signals rather than as attempts to ease governments' financing conditions. It simultaneously reaffirmed commitment to its constitutional mandate, price stability, and a rapid unwinding of extraordinary crisis measures that would allow the return to the pre-crisis policy framework (ECB 2010a; Trichet 2009). Two years later, the ECB went further, and announced that it would do whatever it takes through the Outright Monetary Transactions program, a commitment to buy government bonds in order to stabilize the European financial system.

Theoretical accounts of central banks' presence in financial markets distinguish between normal and crisis periods. During "normal" times, interventions occur in one market, the interbank market, where banks trade liquidity to enforce model-guided policy decisions (Allen et al. 2008). Under the efficient market hypothesis, steering the interbank rate allows central banks to influence broader financing conditions in the economy. In contrast, the theoretical foundations of crisis interventions are less straightforward. Central banks may resort to non-standard interventions once policy interest rates have been 
lowered to zero (Bernanke and Reinhart 2004). Unconventional measures then require the abandonment of the efficient market hypothesis, forcing an overt re-politicization of central banks' presence in financial markets. Policy narratives distinguish between market-based and bank-based measures that reflect different financial structures (Fahr et al. 2011), and, particularly in the ECB's discourse, the political constraints on exit strategies (Bini Smaghi 2009; Trichet 2009).

This chapter instead argues that the ECB has refused to engage systematically with the consequences of European banks' shift to collateralized funding, well documented by the Liikanen Report (2012). Its key premise is that the collateral management strategies of European banks matter for the design of crisis interventions in general, and for understanding the European sovereign debt crisis in particular. The emergence of "coordinated risks" between counterparty (bank) and collateral (sovereign bond) on key funding markets raises complex questions about the remit of central banks in monetary unions, and the relationship between banks' collateral management strategies, the unwinding of extraordinary measures, and the liquidity of distinctive sovereign bond markets. It provides further support for De Grauwe's (2011) argument that the ECB should become the lender of last resort for governments.

The chapter is organized as follows. The first section explores theoretical perspectives on central banks' presence in financial markets during periods of stability and crisis. The chapter then contrasts the increasingly "delocalized" nature of bank funding markets with crisis-contingent "re-localizations," focusing on the operations of the key source of collateralized funding for European banks, the repo (repurchase) market. It then considers the ECB's policy decisions since 2008 in light of the relationship between repo markets and the markets for collateral. As a caveat, the chapter does not aim to explain the structural imbalances underlying the European crisis, but to highlight specific structural changes in financial systems stemming from processes of financialization (see Stockhammer 2011 for a review).

\section{Theoretical Perspectives: Gentral Banks' Intervention in Financial Markets}

\section{The relationship between central banks and financial markets during "normal times"}

Although the dominant pre-crisis model of central banking recognized that monetary policy works through financial markets (Bernanke and Reinhart 2004), its reliance on the efficient market hypothesis rendered the details of financial intermediation irrelevant for the conduct of monetary policy (Blanchard et al. 2010). The recognition that banks played a special role, particularly in the European financial systems dominated by banks, gave rise to theoretical discussions about the "bank lending channel" (Kashyap and Stein 2000), but had little impact in policy practice (Blanchard et al. 2010). Indeed, central banks carefully distinguished between monetary policy per se and its implementation in financial markets, typically described as liquidity policies. The dominant New Keynesian models postulated that monetary policy should focus on setting short-term interest rates 
to deliver price stability: central banks that anchor expectations of the short-term interest rate path can effectively control investment and consumption decisions (further, in the usual transmission mechanism, aggregate demand and price stability), since efficient financial markets link short-term to long-term interest rates and asset prices through arbitrage. Indeed, pre-crisis policy discussions typically debated the direction and speed of interest rate changes while treating central banks' liquidity policies as a passive exercise of implementing interest rate decisions (Gonzales-Paramo 2008).

The one instrument-one objective framework, embedded in the ECB's economic pillar and guiding the operations of most large central banks (Fahr et al. 2011), further established that central banks should manage liquidity conditions in one market segment to implement interest rate decisions: the unsecured interbank market that redistributes liquidity between banks without the guarantee of collateral (ECB 2010a; Klee and Stebunovs 2011). Given the arbitrage assumption underlying the efficient market hypothesis, central bank interventions "in more than one market, say in both the shortterm or the long-term bond markets, is either redundant, or inconsistent" (Blanchard et al. 2010, 4; also Bini Smaghi 2009). Liquidity policies entail open-market operations that adjust the supply of central bank money to ensure that the overnight interbank interest rate tracks closely the policy rate. For instance, the ECB's overnight target, the EONIA, ${ }^{1}$ fluctuated up to 10 basis points above the policy rate, reflecting an aggregate deficit of liquidity arising from banks' funding gaps: loan activity in excess of retail deposit funding (Lenza et al. 2010). Open-market operations have banks as traditional counterparties and can take two forms: outright purchases of debt instruments (usually sovereign bonds to minimize risks to the central bank's balance sheet) or repurchase operations (repos), through which central banks lend against collateral, with a commitment to resell the collateral at the end of the repo operation. The design of open-market operations owes more to historical circumstances than firm theoretical foundations: the ECB's large refinance operations pre-crisis (termed MROs - marginal refinancing operations), with weekly allotments of around $€ 300$ billion, compared with around $\$ 30$ billion in the USA, a wider range of counterparties, and eligible collateral (highly rated private and sovereign debt instruments), reflect the reluctance to hold large volumes of sovereign bonds given the Maastricht Treaty prohibition of public debt monetization (Cheun et al. 2009).

\section{The relationship between central banks and financial markets during crisis}

Since the nineteenth century, central bankers have recognized that containing a crisis requires decisive intervention in the unsecured interbank market - a good barometer of financial distress because concerns with counterparty risk render banks reluctant to lend to each other. As historical experience has repeatedly demonstrated, individual banks' difficulties to raise interbank funding may quickly gain systemic dimensions and trigger bank runs unless the central bank becomes the lender of last resort (Goodhart 1994).

But lender-of-last-resort activity may not be enough to address a serious financial crisis. When the central bank wants to do more, it typically relies on two theoretical 
frameworks to guide interventions: the signaling and portfolio-rebalancing channels (Cecioni et al. 2011; Lenza et al. 2010). The signaling channel retains the centrality of the New Keynesian concern with anchoring market expectations. For central banks that choose to remain strictly within New Keynesian frameworks, a credible commitment to keep short-term interest rates low, conditional perhaps on an indicator of economic recovery, should bring long-term interest rates down, and ease financing conditions (Eggertsson and Woodford 2003). Through the signaling channel, crisis central banking operates as an exercise in expectations management.

Extraordinary circumstances may render central banks reluctant to rely on the signaling channel alone once interest rates have reached the zero bound. Instead, unconventional central banking may aim to trigger portfolio-rebalancing effects by changing relative supplies in different asset markets in order to change asset prices and long-term interest rates (Joyce et al. 2010). The effectiveness of the portfolio-rebalancing channel relies on the abandonment of the efficient-market hypothesis where financial markets treat all assets as equal (Bernanke and Reinhart 2004; Borio and Disyatat 2009; Cecioni et al. 2011). ${ }^{2}$ Unconventional policies mean unconventional liquidity policies, since central bank interventions in financial markets can no longer rely on the theoretical guidance of the efficient market hypothesis, and the interest rate instrument. Policy innovations then depend on central banks' appraisal of what is legitimate and feasible, decisions mediated by institutional and political factors as much as economic theories.

\section{A taxonomy of interventions: Market vs bank-based measures}

Unconventional monetary policy interventions can be market based, involving targeted asset purchases, or bank based, through bank-refinancing operations (see Table 10.1). Market-based interventions became popular during Japan's extended period of deflation.

Table 10.1. A literature review: Market vs bank-based unconventional monetary policies

\begin{tabular}{|c|c|c|c|}
\hline & Form of intervention & $\begin{array}{l}\text { Channels of } \\
\text { propagation }\end{array}$ & Transmission mechanism \\
\hline $\begin{array}{l}\text { Market-based } \\
\text { measures }\end{array}$ & $\begin{array}{l}\text { Targeted asset purchases in } \\
\text { private or sovereign debt } \\
\text { markets }\end{array}$ & $\begin{array}{l}\text { Portfolio } \\
\text { rebalancing }\end{array}$ & $\begin{array}{l}\text { Changes in relative supplies } \\
\text { affects asset prices and long- } \\
\text { term interest rates, easing } \\
\text { financing conditions }\end{array}$ \\
\hline \multirow[t]{3}{*}{$\begin{array}{l}\text { Bank-based } \\
\text { measures }\end{array}$} & \multirow{3}{*}{$\begin{array}{l}\text { Long-term refinancing } \\
\text { operations (LTROS) } \\
\text { Open-market operations } \\
\text { with longer maturity, } \\
\text { extended number of } \\
\text { counterparties, relaxed } \\
\text { collateral requirements } \\
\text { (acceptance of illiquid } \\
\text { collateral) }\end{array}$} & Money multiplier & $\begin{array}{l}\text { Increased bank reserves } \\
\text { stimulate bank lending }\end{array}$ \\
\hline & & Collateral channel & $\begin{array}{l}\text { High-quality collateral } \\
\text { redirected to access private } \\
\text { market funding, restoring } \\
\text { funding and market liquidity }\end{array}$ \\
\hline & & $\begin{array}{l}\text { Indirect portfolio } \\
\text { rebalancing }\end{array}$ & $\begin{array}{l}\text { Activated if banks use } \\
\text { central bank liquidity } \\
\text { to purchase private or } \\
\text { sovereign debt }\end{array}$ \\
\hline
\end{tabular}


Bernanke and Reinhart (2004) proposed that from a theoretical perspective, the Bank of Japan's purchase of private and government securities could be geared to change the composition of the central bank's balance sheet (replacing short-term with long-term government securities, termed a credit-easing approach) or to expand it through largescale asset purchases (a quantitative easing approach).

The transmission mechanism premises changes in asset prices. Purchases of longterm government bonds would lower long-term interest rates by shifting investors' demand to riskier, higher-yielding private assets, particularly where the central bank allowed its balance sheet to expand (quantitative easing), and increase the opportunity cost of holding money. The most effective approach to change asset prices would be to target the "risk free" or benchmark rate, the interest rate on government bonds (ECB 2010a; Joyce et al. 2010).

The early literature on quantitative easing recognized that central banks may face political difficulties in designing crisis interventions, but associated these with interventions in private securities markets rather than government bond markets. Bernanke and Reinhart (2004) pointed to the legal frameworks that sought to prevent central banks from assuming the credit risks of illiquid private assets. More importantly, however, they recognized that even if the central bank overcame legal obstacles, its efforts may be ineffective if countercyclical fiscal policies pushed the "risk-free rate" on government bonds higher. In other words, the early literature recognized that coordination between the central bank's unconventional monetary policies and the government's fiscal policies were crucial to the functioning of the portfolio channel. ${ }^{3}$ In contrast, post-Lehman research became more explicitly concerned with central bank independence (Blinder 2010). Purchases of private assets could be easily interpreted as industrial policy since these prioritize some economic sectors. Purchases of government bonds in turn may be construed as disincentives for governments to pursue fiscal discipline (Trichet 2009) given the "quasi-debt management" nature of outright asset purchases (Borio and Disyatat 2009).

The ECB proposed to address this dilemma by introducing bank-based unconventional measures. It claimed conceptual legitimacy by highlighting the analytical importance of distinctive financial systems, defined through the traditional market-based and bank-based dichotomy (Bini Smaghi 2009). According to this view, bank-based liquidity measures rather than targeted asset purchases are better suited to improve credit conditions in bank-based financial systems (ECB 2010a; Fahr et al. 2011; Trichet 2009). ${ }^{4}$

Bank-based interventions, known as long-term refinancing operations (LTROs) in the Eurozone, are an extension of open-market operations. Central banks offer higher volumes of liquidity, at longer maturities, to more counterparties, and with easier collateral requirements (ECB 2010a). LTROs can impact the economy through distinctive channels. The money multiplier channel assumes that banks would deploy the additional reserves provided by the central bank to revive credit activity (Fahr et al. 2011). In this, banks act as the passive intermediaries imagined in monetarist theories. In contrast, the collateral channel premises more complex banks with lending and trading activities. Lending may be restricted if banks hold illiquid assets (such as asset-backed securities) that impair access to market funding. To unblock this channel, the central bank exploits the collateral consequences of bank-based crisis policies. It "liquefies" the bank balance 
sheet (Bini Smaghi, 2010) by accepting illiquid (lower-quality) private assets as collateral in extraordinary liquidity operations so that high-quality collateral ${ }^{5}$ can be used for private market funding. Thus, adjustments to collateral policies contribute to normalizing liquidity conditions in financial markets disrupted by increased risk aversion. In order to contain the key pitfalls of relaxed collateral policies, moral hazard, and credit risk, collateral is marked to market (valued at market prices); in addition, the central bank may impose a haircut as protection against asset price volatility by subtracting a percentage from the market value of the collateral. ${ }^{6}$ Additionally, bank-based measures can indirectly trigger portfoliorebalancing effects similar to market-based measures if private banks use the liquidity obtained from the central bank to purchase sovereign or private debt (see Table 10.1).

\section{Exit strategies}

Central bank interventions in financial markets require metrics for policy success. During normal times, central banks use one financial metric: liquidity operations maintain the unsecured interbank interest rate in a symmetrical corridor around the policy rate (typically 25 basis points). In contrast, "unconventional" commitments may be guided by financial or economic variables (Cecioni et al. 2011). The "extreme" case for market-based measures would be a ceiling on the yield of a particular instrument, such as a long-term government bond (Bernanke and Reinhart 2004), or a particular risk spread (for instance, between commercial paper and T-bills). In this case, the central bank commits to unlimited purchases at the announced yield or spread. Alternatively, outright purchases can be tailored to broader goals: overcoming deflationary pressures (as in Japan) or economic growth. Bank-based measures similarly engender a variety of possible commitment scenarios, contingent on banks' collateral portfolios, judged to be effective for resuming bank lending or for a return to "normality" in financial markets (ECB 2010a).

Once the underlying objective has been achieved, central banks are confronted with the political economy aspects of unwinding extraordinary measures. The "exit" literature portrays market-based measures as politically contentious since central banks must decide whether to hold assets to maturity, or to immediately sell these to avoid the potential inflationary consequences of oversized balance sheets (Lenza et al. 2010). Decisions have to reconcile the moral-hazard dimension of central bank support with political pressures to delay exit because of concerns about the impact on recovery (Borio and Disyatat 2009). In contrast, bank-based measures are applauded for engendering an automatic exit mechanism that diminishes the scope for political pressures (Fahr et al. 2011; Trichet 2009). With a predetermined maturity for bank-based liquidity injections, balance sheets adjust automatically for all counterparties when banks return the borrowed liquidity, and central banks the collateral pledged. The consequences of exiting bank-based crisis strategies for banks reliant on collateralized funding are rarely considered since it is assumed that restored market liquidity will allow banks to easily redeploy the collateral pledged with the central bank to raise market funding (ECB 2010a).

In sum, while discussions of unconventional monetary policies identify various difficulties arising from "weak" theoretical foundations, it is suggested that these 
vary across heterogeneous financial structures (Fahr et al. 2011; Lenza et al. 2010). Nevertheless, it is important to recognize that the distinction "bank versus market based" might be artificial, the result of strategic choices central banks rely on to justify controversial policies given particular constraints that impact their ability to adopt policies formulated in different contexts. Indeed, mutations usually occur when policies travel across institutional landscapes (Peck and Theodore 2012). For instance, outright asset purchases are often the result of explicit decisions to bypass banks since these may use the additional liquidity to deleverage rather than expand credit, as the Japanese experience demonstrated (Borio and Disyatat 2009). Similarly, bank-based measures cannot avoid politicized choices since there is little theoretical guidance for decisions about the type of risky private assets acceptable as collateral, the duration of extraordinary liquidity injections, and the timing of exit strategies - in this last case, the central bank must judge what represents a "normalization" of financial markets in the wake of a prolonged financial crisis.

The reversibility of extraordinary measures is portrayed to be an important difference, opposing an automatic mechanism for bank-based liquidity measures with the potentially controversial decisions to offload assets acquired through direct purchases. Yet, the discussion of exiting bank-based measures, as for example in Belke (2010), Lenza et al. (2010), or Fahr et al. (2011), neglects one key consideration: the collateral consequences of reverting to "normal" liquidity policies. Indeed, the important question that arises is what happens if central banks' measure for policy success - the "normalization of financial and economic conditions" - is not simultaneous with fully restored liquidity in the markets for collateral accepted by the central bank under exceptional circumstances. If collateral markets are still suffering, the central bank's exit may leave banks unable to substitute central bank funding with market funding on similar collateral requirements. This question goes to the core of the ECB's policy dilemmas since 2008 in the context of European banks' funding.

Strategies of Bank Funding and Collateral Management Strategies Bank funding strategies are under-studied in mainstream and critical analysis of monetary policy during crisis. During normal times, the efficient market hypothesis premises that assets are perfectly substitutable everywhere. Bank-based crisis policies that invoke the multiplier mechanism portray banks as tied to the decisions of the central bank. Similarly, the "collateral channel" discussions demonstrate little concern for distinctive collateral markets, again suggestive of the perfect substitutability assumption.

Yet increasingly, central bank research grapples with the consequences of changing financial landscapes, an important theme in the economic geography literature addressing the financial crisis (Wojcik 2011). The ECB (2008) recognized that new business models in banking blur the traditional bank vs market-based dichotomy, as noted in the discussions between economic geography and varieties of capitalism (see Dixon 2011). The departure from traditional banking involves an increasing reliance on non-deposit sources of funding (i.e. larger funding gaps) coupled with strategies to minimize credit risk through off-balance sheet activity. Indeed, the ECB (2010b) contrasts the growing importance of cross-border, wholesale bank funding in the Eurozone to the segmentation of retail banking (less than 5 percent of overall lending to non-banks came from 
cross-border banks) throughout the pre-Lehman period. As Figure 10.1 suggests, European banks became increasingly less dependent on traditional retail funding (relatively less so for Spain), covering funding gaps from wholesale market sources either through the issue of debt securities ${ }^{7}$ or through borrowing from external or domestic short-term interbank money markets - particularly for the French, German, and Italian banking systems. While national funding-gap figures mask important differences between individual banks' business models (e.g. large German banks are more reliant on market funding than smaller banks; see Hardie and Howarth 2009), their usefulness rests on indicating the substantial reliance on (cross-border) wholesale money markets, often associated with centralized funding models for transnational European banks (Bruno and Shin 2012).

Indeed, it is increasingly recognized that leveraged cross-border banking rather than central banks set the stance for financial conditions in financially integrated economies (Bruno and Shin 2012; Kamin 2010). ${ }^{8}$ Global banks can circumvent central banks' attempts to tighten credit conditions by resorting to delocalized funding strategies - through cross-border borrowing on wholesale markets with lower costs of funding or by activating cross-border internal markets to mobilize liquidity (Cetorelli and Goldberg 2011). For instance, the unprecedented involvement of European banks in the US financial system before Lehman relied on their ability to tap wholesale US funding markets (Bruno and Shin 2012). Rather than the transmission mechanism in standard equilibrium models, Adrian and Shin (2009) argue that central bank decisions increasingly matter more through the "risk-taking channel." Low policy interest ratesas during the pre-Lehman period of price stability, known as the Great Moderationcontribute to more aggressive risk taking by cementing banks' confidence that short-term market funding can be easily rolled over.

Figure 10.1. Sources of funding, selected European banking systems, June 2010

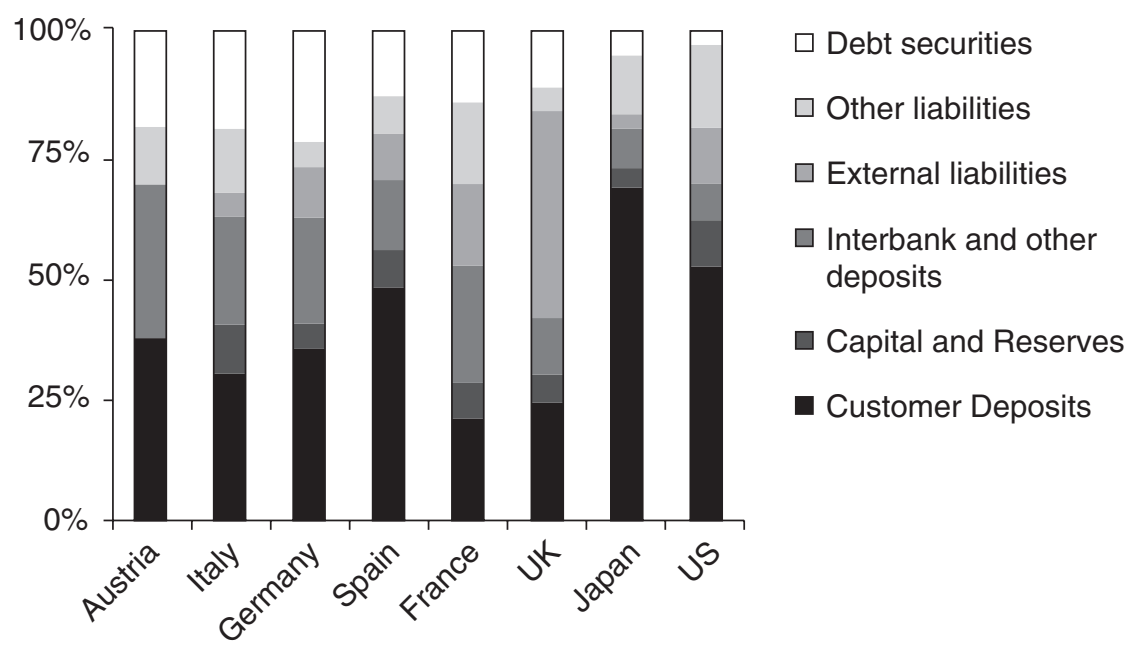

Source: BIS statistics. 
Bank funding strategies thus become an important channel for the propagation of financial distress across different financial systems (Bruno and Shin 2012; Gorton and Metrick 2009). Paradoxically, however, the burgeoning literature documenting the erosion of central bank influence over national financial conditions is largely silent about the policy implications of a crisis-contingent process through which market-reliant banks become re-embedded in the national economy through two distinctive mechanisms.

\section{Sovereign funding costs as benchmark for banks' debt issuance during crisis times}

During "normal" times, the cost of issuing new debt typically reflects issue-specific and bank-specific factors. In contrast, bank and sovereign funding conditions become closely correlated in times of crisis; a key reason that the literature on market-based unconventional measures invokes support for direct central bank interventions to lower sovereign yields (Bernanke and Reinhart 2004; Cecioni et al. 2011; Joyce et al. 2010). According to the BIS (2011), in European countries heavily affected by the sovereign debt pressures since 2010, as much as 50 percent of the spread on new bank bond issuance reflected the conditions of the home sovereign, and only 10 percent reflected bank-specific factors. This creates conflicting incentives for banks with lower-rated domestic sovereigns: the willingness to purchase home government bonds may reduce their borrowing costs (by reducing sovereign yields), but it may prompt other market participants to curtail funding because of concerns with banks' exposure to the sovereign. Under such conditions, the structure of the banking system acquires new relevance for the design of unconventional monetary policies. Large cross-border banking groups may issue debt through their subsidiaries located in jurisdictions with better-rated sovereigns. Without this avenue, banks have to rely on either central banks or secured market funding to cover funding gaps, where access depends on the quality of collateral that banks can pledge from their portfolios.

\section{Repo (collateralized market) funding and collateral management strategies}

Repo markets are funding markets where banks or other financial institutions exchange liquidity (typically short-term) against collateral. A private repo transaction is similar to central bank repo transactions in that the provider of liquidity requires collateral to make short-term funding available, thus reducing both counterparty and credit risk. Repo markets are crucial to delocalized market-funding strategies: the use of collateral enables the growth of cross-border wholesale funding, since risk management strategies no longer require the detailed assessments and relationships that are characteristic of unsecured interbank lending. Indeed, private repo markets have rapidly grown to represent a much larger source of private liquidity than the unsecured interbank market traditionally used as the target of monetary policy implementation on the premise that it determined financing costs (Klee and Stebunovs 2011). For example, the August 2008 outstanding value of Eurozone unsecured interbank transactions rose to around $€ 120$ billion (Heijmans et 
al. 2010), compared with $€ 6$ trillion (around 70 percent of Eurozone GDP) in the repo segment, a ratio similar to the USA (Klee and Stebunovs 2011), and evidence of what Bini Smaghi (2010) termed the rise of "collateralized finance." In comparison to the predominantly short-term repo markets, the largest source of long-term secured funding for European banks, the covered bond market, where banks issue securities against a pool of assets, reached $€ 2.4$ trillion before Lehman (Beirne et al. 2011).

Private repo transactions involve two types of collateral: sovereign and private debt securities. General collateral $(\mathrm{GC})$ repos are done for funding purposes and the cash lender accepts any security in its class as collateral. In contrast, "special" repos reflect the cash lender's preference for a particular security, usually to cover shorting positions. Repos can be conducted on bilateral terms, between two parties (over the counter), or through a tri-party agreement, where a clearing bank intermediates between the collateral provider and the cash lender (Copeland et al. 2011). Similar to central bank repos, collateral quality determines the haircut so that lower-rated collateral bears higher haircuts. To avoid the under-collateralization arising from fluctuations in collateral value, repo transactions are usually marked to market daily. This renders perceptions of collateral liquidity essential to collateral management strategies: when collateral falls in price (equivalent to a rise in yield for sovereign bonds), the cash borrower may be required to post additional collateral, thus increasing the cost of repo funding.

US repo market growth is attributed to the increasing importance of non-bank financial institutions (shadow banks) (Pozsar 2011). In contrast, the European repo market is dominated by large European banks, trading primarily at short maturities (under a month). The different institutional setup translates into a different sovereign GC collateral framework; whereas in the USA or UK, sovereign GC collateral refers to a homogeneous basket of sovereign debt instruments, the European sovereign GC rates are compiled on a basket of sovereign bonds issued by any of the euro area countries (Hördahl and King 2008). Indeed, regulatory efforts to allow collateral use across Eurozone jurisdictions enlarged the pool of sovereign GC collateral available for repo transactions, rendering sovereign bonds the most important form of marketable collateral for European banks. The ECB's collateral policies before the crisis further contributed to this process. As the ECB accepted a wide range of sovereign and high-quality private collateral, banks redirected sovereign collateral to private repo transactions. Thus, the share of sovereign assets in euro-denominated collateral used for ECB repos fell from around 40 percent in 2003 to around 10 percent by 2008, but dominated private repo funding markets: around 80 percent of private repos were securitized by sovereign instruments, a share that has remained constant since early 2000 (ECB 2010b). This offers a clear indication of the importance of collateral-driven activity in sovereign bond markets: by 2008, the European repo market was similar in size to the Eurozone sovereign debt market, at around $€ 6$ trillion. In rough terms, up to 80 percent of outstanding sovereign debt instruments were used in private repo transactions. ${ }^{9}$ German debt instruments collateralized around 25 percent of repo transactions, followed by Italian (12.4 percent), French (11 percent), Spanish (5 percent), and Belgian (3 percent) instruments (ICMA 2008).

For the Eurozone, the increasing importance of repo markets has two important consequences. First, it clarifies European banks' pre-crisis willingness to increase exposure 
to European governments other than those in their home country and disregard the credit risk associated with individual sovereign borrowers despite the repeated violations of the Growth and Stability Pact. ${ }^{10}$ Indeed, bank reliance on market funding renders collateral portfolio diversification as a key driver of bank demand for sovereign debt issued outside the home jurisdiction (Bolton and Jeanne 2010). Given the institutional setup of the repo market, European banks with large funding gaps increased exposure to other European sovereigns, since any sovereign collateral enabled access to sovereign GC repo funding. Stress-test figures for 2010 (before the contagion from the Greek crisis) indicated that at one end of the international diversification spectrum, less than 40 percent of Belgian, Dutch, or French banks' sovereign debt portfolios consisted of home sovereign - in contrast to Greek, Spanish, and Italian banks that mostly held debt issued by their own government (see Figure 10.2).

Second, perceptions of funding risk in repo markets can impact the liquidity of collateral markets (Hördahl and King 2008). In US repo markets, the post-Lehman risk aversion narrowed acceptable collateral to increasingly scarce "safe haven" government bonds. Yet this is not the only possible scenario. Collateral management strategies can amplify stress in sovereign bond markets, particularly in monetary unions with independent fiscal policies, because of the importance of perceptions of collateral liquidity (Bolton and Jeanne 2010; Hördahl and King 2008; Gorton and Metrick 2009; BIS 2011). Well-rated sovereigns (such as Germany) reap "collateral premiums" as repo-related demand for high-quality collateral preserves market liquidity and lowers financing costs (Bolton and Jeanne 2010). In turn, concerns about the impact of countercyclical fiscal measures on perceptions of sovereign risk reduce collateral-driven demand for lower-rated sovereign bonds that might not be eligible, or require high haircuts, in private repo transactions. The European repo market offers a good example of such crisis-contingent collateral discrimination: the spread between single-A-rated Greek and AAA-rated German overnight repo rates on 10-year sovereign collateral widened from around zero basis

Figure 10.2. The share of foreign government bonds in banks' sovereign bond portfolios

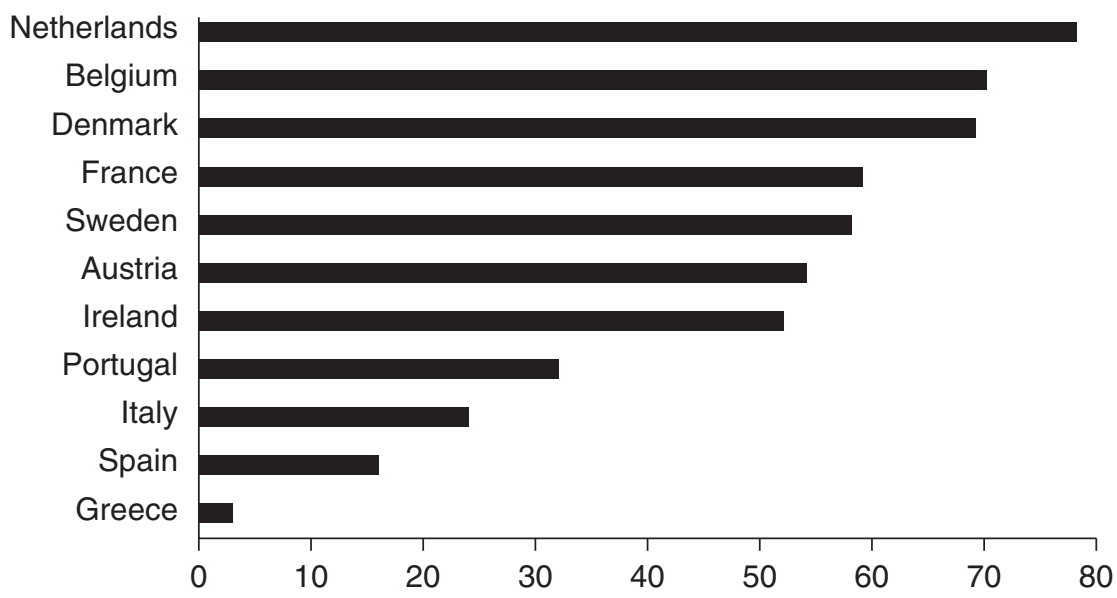

Source: Data from BIS (2011). 
points before Lehman to more than sixty basis points by October 2008, similar to IrishGerman spreads (Hördahl and King 2008). Lower-rated sovereigns may thus be trapped in a vicious cycle as collateral concerns reduce demand for sovereign debt instruments, particularly if repo collateral is marked to market daily. Increased scrutiny of collateral portfolios paradoxically may render private banks reluctant to hold own government debt in order to avoid becoming part of correlated risks on the repo market between counterparty (bank) and collateral (sovereign bond), even though higher home sovereign yields feed into higher costs on banks' unsecured debt issuance. The extent to which coordinated risks become significant depends on the degree of internationalization of banks' portfolio of sovereign bonds: the higher holdings of home sovereign debt instruments (as for instance in Spain, Greece, or Italy), the higher the adverse effects on bank secured funding costs stemming from pressures in the sovereign bond market.

Indeed, in contrast to the pre-crisis celebration of the improved risk management strategies available through collateralized funding, the collapse of Lehman Brothers drew attention to the crisis-contingent nature of private liquidity creation: uncertainties associated with collateral and counterparty risk increased difficulties of rolling over short-term repo funding (Gorton and Metrick 2009). The distinctive choices about the design of crisis interventions, particularly the collateral consequences, become critical when private liquidity can only be replaced by central bank liquidity. The repo market then becomes a conduit of banking funding pressures into sovereign funding pressures, and vice versa, complicating central bank attempts to stabilize banks' funding markets without stabilizing sovereign debt markets, as the ECB policy experiments since October 2008 suggest.

\section{Understanding the EGB's Dilemmas}

The ECB's actions since the onset of the financial crisis have been bold, and yet firmly anchored within the medium-term framework of our monetary policy strategy. (Trichet 2009)

Since October 2008, the ECB's policies often underwent changes of trajectory, reflecting the complex political context of its policy formulation on one hand, and the ongoing attempts to create, at European level, an institutional framework well equipped to address banking or sovereign risk on the other hand. The ECB combined bank-based with market-based measures and unsuccessfully attempted, on at least three separate occasions, to exit its extraordinary crisis measures (see Table 10.2). Furthermore, bankbased liquidity injections played a far greater role, in quantitative terms, than outright asset purchases (see Figure 10.3).

Despite the challenges of stabilizing markets heavily impaired by Lehman's collapse, 2009 was the least politically difficult year for the ECB. Bank- and market-based measures sought to mitigate European banks' difficulties to access market funding after Lehman's collapse (ECB 2010a; Trichet 2009). As banks tapped extraordinary liquidity facilities offered first through the Enhanced Credit Support Strategy (October 2008) and then the three, one-year LTROs announced in May 2009, demand for one-year liquidity reduced 
Table 10.2. The ECB's unconventional crisis policies

Nature of commitment Interactions with funding markets

Bank-based crisis measures (start date)

Enhanced credit support Full-allotment, longer (Oct 2008)

LTRO I (May 2009)

LTRO II (May 2010)

LTRO III (Oct 2011)

LTRO IV (Dec 2011) maturity (3 to 6 months); relaxed collateral requirements

Three 1-year LTROs (fun, Sep, and Dec 09)

One 6-month LTRO (May 2010)

Two 1-year LTROs (Oct and Dec 2011)

Two 3-year LTROs (Dec 2011 and Feb 2012); relaxed collateral requirements
Allow collateral substitution given sovereign collateral discrimination in European repo markets

Lengthen liquidity planning horizon (Trichet 2009) and collateral substitution

Address tensions in markets for collateral and possible contagion

Mitigate scarcity of eligible collateral (Draghi 2011) and collateral discrimination; immediate and temporary effect on Spanish and Italian yields

\section{Market-based crisis measures}

\begin{tabular}{|c|c|c|}
\hline $\begin{array}{l}\text { Covered Bond Program } \\
\text { I (May } 2009 \text { to Fun 2010) } \\
\text { and II (Nov } 2011 \text { to Oct } \\
\text { 2012) }\end{array}$ & $\begin{array}{l}\text { Commitment to volumes } \\
\text { CBPP I = } 60 \text { bn } \\
\text { CBPP II = } € 40 \text { bn } \\
\text { (Hold to maturity) }\end{array}$ & $\begin{array}{l}\text { Lower cost of funding in the covered } \\
\text { bond market, a long-term source of } \\
\text { market funding for European banks }\end{array}$ \\
\hline $\begin{array}{l}\text { Securities Market } \\
\text { Programme (May 2010; } \\
\text { suspended by Fan 2011; } \\
\text { restored in Ful 2011) }\end{array}$ & $\begin{array}{l}\text { Sterilized, one-off purchases; } \\
\text { no commitment to volume; } \\
\text { no disclosure of originator } \\
\text { of instrument }\end{array}$ & $\begin{array}{l}\text {; Restore liquidity in sovereign bond } \\
\text { markets important for bank funding } \\
\text { (collateral); temporary effect on low- } \\
\text { rated sovereign yields }\end{array}$ \\
\hline $\begin{array}{l}\text { Outright Monetary } \\
\text { Transactions (announced } \\
\text { Aug 2012) }\end{array}$ & $\begin{array}{l}\text { 'Do what it takes': purchase } \\
\text { of government bond } \\
\text { markets, conditional on } \\
\text { IMF agreement }\end{array}$ & $\begin{array}{l}\text { No interventions yet; strong signaling } \\
\text { effect that stabilized government bond } \\
\text { markets across Eurozone }\end{array}$ \\
\hline Exit strategies & Exit narrative & Interactions with market funding \\
\hline $\begin{array}{l}\text { LTRO phasing out } \\
\text { announced (Dec 2009) }\end{array}$ & $\begin{array}{l}\text { Stabilized market } \\
\text { conditions }\end{array}$ & $\begin{array}{l}\text { Increased collateral scrutiny as return } \\
\text { to market funding dependent on market } \\
\text { perceptions of collateral quality }\end{array}$ \\
\hline $\begin{array}{l}\text { Tightening of collateral } \\
\text { requirements } \\
\text { (fan 2011) }\end{array}$ & $\begin{array}{l}\text { Haircut differentiated } \\
\text { according to credit ratings } \\
\text { of collateral to protect } \\
\text { ECB from credit risk }\end{array}$ & $\begin{array}{l}\text { Increased costs of using lower-rated } \\
\text { sovereign debt reduces repo-driven } \\
\text { demand }\end{array}$ \\
\hline $\begin{array}{l}\text { Increase interest rate } \\
\text { (Mar 2011) }\end{array}$ & $\begin{array}{l}\text { Return to interest rate as } \\
\text { policy instrument to tackle } \\
\text { inflation }\end{array}$ & Interest rate risk \\
\hline
\end{tabular}

Note: LTRO $=$ long-term refinancing operations. 
substantially from the June LTRO operation (around $€ 350$ billion) to the September and December auctions (see Figure 10.3). Furthermore, the ECB adopted a small-scale asset purchase programme in the European covered bond market, a source of long-term secured market funding (Beirne et al. 2011).

The LTROs further contributed to the stabilization of collateral markets in two distinctive ways. First, relaxed collateral requirements would allow banks to use sovereign bonds in private repo markets (Trichet 2009), although the impact of collateral reallocations was limited by the small share of sovereign collateral used for accessing ECB funding pre-crisis (around 10 percent, see Cheun et al. 2009). Second, banks used ECB liquidity to purchase government bonds because these offered attractive yields in a context of scarce profit opportunities (Lapavitsas et al. 2010), and to strengthen collateral portfolios that would allow them to replace ECB funding with market funding once the ECB initiated its exit measures. Indeed, perceptions of risk attached to the Greek and Irish collateral improved in European repo markets, reversing the post-Lehman reduction in volumes (BIS 2011). Furthermore, spreads between different European sovereign yields narrowed despite several factors pushing governments' funding costs higher, including the ECB's refusal to purchase sovereign debt similar to high-income peers after March 2009 (Dale et al. 2010) or the "timely, temporary and targeted" fiscal activism in Europe supported by the European Commission (2009). Encouraged by the apparent stabilization of financial markets and concerned about inadvertently feeding a return to excessive risk-taking behavior, the ECB announced the phasing out of its extraordinary liquidity injections in December 2009 (ECB 2010a; Fahr et al. 2011).

Figure 10.3. Bank-based and market-based crisis measures, ECB, 2008-11

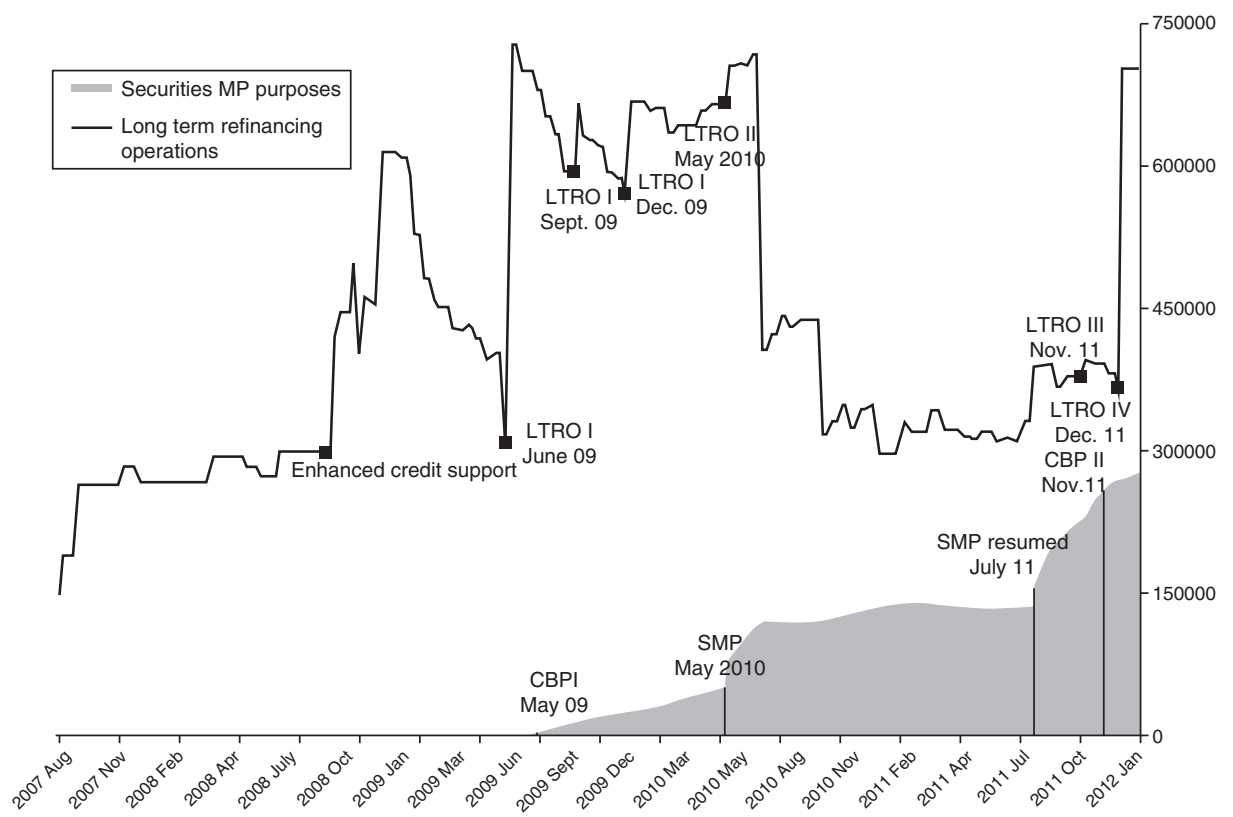

Source: ECB data. 
The ECB faced different policy challenges throughout 2010. The Greek crisis worsened banks' access to market funding, threatening to derail its phasing-out strategy and resulting in politically unpalatable choices: the stabilization of bank-funding markets would now involve "bailing out" both banks and governments if the ECB was to explicitly intervene in markets for collateral.

Funding through unsecured markets reduced because of worsening risk perceptions (reported in the financial press as the "disappearance of the interbank market") while collateral discrimination reappeared in private repo markets, this time spreading to other lower-rated European sovereigns (Ireland, Portugal, Italy, Spain) that together provided around 20 percent of overall Euro repo collateral (ICMA 2011). The BIS (2011) reported that the share of repo transactions collateralized by Greek and Irish sovereign bonds halved by June 2010, whereas the ECB (2010b) recognized the emergence of "two highly correlated risks" (bank and sovereign) that increased banks' difficulties to raise repo finance collateralized by the debt of their own sovereign. The correlated risk between counterparty (bank) and collateral (sovereign) particularly affected Greek and Spanish banking systems, where foreign government debt amounted to less than 10 percent of banks' overall government debt portfolios (Bolton and Jeanne 2010). Despite these adverse developments in funding and collateral markets, further worsened by the automatic unwinding of the first (and largest) one-year LTRO injection in June 2010, the ECB ostensibly maintained its commitment to exit strategies. Its initial response reflected the European consensus that Greece alone was responsible for resolving its crisis (Featherstone 2011). Indeed, bailout negotiations unfolded during April 2010 without envisaging a direct role for the ECB. Then, after intense political pressure, on May 3 the ECB relaxed collateral constraints to accept downgraded Greek sovereign (guaranteed) debt, under the proviso that a European political solution had to cement the credibility of the fiscal consolidation plan. A week later, it introduced the second type of market-based measures - the Securities Market Programme (SMP) - committing to purchase Eurozone government bonds in the secondary market, and reabsorb the additional liquidity through sterilizations to avoid any associations with the quantitative easing programs in the USA and UK. The ECB portrayed outright purchases as temporary measures undertaken to stabilize market segments crucial to the transmission of monetary policy signals (ECB 2010a), refusing to make any commitments to volume or to disclose the nationality of the targeted markets.

It is important to point out that the intense criticism leveled at the SMP for discouraging fiscal discipline (Belke 2010; Gerlach 2010) rarely recognizes that sovereign bond purchases throughout 2010 were of a much smaller volume than bank-based liquidity injections, and were negligible compared to the overall size of the European sovereign debt market ( $€ 60$ billion compared to $€ 6$ trillion). Indeed, the pace of purchases slowed markedly after June 2010 even as sovereign spreads again widened to pre-SMP levels. This suggests that the ECB viewed the SMP as a temporary setback to its exit strategy, rather than as a strategy to contain collateral contagion affecting banks that were reliant on market funding or as a subsidy to "deviant" governments. Indeed, once the European Financial Stability Fund (EFSF) was established in June 2010, the ECB warned governments to assume responsibility for banks addicted to its extraordinary 
liquidity injections and recast its policy problem strictly through the impediments that "addicted banks" placed on its exit strategy (Financial Times 2010).

The consequences of neglecting the collateral implications of exit strategies came in sharp focus during Ireland's bailout. Unlike Greece, Ireland did not fit the "irresponsible government" narrative neatly, since it had a strong fiscal position before 2008, and had adopted a harsh austerity program since 2009. Its crisis reflected the banking sector's reliance on short-term market funding to finance a housing bubble. The Irish banking system was particularly affected by exit strategies, having to replace $€ 130$ billion of ECB liquidity with market liquidity while pressures mounted in the Irish sovereign bond market as LCH Clearnet, a key repo market intermediary, repeatedly raised haircuts on Irish sovereign collateral throughout October 2010 (BIS 2011). Although it recognized that "correlated risks" between counterparty and collateral excluded Irish banks from private funding markets (ECB 2010b), the ECB refused to restore the marketable collateral properties of Irish sovereign debt; as Figure 10.3 shows, no significant sovereign bond purchases occurred during that period. Instead, it pushed for an international bailout plan that would enable the Irish government to finance the recapitalization of its banking sector. The ECB's reluctance to resume extraordinary crisis measures continued even as increasingly apocalyptic scenarios accompanied the Portuguese bailout in April 2011 , the second Greek bailout, and the Italian and Spanish sovereign bond market pressures in June 2011. Indeed, throughout the first half of 2011, the ECB increased interest rates (March 2011), suspended SMP purchases, and introduced differentiated haircuts depending on collateral quality. This last measure was particularly detrimental to funding markets, analysts argued, because prudent central banking increased the costs of posting lower-rated sovereign bonds as collateral, reinforcing the collateral discrimination prevailing in private repo markets (Mandy 2011).

The ECB eventually recognized the urgency of addressing the scarcity of eligible collateral (Draghi 2011), particularly considering speculations about an imminent Italian bailout after several large Italian banks were downgraded in September 2011. The second largest in Europe, the Italian sovereign bond market provided around 10 percent of collateral circulating through the European repo market (ICMA 2011). The ECB had two policy choices to mitigate collateral scarcity. In the radical scenario-later materialized in the OMT commitments - outright bond purchases could underpin a firm commitment to stabilize collateral markets. Alternatively, it could revive its 2009 strategy, using bankbased LTROs as indirect support for collateral markets conditional on banks' willingness to increase holdings of sovereign debt. Initially, it appeared that the ECB had chosen the radical option, resuming SMP purchases at a pace comparable to the Greek bailout moment (see Figure 10.3). However, by October 2011, it became clear that the institution was failing to reconcile the scale of required interventions with the opposition to the SMP purchases: interest rates on German collateralized repos entered negative territory, indicating the scarcity of German sovereign collateral, while risk aversion reduced the use of Italian sovereign collateral in private repo markets (ICMA 2011). This eventually prompted the ECB to resume bank-based measures, reintroducing one-year LTROs in October 2011, and then three-year LTROs in December 2011 (see Table 10.1). The immediate effects echoed the 2009 sovereign-bank loop. Bank demand for three-year LTRO liquidity, similar to the first LTRO (June 2009), translated into lower Italian and Spanish spreads to German yields and 
stabilized repo markets (FT Alphaville 2012). Predictably, however, tensions re-emerged in the Spanish sovereign bond market once the Spanish government recognized that it would not be able to comply with the initial austerity targets because of the worsening economic outlook. The threat to Spanish and Italian government bond markets, both important suppliers of collateral to European repo markets, eventually prompted the ECB to announce that it would do whatever it takes to stabilize government bond yields, through the Outright Monetary Transactions program announced in August 2012.

\section{Conclusion}

Central banking turns into an overtly politicized, highly contestable policy terrain during crisis. The chapter discussed two reasons for this. First, central banks cannot rely on well-established theoretical foundations to design crisis interventions. Second, policy implementation, a usually obscure subtheme of central banking, comes to the fore of policy discussions, since central banks are compelled to assume a far more prominent role in financial markets once the traditional policy instrument, the interest rate, can no longer be manipulated to mitigate the adverse consequences of financial tensions. When the communicative task changes from signaling the direction of interest rate changes, central banks rely on bank- vs market-based dichotomies and concerns with political consequences of exit strategies to explain policy decisions.

The chapter argued that the analysis of central banking during crisis should be extended to consider the importance of banks' collateral management strategies in the context of delocalized funding strategies. During periods of stability, financial integration enables banks to circumvent the constraints of domestic monetary policy decisions by resorting to cross-border wholesale funding. In the Eurozone, the success of systematic regulatory efforts to integrate wholesale funding markets rendered European sovereign bonds as the key source of marketable collateral for secured funding, and thus contributed, perhaps inadvertently, to increased depth, liquidity, and yield convergence in Eurozone government debt markets. Before the crisis, banks could raise short-term liquidity in the rapidly growing repo markets on identical terms for German, Greek, or Irish collateral.

Since Lehman, however, the reliance of European banks on short-term secured market funding has tested the political limits of the existing institutional architecture. Initially, it appeared that bank-based liquidity measures successfully restored banks' access to market funding, lengthened banks' funding horizons, and mitigated the negative consequences of post-Lehman sovereign collateral discrimination in private repo markets. Yet, the Greek fiscal deficit scandal in late 2009, simultaneous with the ECB's initiation of exit strategies, exposed an unresolved conflict at the heart of a monetary union with integrated funding markets: exit strategies may increase stress in short-term repo markets when tensions prevail in markets for collateral, and vice versa, as banks are unable to substitute central bank funding with market funding on similar collateral requirements. The trajectory of the European sovereign debt crisis demonstrates that the constraints on the central bank's ability to stabilize collateral markets can have adverse effects for both bank and government funding conditions.

From this perspective, the return to long-term extraordinary liquidity injections in December 2011 and then the OMT announcement postponed rather than addressed 
the crucial institutional question for Europe: how to sustain the strict separation between monetary and fiscal policy, if, during crisis, what the ECB must do in order to improve funding conditions for market-based banks is to commit to intervene in sovereign bond markets. The fiscal-pact approach preserves the status quo by implicitly assuming that governments should, and can, assume responsibility for the stability of sovereign bond markets even in the new mode of key collateral markets. This is equally problematic when contrasting the short-term nature of collateral management strategies with the time lags involved in fiscal adjustment typically associated with welfare states.

\section{Notes}

1 The ECB computes the Euro Overnight Index Average (EONIA) as a weighted average of all overnight unsecured lending transactions in the interbank market settled daily before 6 p.m. CET.

2 Bernanke and Reinhart (2004: 86) argue that where "liquidity or risk characteristics of securities differ, so that investors do not treat all securities as perfect substitutes, then changes in relative demands by a large purchaser have the potential to alter relative security prices."

3 Such ostensibly limited concern with the inflationary consequences of monetizing government debt appeared to be vindicated by Japan's experience: the Japanese central bank spent five years (2001-2006) and $¥ 35$ trillion to reverse deflationary pressures. In policy practice, this allowed several large central banks (the US Federal Reserve, the Bank of England) to invoke the Japanese experience and introduce large-scale asset purchases in the aftermath of the Lehman collapse (Lenza et al. 2010). The early credit-easing measures were accompanied by purchases of sovereign bonds under quantitative easing programs initiated in early 2009 (Joyce et al. 2010).

4 Banks amount to around 70 percent of European non-financial companies' external financing, compared with around 20 percent in the market-based system, such as the USA.

5 High-quality collateral refers to marketable debt instruments "accepted by both policy makers and market participants for all activities that require the use of collateral" (Levels and Capels 2012, 5), typically with a credit rating above BBB- for sovereigns and AA- for corporate and covered bonds.

6 For example, a 0.5 percent haircut implies that for every $€ 1$ million worth of collateral, a bank will get $€ 995,000$ of ECB liquidity in return.

7 Including residential-backed mortgage securities, commercial mortgage-based securities, covered bonds, and collateralized debt obligations.

$8 \operatorname{Kamin}(2010,19)$ put it as follows: "Thus, ironically, the more successful is monetary policy at stabilizing inflation, the less effective may monetary policy actions appear to be at influencing financial conditions."

9 Singh (2011) documents that most legal jurisdictions allow for reuse of collateral in repo transactions. A rough estimate places the velocity of collateral for the US repo market at around 3 percent before the crisis, decreasing with deleveraging. Even so, this would suggest that between 40 and 80 percent of outstanding government debt in the Eurozone was deployed in collateral management strategies of European banks.

10 Despite the 97 instances of excessive deficits before 2008, 60 of which would have warranted sanctions according to the Stability and Growth Pact (EEAG 2011), bond markets discarded the credit risk associated with individual sovereign borrowers.

\section{References}

Allen, F., E. Carletti, and D. Gale. 2008. "Interbank Market Liquidity and Central Bank Intervention." Fournal of Monetary Economics 56 (5): 639-52. 
Beirne, J., L. Dalitz, J. Ejsing, M. Grothe, S. Manganelli, F. Monar, B. Sahel, and T. Vong. 2011. "The Impact of the Eurosystem's Covered Bond Purchase Programme on the Primary and Secondary Markets." Occasional Paper Series. Frankfurt am Main: European Central Bank.

Bernanke, B., and V. Reinhart. 2004. "Conducting Monetary Policy at Very Low Short-Term Interest Rates." American Economic Review 94 (2): 85-90.

Belke, A. 2010. "Financial Crisis, Global Liquidity and Monetary Exit Strategies." DIW Discussion Paper, no. 995. Berlin: German Institute for Economic Research.

Bini Smaghi, L. 2009. "Conventional and Unconventional Monetary Policy." Keynote lecture at the International Centre for Monetary and Banking Studies (ICMB), Geneva, April 28.

2010. "Could Monetary Policy Have Helped Prevent the Financial Crisis?" Speech at the workshop on "Monetary Policy: Recent Experience and Future Directions," Toronto, April 9.

Blanchard, O., G. Dell'Ariccia, and P. Mauro. 2010. "Rethinking Macroeconomic Policy." IMF Staff Position Note. Online: http://www.imf.org/external/pubs/ft/spn/2010/spn1003.pdf (accessed August 16, 2014).

Blinder, A. 2010. "Quantitative Easing: Entrance and Exit Strategies." Federal Reserve Bank of St Louis 92 (6).

Bolton, P., and O. Jeanne. 2010. "Sovereign Default Risk in Financially Integrated Economies." Paper presented at the 11 th Jacques Polak Annual Research Conference, Washington, DC, November 5-6. Online: http://www.imf.org/external/np/res/seminars/2010/arc/pdf/boj. pdf (accessed August 16, 2014).

Borio, C., and P. Disyatat. 2009. "Unconventional Monetary Policies: An Appraisal." BIS Working Papers, no. 292. Basel: BIS.

Bruno, V., and H. S. Shin. 2012. "Capital Flows, Cross-Border Banking and Global Liquidity." AFA 2013 San Diego Meetings Paper. Online: http://ssrn.com/abstract=2020556 or http:// dx.doi.org/10.2139/ssrn.2020556 (accessed August 16, 2014).

Cecioni, M., G. Ferrero, and A. Secchi. 2011. "Unconventional Monetary Policy in Theory and Practice.” Banca D'Italia Occasional Papers, no. 102. Rome: Banca D'Italia.

Cetorelli, N., and L. Goldberg. 2011. "Global Banks and International Shock Transmission: Evidence from the Crisis." IMF Economic Review 59: 41-76.

Cheun, S., I. von Kappen-Mertes, and B. Weller. 2009. "The Collateral Frameworks of the Eurosystem, the Federal Reserve System and the Bank of England and the Financial Market Turmoil.” Frankfurt am Main: European Central Bank. Online: http://ideas.repec.org/p/ ecb/ecbops/20090107.html (accessed March 13, 2011).

Copeland, A., A. Martin, and M. Walker. 2010. "The Tri-party Repo Market before the 2010 Reforms." Federal Reserve Bank of New York Staff Reports, no. 477, November.

De Grauwe, P. 2011 . "The Governance of a Fragile Eurozone.” University of Leuven and CEPS. Online: http://www.econ.kuleuven.be/ew/academic/intecon/Degrauwe/PDG-papers/ Discussion_papers/Governance-fragile-eurozone_s.pdf (accessed August 16, 2014).

Dixon, A. 2011. "Variegated Capitalism and the Geography of Finance: Towards a Common Agenda." Progress in Human Geography 35 (2): 193-210.

Dow, S., and A. Montagnoli. 2007. "The Regional Transmission of UK Monetary Policy.” Regional Studies 41: 797-808.

EEAG. 2011. "The EEAG Report on the European Economy.” CESifo, Munich, 2011: 71-96. Eggertsson, Gauti, and Michael Woodford. 2003. "The Zero Bound on Interest Rates and Optimal Monetary Policy." Brookings Papers on Economic Activity 1: 139-233.

European Central Bank (ECB). 2010a. "The ECB's Response to the Financial Crisis." ECB Monthly Bulletin, October: 59-74.

2010b. Money Market Survey and Money Market Study. December. Frankfurt am Main: European Central Bank. 
Fahr, S., R. Motto, R. Rostagno, F. Smets, and O. Tristani. 2011. "Lessons for Monetary Policy Strategy from the Recent Past." ECB Working Paper Series, no. 1336. Frankfurt am Main: European Central Bank.

Featherstone, K. 2011. "The Greek Sovereign Debt Crisis and EMU: A Failing State in a Skewed Regime." Fournal of Common Market Studies 49 (3): 193-217.

Financial Times. 2010. "Draghi versus the Banks." Money Supply. October 3. Online: http://blogs. ft.com/money-supply/2010/10/03/draghi-versus-the-banks/\#axzz1Rncd5FuM (accessed August 16, 2014).

Gabor, D. 2010. "(De)Financialization and Crisis in Eastern Europe." Competition and Change 14 (3-4): 248-70.

González-Páramo, J. 2008. "Credit Market Turmoil in 2007-08: Implications for Public Policy." Speech at the Eleventh Annual International Banking Conference, Federal Reserve Bank of Chicago, September 25.

Goodhart, C. 1994. "What Should Central Banks Do? What Should Be Their Macroeconomic Objectives and Operations?" Economic fournal 104: 1424-36.

Gorton, G., and A. Metrick. 2009. "Securitized Banking and the Run on Repo." Yale ICF Working Paper, no. 09.

Hardie, I., and D. Howarth. 2009. "Die Krise but Not La Crise? The Financial Crisis and the Transformation of German and French Banking Systems." Journal of Common Market Studies 47 (5): 1017-39.

Hördahl, P., and M. King. 2008. "Developments in Repo Markets during Financial Turmoil.” BIS Quarterly Review, September: 37-53.

Joyce, M., A. Lasaosa, I. Stevens, and M. Tong. 2010. "The Financial Market Impact of Quantitative Easing." Bank of England Working Paper, no. 393. London: BoE.

Kashyap, A., and J. Stein. 2000. "What Do a Million Observations on Banks Say about the Transmission of Monetary Policy?" American Economic Review 90 (3): 407-28.

Klee, E., and V. Stebunovs. 2011. A Target Treasury General Collateral Repo Rate: Is a Target Repo Rate a Viable Alternative to the Target Federal Funds Rate? Washington, DC: Board of Governors of the Federal Reserve System.

Lenza, M., H. Pill, and L. Reichlin. 2010. "Monetary Policy in Exceptional Times." European Central Bank Working Paper Series, no. 1253. Frankfurt am Main: European Central Bank.

Mandy, G. 2011. Funding Tensions Require ECB Action. Nomura Fixed Income Research. December 7. London: Nomura International.

Mann, G. 2010. "Hobbes' Redoubt? Toward a Geography of Monetary Policy." Progress in Human Geography. First published on January 28, 2010. doi: 10.1177/0309132509353817.

Peck, J, and N. Theodore. 2012. "Follow the Policy: A Distended Case Approach." Environment and Planning A 44: 21-30.

Pozsar, A. 2011. "Institutional Cash Pools and the Triffin Dilemma of the US Banking System." IMF Working Paper, WP/11/190. Washington, DC: IMF.

Trichet, J. C. 2009. "The ECB's Enhanced Credit Support." Keynote address at the University of Munich, July 13. Online: http://www.ecb.int/press/key/date/2009/html/sp090713.en.html (accessed August 16, 2014).

Stockhammer, E. 2011. "Peripheral Europe's Debt and German Wages: The Role of Wage Policy in the Euro Area." International Fournal of Public Policy 7: 83-96.

Wojcik, D. 2011. "Finance at the Crossroads: Geographies of the Financial Crisis and Its Implications." Environment and Planning A 43: 1756-60.

Weidmann, J. 2012. "Monetary Policy Is No Panacea for Europe.” Financial Times, May 7. 


\title{
Chapter 11
}

\section{THE BACKSTORY OF THE RISK-FREE ASSET: HOW GOVERNMENT DEBT BECAME "SAFE”}

\author{
Nina Boy
}

\section{Introduction}

Collateral has since antiquity been used as a safeguard for contractual obligations, such as debt. But how did debt, and in particular government debt, itself become the most common form of collateral in the financial system? In other words, how did government debt become "safe"? The safety of sovereign debt corresponds to the establishment of sovereign creditworthiness: from sovereign bonds being charged a significantly higher interest rate than commercial loans in the Middle Ages to circulating "unsecured"that is, no longer requiring additional security in the form of either collateral or a high interest rate but trading merely on "full faith and credit." As such, sovereign safety has underwritten the rise of collateral-based finance in the twentieth century and plays a crucial role both for financial lubrication and financial stability.

Premised on the government's power to tax and print money, modern finance theory and standard economics have treated the safety of sovereign debt as an assumption that has been fundamental to the main pricing models for stocks and derivatives in the form of the risk-free asset. Economic history at the same time, however, tells us that "there is no such thing as a perfectly safe sovereign" even if the "whole development of capitalist institutions can be seen as a succession of attempts at addressing the problem of the production of safe assets" (Flandreau 2013, 24). Safety, as Alberto Giovannini, advisor to the European Commission from 1996-2010, notes, "is, of course, a relative concept, being determined by human perceptions" (2013,3). How can one make sense of both these stories: sovereign safety as an axiom of modern finance as well as its historical contingency, relativism, and dependency on perception?

Much can be learned in this regard from the vantage point of the "increased questioning of sovereign debt representing a genuine risk-free rate" (BlackRock 2011 a) that has spread in the wake of the sovereign debt crisis. The first thing pointed out at numerous conferences over the last few years speculating on the consequences of the waning of the risk-free asset in the form of sovereign debt is generally that sovereign bonds, strictly speaking, were never entirely risk free, not only in the sense of duration 
and inflation risks, but also in the sense of credit risk. But, as Jaime Caruana, general manager of the Bank for International Settlements, put it in January 2013, sovereign risk was so low that investors were willing and able to behave "as if that debt was risk-free" (2013, 4). "As if" can be said to indicate two things: 1) a hypothesis, but also 2) a fiction and, more specifically, a "working fiction"- that is, a fiction that is not identified with falsehood but treated "as if" it were real. ${ }^{2}$

This chapter argues that, in order to understand the axiomatic presence of sovereign safety in modern finance theory against its historical relativism, attention needs to be turned to that which the discipline of history has traditionally sought to distinguish itself from: the genre of fiction. Drawing on influential studies in the field of "new economic criticism," the chapter traces in particular the role of fictional realism in making the financial fictions of fiat money and sovereign bonds creditworthy. What is hereby illustrated is that economic credibility is anchored in wider cultural determinants, and sovereign creditworthiness is crucially related to changing criteria of credibility of fiction.

Section II will draw out two contradictory purposes of economic history, to show that sovereign safety is relative as well as to explain how it came about; Section III will offer a doubtless partial yet nonetheless significant account of a different source of public credit in the form of the forgotten special relationship of literature and economics. Section IV will formulate some conclusions.

\section{The Mystery/History of Sovereign Safety}

How does economic history treat the emergence of the safety of sovereign debt? Two rather different endeavors can be made out. On the one hand, economic historians point out that sovereign debt crises and defaults over the centuries abound and since the early nineteenth century have tended to occur in waves: from the 1870s, the 1890s Baring crisis, to the interwar crisis that represented the largest wave of sovereign defaults in history, the 1980s debt crisis in Mexico, 1990s East Asia crisis and the crises in the 1990s and early 2000s in Latin America. The intention thus is to reveal what Kenneth Rogoff and Carmen Reinhart have termed the "this time is different" syndrome as unfounded, based primarily on the "failure to recognise the precariousness and fickleness of confidence" (2009, x) and the firmly held assumption that "crises do not happen to us, here and now" (15). Similarly Marc Flandreau (2013) points to earlier attempts at calculating sovereign risk and classifying sovereigns according to safety at the end of the nineteenth century only to show how easily these calculations were upset by political and historical events. Sovereign safety, one might infer from these accounts, is "ahistorical."

On the other hand, historical sovereign defaults notwithstanding, it is possible to make out a different narrative of a gradual process of what might be termed sovereign accreditation (or, in other words, a process of amnesia of a default-laden history). The hallmark of sovereign creditworthiness may here be defined as two sides of the same coin: 1) the voluntary repayment by the sovereign and 2) the voluntary investment in sovereign bonds. The first is captured by the peculiar legal definition of sovereign solvency as both "ability and willingness to pay" and has puzzled economic theory to some extent: why would a self-interested sovereign borrower ever repay if he cannot be coerced to do so? Rational- 
choice explanations have resorted to reputation as a disciplining factor to ensure future lending (e.g. Eaton, Gersovitz, and Stiglitz 1986), but these entail the presumption that borrowing continues infinitely: if a terminal year was specified, the borrower would refuse to pay but lenders recognizing this would also not lend; by backward induction for all years, the thought experiment shows that reputation can only be valuable if there is uncertainty about the terminal year (Kolb 2011, 4), thus implying a normalization of indebtedness.

But why did reputation not serve as a disciplining factor in the Middle Ages for sovereigns to repay their debt? Economic history has more to add on this account in its depiction of the shifting character of sovereign bonds from forced loans to voluntary loans: bonds, long-term debt and secondary markets in government debt were features already of the Italian city-states, but their labeling as "public debts" (cf. Ferguson 2009) has been termed a distorting anachronism of a forced loans system (Kirshner 2006). Although the Latin term debitum publicum was widely employed by civilian jurists in the late Middle Ages it "did not refer to government debt for the simple reason that it meant the opposite: monies owed by the taxpayer to civitates" (2006, 3). These loans received interest, which was distinguished from usury and reconciled with canon law as "compensation (damnum emergens) for the real or putative costs arising from a compulsory investment" (Ferguson 2009, 72). The first market in government debt was created in 1345 in Florence as a result of government insolvency: unable to repay its debt, Florence consolidated its outstanding obligations into one fund and decreed that credits could henceforth be transferred to third parties. That way creditors could redeem their investment but it remained a forced contribution in the first place, premised on the moral and patriotic duty of the citizenry to its government. The emergence of public credit, in the sense of a primary and voluntary market in government bonds based on trust, in the return of principal and payment of interest is dated to the British post-revolutionary government at the end of the seventeenth century. Two institutional developments were critical: 1) the parliamentary guarantee of government loans following the Glorious Revolution of 1688, turning the royal debt into "debts of the nation" or "national debt"; and 2) the foundation of a central bank with the Bank of England in 1694. In different ways, these two changes instigated understandings of the "public" that are still with us today: as parliamentary space of public opinion and legislative control and in the form of the public knowledge of financial markets. The first has been said to incite "credible commitment" (North and Weingast 1989) in contrast to medieval royal loans, which were made upon security of estates belonging to the crown and mortgaged to the lender and hence, as Doubleday notes, "public in name but private in fact - private transactions in which the people were not implicated" (1847, 42). Regarding the second, it was paradoxically the newly created and "privately owned Bank of England (that) transformed the sovereign's personal debt into a public debt and, eventually in turn, into a public currency" (Ingham 2004, 128).

Yet one needs to be careful to explain the accreditation of sovereign debt in terms of the neat threshold of private and public implied here, as these categories did not function in the same way as they are conceived of now. At the time the much debated "public credit" was seen as coterminous with the emerging financial market and more generally understood to refer to all new paper instruments or new forms of "virtual" 
property (Moore 2004, 87) emerging in the "financial revolution" including stocks and shares, promissory notes, and insurance services (Dickson 1967). This was partly because, as Carruthers and Stinchcombe (1999) elaborate, government debt was "liquidified" through the indirect capitalization via the three main joint- stock companies of the Bank of England, the South Sea Company, and the East India Company: ${ }^{3}$ these issued shares on the stock market and loaned funds to the government so that buying a share represented an indirect investment into the national debt $(1999,373) .{ }^{4}$ The London stock market had been highly "illiquid" during the seventeenth century due to high transaction costs and the cumbersome transferal of title ${ }^{5}$ but by the early eighteenth century turned "very active, highly centralised, and extremely liquid" (370) while direct forms of government lending such as annuities and lotteries remained illiquid (373). The correspondence of stock prices of the South Sea Company with the French Mississippi Company marked a structural interdependence that further tied national credit to the financial market (Mitchell 2008). Next to this signification of public credit that confounds the modern public/private divide, in particular paper money was seen by contemporaries as "national debt by another name" (De Bolla, 1989, 117). It is in the sense, therefore, that the "publick Faith" (Mitchell 2008, 125) in all new financial instruments was at stake in the development of sovereign credibility.

Even when considered in terms of the wider implications of public credit, sovereign credibility was not a sudden discovery of virtue and linked to a wide array of political and cultural influences: de Goede (2005) for example has described the mastery of "Lady Credit" - the female personification under which public credit was debated in seventeenth and eighteenth century Britain — as crucially hinged on the invention of "financial man"; particularly through the new technique of double-entry bookkeeping, the speculative temptations of "Lady Credit" were disciplined, producing the "public credit" of the gentleman and in turn the public credit of the nation. Other significant factors were the consolidating political competition between the emerging parties of Whigs and Tories (Carruthers 1996), the reform of tax collection and administration (Brewer 1990), the moral legitimization of the insurance trade (Lobo-Guerrero 2012), as well as the dramatic increase of the credibility of contract as such during the eighteenth century (Muldrew 1998), and the pre-existence of a stable monetary standard and thus homogenous monetary space in Britain (Ingham 2004). Over the eighteenth and nineteenth centuries, the British national debt is said to have transformed from a "poorly coordinated, heterogeneous, illiquid and expensive pool of funds into a modern-style national debt" (Quinn 2006, 1) providing the "blueprint of public credit" and the precedent of modern fiscal credibility. The occurrence of sovereign defaults notwithstanding, there was a marked difference to the earlier, "financial and commercial distractions which prevailed when States openly violated their solemn contracts, laughed at their obligations, and appeared insensible of the disgrace of disregarding their plighted honour" (New York Times 1865). Where previous sovereigns resorted to coercion justified by the necessity of war to preserve freedom and independence, contemporary debts had come to be seen as "by definition inherently lawful and legitimate," eliminating justification by higher norms (cf. Kirshner 2006, 15). ${ }^{6}$ Since the 1940s, so-called "advanced economies" have not defaulted on their debt (Economist 2009) ${ }^{7}$ and sovereign creditworthiness as a concept 
developed into a combination of "risk free" in theory and liquid in practice that enabled the investment company BlackRock, in a reassessment of sovereign bonds in 2012, to identify four "traditional" elements characterizing sovereign debt as an asset class: 1) an apparently riskless rate of return upon which all other assets trade at a risk premium; 2) a very high degree of liquidity, whereby government debt assumed high-powered money characteristics; 3) its function as a reference point for the valuation of virtually all other asset categories; and 4) its role as a safe-haven asset during times of market stress.

If debt as a "conditionality spanning the future" (Lepinay 2007: 95) entails uncertainty, the price of which is paid in the form of interest, the peculiar phenomenon of liquid debt has come to be instilled with the certainty (and unprofitability) of the present - as Keynes held, interest is not a reward for saving but for parting with liquidity ([1936] 2008, 108). Liquidity, as Lepinay notes, is "an index of a common world" and depends on plausible narratives and trust, while periods of high volatility are described as "moments of high uncertainty about the definition of individuals and goods, moments in which stable ontologies crumble" (2007, 99). The next section will turn attention to those cultural determinants that contributed to imbue financial instruments with plausible narratives and trust.

\section{Fiction and Public Gredit}

This chapter argues that a neglected but fundamental dimension to the underwriting process of sovereign credit hinges on concurrent transformations in the genre of fiction. Particularly fruitful work on the historical connections between financial and literary fictions has been undertaken in the field of the "new economic criticism" (NEG), an Anglo-Saxon movement in literature studies beginning in the 1990s influenced by Marc Shell (1978, 1982), Jean-Joseph Goux (1973, 1994) and Kurt Heinzelman (1980) that set out both to "unveil the buried metaphors and fictions" of the discipline of economics as well as investigate the economic - for example, exchanges of tropes and metaphorsas the ordering principle of literary works (Woodmansee and Osteen 1999, 3-4). As Nicky Marsh states, "The paradox of credit, its transmutation of the insubstantial into the substantial, has been a productive one for literary critics as it suggests an obvious parallel with the action of literature itself" $(2010,1)$. Thus financial instruments like fiduciary money and stocks are understood as forms of writing, and subject to "credit" in the sense of conferred belief in the same way as literary fiction (Shell 1999, 53). Both drew a substantial attribution of credit from the new technology of print. As Mary Poovey's (2008) work has shown, economic and literary fictions not only share common features and principles but they were not explicitly or consistently distinguished until the mid-eighteenth century. Financial instruments and "economic" and "imaginative" writing presented a "continuum" in which objective data and imaginative or rhetorical representations were not differentiated. Thus, "A shipping list was identical in format to the lists that appeared in poetic blazons or satiric catalogues, for example, and the promissory note used to acknowledge a debt contained phrases that also appeared in fictional texts" (2008, 2). Early writings on credit mixed "satire, analogy, allegory, polemics, history, pseudologic, irony, panegyric, parody and news reporting” (Backscheider 1981), 
and early political economic texts shared many features with the literary form of the novel (Poovey 2008, 92). According to Poovey, it was the gradual differentiation of these two genres of writing based on stabilizing a distinction between fact and fiction that effected the naturalization of credit instruments - that is, a state where their feature as forms of writing has "passed beneath the horizon of cultural visibility" $(2008,4)$ and the historical linkage between the genres of economic and imaginative writing was erased. Neither economic nor imaginative writing lost their visibility as writing in the same way as financial instruments: yet the authority of economic writing came to be based in characterizing itself as writing that was transparent, describing economic and financial matters, while imaginative writing sought evaluation in terms of internal criteria and disclaimed any reference to the real world. The thus propelled fact/fiction distinction was modeled on, and always bore close reference to, a similar distinction between valid and invalid monetary tokens $(2008,80)$ - a relationship still evident today when financial claims are revealed as fraudulent.

It is not merely the differentiation of economic and imaginary writing and credit instruments, however, that fostered public credit, but particularly the special relationship that continued between these as they evolved. Thus a critical role in the underwriting of public credit is accorded by a number of authors to changes brought about by the realist novel (Brantlinger 1996; Vernon 1984; Thompson 1996; Poovey 2008). As political economy - the "adjacent legislating discourse" of public credit-dropped its early theories of the intrinsic value of coins in favor of nominalist views of the value of paper money over the eighteenth century, the concept of intrinsic value "migrated generically from political economy to the novel, which asserts and regrounds intrinsic value" (Brantlinger 1996, 156). The sincerity of the novel warrants the secure investment of the reader, who can "give as full credit to the narrative as to 'the funds' because it will contain nothing extravagantly romantic, sensational, or improbable" (1996, 156). The crediting effect of fictional realism functioned precisely not because it claimed to imitate reality but because it created a second world like reality with plots and characters marked by probability in the sense of verisimilitude (Poovey 2008). Rather than real referentiality, the novel performed a fictive referentiality and thus "helped readers practice trust, tolerate deferral, evaluate character, and in a general sense, believe in things that were immaterial" $(2008,89)$. This implied a major transformation of the criteria of credibility of fiction: where the classical plausibility of fiction was premised on its moral content, and truth or lie decided on its (im)morality, the novel grounded plausibility in the internal criteria of text such as unity and consistency of character, "enabling us to conjecture what a Person of the Drama will do in the future, from what already he has done in the past" (James Harris, quoted in Poovey 2008, 116). This development of character, from outside features based on the legibility of physical marks to characteristics of inner depth, was a central feature of the novel, providing a "means by which cultural coherence was produced" and the ground for the inexhaustible re-readability of literary works since the nineteenth century (Lynch 1998, 17). While earlier pastoral fiction had defended itself against the latent accusation of lying by depicting clearly fantastical and unreal events, making its fictional status transparent, the modern novel - though equally self-conscious of its fictive character - grounds its plausibility in a structured coherence that surpasses 
that of reality: it represents the conditions (not observable in the real world) under which something appears realistic: as Esposito states, "To be realistic, the novel cannot be real" (2007, 17). By thus reforming the criteria of credibility, the novel contributed to the "increasing acceptance of increasingly realistic fictional realities" $(2007,13)$, or in Vernon's words, as "money was becoming more fictional, fiction was becoming [...] more realistic" $(1984,18)$. The era of the "final generalisation - and general acceptance - of credit as a basic, unavoidable aspect of modern money and modern economic processes" (Brantlinger 1996, 139) that comes with the rise of realism further entails a peculiar disconnection of public and private credit. Social critical discourse begins to portray the negative effects of a society defined by monetary relations in "private" terms, while the governmental institutions responsible for producing the paper currency and creating and managing the national debt come to be seen as "virtuously constructive" $(1996,157)$ : in the Victorian realist novel the focus changes from government bankruptcy to the private insolvency of "spendthrift, shiftless individuals" and to country banks as opposed to the central bank. Allusions to the national debt are rare, and if made, refer to the "security" of the money the characters have invested in "the funds" (1996, 155). Later eras of modern and postmodern cultural criticism are similarly directed at the commodity fetishism and consumer society associated with the Second Industrial Revolution, and since the nineteenth century public credit has not been perceived as a visible target. That is, while the novel seems to have played an instrumental part in providing the credit economy with plausible narratives and models for "character," it underwrote the credibility of government debt as much by letting its fragility "disappear."

Brantlinger points to the irony that despite the novel's powerful structural role in eliciting public credit it generally sought to undermine the sociopolitical as much as the literary status quo, and its "intrinsically novelistic" character was directed against the state-founding theme of the epic; yet this did not prevent its inclusion in the canons of "national literature" $(1996,155)$. Public credit seems not only to have been paradoxically promoted through discourses intended as critique and attempts of "unmasking," but its hallmarks also to have been born from crisis: the first market in government debt in medieval Florence, the creation of the Bank of England, and the first paper money era in 1797 were all born out of insolvency. The normalizing role of crisis, which should be seen to instigate a new norm rather than re-establish a predefined norm, can also be seen at work in the aftermath of the sovereign debt crisis of 2010-2012: until then sovereign creditworthiness was defined in terms of size and liquidity, as represented by the closest proxy to the safe asset in the form of the US Treasury. This particular view also informed a practice of bond indexing based on issuance weighting, or market capitalization, that weighed bond portfolio shares according to the countries who issued the most debt. Index funds based on issuance weights trace their origins to the capital asset pricing model, introduced by Sharpe in 1964, that suggests that the market portfolio - the capitalization-weighted portfolio of all assets - should have the highest return per unit of risk (Goldsticker and Lowell $2012,4)$. This definition is increasingly being challenged, and bond indexes based on capitalization, liquidity, and demand are now accused to overweight large issuers of liabilities and thus to "reward failure [...] and penalize success" (BlackRock 2011c, 16). 
BlackRock in particular has promoted new criteria for sovereign creditworthiness in launching its own sovereign risk index as a deliberate move away from issuance weighting: the most creditworthy countries are here not the most liquid but the most isolated from external shock, such as Norway, Sweden, and Switzerland. ${ }^{9}$ As this last point demonstrates it is not contemporary fiction that is seen to exert the most palpable influence on sovereign creditworthiness and as much as the realist novel has coined a "semantic of the modern" (Esposito 2007, 12), the present interlinkages of economic theory, monetary policy, fiction, and financial instruments remain to be defined further.

\section{Conclusion}

There is an obvious discrepancy between the assumption of sovereign safety in economic and financial theory on the one hand and economic history that tends to question the "givenness" of sovereign safety on the other. Yet both need to be explained. Rather than denouncing economic theory for its "unrealistic" abstractions such as the efficient market, homo oeconomicus, and the risk-free asset, the aim of this chapter was to better understand the phenomenon of "working fictions" of the economy. Recourse to modern finance theory/standard economics or economic history alone is not capable of supplying an answer, and misses a critical dimension of the accreditation of sovereign debt that took place in the wider cultural context. The "securitization" of sovereign debt (Quinn 2006) occurred not only in the broader domain connoted by the historical term "public credit" and thus requires a careful treatment of the modern terminology of public/private. Public credit as such was mediated, negotiated, and supported by a differentiation of a continuum of "writing," broadly speaking, into the economic and imaginary genres that we are familiar with, as well as the "invisibility" of credit instruments as writings that their taking at face value implies. Here the genre of fictional realism is argued to have developed critical features to support plausible narratives of public credit in the form of a new conception of probability, the evolution of character and self-referentiality that redefined the criteria of credibility of both financial and literary fictions. As a result, as Heinzelman put it, "fictions work even when they are recognised as fictions" $(1980,101)$. This is not to say that crucial economic debates such as the bullionist controversy in the nineteenth century have not influenced perceptions of sovereign credit, or that the developments presented here were the only determining factor in the perception of sovereign safety. Yet the forgotten linkage of financial and imaginary fictions suggests that it is in the wider history of the public/private and fact/ fiction distinctions as well as in their co-evolution that one should seek to place a history of sovereign safety.

\section{Notes}

1 In the fifteenth century, Italian banks charged Charles VIII of France an interest rate of 100 percent on war loans while charging Italian merchants 5-10 percent, and the Bank of England's first loan to government carried double the interest of that at which it discounted trade bills (Haldane 2009b, 1). 
2 See Vaihinger, The Philosophy of "as if": A System of the Theoretical, Practical and Religious Fictions of Mankind (1911) for a seminal analysis of the productive, heuristic function of fiction in the sciences.

3 Of the three, two were explicitly created to fund the public debt: the Bank of England in 1694 and the South Sea Company in 1711, while the East India Company, incorporated since 1600, loaned funds to the government from 1709.

4 Joint-stock companies in themselves somewhat defy the modern public/private distinction as they were central colonizing forces equipped with their own armies and authorized to extend and defend their trade routes (de Goede 2010).

5 The most active trader in Royal Africa Company stock (John Bull) traded 13 times from 1672 to 1679 (Carruthers and Stinchcombe 1999, 370).

6 The moral connotation nonetheless endures: for a modern recurrence of a patriotic rationale for investing in government bonds see Aitken's (2006) analysis of US savings and defense bonds in the name of national security during the Cold War.

7 With the exception of Greece's default on March 9, 2012, which triggered sovereign CDS payments.

8 Other underwriting factors were of course the establishment of a national reserve system and the status of the pound/dollar as global reserve currencies: yet even here liquidity relies on the fiction that all promises-to-pay in circulation could be converted simultaneously - the realization of that illusory guarantee is the classic motivation for the bank run.

9 The overall methodology is more complex but the result is a new sovereign risk global order where the traditional safe haven countries figure in the medium range of the index and emerging economies such as Singapore, Chile, and Taiwan feature in the top ten.

\section{References}

Aitken, Rob. 2006. "Performativity, Popular Finance and Security in the Global Political Economy." In International Political Economy and Post-structuralist Politics, ed. Marieke de Goede, 77-96. London: Palgrave.

BlackRock. 2011 a. A Rapidly Changing Order: The Rising Prominence of Asian Debt Markets. October. New York: BlackRock Investment Institute. Online: http://www.blackrock.com/investing/ literature/whitepaper/rising-prominence-of-asian-debt-markets-us.pdf (accessed October 29, 2013).

BlackRock. 201 lb. Introducing the BlackRock Sovereign Risk Index: A More Comprehensive View of Credit Quality. June. New York: BlackRock Investment Institute. http://www.blackrock.com/ investing/literature/whitepaper/introducing-the-blackrock-sovereign-risk-index-us.pdf (accessed October 29, 2013).

BlackRock 2011c. Strategic Solutions, Q4 2011 International Edition. New York: BlackRock Investment Institute. Online: http://www.scribd.com/doc/88532146/BlackRock-StrategicSolutions-Q4-2011-International-Edition (accessed September 18, 2014).

Brantlinger, Patrick. 1996. Fictions of State: Culture and Credit in Britain, 1694-1994. Ithaca, NY: Cornell University Press.

Brewer, John. 1990. The Sinewes of Power: War, Money and the English State 1688-1783. Cambridge, MA: Harvard University Press.

De Bolla, Peter. 1989. The Discourse of the Sublime: Readings in History, Aesthetics and the Subject. Oxford: Basil Blackwell.

Carruthers, Bruce. 1996. City of Capital: Politics and Markets in the English Financial Revolution. Princeton, NJ: Princeton University Press.

Carruthers, Bruce, and Arthur Stinchcombe. 1999. "The Social Structure of Liquidity: Flexibility, Markets and States." Theory and Society 28: 353-382.

Caruana, Jaime. 2013. "Welcoming Remarks.” BIS Papers, no. 72. Basel: BIS.

Dickson, P. G. M. 1967. The Financial Revolution: A Study in the Development of Public Credit 1688-1756. London: Macmillan. 
Doubleday, Thomas. [1847] 2005. A Financial, Monetary and Statistical History of England: From the Revolution of 1688 to the Present Times. London: Elibron.

Eaton, Jonathan, Mark Gersovitz, and Joseph Stiglitz. 1986. "The Pure Theory of Country Risk." European Economic Review 30 (3): 481-514.

Esposito, Elena. 2007. Die Fiktion der wahrscheinlichen Realität. Frankfurt am Main: Suhrkamp Verlag. Ferguson, Niall. 2009. The Ascent of Money. London: Penguin.

Finn, Margot C. 2003. The Character of Credit: Personal Debt in English Culture, 1740-1914. Cambridge: Cambridge University Press.

Flandreau, Marc. 2013. "Do Good Sovereigns Default? Lessons of History." BIS Papers, no. 72. Basel: BIS.

Gaillard, Norbert. 2012. A Century of Sovereign Ratings. New York: Springer.

De Goede, Marieke. 2005. Virtue, Fortune and Faith: A Genealogy of Finance. Minneapolis: University of Minnesota Press.

Giovannini, Alberto. 2013. "Risk-Free Assets in Financial Markets." BIS Papers, no. 72. Basel: BIS. Goldsticker, Ralph, and Bennett Lowell. 2012. Rethinking Bond Index Weightings and Concentration Risk.

Mellon Capital, January. Online: http://us.bnymellonam.com/core/library/documents/ knowledge/AssetAllocation/sISSG_BondIndex.pdf (accessed August 16, 2014).

Goux, Jean-Joseph. 1990 [1973]. Symbolic Economies: After Marx and Freud. Ithaca, NY: Cornell University Press.

Goux, Jean-Joseph. 1994. The Coiners of Language. Norman: University of Oklahoma Press.

Heinzelman, Kurt. 1980. The Economics of the Imagination. Amherst: University of Massachusetts Press. Ingham, Geoffrey. 2004. The Nature of Money. Cambridge: Polity Press.

Keynes, John Maynard. [1936] 2008. The General Theory of Employment, Interest and Money. Macmillan: Cambridge University Press.

Kirshner, Julius. 2006. "States of Debt." Paper for Mellon Sawyer Seminar on "Debt, Sovereignty and Power." Paper presented at the University of Cambridge, November 18.

Kolb, Robert W., ed. 2011. Sovereign Debt: From Safety to Default. Hoboken, NJ: John Wiley.

Lepinay, Vincent Antonin. 2007. "Decoding Finance." In Do Economists Make Markets? On the Performativity of Economics, ed. Donald A. MacKenzie, Fabian Muniesa, and Lucia Siu, 87-127. New York: Routledge.

Lobo-Guerrero, Luis. 2012. Insuring War: Sovereignty, Security and Risk. New York: Routledge.

Lynch, Deidre. 1998. The Economy of Character: Novels, Market Culture and the Business of Inner Meaning. Chicago: University of Chicago Press.

Moore, Sean. 2004. "The Culture of Paper Credit: The New Economic Criticism and the Postcolonial Eighteenth Century." Eighteenth Century 45 (1): 87-108.

Muldrew, Craig. 1998. The Economy of Obligation: The Culture of Credit and Social Relations in Early Modern England. Basingstoke: Palgrave Macmillan.

New York Times. 1865. "Government Securities: The Public Credit." December 1. Online: http:// www.nytimes.com/1865/12/01/news/government-securities-the-public-credit.html (accessed August 16, 2014).

Nicholson, Colin. 1994. Writing and the Rise of Finance: Capital Satires of the Early Eighteenth Century. Cambridge: Cambridge University Press.

North, D. C., and B. R. Weingast. 1989. "Constitutions and Commitments: The Evolution of Institutions Governing Public Choice in Seventeenth-Century England." Fournal of Economic History 49: 803-32.

Poovey, Mary. 2008. Genres of the Credit Economy: Mediating Value in Eighteenth- and Nineteenth-Century Britain. Chicago: University of Chicago Press.

Quinn, S. 2007. "Securitisation of Sovereign Debt: Corporations as a Sovereign Debt Restructuring Mechanism in Britain 1688-1750." Paper presented at the University of Cambridge, November 18.

Reinhart, Carmen M., and Kenneth S. Rogoff. 2009. This Time Is Different: Eight Centuries of Financial Folly. Princeton, NJ: Princeton University Press. 
Economist. 2009. "Government Debt: The Big Sweat." 11 June. Online: http://www.economist. com/node/13825211 (accessed 21 August 2014).

Shell, Marc. 1978. The Economy of Literature. Baltimore: John Hopkins Press. . 1982. Money, Language and Thought. Berkeley: University of California Press. . 1999. "The Issue of Representation." In The New Economic Criticism: Studies at the Intersection of Literature and Economics, ed. Martha Woodmansee and Mark Osteen, 53-74. London: Routledge. Thompson, James. 1996. Models of Value: Eighteenth-Century Political Economy and the Novel. Durham, NG: Duke University Press.

Vaihinger, Hans. 1935. The Philosophy of 'as if': A System of the Theoretical, Practical and Religious Fictions of Mankind. Trans. C. K. Ogden. London: Routledge.

Vernon, John. 1984. Money and Fiction: Literary Realism in the Nineteenth and Early Twentieth Centuries. Ithaca, NY: Cornell University Press.

Woodmansee, Martha, and Mark Osteen. 1999. (eds) The New Economic Criticism: Studies at the Intersection of Literature and Economics. London: Routledge. 

Part 4

WHERE NEXT FOR GENTRAL BANKING? 



\title{
Chapter 12
}

\section{CENTRAL BANKING POST-CRISIS: WHAT COMPASS FOR UNCHARTED WATERS?}

\author{
Claudio Borio
}

\section{Introduction ${ }^{1}$}

Central banking will never be quite the same again after the global financial crisis. The crisis will no doubt prove to be one of those rare defining moments in the history of this institution - an institution that, from its faltering first steps in the seventeenth century, has grown to become widely regarded as indispensable.

At first glance, central banks have emerged as the great winners among policy institutions. They have been rightly hailed as saviors of the global financial system: their swift and internationally coordinated action, through liquidity support and interest rate cuts, prevented the system's implosion. And they have gained much broader powers: no one questions any longer their crucial role in financial stability, which is being hardwired into legislation, while some are regaining the regulatory and supervisory functions lost in previous decades.

And yet, beneath this glittering surface, the picture is less reassuring. The crisis has shaken the foundations of the deceptively comfortable central banking world. Pre-crisis, the quintessential task of central banks was seen as quite straightforward: keep inflation within a tight range through control of a short-term interest rate, and everything else will take care of itself. Everything was simple, tidy, and cozy. Post-crisis, many certainties have gone. Price stability has proven no guarantee against major financial and macroeconomic instability. Central banks have found themselves reaching well beyond interest rate policy, aggressively deploying their balance sheet in a variety of "unconventional" monetary policies. As a result, the line between monetary and fiscal policy has become blurred precisely at a time when public sector debts are ballooning and sovereign risk is rising again. And many increasingly question the very ability of central banks to maintain inflation within acceptable ranges, notably to avoid deflation. Nor is the boom underway in the price of gold precisely a vote of confidence in the international monetary system.

The years ahead will be a period of experimentation in central banking (Goodhart 2010). Central banks face a threefold challenge: economic, intellectual, and institutional. First, they will operate in a hostile economic environment. The Great Moderation has ushered in the Great Recession. Mature economies will carry the 
long-lasting scars of the crisis, while emerging economies may well continue to boom and face problems not dissimilar to those that heralded the crisis elsewhere. Second, central banks will take decisions in full knowledge that their benchmark macroeconomic paradigms have failed them. These paradigms, and the macroeconomic models that underpin them, provided no guidance to anticipate, ward off, or fight the crisis. The crisis has exposed a chasm between the theory and practice of policy. Third, central banks will have to adjust their policy frameworks while preserving their reputation and independence in an environment in which that independence is likely to come under increasing threat. As central banks cope with the legacy of the crisis and take on broader tasks, governance arrangements will face considerable strains. And the threat of rising public debts and sovereign risk will loom large, raising the specter of fiscal dominance. In other words, they will need a new compass with which to sail in largely uncharted waters.

What follows explores these challenges in search of a compass. It argues that the compass should have three characteristics. First, the tight interdependence between monetary and financial stability will need to be much more fully recognized and policy frameworks adjusted accordingly. This, in turn, will require bolder steps to develop analytical frameworks in which monetary factors play a core role, not a peripheral one as hitherto - an intellectual rediscovery of the roots of monetary economics. Second, there should be a keener awareness of the global, as opposed to purely domestic, dimensions of those tasks. The common view that keeping one's house in order is sufficient for global stability should be reconsidered (Padoa-Schioppa 2008). This calls for an intellectual shift that is analogous to the one that has already occurred in financial regulation and supervision, from a microprudential to a macroprudential perspective. Finally, the autonomy of central banks will need to be protected and strengthened. An overarching challenge will be to manage expectations, recognizing the limitations of policy as a tool to manage the economy. Central banks were never as powerful as generally believed. To pretend otherwise risks undermining their credibility and public support.

Section I discusses the evolution of the intellectual backdrop, comparing the pre-crisis prevailing consensus with the post-crisis more heterogeneous picture. Section II puts forward a number of working hypotheses to guide the search for a new compass. Section III draws their implications for the adjustments to policy frameworks, and explores the remaining challenges and open questions.

\section{The Evolving Intellectual Backdrop}

Historically, albeit with important differences over time and across countries, monetary and financial stability have been core central bank objectives (De Kock 1974). At the cost of some oversimplification, the prevailing pre-crisis consensus had gravitated toward a "narrow" view of central banking, heavily focused on price stability and supported by a belief in the self-equilibrating properties of the economy. Post-crisis, a shift back toward a broader view, more in line with the historical origins of the institution, has been gaining ground. 


\section{Pre-crisis}

In intentionally highly stylized terms, glossing over differences across central banks in order better to highlight the nature of the shift underway, the prevailing pre-crisis view of central banking can be summarized in four propositions. ${ }^{2}$

Price stability is sufficient for macroeconomic stability. If central banks succeed in stabilizing inflation in the short term (say, over a two-year horizon), and absent major exogenous "shocks," such as from fiscal policy, the economy will broadly take care of itself. This is the strong version of the view that price stability is the best contribution monetary policy can make to macroeconomic stability. It is the belief that underpinned inflation targeting and that drew strength from the "Great Moderation"- the long period of low output volatility and low and stable inflation that most industrial countries enjoyed before the crisis. Analytically, this strong version found comfort in the canonical macroeconomic models of the day, in which the only departure from a fully equilibrating and well-functioning economy took the form of price rigidities (Woodford 2003; Walsh 2010). ${ }^{3}$

Almost as a corollary, there is a neat separation between monetary and financial-stability functions. True, as ultimate providers of liquidity, central banks have always been seen as indispensable in crisis management - the lender-of-last-resort role that Bagehot popularized. But the previous view permitted the decoupling of the two functions in crisis prevention: monetary policy would take care of price stability while regulation and supervision would take care of financial stability. Moreover, regulation and supervision did not need to be a central bank task. After all, the prevailing "microprudential" orientation of regulation and supervision - mainly focused on the soundness of individual institutions - was regarded as sufficient to ensure the stability of the system as a whole (e.g. Borio 2010). This did not call for a close understanding of the nexus between the financial system and the macroeconomy or of market dynamics - areas in which central banks had a natural comparative advantage. Analytically, it was essentially a partial equilibrium approach.

A short-term interest rate is sufficient to capture the impact of monetary policy on the economy. Specifically, policy was seen as operating exclusively through the control of a short-term (often overnight) interest rate that, together with expectations about its future path, fully determined the term structure of interest rates (e.g. Svensson 2003). Supporting the practical relevance of this view, it was believed that the probability that central banks would have to drive policy rates to zero in nominal terms was remote (Orphanides and Wieland 1998): the Japanese experience was dismissed as an aberration and as the result of policy mismanagement (Ahearne et al. 2002). Analytically, this view was based on the assumption that, as a first approximation, government securities at different maturities are perfect substitutes. If so, changes in their relative supply would have little effect on yields.

If each central bank looks after its own economy, the global monetary stance will also be appropriate. This specific version of the "keep your house in order" doctrine is, in effect, analogous to the reasoning behind the microprudential approach to financial stability: make sure that each institution on a standalone basis (read "country") is sound and the whole financial system (read "world") will be sound. All central banks had to do was to ensure price 
stability in their own economy and let the exchange rate float (e.g. Rose 2007). A possible exception involved very small and highly open economies, which could achieve the same result by pegging to the currency of a credible low-inflation, larger economy. Analytically, in its strongest form, the proposition drew strength from models that assume that goods produced in different countries, and assets denominated in different currencies are perfect substitutes while market participants do not make systematic expectational errors (the "law of one price" and "uncovered interest parity," respectively).

\section{Post-crisis}

The post-crisis intellectual backdrop is more heterogeneous and in flux. It may be summarized by three areas of agreement and two of disagreement.

It is now generally agreed that low and stable inflation does not guarantee financial and macroeconomic stability. After all, the seeds of the global financial crisis were sown during the Great Moderation. Hardly anyone disputes that the crisis is best seen as the bust of a major financial cycle whose upswing lasted at least a whole decade. In the economies at the origin of the turmoil, the upswing saw a major expansion in credit and asset prices, especially those of real estate. Leverage grew in both overt and hidden forms on the back of aggressive risk taking. Balance sheets became overstretched. The boom did not just precede but caused the subsequent bust, as the financial imbalances unwound.

It is also agreed that "cleaning" the debris through monetary policy is costly and that interest rate policy is not enough. Contrary to what was commonly believed, aggressive reductions in interest rates have not been sufficient to avert the enormous costs of the crisis and to reignite a solid recovery. And central banks have scrambled to deploy their balance sheets to influence longer-term interest rates and broader financial conditions, such as credit terms and credit spreads (so-called unconventional monetary policies or, more precisely, "balance sheet" policies; Borio and Disyatat 2010). Hence, the large-scale purchases of government and private sector assets, such as mortgage-backed securities, or the unprecedented extension of large-scale, long-term liquidity support to the banking sector.

Finally, there is a consensus that the regulation and supervision of financial institutions need to go beyond a microprudential perspective and adopt a macroprudential orientation, with central banks playing a key role (e.g. G20 2009; CGFS 2010; Brunnermeier et al. 2009; Borio 2010). This means that regulation and supervision should focus squarely on the financial system as a whole, not on individual institutions. And they should take fully into account the potentially amplifying feedback between the financial system and the macroeconomy that lies at the heart of financial instability ("procyclicality"). By virtue of their specific know-how, central banks are naturally seen as key players in macroprudential frameworks. Major efforts are underway nationally and internationally to put such frameworks in place.

This, however, is where the consensus stops. The areas of disagreement are equally important.

There is no agreement on whether or how far monetary policy regimes should be adjusted to lean against the buildup of financial imbalances. One view is that monetary policy regimes should continue to focus on price stability, much as they did before the crisis. To be sure, 
macroeconomic models should be augmented to better capture the interplay between financial factors and the real economy. But financial stability is best ensured through the newly established macroprudential frameworks (e.g. Bean 2009; Bernanke 2009). To do otherwise would risk overburdening monetary policy and compromising its credibility. An alternative view, which is gaining ground, is that implementing a macroprudential framework can help, but that it is not sufficient. The role of monetary policy is simply too important (e.g. Trichet 2009; Shirakawa 2010; Bloxham et al. 2010; Issing 2011).

Nor is there agreement on the proper role of monetary policy, be it interest rate or balance sheet policy, in the aftermath of a financial crisis. One view is that policy should be as accommodative as possible, driving policy rates to zero, and committing to keep them there for as long as it takes while deploying the central bank's balance sheet aggressively. Another view highlights the collateral damage of such an accommodative stance if kept beyond the crisis management phase (e.g. BIS 2010; Hannoun 2010; Borio and Disyatat 2010). After all, if the origin of the problem was too much debt, how can a policy that encourages the private and public sectors to accumulate more debt be part of the solution (see below)?

\section{A Way Forward? Working Hypotheses}

The areas of disagreement reflect genuine difficulties in adjudicating between competing hypotheses. The debate has just started. To choose a compass for the way forward, however, it is necessary to take a stand, based on a specific reading of the available evidence, limited as this may be. What follows, therefore, highlights three observations best regarded as working hypotheses.

First, monetary policy contributed significantly to the financial crisis. It stands to reason that if monetary policy responds only to near-term inflation pressures, and these remain subdued or even decline during an unsustainable financial boom, then policy will pose no resistance, and could even encourage the buildup of imbalances (e.g. Borio and White 2003; Borio 2009). ${ }^{5}$ After all, monetary policy sets the universal price of leverage in a given currency area.

There is considerable, albeit by no means undisputed, evidence supporting this view. The years that preceded the crisis saw unusually and persistently low policy rates, even negative in real terms - the lowest since the 1970s. For the USA, for instance, according to some estimates, these rates were also lower than the typical reaction function consistent with maintaining stable inflation (e.g. Taylor 2008) ${ }^{6}$ - let alone, therefore, with leaning against the buildup of imbalances (Borio and Lowe 2004). In addition, there is growing empirical evidence that low interest rates may encourage risk taking - the so-called risktaking channel of monetary policy. ${ }^{7}$ The effect is strongest when rates are unusually low by historical standards for long periods or agents anticipate that monetary policy will be eased to counteract the unwinding of the imbalances, providing a form of (fuzzy) insurance.

Second, an aggressive and prolonged easing of monetary policy, through interest rate and balance-sheet measures, to respond to the bust of a major financial boom has serious limitations. These limitations reflect the nature of the economic contraction and its impact on the transmission mechanism of policy. 
Not all recessions are born equal. The typical recession during the first decades following World War II in advanced economies was triggered by a monetary tightening to fight inflation or balance-of-payments crises. The upswing was relatively short and, with financial systems heavily regulated, the recession did not trigger a major financial crisis or involve large debt and capital overhangs. Even when debt burdens were large and financial strains emerged, higher inflation and rising nominal asset values reduced them over time.

The current recession is quite different. The preceding boom was much more prolonged, the subsequent debt and asset price overhang much larger, the financial sector much more seriously affected, and inflation much lower before and after. The Japanese experience of the early 1990s is the closest parallel. There is considerable cross-country evidence that banking crises tend to be preceded by unusually strong credit and asset price booms (see below), that those crises go hand in hand with permanent output losses (BCBS 2010), ${ }^{8}$ and that subsequent recoveries tend to be slow and protracted (e.g. Reinhart and Rogoff 2009; Reinhart and Reinhart 2010). In all probability this reflects a mixture of an overestimation of potential output and growth during the boom, the corresponding misallocation of resources, notably capital, the headwinds of the subsequent debt and real capital stock overhangs, and disruptions to financial intermediation. Fiscal expansions in the wake of the crises can add to these problems by piling government debt on top of private debt and sometimes threatening a sovereign crisis. ${ }^{9}$

All this reduces the effectiveness of monetary policy in dealing with the bust and exacerbates its unwelcome side effects. These become apparent once the easing is taken too far after averting the implosion of the financial system. The economy needs balance sheet repair, but very low interest rates together with ample central bank funding and asset purchases delay the recognition of losses and the repayment of debt. ${ }^{10}$ Too much capital has been accumulated in the wrong sectors, but the easing tends to favor investment in the very long-lived assets in excess supply (e.g. construction). The bloated financial sector needs to shrink, but the easing numbs the incentives to do so and may even encourage punting. The financial sector needs to generate healthy earnings, but as short-term interest rates approach zero and the yield curve flattens, they compress banks' interest margins ${ }^{11}$ unless banks take on more interest rate and, possibly, sovereign risk; and as long-term rates decline, they can generate strains in the insurance and pension fund sectors. Thus, as the easing continues, it raises the risk of perpetuating the very conditions that make eventual exit harder. A vicious circle can develop.

Put differently, when dealing with major financial busts, monetary policy addresses the symptoms rather than the underlying causes of the slow recovery. It alleviates the pain, but masks the illness. It gains time, but makes it easier for policymakers to waste it.

This analysis suggests that, when considering the boom and bust phases together, financial cycles may be giving rise to a new form of time inconsistency (e.g. Borio and White 2003). We are all familiar with time inconsistency in the context of inflation. In this case, taking wages and prices as given, policymakers may be tempted to produce inflation in an ultimately unsuccessful effort to raise output and employment, as prices and wages catch up (Kydland and Prescott 1977). Over time, inflation trends higher without lasting gains in output or employment. In the case of financial cycles, the end result can be 
a downward trend in policy rates across cycles and increasing resort to balance sheet policies without any gains in terms of financial and macroeconomic stability. Moreover, this form of time inconsistency is even more insidious. During the boom phase, the lag between the buildup of risks and the materialization of financial distress is considerably longer than that between excess demand and inflation (e.g. Borio 2010). And while there are constituencies against inflation, none exists against the inebriating feeling of getting richer. During the bust, failure to repair balance sheets can leave central banks with little choice but to seek to gain time. In both cases, the costs are incurred immediately and are quite visible; the benefits accrue much later and may even be hard to establish ex post.

All this raises serious political economy challenges for central banks. One institutional answer to the problem of time inconsistency is to ensure that central banks are sufficiently insulated from the political cycle. This is a key, though not the only, justification for central bank operational independence. Unfortunately, financial busts and an aggressive and prolonged monetary response to them can undermine such independence. If governments allow public debt to grow beyond sustainable levels, pressures to compromise the central bank's independence will grow at some point in order to avoid default. If central banks engage in extensive balance-sheet policy, that independence will come under threat even earlier. Purchases of private sector claims open central banks to the criticism of favoring some sectors at the expense of others, and those of public sector claims to that of having become subservient to the government. Either way, balance sheet policy can put central banks' budgetary independence and reputation at risk as they take on financial risks. And while assets may not be perfect substitutes, their substitutability is quite high. As a result, operations have to be very big, or expected to be big, in order to have significant and long-lasting effects on risk premia and relative yields. This heightens the vulnerability to financial risks and political economy pressures (Borio and Disyatat 2010; Stella 2010).

The specific drawbacks of balance sheet policy reflect a simple fact. The central bank has a monopoly over interest rate policy, not over balance sheet policy. Almost any balance sheet policy can or could be replicated by the government; conversely, any balance sheet policy the central bank implements has an impact on the consolidated government sector balance sheet. Balance sheet policy needs to be viewed as part of this larger balance sheet. For example, the central bank may purchase long-term bonds, but its efforts could be frustrated if government debt managers lengthen maturity in order to lock in unusually low yields (e.g. McCauley and Ueda 2009). In this context, the very meaning of operational independence becomes somewhat unclear. The line between monetary and fiscal policy becomes blurred.

Third, to keep one's house in order is not enough. ${ }^{12}$ This follows from two considerations.

For one, flexible exchange rates provide only limited insulation from policies pursued in large economies. For many economies, especially small, highly open ones with large manufacturing bases, the exchange rate is too important a price to be allowed to fluctuate freely-hence the so-called fear of floating (Calvo and Reinhart 2002). ${ }^{13}$ And the exchange rate is subject to those very forces that can lead to domestic financial instability: destabilizing cross-currency flows are the mirror image of the destabilizing financial imbalances that build up and unwind within individual currency areas (e.g. Borio and Disyatat 2011). The outcome is currency overshooting. 
In addition, and more generally, there is a sense in which the whole is more than the sum of its parts. In a highly globalized world, in which markets for goods and services, for factors of production, and for financial instruments are tightly integrated, purely countrycentric approaches to understanding the workings of the economy and formulating policies are bound to be inadequate. A more globe-centric approach is called for. Quite apart from being influenced by the interlinkages between countries and currency areas, aggregate outcomes will be different depending on whether several countries are experiencing similar conditions or not. In other words, correlations of conditions across countries, or exposures to common, "global" factors matter a lot. ${ }^{14}$ And those global factors, while appearing as independent of each country's actions ("exogenous"), are inevitably influenced by their collective behavior ("endogenous").

This has significant policy implications. Prospects for output strength or weakness, inflation or disinflation, ${ }^{15}$ financial stability or instability cannot be evaluated purely as the bottom-up sum of each country's conditions assessed on a standalone basis; this, by construction, underplays the role of common factors and interlinkages. A more top-down approach is needed. And the risk of fallacies of composition should not be underestimated: actions that may appear reasonable from an individual country's perspective need not result in desirable aggregate outcomes. Analytically, this calls for a shift equivalent to that which has already occurred in regulation and supervision, from a micro- to a macroprudential perspective: individual countries cannot be "safe" unless the global economy is safe and their safety can only be assessed in a global context.

One way of illustrating this point is by reference to inflation. It is quite common for countries to treat commodity price increases as "imported," and hence exogenous, sometimes even formally excluding them from the price index used as a guide for monetary policy (e.g. a measure of "core inflation"). This is reasonable from a partial equilibrium perspective. But the commodity price increase itself may also be the result of the aggregate monetary policy stance for the world, in which all countries participate. And being determined in auction markets, commodity prices are more flexible than prices of goods and services. They are thus more likely to be the first to adjust, acting as a signal of aggregate demand pressures, and hence of limited economic slack for the world economy - a possible harbinger of further inflationary pressures down the road. This is the experience of the early 1970s (OECD 1977) and may also help to read what is happening at the time of writing (early 2011). ${ }^{16}$

As a second illustration, consider the run-up to the recent crisis and its aftermath, which highlights the role of exchange rates in particular (e.g. Borio and Disyatat 2011). Unusually, low policy rates in the core industrial countries in the years preceding the crisis were transmitted to the rest of the world through resistance to exchange rate appreciation, either in the form of foreign exchange intervention or a reluctance to increase policy rates. This either put further downward pressure on long-term rates in industrial economies, via reinvestment of the intervention proceeds, or loosened conditions in those economies that kept policy rates low. The end result was to reinforce and generalize the unusually accommodative global monetary policy stance at a time of record global growth (Figure 12.1). This arguably amplified the global credit and asset price boom, magnifying and extending the damage of the subsequent bust. And post-crisis, the extraordinarily loose 
policy stance in mature economies is again inducing potentially destabilizing cross-currency and capital inflows into booming emerging markets, while the gap between world growth and interest rates has widened again (Figure 12.1). In other words, ceteris paribus, and as a first approximation, exchange rate changes per se simply redistribute global demand; but they can have a first-order effect on it through the monetary (or fiscal) policy response that they induce.

Figure 12.1. Very accommodative global monetary conditions

Inflation and the real policy gap ${ }^{(a)}$ Interest rates and trend growth ${ }^{(c)} \quad$ Credit and money ${ }^{(a)(f)}$

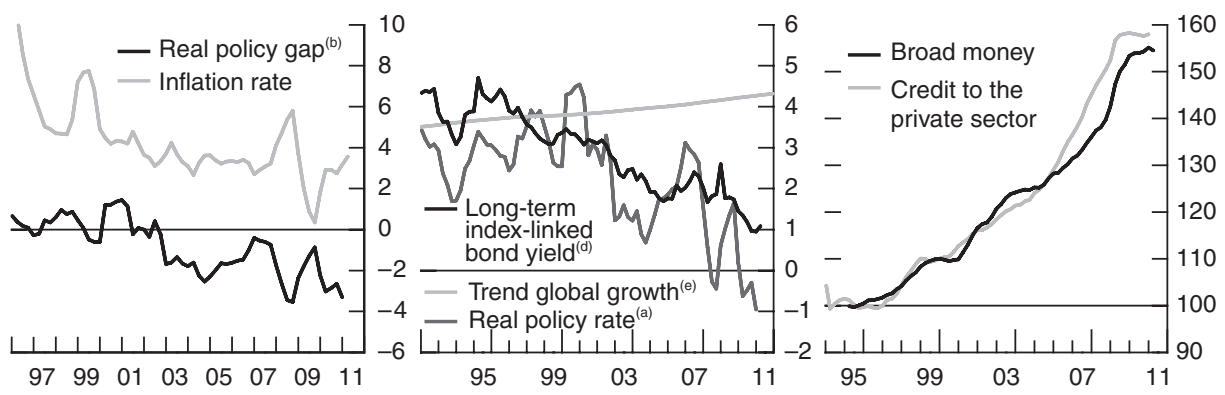

Sources: IMF; OECD; Bloomberg; national data; BIS calculations and estimates.

(a) G20 countries; weighted averages based on 2005 GDP and PPP exchange rates.

(b) Real policy rate minus natural rate. The real rate is the nominal rate adjusted for four-quarter consumer price inflation. The natural rate is defined as the average real rate 1985-2005 (for Japan, 1985-95; for Brazil, China, India, Indonesia, Korea, Mexico, Russia, Saudi Arabia, and South Africa, 2000-2005; for Argentina and Turkey, 2003-2005) plus the four-quarter growth in potential output less its long-term average.

(c) In percent.

(d) From 1998; simple average of Australia, France, the UK, and the USA; otherwise only Australia and the UK.

(e) Trend world real GDP growth as estimated by the IMF in WEO 2009 April.

(f) Relative to nominal GDP; $1995=100$.

\section{A Way Forward? Implications for Central Banking}

The previous analysis helps identify the broad contours of a new compass to guide central banks in the years ahead. At the same time, it leaves open some troubling questions.

\section{Proposed adjustments to policy regimes}

First, edging closer to lasting monetary and financial stability requires adjustments to current policy frameworks to constrain the buildup of financial imbalances even in the context of low and stable inflation. Part of the answer is establishing fully fledged macroprudential frameworks, with central banks playing a leading role. ${ }^{17}$ But beyond this, it is necessary to adopt monetary policy strategies that allow central banks to tighten so as to lean against the buildup of financial imbalances even if near-term inflation remains subdued (e.g. BIS 2010; and Caruana 2010). ${ }^{18}$ Neither of the two policies, on its own, is up to the task. In particular, expectations about what a macroprudential framework can achieve on its own are unrealistically high (Borio 2010). As a result, a "narrow" conception of central banking and monetary policy is not a valid blueprint for the future. 
Second, there is a need to reconsider monetary policy responses to the financial busts that follow the unwinding of imbalances. The prevailing view, which envisages very aggressive and prolonged monetary easing, underestimates the resulting collateral damage in both economic and political economy terms. Monetary policy should pull out all the stops to prevent the implosion of the system as the crisis erupts. But thereafter, as the focus shifts from crisis management to crisis resolution, the priority should be policies to repair balance sheets and facilitate the necessary adjustments in the real economy (e.g. BIS 2009; Borio et al. 2010). Only then can the effectiveness of monetary policy be fully restored. The end result would be a more symmetric evolution of policy rates than that seen over the past decade, during which policy rates have gradually trended to zero: a greater increase during the boom and a smaller reduction during the bust.

Third, the operational independence of central banks should be strengthened. Otherwise, it is not possible to address effectively the consequences of financial cycles. Operational independence is critical for both their monetary and macroprudential policy functions: it protects central banks from the political economy pressures that undermine their ability to take the punchbowl away as the party gets going. To be sure, this also calls for drawing a clear distinction between crisis prevention and crisis management, something which is often overlooked. In crisis management, the role of the government is inevitable; in crisis prevention, the autonomy of those in charge of macroprudential decisions is essential. ${ }^{19}$

Finally, ways need to be found to internalize the externalities associated with monetary policy spillovers across currency areas and with individual central bank contributions to global monetary conditions. A precondition is to recognize fully the importance of these effects - the shift to a more top-down, global, analytical approach discussed above that resembles the one from a micro- to a macroprudential orientation in regulatory and supervisory frameworks. One's house cannot be in order unless the global village is too.

\section{Challenges and open questions}

The challenges ahead are huge. It is one thing to identify the broad outline for the direction of policy; it is quite another to generate the necessary intellectual consensus and to implement the corresponding adjustments. Consider each in turn.

At a minimum, to promote a new intellectual consensus we need better analytical frameworks and better technical tools.

The mainstream analytical frameworks at policymakers' disposal are unable to incorporate the necessary elements systematically. The role of monetary and financial factors is too peripheral in today's macroeconomic models. In particular, the paradigms do not capture the essence of what Wicksell ([1898] 1936) called "pure credit" economies. This is the true essence of current fiat money arrangements, in which the creation of credit, and hence of purchasing power, is only constrained by the central bank's control over short-term rates (Borio and Disyatat 2011). The models are, in effect, "real" models disguised as "monetary" ones. ${ }^{20}$ In addition, the critical 
influence of risk perceptions and attitudes toward risk in fuelling expansions and driving contractions is largely absent. Default, ${ }^{21}$ debt overhangs, and the misallocation of physical capital are not meaningfully included. And the role of global factors is badly underestimated.

Even short of developing better macroeconomic models, there is scope to improve further the technical tools that can help implement policies. Real-time indicators of the buildup of financial imbalances play a critical role. These can guide decisions concerning when to tighten monetary and macroprudential policies in order to constrain unsustainable booms even if inflation remains subdued. In recent years, considerable progress has been made (e.g. Borio and Drehmann 2009; Alessi and Detken 2009). That said, further work would increase policymakers' degree of comfort with the feasibility of these strategies. A deeper empirical understanding of the relationship between the financial and business cycles could usefully complement this line of work. And as the authorities deploy more actively macroprudential tools, such as adjustments to capital buffers, loan-to-value ratios, and margin standards, they will learn more about their efficacy relative to monetary levers (e.g. MAG 2010; BCBS 2010; and CGFS 2010).

But the main challenges ahead are not analytical or technical; they are of a political economy nature.

First, in the years ahead, the independence of central banks is likely to come under growing pressure. The importance of operational independence for macroprudential authorities has so far not been fully appreciated. In addition, in some jurisdictions, the aggressive monetary policy response, seen as consistent with current mandates, may, over time, paradoxically sap that independence. As already noted, balance sheet policies inevitably blur the line between monetary and fiscal policy. A legitimate question is how far such policies could be transferred to government agencies (e.g. Stella 2010). Moreover, persistently ultra-low interest rates could undermine the fiction that interest rate policy, in contrast to balance sheet policy, is neutral and does not have significant distributional effects. ${ }^{22}$ Not least, the very low returns on savings can generate serious intergenerational tensions, as they thwart savers' efforts to accumulate assets for their retirement. And all of this is occurring as public sector debts in many economies threaten to continue rising along an unsustainable path (e.g. Cecchetti et al. 2010; IMF 2010), raising the specter of "fiscal dominance." The problem is not new, but the challenge no less daunting because of that.

Second, the prospects for deeper international policy cooperation are not bright. International policy cooperation has had a checkered history. Countries have profoundly different analytical approaches to the issues at stake, even when the political colors of the day may not be all that dissimilar. And even if the approaches are consistent, the notion of "enlightened self-interest" remains a hard political sell domestically. As history teaches us, only in very special circumstances can cooperation arise. Nor is there any guarantee that it will be rooted in the right analytical view of the world.

If we are to make progress toward a more successful model of central banking, it is critical to be realistic about what central banks can and cannot achieve. No monetary and financial regime in history has proved up to the task of delivering lasting monetary and financial stability-neither the gold standard nor the fiat 
standard that followed. Despite the restless search for reliable anchors in the financial and monetary spheres, the goal has remained elusive (Borio and Crockett 2000). Valiant attempts to put the system on "autopilot," through strict rules that limit the authorities' discretion, have failed. And the exercise of discretion has also not yielded the hoped-for benefits.

At a minimum, therefore, there is a need to manage expectations. During the Great Moderation, central banks sometimes came to be seen as all-powerful by the markets and the public at large. Nor, in all honesty, did they do much to dispel that belief. Now that the crisis has struck, they are facing enormous pressures to prove that they can manage the economy, restore full employment, ensure strong growth, and preserve price stability. This, in fact, is a taller order than many believe, and one that central banks alone cannot deliver. To pretend otherwise risks undermining their credibility and public support in the longer run.

\section{Conclusion}

Back in 1990, Paul Volcker entitled his Per Jacobsson lecture "The Triumph of Central Banking?" He was taking his cue from Arthur Burns's own go at the subject a decade earlier, in which he had reflected on the "anguish" of the central banking community as it struggled unsuccessfully to bring inflation down (Burns 1979). It was extraordinary, Volcker noted, how much the world had changed and the reputation of central bankers had improved. But the question mark in the title was important. He remained, at heart, skeptical about how long-lasting that success would be. In the years that followed, the triumph appeared to become ever more solid and the question mark to dissolve in the Great Moderation. And yet, in many respects, what he called "unfinished business" at the time is still unfinished business today. It has proved to be the Achilles heel of central banks' success: financial stability - which he always mentioned in the same breath as price stability - and exchange rates. The speech was remarkably prescient for those who wanted to hear.

If one had to choose a fitting title for a corresponding lecture today, it would probably be: "The Doubts of Central Banking." The certainties of the Great Moderation have gone. And there is much soul searching, although the temptation to hark back to the deceptive simplicity of the pre-crisis world is strong. Some core propositions command agreement. Alongside price stability, central banks cannot relinquish responsibilities for financial stability and should play a key role in the macroprudential frameworks being put in place. And their operational autonomy in pursuing price stability should be safeguarded. Beyond that, however, disagreement exists concerning how far monetary policy should incorporate financial-stability considerations, both during the buildup of the risks, and following the materialization of financial distress. And there is a danger that the greater involvement in financial stability, their bloated balance sheets, and ballooning public sector debts will threaten central banks' independence. How to meet these challenges in what is bound to be a more hostile environment remains an open question. 
This essay has put forward a compass to help central banks sail in the largely uncharted waters ahead. That compass is based on a tighter integration of the monetary and financial-stability functions, a keener awareness of the global dimensions of the tasks, and stronger safeguards against threats to central bank independence. Above all, there is a need to manage expectations, recognizing the limitations of our ability to manage the economy and of what central banks can achieve. There will always be "unfinished business," and it will be far from marginal.

\section{Postscript $^{23}$}

The previous essay was largely written at the end of 2010; two and a half years later, how has the situation changed? Of course, two and a half years amount to hardly more than a heartbeat in the life of an institution. Even so, it is worth taking stock of the main developments since then.

The conclusion is that, judged against the benchmark of the suggested compass, progress has been limited at best. Several risks bear watching. And at least one of themthat of central banks becoming overburdened - has already materialized.

By way of background, what follows first highlights some stylized facts about the recent economic environment and central bank policy. It then explores the extent to which the proposed compass has been followed. Finally, it turns to an assessment of the possible reasons for this and of the risks ahead.

\section{Some Stylized Facts}

First, the economic environment. At the time of writing, the picture remains at least as challenging as it was at end-2010 (Borio 2013). To be sure, there are signs that, after a natural period of private sector deleveraging, some of the large mature economies that experienced domestic financial booms and busts, and that were at the origin of the crisis are recovering, not least that of the USA. But darker clouds prevail. In particular, globally, the threat from high private and public sector debt looms large (BIS 2013a and Figure 12.2). In some of the countries whose banks were exposed to the crisis largely through cross-border, as opposed to domestic exposures, banks' balance sheet repair is lagging, notably in Europe. At the other end of the spectrum, several emerging market economies and smaller advanced economies, especially commodity exporters, exhibit troubling signs of late financial-cycle risks, following strong domestic financial booms. And concerns with public sector debt are hardly abating. Admittedly, in the euro area, a welcome lull has followed the most acute phase of the sovereign crisis, reflecting to a considerable extent extraordinary central bank short-term measures (see below). But fiscal consolidation has been timid, and in some countries has been put on the back burner. As a result, public sector debt-toGDP ratios have generally continued to increase. Moreover, in those countries that have been experiencing financial booms, underlying fiscal vulnerabilities have been masked. 
Figure 12.2. Total non-financial debt
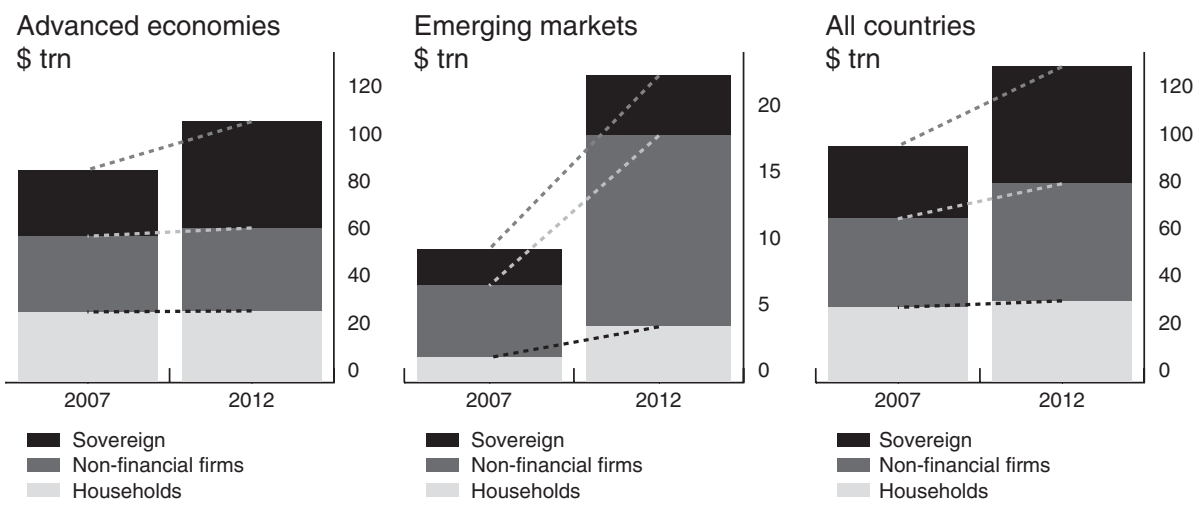

Sources: IMF; OECD; national data; BIS calculations.

Advanced economies: Australia, Canada, the euro area, Japan, the UK, and the USA.

Emerging markets: China, India, Indonesia, Korea, Mexico, and Turkey.

\section{Figure 12.3. Monetary policy eases further}

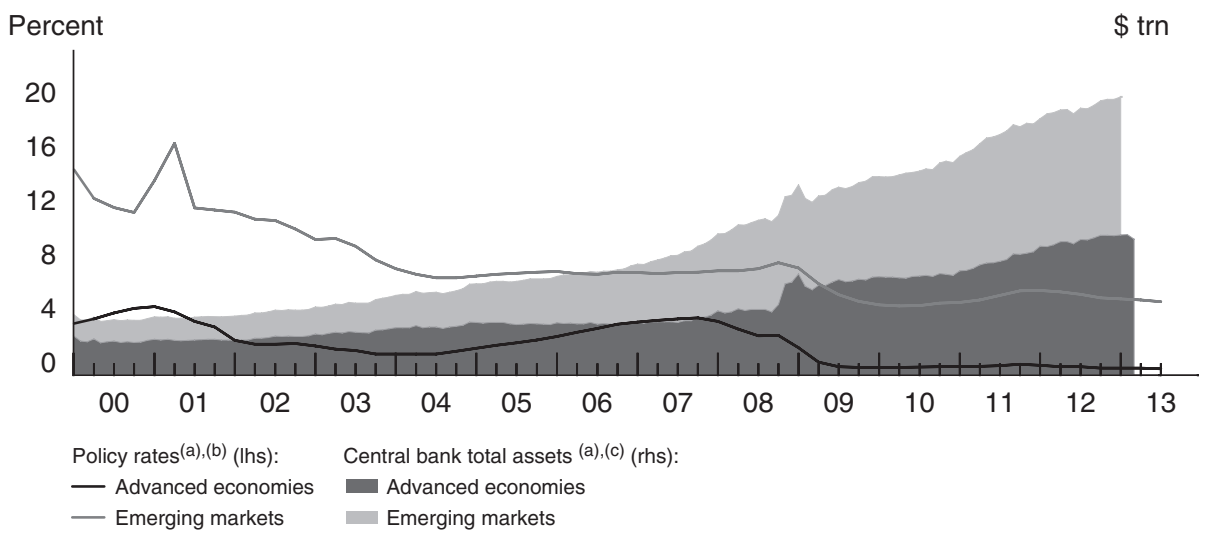

Sources: IMF, International Financial Statistics; Bloomberg; DataStream; Global Financial Data; national data.

(a) Advanced economies: Australia, Canada, Denmark, the euro area, Japan, New Zealand, Norway,

Sweden, Switzerland, the UK, and the USA; emerging markets: Argentina, Brazil, Chile, China, Chinese Taipei, Colombia, the Czech Republic, Hong Kong SAR, Hungary, India, Indonesia, Korea, Malaysia, Mexico, Peru, the Philippines, Poland, Russia, Saudi Arabia, Singapore, South Africa, Thailand, and Turkey.

(b) Weighted average based on 2005 GDP and PPP weights.

(c) Sum across the economies cited.

Next, central bank policy. Central banks in many advanced economies have explored further the limits of monetary policy in an effort to support demand and, in the euro area, to ward off the risk of a breakup (e.g. BIS 2013a and Figure 12.3).

For one, central bank balance sheets have ballooned further. In particular, largescale asset purchases of government debt have continued, notably in the USA and UK. The Eurosystem's daring Outright Monetary Transactions have provided assurance of 
purchases of government debt from countries in difficulties subject to certain conditionsby far the most effective measure in calming euro area markets. The Bank of Japan has announced a bold new program combining large-scale asset purchases and a doubling of the monetary base. And the accumulation of foreign exchange reserves has continued, albeit lately at a slower pace. As a result of all these measures, for instance, central banks are estimated to hold no less than one-third of all US Treasuries outstanding.

In addition, with interest rates at their effective zero lower bound in a number of jurisdictions, central banks have relied even more on forward guidance to drive down yields at longer maturities and to reassure markets. Going beyond vague references to "extended periods" or announcements of exits linked exclusively to the evolution of inflation, at least one central bank so far, the Federal Reserve, has established thresholds related to the behavior of a real variable - unemployment. Discussion of the possibility of shifting to a nominal GDP target (Woodford 2012), especially prominent in the UK, has reflected the same underlying objective: how to provide further accommodation when traditional measures are reaching their limits.

\section{How Far Has the Gompass Provided Guidance?}

What about the extent to which the suggested compass has been followed? This compass proposes three adjustments to pre-crisis policy regimes. First, fully integrate financialstability considerations in monetary policy frameworks, based on a less asymmetric stance over the course of the financial cycle. This means leaning more strongly against financial booms even if near-term inflation remains under control, and easing less aggressively and persistently during busts. Second, strengthen safeguards for central bank independence. Finally, internalize the externalities associated with monetary policy spillovers across currency areas and with individual central bank contributions to global monetary conditions. Progress has been uneven across areas and, on balance, limited. Consider each in turn.

No doubt, the intellectual recognition that monetary policy has a role to play in constraining the buildup of financial imbalances has been gaining further ground. Increasingly, central banks have been making more explicit statements to that effect, ${ }^{24}$ and even acknowledged having shaded policy accordingly (e.g. Ingves 2010). In fact, the possibility of relying on monetary policy is slowly becoming the new consensus.

That said, actual policy decisions have been quite timid in practice. Moreover, the temptation to rely exclusively on macroprudential policies has proved irresistible. This has been so even in countries that are philosophically more favorably disposed toward resorting to changes in interest rates to address financial booms, such as several in Asia (see also below). ${ }^{25}$ As a result, relying on macroprudential measures has been the rule in those countries that have experienced the buildup of financial imbalances post-crisis.

Similarly, in practice, there has been only limited appreciation of the limitations and possible collateral damage of extraordinarily easy monetary policy in addressing financial busts and the concomitant balance sheet recessions (see Bech et al. 2012 for empirical evidence). Admittedly, the limitations have been increasingly debated and highlighted 
(e.g. IMF 2013; Rajan 2013; Volcker 2013; Trichet 2013). Similarly, a growing number of central banks have, to varying degrees, recognized their existence (e.g. Praet 2012; Dale 2013; Weidmann 2013). Moreover, at least one central bank, Norges Bank, has adjusted its framework to explicitly include such costs (Olsen 2013; Norges Bank 2013; Sveriges Riksbank 2013). That said, it is hard to trace in actual policy decisions a significant footprint of these considerations.

All central banks fully recognize the importance of retaining independence so as to preserve long-term economic stability. The issue has received a great deal of attention as central banks have assumed further responsibilities in financial stability, not least in the light of their new macroprudential tasks. At the same time, the governance arrangements in place have not recognized the distinction between crisis prevention and crisis management: the degree of involvement of ministries of finance in this area, which is often substantial, is the same in the two phases. And the inroads central banks have made in balance sheet policies have blurred further the line between monetary and fiscal policies, making them more vulnerable to political economy pressures that could undermine their autonomy.

Not surprisingly, internalizing the externalities associated with monetary policy spillovers has proved beyond reach. Apart from legitimate analytical disagreements, it is here that the clash between national mandates and the collective interest of the global community is starkest. As noted in the essay, the conjunction of extraordinarily easy monetary conditions in advanced economies with resistance to exchange appreciation elsewhere has arguably resulted in an unduly easy global monetary policy stance. ${ }^{26}$ And the situation has not changed over the last couple of years. At the global level, policy rates, even adjusted for inflation, have been trending down for decades, even as the trend growth of the world economy - a common yardstick to gauge their appropriate level-has picked up. Likewise, more refined yardsticks that seek to take into account output and inflation-so-called Taylor rules - indicate that policy rates are globally unusually low (Figure 11.3, from Hofmann and Bogdanova 2012). ${ }^{27}$ And partly as a result of purchases at the long end of the yield curve and foreign exchange intervention, bond yields have declined further. ${ }^{28}$ Focusing on the behavior of inflation, rather than on the buildup of financial imbalances, may again have been providing a false sense of comfort.

\section{Assessment of Outcomes and Risks}

There are several reasons why the compass has, so far, provided only limited guidance to actual policy decisions. Some are of a more analytical nature. There are disagreements about the diagnosis of the ills afflicting the global economy and the efficacy of policy. Moreover, while progress has been made in formally incorporating financial factors into macroeconomic paradigms, it has been necessarily slow. This obviously raises the bar for the comfort level central banks require before they can adjust their policies. Other reasons are of a more political economy nature. One should not underestimate the pressure central banks have come under to fill the void that other policies have created (BIS 2013a; Caruana 2013a, 2013b). 
Figure 12.4. Global Taylor Rule

In percent

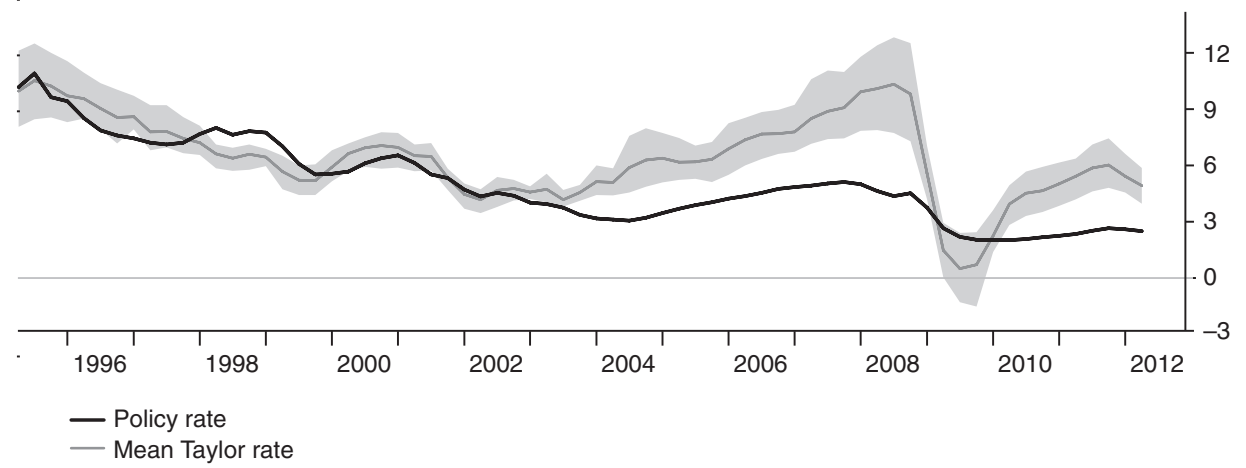

Source: Hoffmann and Bogdanova (2012).

The Taylor rates are calculated as $\mathrm{i}=\mathrm{r}^{*}+\mathrm{p}^{*}+1.5\left(\mathrm{p}-\mathrm{p}^{*}\right)+1.0 \mathrm{y}$, where $\mathrm{p}$ is a measure of inflation, $y$ is a measure of the output gap, $p^{*}$ is the inflation target, and $r^{*}$ is the long-run level of the real interest rate. For an explanation on how this Taylor rule is calculated, see Hoffmann and Bogdanova (2012).

In addition, there is a catch-22 dilemma concerning communication. One of the implications of the suggested compass is that central banks should be more forthcoming in acknowledging the limitations of their policies, especially when confronted with balance sheet recessions. But doing so would open them up to the criticism that they are undercutting those policies' very effectiveness: confidence can be important, at least in the short run. This could undermine the central banks' perceived competence, legitimacy, and ultimately, independence. Not acknowledging the limitations, however, would raise the very same risk in the long run, once their ineffectiveness is inevitably revealed.

Of course, the compass may not be the right one. It is quite legitimate to argue that macroprudential policies, on their own, may be sufficient to address the financial imbalances; that monetary policy is, after all, more effective than suggested here in addressing financial busts without collateral damage; and that the "own house in order" doctrine is still the best guide to policymaking even in a highly integrated global economy. ${ }^{29}$ In this case, and possibly even if some of these propositions do not hold, the evolution of the picture since the essay was written would be reassuring.

But if the compass is a valid one, it is hard to avoid the conclusion that there are tangible risks, some of which may well have already materialized at least to some extent. Let me mention five interrelated ones (Borio 2013). The first three pertain to central banks in general, the last two to their interaction internationally.

The first is the time inconsistency risk highlighted in the essay. Policies that are too timid in leaning against financial booms but that respond aggressively and persistently to financial busts may end up leaving the authorities without any ammunition left over successive financial and business cycles. Importantly, this applies not just to monetary policy, but also to fiscal and prudential policies (Borio 2013, 2014). The fact that central banks keep exploring the outer limits of monetary measures, that fiscal positions are on an unsustainable long-term path in several jurisdictions, and that resistance to the 
implementation of tougher capital and liquidity prudential standards for banks has been fierce are all symptoms consistent with the materialization of this risk.

The second is the risk of overburdening central banks. Indeed, as argued in the most recent BIS Annual Report (BIS 2013a), this risk has already materialized. ${ }^{30}$ If monetary policy is ill-equipped to address balance sheet recessions, it follows that relying heavily on it is not the right response. Extraordinarily easy monetary policy cannot repair balance sheets, cannot ensure the long-term sustainability of public finances, and cannot address the real-economy constraints that hold back robust sustainable growth, not least those associated with the misallocation of resources during the preceding financial booms (Borio 2014; Caruana 2013a; BIS 2013a). As discussed in the essay, monetary policy can gain time; but it cannot address these underlying problems. And, in some respects, it can actually make it easier to waste time because of the incentives it inevitably generates. ${ }^{31}$

The third is the risk of an insidious "expectations gap" becoming entrenched, between what central banks are expected to deliver and what they can deliver (Borio 2013, 2014; Caruana 2013a, 2013b). A vicious circle can develop. As policy fails to produce the desired effects and adjustment is delayed, central banks come under growing pressure to do more. An "expectations gap" yawns open. All this makes the eventual exit more difficult and may ultimately threaten the central bank's credibility. One may wonder whether some of these forces have not been at play in Japan, a country where the central bank has not yet been able to exit and has felt compelled to adopt increasingly bold steps.

The fourth is the risk of financial developments derailing the global economy once again. It is possible that the financial booms that have taken root in several emerging market economies and also some commodity exporting countries could generate unwelcome financial busts. And this could occur before the mature economies most affected by the Great Financial Crisis and its aftershocks are completely out of the woods. Signs of late financial cycle risks are not particularly encouraging (Caruana 2012b, 2013c). All this could cause serious strains in the global economy and put further pressure on exchange rate relationships, which are already quite strained, as indicated by unwelcome references to "currency wars."

But the ultimate risk is that of yet another epoch-defining change in the underlying economic regimes that hold the best promise for long-term prosperity, viz. a global economy that is integrated in real and financial terms, underpinned by monetary regimes that deliver long-lasting price stability (Borio 2013). As historians such as Niall Ferguson (2010) and Harold James (2009) keep reminding us, such disruptive changes often occur quite abruptly and when least expected. So far, institutional setups have proved remarkably resilient to the huge shock of the Great Financial Crisis and its tumultuous aftermath. But there are also troubling signs that globalization may be in retreat, as states struggle to come to grips with the de facto loss of sovereignty. Meanwhile, the consensus on the merits of price stability is fraying at the edges. As memories of the costs of inflation fade, the temptation to get rid of the huge debt burdens through a combination of inflation and financial repression grows. Taking all these hard-won gains for granted is the surest way of losing them. This would be an especially hostile world for the institution of central banking. But it is a possibility that should not be ruled out if monetary, fiscal, and prudential policies fail to adjust sufficiently to address the risks posed by financial booms and busts. 


\section{Conclusion}

Two and a half years after the previous essay was written, central banks are experimenting further in search of a new compass. This search is bound to continue for the foreseeable future. The waters they are navigating are treacherous. And at least one compass - the one put forward in the original essay - is pointing to growing hazards. The stakes are high. Navigating those waters successfully will require great intellectual acumen, wisdom, and, as always, a dose of good luck.

\section{Notes}

1 This paper was released as a BIS Working Paper, no. 353, September 2011. With minor changes, it had already been published in C. Jones and R. Pringle (eds), The Future of Central Banking, London: Central Banking Publications, 2011. It is a slightly revised and updated version of a keynote address given at the SUERF-National Bank of Poland conference, "Monetary Policy after the Crisis," Warsaw, March 4, 2011. I would like to thank Piti Disyatat, Leonardo Gambacorta, Otmar Issing, Robert McCauley, Robert Pringle, Paul Tucker, and Ignazio Visco for helpful comments. The views expressed are my own and do not necessarily reflect those of the Bank for International Settlements.

2 See Borio (2007) for a more complete and nuanced picture.

3 To be sure, the models also allowed for other frictions, such as real wage rigidities (e.g. Blanchard and Gali 2010) and, in some cases, financial ones (e.g. Bernanke et al. 1999). But as a broad justification for policy, these frictions played a secondary role.

4 On the former view, see also, for instance, Bernanke and Gertler (1999) and Blanchard et al. (2010); on the latter, see, for instance, Cecchetti et al. (2000), BIS (2010), and Borio (2010). Borio and Lowe (2004), Borio (2007), and Papademos and Stark (2010), Chapter 6, contain references to the large literature on this topic.

5 On this point, and for a historical perspective on the role of central banks in financial stability, see also Giannini (2011).

6 That said, inflation did not turn out to be a problem and, if forecast-based rules are used, the picture is less clear (Bernanke 2009). Arguably, the apparent deviations from the specific version of the rule reflect more unusual economic circumstances than a break in the central bank's behavior. For an intermediate position, see Catte et al. (2010).

7 For an elaboration on the nature of the risk-taking channel, see Borio and Zhu (2008), Rajan (2005), Adrian and Shin (2010), and Farhi and Tirole (2009); for the empirical evidence, see Gambacorta (2009) for a recent summary.

8 "Permanent" here means that while growth may return to its long-term, pre-crisis trend, output does not return to its pre-crisis trajectory. In other words, the trajectory remains below the original one.

9 Importantly, credit and asset price booms tend to flatter the fiscal accounts. They lead to an overestimation of potential output and potential growth, and temporarily boost the sensitivity of tax revenues to GDP growth. As a result, the authorities can easily mistake cyclical improvements in the fiscal accounts for structural ones. Recall, for instance, that the fiscal accounts of Spain and Ireland looked quite strong during the boom. See Eschenbach and Schuknecht (2004) and BIS (2011a).

10 For example, given the low cost of forbearance, very low interest rates may disguise underlying credit weakness encouraging banks to "extend and pretend" that loans of low-quality borrowers will become good ("evergreening"). See Caballero et al. (2008) for the Japanese experience in the 1990s and Albertazzi and Marchetti (2010) for the Italian case during the latest credit crisis. 
11 This reflects two factors. First, there is the well-known "endowment effect": retail deposit rates tend to be lower (sometimes zero) and stickier than wholesale rates, so that reducing policy rates compresses interest margins. Second, the flattening of the term structure, especially if it reflects a compression of term premia, reduces the net income associated with maturity transformation.

12 For a critique of this view from a broader perspective, see Padoa-Schioppa (2008).

13 That said, apparent "fear of floating" may simply reflect the operation of domestic inflationtargeting regimes in which the exchange rate plays a large role in the inflation process, as documented by Ho and McCauley (2003).

14 This argument holds regardless of whether asymmetries exist because, for some international currencies, notably the US dollar, the direct area of influence goes well beyond national borders. For a more in-depth discussion of these issues, see, for example, Borio and Disyatat (2011).

15 On the growing role of global forces in influencing inflation, see Borio and Filardo (2007). For a contrasting view, see, for example, Ball (2006).

16 Very low interest rates may also have an impact on at least some commodity prices by inducing portfolio shifts, including by encouraging a search for yield.

17 See Tucker (2011) for how the relationship between macroprudential and monetary policy has been addressed in the new institutional structure in the UK, in which the central bank plays a leading role.

18 Operationally, this calls for extending policy horizons beyond the roughly two-year ones typical of inflation-targeting regimes and for giving greater prominence to the balance of risks in the outlook (Borio and Lowe 2002). The reason is that the lag between the buildup of systemic risks and the emergence of financial distress is considerably longer than the lag associated with keeping inflation under control. And as the timing of the unwinding of financial imbalances is highly uncertain, extending the horizon should not be interpreted as extending point forecasts mechanically. Rather, it is a device to help assess the balance of risks faced by the economy, and the costs of policy action and inaction in a more meaningful and structured way.

19 Many central banks already combine monetary policy functions with responsibility for regulation and supervision of individual institutions; as a result, they face risks to their reputation and independence. In principle, responsibility for the system as a whole should involve less reputational risk, as the authorities would be insulated from individual failures caused by idiosyncratic factors. Moreover, relying on well-designed macroprudential overlays, in the form of explicit adjustments to the calibration to prudential instruments, could help to retain some distance (BIS 2009; Borio 2010). For an in-depth discussion of the governance implications of central bank responsibilities for financial stability, see BIS (2011b).

20 See Schumpeter (1954) and Kohn (1986) for useful discussions of the distinction between "monetary" and "real" models.

21 An observer who has been stressing the importance of including default in a meaningful way is Goodhart (2004).

22 It is hard to see how central banks could resist pressures to keep interest rates ultra low and use the balance sheet aggressively unless inflation increases from its current very low levels. And in a world in which the globalization of the real economy and rise of the new emerging market giants has dealt a big blow to the bargaining power of labor, inflation may well remain subdued even if the true underlying resource slack measured in terms of potential output is not large.

23 I would like to thank Boris Hofmann and Andy Filardo for helpful comments and suggestions. The views expressed are my own and not necessarily those of the BIS.

24 See, for instance, Stevens (2012), Carney (2013), King (2013), Stein (2013), Ingves (2013), Olsen (2013), Wheeler (2013), Kim (2013), Bank Negara Malaysia (2012), Menon (2013), and Subbarao (2013).

25 One should qualify the statement substantially if the set of monetary policy tools is extended to cover the active use of reserve requirements, which has been quite common. 
26 Caruana (2012a) elaborates on the underlying mechanisms and final outcomes in detail. On this, see also Taylor (2013).

27 The conclusion would be stronger if one took into account three factors that are not incorporated in the benchmarks shown in the graph: the impact of balance sheet policies; that of forward guidance; and that of financial imbalances on potential output, as financial booms may make output unsustainable even if inflation remains under control (Borio et al. 2013).

28 At the time of writing (October 2013), the sovereign bond yields in the jurisdictions that are home to the main international currencies are off their lows. In June, what markets took as indications that the Federal Reserve would start to "taper off" purchases in the near future produced tremors in global financial markets and a backup in sovereign yields across the board (BIS 2013b). The Fed subsequently clarified that markets had misunderstood the message, providing reassurance that any exit was still distant. As a result, yields partly retraced their movement. The episode was a vivid reminder that exiting policies in all probability will not be a smooth affair (e.g. Caruana 2013b).

29 A natural concern with monetary policy going beyond the "own house in order" doctrine is that this could undermine central banks' independence and make them hostage to unwarranted considerations. This, for instance, was the reason for the Bundesbank's long-standing resistance to G7 international macroeconomic policy coordination attempts. The Bundesbank was concerned, and justifiably so, that they could undermine its ability to preserve price stability. Any mechanisms to internalize spillovers should address these concerns effectively. See, for instance, Eichengreen et al. (2011).

30 Orphanides (2013) reaches the same conclusion, exploring the issues exclusively from the perspective of ensuring price stability.

31 It may not be a coincidence that some of the countries in which fiscal adjustment since the crisis has been smaller are also those in which central banks have been more active in largescale purchases of government bonds; see BIS (2013a).

\section{References}

Adrian, T., and H. Shin. 2010. "Financial Intermediaries and Monetary Economics." In Handbook of Monetary Economics, vol. 3, edited by B. Friedman and M. Woodford, 601-50. Amsterdam: North-Holland.

Ahearne, A., J. Gagnon, J. Haltmaier, S. Kamin et al. 2002. "Preventing Deflation: Lessons from Japan's Experience in the 1990s." International Finance Discussion Papers, no. 729. Board of Governors of the Federal Reserve System.

Albertazzi, U., and D. Marchetti. 2010. "Credit Supply, Flight to Quality and Evergreening: An Analysis of Bank-Firm Relationships in Italy after Lehman." Banca d'Italia, Temi di discussione, no. 746 .

Alessi, L., and C. Detken 2009. "Real Time Early Warning Indicators for Costly Asset Price Boom/ Bust Cycles: A Role for Global Liquidity.” ECB Working Paper no. 1039. Frankfurt: ECB.

Ball, L. 2006. "Has Globalization Changed Inflation?" NBER Working Paper no. 12687, November. Cambridge, MA: NBER.

Bank for International Settlements (BIS). 2009. 79th Annual Report, June. Basel: BIS. 2010. 80th Annual Report, June. Basel: BIS.

2011 a. 81st Annual Report, June. Basel: BIS.

2011b. Central Bank Governance and Financial Stability: A Report by a Study Group ("Ingves Report"), June. Basel: BIS.

2013a. 83rd BIS Annual Report, June. Basel: BIS.

2013b. "Markets Precipitate Tightening." BIS Quarterly Review, September: 1-11.

Bank Negara Malaysia. 2012. Annual Report. Kuala Lumpur: BNM.

Basel Committee on Banking Supervision (BCBS). 2010. An Assessment of the Long-Term Economic Impact of Stronger Capital and Liquidity Requirements, August. Basel: BIS. 
Bean, C. 2009. "The Great Moderation, the Great Panic and the Great Contraction." Annual Congress of the European Economic Association, Barcelona, 25 August.

Bech, M., L. Gambacorta, and E. Kharroubi. 2012. "Monetary Policy in a Downturn: Are Financial Crises Special?” BIS Working Papers, no. 388, September. Basel: BIS.

Bernanke, B. 2009. "Monetary Policy and the Housing Bubble." At the Annual Meeting of the American Economic Association, Atlanta, Georgia, January 3.

Bernanke, B., and M. Gertler. 1999. "Monetary Policy and Asset Price Volatility." In "New Challenges for Monetary Policy." Proceedings of a symposium sponsored by the Federal Reserve Bank of Kansas City, Jackson Hole, WY, August 26-29.

Bernanke, B., M. Gertler, and S. Gilchrist. 1999. "The Financial Accelerator in a Quantitative Business Cycle Framework." In Handbook of Macroeconomics, edited by J. Taylor and M. Woodford, 1341-93. Amsterdam: North-Holland.

Blanchard, O., G. Dell'Ariccia, and P. Mauro. 2010. "Rethinking Monetary Policy.” IMF Position Note, February. Washington, DC: IMF.

Blanchard, O., and J. Gali. 2010. "Labor Markets and Monetary Policy: A New Keynesian Model with Unemployment." American Economic Journal: Macroeconomics, American Economic Association 2 (2): $1-30$.

Bloxham, P., C. Kent, and M. Robson. 2010. "Asset Prices, Credit Growth, Monetary and Other Policies: An Australian Case Study." Research Discussion Papers, no. 2010-6, Reserve Bank of Australia.

Borio, C. 2007. "Monetary and Prudential Policies at a Crossroads? New Challenges in the New Century." Moneda y Crédito 224: 63-101. Also available as BIS Working Papers, no. 216, September 2006.

2010. "Implementing a Macroprudential Framework: Blending Boldness and Realism." Keynote address for the BIS-HKMA research conference on "Financial Stability: Towards a Macroprudential Approach.” Honk Kong SAR, July 5-6, 2010. Online: http://www.bis.org/ repofficepubl/hkimr201007.12c.htm (accessed September 18, 2014).

2013. "On Time, Stocks and Flows: Understanding the Global Macroeconomic Challenges." National Institute Economic Review, August. Slightly revised version of the lecture at the Munich Seminar series, CESifo Group and Sueddeutsche Zeitung, October 15, 2012. Also available in BIS Speeches.

2014. "The Financial Cycle and Macroeconomics: What Have We Learnt?" fournal of Banking \& Finance 45: 182-98.

Borio, C., and A. Crockett. 2000. "In Search of Anchors for Financial and Monetary Stability." Greek Economic Review 20 (2) (Autumn): 1-14.

Borio, C., and P. Disyatat. 2010. "Unconventional Monetary Policies: An Appraisal." The Manchester School 78 (1) (September): 53-89. Also available as BIS Working Papers, no. 292, 2009, November. Basel: BIS.

2011. "Global Imbalances and the Financial Crisis: Link or No Link?" BIS Working Papers, no. 346, May. Basel: BIS. Revised and extended version of "Global Imbalances and the Financial Crisis: Reassessing the Role of International Finance." Asian Economic Policy Review 5: 198-216.

Borio, G., P. Disyatat, and M. Juselius. 2013. "Rethinking Potential Output: Embedding Information about the Financial Cycle.” BIS Working Papers, no. 404, February. Basel: BIS.

Borio, C., and M. Drehmann. 2009. "Assessing the Risk of Banking Crises: Revisited." BIS Quarterly Review, March: 29-46.

Borio, C., and A. Filardo. 2007. "Globalisation and Inflation: New Cross-Country Evidence on the Global Determinants of Domestic Inflation." BIS Working Papers, no. 227, May. Basel: BIS.

Borio, C., and P. Lowe. 2002. "Asset Prices, Financial and Monetary Stability: Exploring the Nexus." BIS Working Papers, no. 114, July. Basel: BIS. 
2004. "Securing Sustainable Price Stability: Should Credit Come Back from the Wilderness?" BIS Working Papers, no. 157, July. Basel: BIS.

Borio, C., B. Vale, and G. von Peter. 2010. "Resolving the Financial Crisis: Are We Heeding the Lessons from the Nordics?" Moneda y Crédito 230: 7-47. Also available as BIS Working Papers, no. 311, July. Basel: BIS.

Borio, C., and W. White. 2003. "Whither Monetary and Financial Stability? the Implications of Evolving Policy Regimes." In "Monetary Policy and Uncertainty: Adapting to a Changing Economy," proceedings of a symposium sponsored by the Federal Reserve Bank of Kansas City, Jackson Hole, WY, August, 28-30, 131-211. Also available as BIS Working Papers, no. 147, February 2004. Basel: BIS.

Borio C., and H. Zhu. 2008. "Capital Regulation, Risk-Taking and Monetary Policy: A Missing Link in the Transmission Mechanism?" BIS Working Papers, no. 268, December. Basel: BIS.

Brunnermeier, M., A. Crockett, C. Goodhart, M. Hellwig, A. Persaud, and H. Shin. 2009. The Fundamental Principles of Financial Regulation. Geneva Reports on the World Economy, no 11. Geneva: ICMB.

Burns, A. 1979. "The Anguish of Central Banking." Per Jacobsson Lecture, Per Jacobsson Foundation, Washington, DC.

Calvo, G., and C. Reinhart. 2002. "Fear of Floating." Quarterly fournal of Economics 107 (2): 379-408. Carney, M. 2013. "Monetary Policy after the Fall." Remarks at Eric J. Hanson Memorial Lecture, Edmonton, May 1, 2013.

Caballero, R., T. Hoshi, and A. Kashyap. 2008. "Zombie Lending and Depressed Restructuring in Japan." American Economic Review 98: 1943-77.

Calvo, G., and C. Reinhart. 2002. "Fear of Floating." Quarterly Journal of Economics 107 (2): 379-408. Caruana, C. 2012a. "International Monetary Policy Interactions: Challenges and Prospects." Speech at the CEMLA-SEACEN conference on "The Role of Central Banks in Macroeconomic and Financial Stability: The Challenges in an Uncertain and Volatile World," Punta del Este, Uruguay, November 16.

2012b. "Assessing Global Liquidity from a Financial Stability Perspective." Speech at the 48th SEACEN Governors' Conference and High-Level Seminar, Ulaanbaatar, November $22-4$.

2013a. "Hitting the Limits of 'Outside the Box' Thinking? Monetary Policy in the Crisis and Beyond." Speech to OMFIF (Golden Series Lecture), London, May 16.

2013b. "The Changing Nature of Bank Independence." Panel remarks at the Banco de

México International Conference "Central Bank Independence: Progress and Challenges," Mexico City, October 14-15.

2013c. "Global Liquidity: Where Do We Stand?" Speech at the Bank of Korea International Conference 2013 on "Assessing Global Liquidity in a Global Framework," Seoul, June 4.

Catte, P., P. Cova, P. Pagano, and I. Visco. 2010. "The Role of Macroeconomic Policies in the Global Crisis." Bank of Italy Occasional Papers, no. 69.

Cecchetti, S., H. Genberg, J. Lipsky, and S. Wadhwani. 2000. Asset Prices and Central Bank Policy. Geneva Reports on the World Economy, no. 2. Geneva: ICMB.

Committee on the Global Financial System (CGFS). 2010. Macroprudential Instruments and Framerworks: A Stocktaking of Issues and Experiences. CGFS Papers, no. 38. Basel: BIS.

Dale, S. 2013. "Limits of Monetary Policy." Speech delivered at the 44th annual Money, Macro and Finance Conference at Trinity College, Dublin, September 2012.

De Kock, M. 1974. Central Banking, 4th edition. New York: St Martin's Press.

Eichengreen, B., M. El-Erian, A. Fraga, T. Ito, J. Pisani-Ferry, E. Prasad, R. Rajan, M. Ramos, C. Reinhart, H. Rey, D. Rodrik, K. Rogoff, H. S. Shin, A. Velasco, B. Weder di Mauro, and Y. Yu. 2011. Rethinking Central Banking. Committee on International Economic Policy and Reform, September. Washington, DC: Brookings Institution. 
Eschenbach, F., and L. Schuknecht. 2004. "Budgetary Risks from Real Estate and Stock Markets." Economic Policy 19 (39): 315-46.

Farhi, E., and J. Tirole. 2009. "Leverage and the Central Banker's Put." American Economic Review 99 (2): 589-93.

Ferguson, N. 2010. "Complexity and Collapse: Empires on the Edge of Chaos." Foreign Affairs, March/April: 18-32.

Gambacorta, L. 2009. "Monetary Policy and the Risk-Taking Channel." BIS Quarterly Review, December: 43-53.

Giannini, C. 2011. The Age of Central Banks. Cheltenham: Edward Elgar.

Goodhart, C. 2004. "Some New Directions for Financial Stability?" The Per Jacobsson Lecture, Per Jacobsson Foundation, Zürich, Switzerland, June 27.

Goodhart, C. 2010 "The Changing Roles of Central Banks." BIS Working Papers, no. 326, November. Basel: BIS.

G20. 2009. "Enhancing Sound Regulation and Strengthening Transparency." G20 Working Group 1, 25 March.

Hannoun, H. 2010. "The Expanding Role of Central Banks Since the Crisis: What Are the Limits?" Speech delivered at the 150th Anniversary of the Central Bank of the Russian Federation, Moscow, June 18, BIS Speeches.

Hofmann, B., and B. Bogdanova. 2012. "Taylor Rules and Monetary Policy: A Global 'Great Deviation'?" BIS Quarterly Review, September: 37-49.

Ho, C., and R. McCauley. 2003. "Living with Flexible Exchange Rates: Issues and Recent Experience in Inflation Targeting Emerging Market Economies." BIS Working Papers, no. 130, February. Basel: BIS.

IMF. 2010. Fiscal Monitor: Navigating the Fiscal Challenges Ahead. Washington, DC: IMF. 2013. Unconventional Monetary Policies: Recent Experience and Prospects, April. Washington, DC: IMF.

Ingves, S. 2010. "Introduction on Monetary Policy." Speech at Riksdag Committee on Finance, Stockholm, November 11.

2013. "Central Bank Policies: The Way Forward after the Crisis." Speech at the Royal Bank of Scotland, Stockholm, October 4.

Issing, O. 2011. "Lessons for Monetary Policy: What Should Be Consensus?" Paper presented at the IMF conference "Macro and Growth Policies: A Post-crisis Conversation," Washington, DC, March 7-8.

James, H. 2009. The End of Globalization: Lessons from the Great Depression. Harvard: Harvard University Press.

Kydland, F., and E. Prescott, 1977. "Rules Rather Than Discretion: the Inconsistency of Optimal Plans." Fournal of Political Economy 85 (3): 473-92.

Kim, C. 2013. "Harmonious Operation of Macroprudential and Monetary Policies, and Challenges." Speech at the International Seminar on "Macroprudential and Monetary Policies," Bank of Korea, Seoul, April 8.

King, M. 2013. "Monetary Policy: Many Targets, Many Instruments; Where Do We Stand?" Remarks at the IMF conference on "Rethinking Macro Policy II: First Steps and Early Lessons," Washington, DC, April 16.

Kohn, M. 1986. "Monetary Analysis, the Equilibrium Method, and Keynes's 'General Theory."' Fournal of Political Economy 94 (6): 1191-1224.

Macroeconomic Assessment Group (MAG). 2010. Interim Report: Assessing the Macroeconomic Impact of the Transition to Stronger Capital and Liquidity Requirements, August. Basel: BIS.

Menon, R. 2013. "Securing Price Stability as Singapore Restructures." Speech at the Asian Bureau of Financial and Economics Research (ABFER) Opening Gala Dinner, Singapore, May 21.

McCauley, R., and K. Ueda. 2009. "Government Debt Management at Low Interest Rates." BIS Quarterly Review, June 2009. 
Norges Bank. 2013. Monetary Policy Report, September. Oslo: Norges Bank.

OECD. 1977. Towards Full Employment and Price Stability: A Report to the OECD by a Group of Experts ("McCracken Report"). Paris: OECD.

Olsen, Ø. 2013. "The Conduct of Monetary Policy." Introductory statement at the hearing before the Standing Committee on Finance and Economic Affairs of the Storting. Norwegian parliament, May 21.

Orphanides, A. 2013. "Is Monetary Policy Overburdened?" Paper prepared for the twelfth BIS Annual Conference on "Navigating the Great Recession: What Role for Monetary Policy?" Lucerne, Switzerland, June 20-21.

Orphanides, A., and V. Wieland. 1998. "Price Stability and Monetary Policy Effectiveness When Nominal Interest Rates Are Bounded at Zero.” Finance and Economics Discussion Series, no. 98-35. Board of Governors of the Federal Reserve System, June.

Padoa-Schioppa, T. 2008. "Interdependence and Cooperation: An Endangered Pair?" In Past and Future of Central Bank Cooperation, edited by C. Borio, G. Toniolo and P. Clement, 4-7. Cambridge: Cambridge University Press.

Papademos, L., and J Stark. 2010. Economic Monetary Analysis. Frankfurt: European Central Bank.

Praet, P. 2012. "Deleveraging and the Role of Central Banks." Speech at the conference: "The Effect of Tighter Regulatory Requirements on Bank Profitability and Risk-Taking Incentives," Milan, October 26.

Rajan, R. 2005. "Financial Markets, Financial Fragility, and Central Banking." Paper presented at "The Greenspan Era: Lessons for the Future": symposium sponsored by the Federal Reserve Bank of Kansas City, Jackson Hole, WY, August 25-27.

2013. "A Step in the Dark: Unconventional Monetary Policy after the Crisis." Andrew Crockett Memorial Lecture, BIS, Basel, June 23.

Reinhart, G., and V. Reinhart. 2010. "After the Fall.” NBER Working Paper no. 16334, September. Cambridge, MA: NBER.

Reinhart, C., and K. Rogoff. 2009. This Time Is Different: Eight Centuries of Financial Folly. Princeton, NJ: Princeton University Press.

Rose, A. 2007. "A Stable International Monetary System Emerges: Inflation Targeting Is Bretton Woods, Reversed." Fournal of International Money and Finance 26 (5): 663-81.

Schumpeter, J. 1954. History of Economic Analysis. London: Allen and Unwin.

Shirakawa, M. 2010. "Revisiting the Philosophy behind Central Bank Policy." Speech delivered at the Economic Club of New York, April 22.

Stein, J. 2013. "Overheating in Credit Markets: Origins, Measurement, and Policy Responses." Remarks at a research symposium sponsored by the Federal Reserve Bank of St Louis, February 7.

Stella, P. 2010. "Minimising Monetary Policy.” BIS Working Papers, no. 330, November. Basel: BIS.

Stevens, G. 2012. "Challenges for Central Banking." Address to the Bank of Thailand 70th Anniversary and 3rd Policy Forum, Bangkok, December 12.

Subbarao, D. 2013. "Five Years of Leading the Reserve Bank: Looking Ahead by Looking Back." Speech at Tenth Nani A. Palkhivala Memorial Lecture, RBI Mumbai, August 29.

Svensson, L. 2003. "Escaping from a Liquidity Trap and Deflation: The Foolproof Way and Others." Fournal of Economic Perspectives 17 (4): 145-66.

Sveriges Riksbank. 2013. "Financial Imbalances in the Monetary Policy Assessment." Monetary Policy Report, July, 42-48. Stockholm: Sveriges Riksbank.

Taylor, J. 2008. Getting Off Track: How Government Actions and Interventions Caused, Prolonged, and Worsened the Financial Crisis. Stanford: Hoover Institution Press.

2013. "International Monetary Policy Coordination: Past, Present and Future." Paper prepared for the twelfth BIS Annual Conference on "Navigating the Great Recession: What Role for Monetary Policy?” Lucerne, Switzerland, June 20-21. 
Trichet, J.-C. 2009. "Credible Alertness Revisited." Remarks at the Federal Reserve Bank of Kansas City symposium on Financial Stability and Macroeconomic Policy, Jackson Hole, WY. 2013. "Central Banking in the Crisis: Concept, Convergence and Open Questions on Unconventional Monetary Policy." Per Jacobsson Foundation lecture, Washington, DC, October 12.

Tucker, P. 2011. "Macroprudential Policy: Building Financial Stability Institutions." Speech at the 20th Annual Hyman Minsky conference, "Financial Reform and the Real Economy," New York, April 13-15.

Volcker, P. 2013. "The Fed and Big Banking at the Crossroads." New York Review of Books, August 15. Walsh, C. 2010. Monetary Theory and Policy, 3nd edition. Cambridge, MA: MIT Press.

Weidmann, J. 2013. "The Euro: Political Project and Prosperity Promise." Introductory statement at the Rencontres Économiques d'Aix-en-Provence, Aix-en-Provence, July 7.

Wheeler, G. 2013. "Forces Affecting the New Zealand Economy and Policy Challenges around the Exchange Rate and the Housing Market." Speech delivered to the Institute of Directors, Auckland, May 30.

Wicksell, K. [1898] 1936. Interest and Prices: A Study of the Causes Regulating the Value of Money. London: Macmillan. (Originally published as: Geldzins und Güterpreise: Eine Untersuchung über die den Tauschwert des Geldes bestimmenden Ursachen. Jena: Gustav Fischer.).

Woodford, M. 2003. Interest and Prices: Foundations of a Theory of Monetary Policy. Princeton, NJ: Princeton University Press.

2012. "Methods of Policy Accommodation at the Interest-Rate Lower Bound." Presented at the Jackson Hole economic policy symposium, "The 'Big C': Identifying and Mitigating Contagion," Federal Reserve Bank of Kansas City, August 31-September 1. 


\section{Chapter 13}

\section{RECONCEPTUALIZING CENTRAL BANK \\ UNCONVENTIONAL POLICIES: LONG \\ POSITIONS ON NO-GROWTH \\ CAPITALISM}

\section{Ismail Ertürk}

\section{Convergence to Gentral Bank Unconventional Policies in Core Capitalist Gountries after the 2007 Crisis}

Central banks in core capitalist countries have acquired unprecedented economic significance and monetary policy powers following the 2007 crisis. Their traditional lender-of-last-resort role after the collapse of Lehman Brothers in 2008 was not temporary, but instead has turned into an almost long-term blank check underwriting the post-crisis recovery in the USA, the Eurozone, and the UK. In 2012, the Bank of Japan joined to its counterparts in the USA and Europe in monetary policy extremism when the newly elected prime minister, Shinzō Abe, announced his radical economic recovery package, now popularly known as Abenomics, to inflate the Japanese economy - through massive quantitative easing programs by the central bank - out of its deflationary state. Consequently, since the 2007 financial crisis, all central banks in major advanced economies have converged into a policy consensus that has turned them into public institutions holding significant amounts of sovereign risk on their balance sheets through large-scale asset purchase programmes in both liberal market economies (LMEs) and coordinated market economies (CMEs). Both types of capitalism that were distinguished in the varieties of capitalism literature (Hall and Soskice 2001) by their institutional characteristics in growth dynamics are unable to generate desired economic growth, and have been constrained in fiscal policy choices due to high budget deficits since 2007. The BIS economist Claudio Borio (2011) sees this policy experimentation in all high-income countries as central banks trying to navigate in "uncharted waters" with theoretically suspect macroeconomic models. Such central bank activism is well beyond the imaginations of the free-marketer Alan Greenspan, who introduced the term "mopping up" in the context of recurring asset bubbles since the early 1990s, or the Keynesian Hyman Minsky, who assigned to central banks the role of restoring stability in capitalism after inevitable endogenous cycles of Ponzi schemes (Greenspan 1999; Minsky 1986). According to Steve Keen, "Bernanke's dilemma is that he is living in a Minskian world 
while perceiving it through Friedmanite eyes" (Keen 2009, 8). Keen's observation can be easily generalized to include all other central bank governors in post-crisis advanced capitalist countries. Institutional economist Zeev Rosenhek (2013) underlines this ideological dilemma of central bankers by analyzing the sense-making practices of the Federal Reserve Bank in the USA and the European Central Bank (ECB) in their responses to the financial crisis. According to Rosenhek (2013, 270): "These sensemaking frames did not represent an overall rupture from the premises of the neoliberal mode of governance; yet, by qualifying them and calling for their reconsideration, they undermined to some extent their hitherto hegemonic status among dominant actors in the global political economy."

Therefore, the urgency to keep the financial system from collapsing by using improvised monetary policy tools increasingly complicates the reference points in economic theory by which central banks are traditionally justified and analyzed. Such interpretative and evaluative difficulties that central banks create for the observers is not limited to academics. Fellow central bankers and market participants frequently also voice their critical views about the effectiveness and consequences of the unconventional central bank policies. Masaaki Shirakawa, the pre-Abenomics ex-governor of the Bank of Japan, warned against the unrealistic expectations from central bank quantitative easing policies: "To raise potential economic growth isn't the job of the central bank - it is the job of the government. But there isn't much of an effort from either the government or the private sector to come up with a precise new template for growth" (Sender 2012). Another central banker, the president of Bundesbank, Jens Weidman, commented that emergency measures of central banks may become "a convenient analgesic for prolonging an unsustainable status quo" (Weidman 2012). Unofficial commentators on central bank activism can be harsher in their criticism of unconventional central bank policies. A seasoned hedge fund manager, Stanley Druckenmiller, when interviewed by the Financial Times, said that "Mr Bernanke is running the most inappropriate monetary policies in the history of the free world" (McCrum and Harding 2013). Against this background of diverse skepticism about central banks' unconventional policies, I will now describe and discuss how they have evolved in the USA, the UK, and the EU since the 2007 crisis.

\section{The Rise of Unconventional Gentral Bank Policies}

Central banks in the USA, the UK, and the EU responded to the banking crisis that started in the summer of 2007 by providing liquidity to the banking system under their traditional lender-of-last-resort role. Such liquidity support operations involved extending the scope of existing facilities by longer-term lending, and by accepting higherrisk and non-tradable bank assets as collateral against such lending. Paul Fisher, one of the executive directors at the Bank of England who is in charge of the balance sheet consequences of the Bank of England's policies, called these liquidity support operations a "game changer" in central banking (Fisher 2010). The ECB also acknowledged the "game changer" nature of its support for the financial system: "Since the intensification of the financial crisis in September 2008 and of the sovereign debt crisis in August 2011, and against the background of rapidly receding inflationary pressures, the ECB 
has introduced a number of measures that are unprecedented in nature, scope and magnitude" (ECB 2013).

In the immediate aftermath of Lehman's collapse, the creditworthiness of counterparties in the interbank market was difficult to assess, and banks consequently stopped lending to each other, causing systemic disturbances in financial markets. In order to restore financial stability, the Fed started buying commercial paper and asset-backed commercial paper in the USA, Bank of England commercial paper and corporate bonds in the UK, and ECB covered bonds in the Eurozone. As the financial crisis deepened and unfolded in unexpected ways in different countries, central banks expanded their purchases of financial assets in kind and size. In the USA, the Federal Open Market Committee (FOMC) started buying government-sponsored enterprises' (Freddie Mac and Fannie Mae) debt, mortgage-backed securities, and longer-term Treasury securities (see Figure 13.1). In 2008, in one month between mid-September and mid-October, the Fed increased its liquidity and credit facilities to the US financial institutions by a multiple of almost twenty from US\$23.5 billion to US\$441.4 billion. The sudden jump in the Fed's total assets around September 2008 was due to the swap facilities through which it had provided US dollars to other central banks during the height of the liquidity crunch in global interbank markets. Through such facilities, the Fed first provided US $\$ 14$ billion in December 2007 and then the facility became permanent, reaching a peak of US\$583 billion in December 2008 soon after the collapse of Lehman. Starting from January 2009, the Fed started to buy mortgage-backed securities to stabilize the mortgage markets and keep the borrowing costs low. The Fed's holding of mortgage-backed securities reached the dizzying heights of US $\$ 1.1$ trillion by May 2010 from a negligible size of US $\$ 5.6$ billion in January 2009. From November 2010 onward, the Fed's quantitative

Figure 13.1. Federal Reserve balance sheet $(\$ \mathrm{mn})$

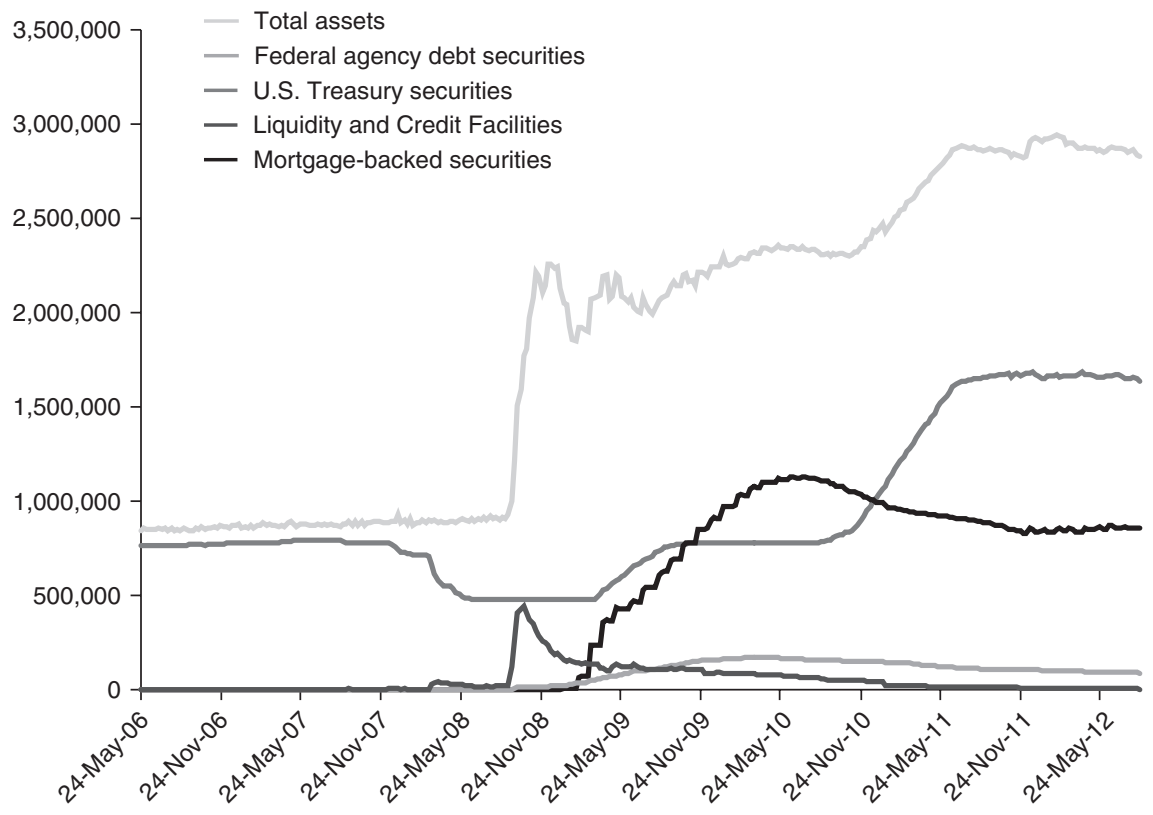


easing policy shifted from the purchase of mortgage-backed securities to the purchase of government securities, almost doubling from US $\$ 776.5$ billion in November 2010 to US\$1.6 trillion in August 2013.

The Bank of England started quantitative easing, purchasing government debt by issuing central bank money in March 2009. The ECB, on the other hand, was not mandated to buy government debt in large quantities directly. Therefore, in October 2008, it started providing unlimited liquidity to the Eurozone banks through its "enhanced credit support" program. Under this program, the ECB provided fixed-rate loans to banks for periods from one week to one year. In May 2010, the ECB started buying, in limited quantities, government bonds under its Securities Markets Programme. As the euro crisis worsened in the fall of 2011, with the downgrading of credit ratings of French banks and the French government when the yields on Italian and Spanish sovereign bonds reached 7 percent p.a., the ECB began its long-term refinancing operation (LTRO) by providing collateralized loans of up to three years totaling about $€ 1$ trillion to some eight hundred Eurozone banks, UK banks, and industrial companies. The major objective of the LTRO was to save the euro by reducing yields on especially Italian and Spanish government bonds that reached 7 percent p.a. The banks in the Eurozone periphery were also expected to use such cheap funds from the ECB to lend to private companies and households to help economic recovery.

Consequently, between 2008 and 2012, over a four-year period, the balance sheets of the central banks of core capitalist countries expanded significantly through purchases

Figure 13.2. Central bank balance sheets as a percentage of GDP

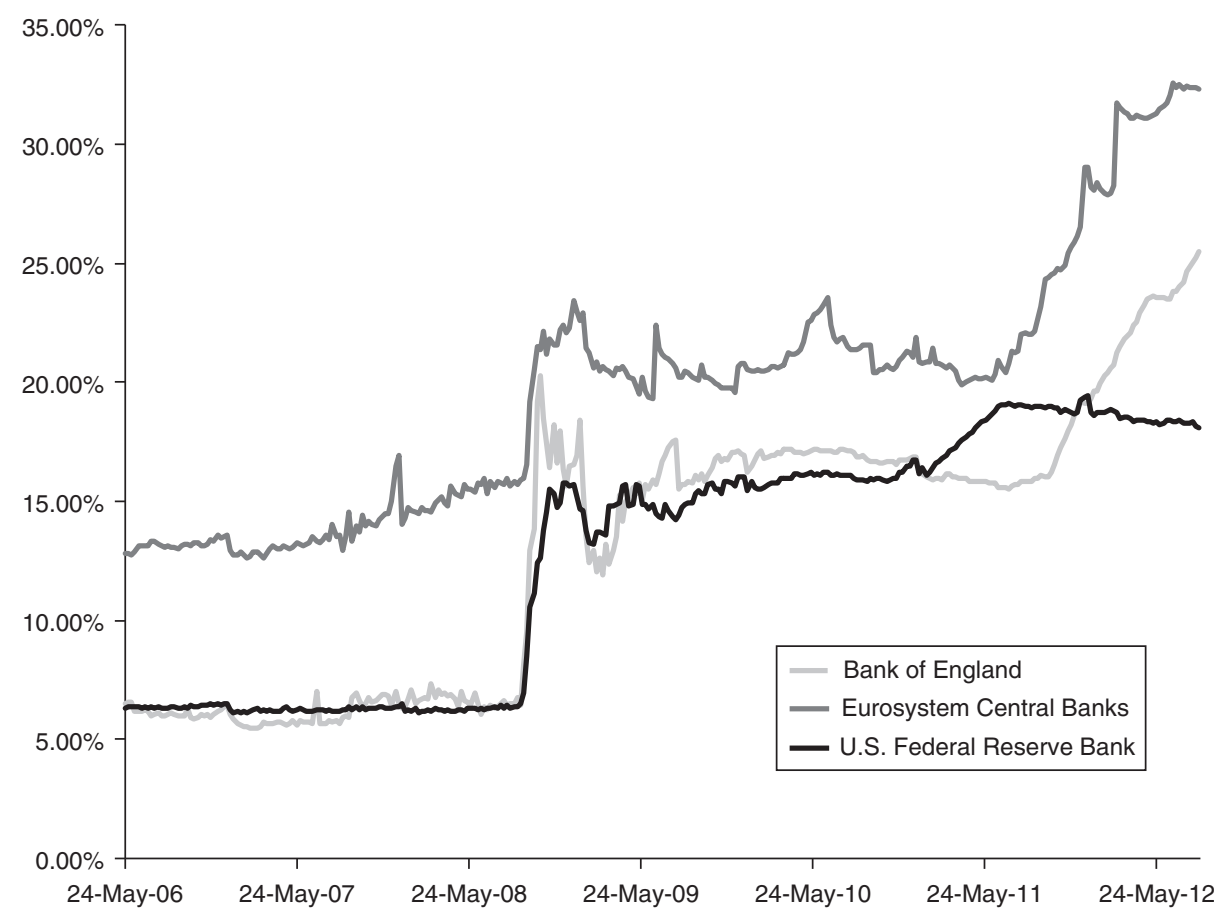


of public and private credit risk through (i) quantitative easing programs - buying public debt through the creation of central bank money; (ii) collateral swaps - swapping lowerquality securities of banks with higher-quality government bonds; and (iii) loans to banks against eligible collateral, which can be anything from government bonds, to residential mortgage-backed assets, to loans to SMEs. The balance sheets of the Federal Reserve and the Bank of England increased between July 2007 and August 2012 from about 6 percent of GDP, to about 18 percent and 25 percent of GDP, respectively. Over the same period, the balance sheet of the European System of Central Banks (ESCB; all central banks in the Eurozone plus the ECB) increased from about 12.5 percent of GDP to about 32 percent of GDP (see Figure 13.2).

\section{Central Banks' Long Position on a Low-Growth Gapitalism}

The unconventional policies of central banks in core capitalist countries that involved largescale asset purchases since the 2007 crisis ultimately aimed to stimulate economic growth by keeping credit markets functioning and interest rates low. The macroeconomic models of the transmission mechanism that link asset purchases by central banks to economic growth assume that multiple economic variables - confidence of economic agents, portfolio rebalancing by investors to achieve desired risk and return outcomes, etc. (see e.g. Joyce et al. 2011) - will collectively respond positively to the monetary easing. However, comprehensive evidence supporting such transition mechanisms does not exist. Although mainstream academics tend to agree that quantitative easing reduced yields on government bonds (Li and Wei 2012) and may have lowered the unemployment rate in the USA (Chung et al. 2011), there remains a significant amount of skepticism about both the measurement of and evidence on the effectiveness of transmission mechanisms. At a conference that the Bank of England organized to evaluate the effectiveness of unconventional monetary policies and quantitative easing, the conclusions drew attention to uncertainties in outcome and shortcomings of the theoretical models. Unconventional central bank policies pose, even for the central banking community itself, more questions than answers:

The use of unconventional monetary policy may have a number of unintended consequences. These include, for example, financial market distortions, exit problems, and the potential loss of central bank independence and credibility [...]. Many participants discussed the links between asset purchases and fiscal policy, but there has been little theoretical work to date that looks at the interactions between the fiscal and monetary authorities in periods where the latter is making asset purchases. (Joyce 2012, 54)

The Bank for International Settlements (BIS) economist Claudio Borio also questioned the theoretical rigor and practical relevance of the macroeconomic models behind unconventional central bank policies:

The mainstream analytical frameworks at policymakers' disposal are unable to incorporate the necessary elements systematically. [...] The models are, in effect, 
"real" models disguised as "monetary" ones. In addition, the critical influence of risk perceptions and attitudes toward risk in fuelling expansions and driving contractions is largely absent. Default, debt overhangs and the misallocation of physical capital are not meaningfully included. And the role of global factors is badly underestimated. (Borio 2011, 10)

The IMF, in its 2012 Financial Stability Report, raised its own concerns about the unintended consequences of unconventional policies that the macroeconomic models could not predict:

The sizable presence of central banks in the long-term government securities markets may limit the room for further policy manoeuvre, and may constrain central bank flexibility in smoothly unwinding current monetary policies. This can lead to a loss of asset safety in real terms and to higher currency risks. Large-scale asset purchases can also have an adverse effect on the political incentives to improve fiscal discipline because the back stop of central bank purchases keeps interest rates and thus funding costs low. (IMF 2012, 21-2)

The theoretical transition mechanism assumes that low yields in bonds will cause a portfolio adjustment, and that investors will shift to riskier asset classes and especially to stocks. Higher stock prices and low borrowing costs will then cause private investment

Figure 13.3. The US and the UK stock market indices and real GDP (August $2007=100$ )

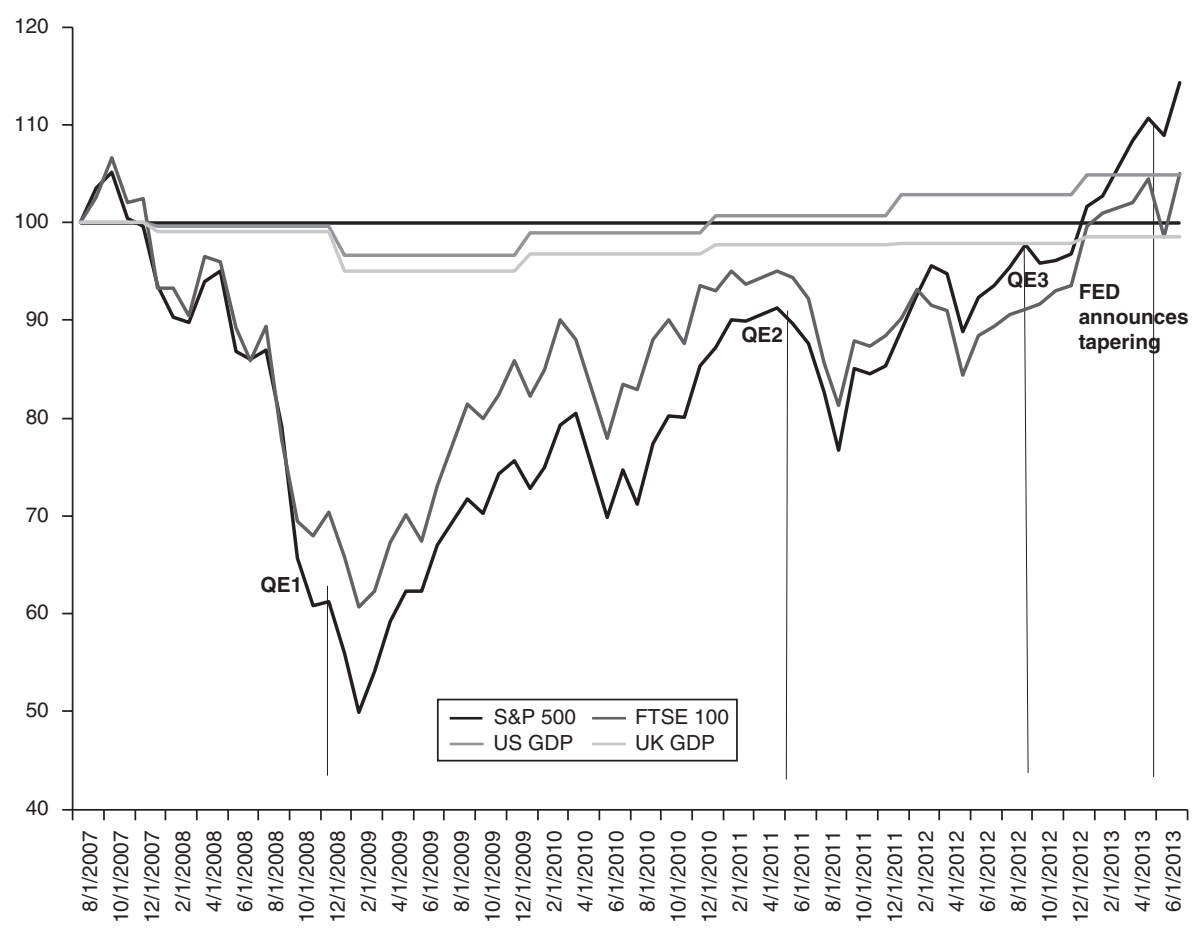


Figure 13.4. The US and the UK stock market indices and private investments as a percentage of GDP (August $2007=100$ )

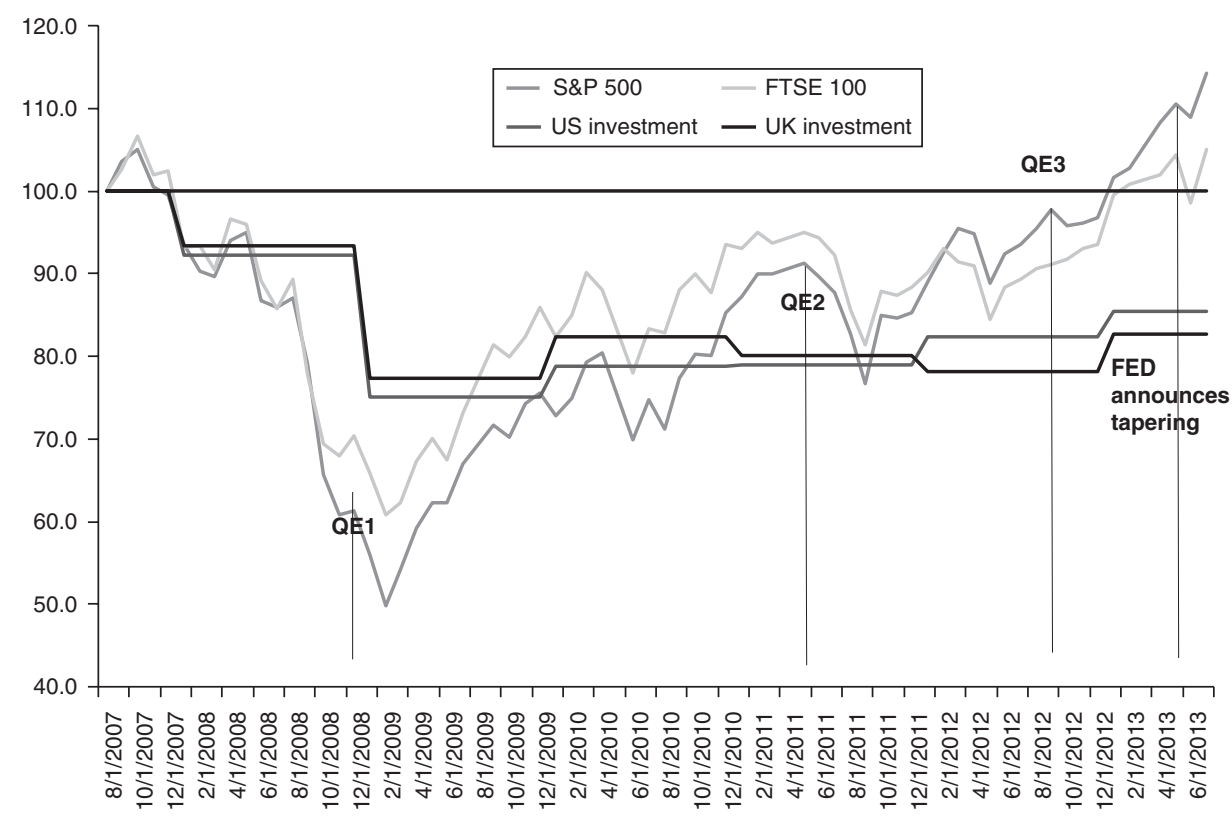

and economic growth. Figure 13.3 shows that quantitative easing in the USA and the UK succeeded in raising the asset prices in the stock market but failed to have a similar effect on GDP. Both in the USA and the UK stock market indices recovered to their pre-crisis levels, but the GDP in the UK is still below its pre-crisis level, and in the USA just over it. However, the US GDP seems to be driven primarily by residential real estate due to very low borrowing costs that may not be sustainable. Richard Fisher, president of the Federal Reserve Bank of Dallas, confirmed the weakness of recent growth in the US economy:

Currently, much of the monetary base has piled up in the form of excess reserves of banks who have not found willing or able borrowers. Other forms of surplus cash are lying fallow on the balance sheets of businesses or being deployed in buying back shares and increasing dividend payouts so as to buttress company stock prices. (Fisher 2013, 7)

As Figure 13.4 shows, private investment in both the USA and the UK, as a percentage of GDP, is still well below the pre-crisis level.

\section{Large-Scale Asset Purchases as a Long Position on Low-Growth Gapitalism}

As a consequence of unconventional policies, also known as balance sheet policies, central banks hold a substantial amount of fixed-income securities on their balance sheets. 
For example, the Bank of England's balance sheet consists almost entirely of UK government debt in the form of gilts. As of March 8, 2012, f291,270 million of the $£ 291,670$ million of total asset purchases under the Asset Purchase Facility were gilts, and the rest, $\mathcal{E}_{400}$ million, were corporate bonds (BoE 2012, 8). Since March 2009, under the Asset Purchase Programme, the Bank of England has become the major purchaser of new government bond issues in the UK while the shares of pension funds, insurance companies, and other financial institutions declined. Long-term and low-yielding gilts are not attractive investments for asset managers in the private sector, but the Bank of England increases its long position on a government with a deteriorating budget and current account deficits. The Federal Reserve, too, has accumulated a long position on the US government by holding long-term, low-yielding government bonds. At the end of January 2012, about 40 percent of the Bank of England's' holdings of gilts and about 30 percent of the Federal Reserve's holdings of government bonds were long term (IMF 2012, 23). According to the IMF, such long positions of the Bank of England and the Federal Reserve on their governments pose serious risks for fiscal discipline: "Large-scale asset purchases can also have an adverse effect on the political incentives to improve fiscal discipline because the back stop of central bank purchases keeps interest rates and thus funding costs low" (IMF 2012, 22). Therefore, not only do central banks in core capitalist economies hold securities of sovereigns with low GDP growth and deteriorating credit ratings, they also potentially increase moral hazard for sovereigns that issue low-yielding and long-maturity debt. The chief economist of Citigroup, Willem Buiter, called the Federal Reserve "the biggest moral hazard machine ever seen in human history" (Financial Times, July 17, 2009).

The unconventional policies of central banks also expose them to the credit risk of banks. For example, the Bank of England uses the government securities on its balance sheet to provide high-quality collaterals to the financial institutions that face funding problems in interbank markets. The Special Liquidity Scheme of the Bank of England, which lasted from April 2008 to January 30, 2012, allowed the UK banks and building societies to swap their unmarketable mortgage-backed and other private sector securities for UK Treasury bills for up to three years. The Bank of England replaced the special liquidity scheme with the operational standing facility and discount window facility. In addition, the Bank of England introduced indexed longterm repo operations in June 2010 to provide central bank reserves against collateral. The collateral involved in such mechanisms with risky financial institutions can be sovereign bonds or private sector securities. As the Eurozone crisis worsened, the Bank of England signaled its willingness to increase its support for the UK financial sector by introducing the extended collateral term repo facility (ECTRF) in December 2011 and by launching its $£ 80$ billion "funding for lending” program in July 2012 to provide cheap, long-term funding of between $\mathcal{E}^{80}$ and $\mathcal{E} 160$ billion to the UK banks. Under the ECTRF, the Bank of England can provide liquidity in extreme shock conditions in the form of central bank reserves against a broader range of risky collateral. With its "funding for lending" scheme, the Bank of England provides cheap, long-term funds to the UK banks if they use these funds to provide credit to the private sector and households. Since 2007, the long position of the Bank of England on the UK 
economy has not only become bigger in size, but has also become riskier, as it commits itself to providing liquidity to the financial institutions with liquidity problems. The Bank of England has developed risk-management practices for the collateral it accepts from the banks, and uses various methods to construct eligibility criteria for collateral, valuations of collateral, and haircuts for collateral. Since in most cases there is no market-produced information on these three variables, the Bank of England uses its own pricing models to value the collateral (John, Roberts, and Weeken 2012, 59). The Federal Reserve and the ECB, too, use their own models to value the collateral that they accept against loans they make to the risky, and, in many cases, undercapitalized banks. Given that the capitalist financial system came to the brink of total collapse because the intellectual capital of the financial elite failed miserably in pricing risk, the presumption that central banks have superior skills in risk pricing in an unaccountable way when holding securities worth about 25 percent of GDP is hubristic to say the least. The tools and algorithms of central banks in acquiring sovereign debt and private bank risks are not properly understood or discussed, causing concerns about their consequences. For example, the IMF economist Singh, in a co-authored paper, raised the following concerns:

Swaps of "good" for "bad" collateral may become part of the standard toolkit. If so, the fiscal aspects and risks associated with such policies — which are virtually nil in conventional QE swaps of central bank money for treasuries - are important and cannot be ignored. Furthermore, the issue of institutional accountability and authority to engage in such operations touches at the heart of central bank independence in a democratic society. (Singh and Stella 2012, 16)

Figure 13.5. Long-term refinancing operation of the European Central Bank

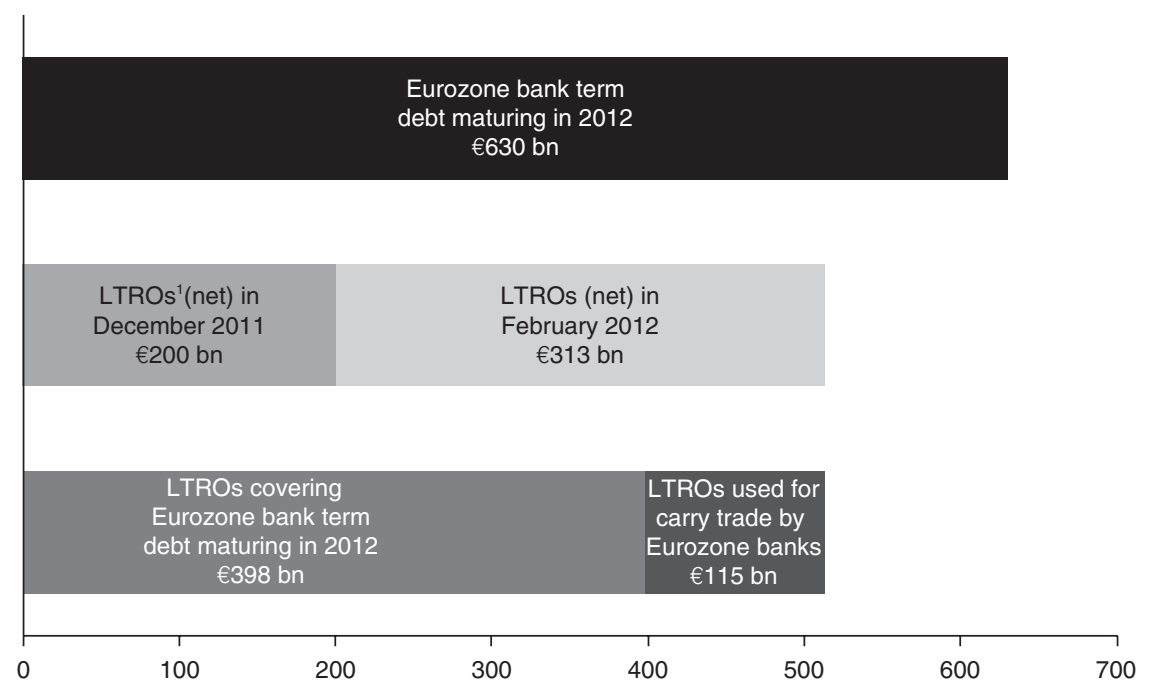

Source: IMF (2012, 77). 
The EGB's long position on the Eurozone economy also increasingly consists of poorquality assets. The share of non-marketable assets in the ECB's total holdings has become the largest component, reaching 23 percent in 2011 (ECB 2012, 85). And the $€ 1$ trillion LTRO of the ECB in 2012 basically provided funding for the Eurozone banks that would be unable to renew maturing debt in credit markets in 2012. As Figure 13.5 shows, the ECB's LTRO covered 63 percent of the 2012 maturing term debt of the Eurozone banks. According to the IMF: "The three-year ECB loans progressively came to be viewed as a crucial measure to curb the tail risk of disastrous bank failures" $(2012,21)$.

\section{Conclusion}

What the central bankers and the mainstream commentators from the media and academia problematize as unconventional monetary policy, which is beyond conventional lender-of-last-resort bank-rescue activities and open-market operations, and has resulted in bloated central bank balance sheets with unpredictable future and present macroeconomic risks, this paper, alternatively, conceptualizes as the "central bank long position on no-growth capitalism." This paper argued that this is a mediumto long-term capitalist growth problematic that defines the nature of post-2007 conjuncture where central banks have morphed into super-economic institutions both in imagination and practice in all varieties of capitalism. Such conceptualization of central bank unconventional policies in present-day capitalism also theoretically differs from a Minskian view of central banks in an endogenously unstable capitalism. The reconceptualization of central banks in this paper is different from a Minskian view for two reasons: (i) The current post-bubble debris on bank balance sheets is different to non-performing loans to private companies in a Minskian expansionary period. The current debris of financial assets that the central banks are trying to mop up consists of the subprime lending-related securities created by a banking system that originated and distributed home loans, and fed itself from the income streams and valuations in a vortex of financial innovation, such as with collateralized debt obligations (see Engelen et al. 2011). (ii) Unlike an unproblematic exit of central banks from a Minskian post-bubble balance sheet cleansing, our current central bank technocrats lack both theoretical and technical exit strategies from the unconventional monetary policies. What we are experiencing is a temporal capitalist space that is being dangerously formed by forces beyond the theoretical and policy imagination of both Minskians and neoliberals, who unconvincingly advocate central bank independence as a politically neutral, universal economic efficiency. Uncannily, this central bank-led capitalist conjuncture is legitimized by an unusual intellectual coalition of New Keynesians and neoliberals. For example, only recently, both Keynesian Paul Krugman and neoliberal Financial Times writer Sebastian Mallaby agreed on the urgency of much bigger quantitative easing as the remedy for avoiding a prolonged capitalist depression of 1930s magnitude (Wolf 2012; Mallaby 2012). Krugman proposes adding another US\$2 trillion on the Federal Reserve's balance sheet by purchasing a wider range of assets including more private sector liabilities. Mallaby does not put a number on a further and bigger quantitative 
easing by the Fed, but he is equally bullish about increasing both the size and riskiness of its long position by urging a "quantitative easing of game-changing magnitude" (Mallaby 2012). Mallaby basically supports an earlier policy position by the president of the Federal Reserve Bank of San Francisco, John Williams, who recommended another round of quantitative easing with the Fed buying mortgage-backed securities rather than Treasuries, as this riskier longer position would be more effective. Williams goes a couple of steps further than Krugman and Mallaby in his idea of central banks as holders of the long position on the economy by advocating an open-ended quantitative easing: "The main benefit from my point of view is it will get the markets to stop focusing on the terminal date [when a program of purchases ends] and also focusing on, 'Oh, are they going to do QE3?' Instead, markets would adjust their expectation of Fed purchases as economic conditions changed" (Harding 2012).

There are, however, increasingly alarming voices coming from policy circles. In its 2012 Annual Report, the BIS harshly depicted the long-term risks to the global economy and economic recovery in core capitalist economies from increasing the long positions of central banks:

In the core advanced economies, if the economy remains weak and underlying solvency and structural problems remain unresolved, central banks may come under growing pressure to do more. A vicious circle can develop, with a widening gap between what central banks are expected to deliver and what they can actually deliver. This would make the eventual exit from monetary accommodation harder and may ultimately threaten central banks' credibility. (BIS 2012, 48)

The BIS's position reflects its influential economist Claudio Borio's long-standing criticism of the narrow technical consensus on the effects of the central bank balance sheet policies: "But the main challenges ahead are not analytical or technical; they are of a political economy nature" (Borio 2011, 11). Bill Gross, the co-founder and co-chief investment officer of Pimco, one of the largest asset management firms, emphasizes the risks created by unconventional policies of central banks in the global financial system:

Functioning yes, but perhaps not so moderately or smoothly - especially since 2008. Policy responses by fiscal and monetary authorities have managed to prevent substantial haircutting of the $\$ 200$ tn or so of financial assets that comprises our global monetary system, yet in the process have increased the risk and lowered the yield of sovereign securities which represent its core. (Gross 2012)

Most commentators on unconventional balance sheet policies of central banks, as the position of a Keynesian such as Krugman above shows, believe in the technical expertise of central banks in preventing the collapse of the financial system. The pivotal role of central banks in post-crisis capitalism, however, needs to be challenged for allocative and distributive reasons. Unconventional central bank policies prevent the reform of a dysfunctional banking system that fails to perform its allocative role, as bank credit does not flow to private companies. Low interest rates punish savers financially but support borrowers. 


\section{References}

Bank of England. 2012. "Markets and Operations." Bank of England Quarterly Bulletin, Q1: 6-18. Bank for International Settlements (BIS). 2012. 82nd Annual Report: 1 April 2011-31 March 2012. Basel: BIS.

Board of Governors of the Federal Reserve System. 2012. Federal Reserve System Monthly Report on Credit and Liquidity Programs and the Balance Sheet. April.

Borio, Claudio. 2011. "Central Banking Post-Crisis: What Compass for Unchartered Waters?" BIS Working Papers, no. 353. September. Basel: BIS.

Chung, H., J.-P. Laforte, D. Reifschneider, and J. C. Williams. 2011. "Estimating the Macroeconomic Effects of the Fed's Asset Purchases." Federal Reserve Bank of San Francisco Economic Letter, 2011-13, January 31.

European Central Bank (ECB). 2012. Annual Report 2011. Frankfurt am Main: EGB. 2013. "Monetary Policy Decisions." Online: http://www.ecb.int/mopo/decisions/html/ index.en.html (accessed August 17, 2014).

Federal Reserve. 2013. "Credit and Liquidity Programs and the Balance Sheet." Online: http:// www.federalreserve.gov/monetarypolicy/bst_crisisresponse.htm (accessed August 17, 2014).

Fisher, Richard W. 2013. "Horseshift! (With Reference to Gordian Knots)." Remarks before the

National Association of State Retirement Administrators 59th Annual Conference, August 5,

2013. http://www.dallasfed.org/news/speeches/fisher/2013/fs130805.cfm (accessed August $17,2014)$.

Gieve, J. 2012. "The Puzzle of the BoE's Insistence on Inflation Targeting." Financial Times, June 11. Greenspan, A. 1999. "Testimony to the Committee on Banking and Financial Services." US House of Representatives, July 22.

Gross, B. 2012. "A Whale in the Waters of Negative Yields." Financial Times, May 14.

Hall, P. A., and D. Soskice. 2001. "An Introduction to Varieties of Capitalism." In Varieties of Capitalism, edited by P. A. Hall and D. Soskice, 1-68. New York: Oxford University Press.

Harding, R. 2012. "Bleak Jobs Outlook Raises Heat on Fed.” Financial Times, July 22.

International Monetary Fund (IMF). 2012. Global Stability Report. Washington, DC: IMF.

John, Sarah, Matt Roberts, and Olaf Weeken. 2012. "The Bank of England's Special Liquidity Scheme." Bank of England Quarterly Bulletin, Q1: 57-66.

Joyce, Michael. 2012. "Quantitative Easing and Other Unconventional Monetary Policies: Bank of England Conference Summary." Bank of England Quarterly Bulletin, Q1: 48-56.

Joyce, Michael, Matthew Tong, and Robert Woods. 2011. "The United Kingdom's Quantitative Easing Policy: Design, Operation and Impact.” Bank of England Quarterly Bulletin, Q3: 200-212.

Keen, Steve. 2009. "Bailing out the Titanic with a Thimble." Economic Analysis \& Policy 39 (1): March, 3-24.

Li, C., and M. Wei. 2012. "Term Structure Modelling with Supply Factors and the Federal Reserve's Large Scale Asset Purchase Programs." Finance and Economics Discussion Series, no. 37. Washington, DC: Federal Reserve Board.

Mallaby, S. 2012. "Show Some Real Audacity at the Fed." Financial Times, July 25.

McCrum, Dan, and Robin Harding. 2013. "Hedge Funds: Fighting the Fed." Financial Times, June 2.

Rosenhek, Zeev. 2013. "Diagnosing and Explaining the Global Financial Crisis: Central Banks, Epistemic Authority, and Sense Making." International Fournal of Politics, Culture and Society 26 (3): 255-72.

Sender, H. 2012. "BoJ's Tests to Hit Other Central Banks." Financial Times, April 26.

Singh, M., and P. Stella. 2012. "Money and Collateral." IMF Working Paper, WP/12/95, April. Washington, DC: IMF.

Weidmann, J. 2012. "Monetary Policy Is No Panacea for Europe." Financial Times, May 7.

Wolf, M. 2012. "Lunch with the FT: Paul Krugman.” Financial Times, May 26. 


\title{
Chapter 14
}

\section{THE RELATIONSHIP BETWEEN GENTRAL BANKS AND GOVERNMENTS: WHAT ARE GENTRAL BANKS FOR?}

\author{
Sheila C. Dow
}

\section{Introduction}

The specification of central banking functions and the institutional arrangements within which these functions are performed are open for discussion. The need for changes in central bank goals and operations in the face of the financial crisis has opened up issues which, during the Great Moderation period, had been regarded as long settled.

One of these issues concerns the goals of central banks. While inflation targeting had been applied for some time by many central banks, the new economic environment seems to many to warrant an alternative; candidates for an alternative include nominal gross domestic product (GDP) targeting, unemployment targeting, and promoting financial stability. But here we consider the merits of a range of goals pursued simultaneously, with potential conflicts addressed by means of judgment. Further, while we will emphasize the importance of the role of central banks, it will be recognized that they cannot exercise direct control, either of macroeconomic aggregates or of the financial sector. In attempting to achieve their goal(s), central banks have always had to tailor their policy instruments to the changing character and strength of financial markets. The liberalization and globalization of finance since the 1970s, and then the financial crisis, dramatically altered both the scale and sophistication of financial markets and the relationship between central banks and financial institutions. But, while such developments challenge the effectiveness of traditional instruments of monetary policy, care must be taken not to exaggerate the power previously exercised by central banks. Even before the 1970s, central banks could only influence the level of credit and money in the economy, not control it.

A further issue concerns the institutional arrangements within which central banks pursue their goals and in particular the case for central bank independence. The return of central banks to major open-market operations in sovereign debt has eroded previous efforts to separate monetary policy and fiscal policy. At the same time, central bank activities have had their own direct political consequences, including substantial redistribution of income. There are good reasons therefore to revisit the presumption 
that central bank independence is beneficial. We will explore this issue in the light of recent experience. But rather than limiting our discussion to the interdependence between fiscal policy and monetary policy, we extend the discussion to an issue which lay at the heart of the banking crisis: the role of the state in providing for society's need for money and credit, which brings us back to the goals for central banks. What are central banks for?

We will see that how we discuss the role of central banks and the appropriate design of institutional arrangements depend crucially on the theoretical framework employed. The general equilibrium approach which has dominated the economic literature on monetary policy and institutional design is ahistorical, founded on assumptions of wellinformed, atomistic, narrowly rational behavior within a stable equilibrium system; the classical dichotomy, which separates the real from the financial, has been a critical feature of this approach for the analysis of central banking. Attention will be drawn here, rather, to the significance of social conventions, both in terms of expectations about the behavior of institutions, but also in terms of markets valuing assets under uncertainty. This alternative approach embeds interdependencies between real and financial variables, between fiscal policy and monetary policy. The first approach treats the complications of policy practice as separable from, but nevertheless directed by, theory (Colander 2002), while we will consider them a necessary element in theory, which is to be useful for policy and institutional design (see further Dow 2012a).

We will consider these pressing current issues for the future of central banking by taking a historical approach, revisiting the rationale for central banking and its relations with the state on the one hand, and banks and society more generally on the other. In the process, we will consider the role of collateral and in particular the possibility of sovereign debt no longer being regarded as a safe asset. This is part of the more general problem of an insufficiency of good collateral, given the fiscal problems of governments and the massive size of the financial superstructure. Put another way, there is not enough reason for confidence in the value of assets.

A major factor in the buildup to the crisis was an overconfidence in the value of assets, which was unwarranted given the weak knowledge base on which such valuations rested. But the fall in capital values during the crisis meant that there was good reason to be concerned about the exposure of retail banking to risk, and the requirement for government involvement in bailouts; reasonable doubts about value thus spread to some sovereign debt. We will thus consider the role of central banks in relation to government in terms of collateral. In the process, we consider collateral broadly, as an asset which may be intangible and where claims on it may not be legally enforceable (such as the source of value of bank deposits). We thus focus on collateral as the basis for confidence in the financial system.

\section{Banking History and the Role of Collateral}

It is important to understand the history of banking and central banking, not only in order to understand how we arrived at the current situation, but also because past experience has been a crucial factor in determining social conventions, in particular the 
degree of trust and confidence (in collateral, broadly defined) which lies at the heart of a successful system (see further Chick and Dow 2013).

In many countries, retail banking and then central banking arose from the sovereign's need to borrow, but in others they emerged (where there was a sufficient basis of trust) in response to society's need both for an alternative to specie and for credit. Banks were able to supply the need for banknotes, and then checking deposits, through the provision of credit. Money thus arose from the social relation between borrower and lender, which included crucially an assessment of default risk (whether or not protected by collateral). ${ }^{1}$ As confidence in lenders increased, this new money in the form of notes, and then checking deposits, was inside money because there was a matching liability on the part of the bank. There was confidence in lenders' liabilities, based on the nature of bank assets: specie, secured and unsecured loans, and corporate and government debt. But these assets were limited as collateral because they were not all liquid; fractional reserve banking meant that not all demands to liquidate deposits could be met. The system nevertheless worked as long as there was further collateral in the form of confidence in bank money as a social relation (based on confidence in the banks' capacity to manage risk and thus to convert deposits to cash on demand), such that the redeposit ratio was high. This kind of confidence is not calculable, as in mainstream theory, but is a social convention, based on experience. ${ }^{2}$ In time, the obligation to redeem deposits with specie lapsed.

Chick (1986) explains how central banking evolved to support the emergence of a banking system. The banking system as a whole could face a crisis if there was a shortage of liquidity in aggregate such that, even with an interbank market, the banks would be unable to meet their liabilities. Because of the risk of contagion in expectations, runs could occur on some banks because of problems identified with other banks. Confidence in banks to honor their liabilities in cash meant that bank liabilities were not generally called in but rather continued in circulation. But the valuation of bank assets rests ultimately on judgment, since there are no demonstrably true measures of default risk. So revisions of judgments with respect to some banks' assets might reasonably alter judgments about other banks' assets. Further, the valuation of bank assets that reassured depositors was more generally endogenous to the system: if loans were called in and collateral acquired on an economy-wide scale, asset values would fall, increasing default risk, and reducing protection against it. A liquidity problem can turn into a solvency problem.

To protect themselves from more minor calls on their assets, the banks held some assets regarded as comparatively or perfectly safe from collapse in capital value: short-term government debt and deposits with the central bank. The latter, together with central bank notes, were regarded as outside money. The central bank had a matching liability, but this was disregarded because, if there was risk of default, the central bank could call on the resources of government. The relationship was mutual. Where central banks managed government debt and the government's bank account, governments could avoid default by borrowing from the central bank. The central bank was thus the lender of last, if not first, resort for the government. But, following recent experience of central bank independence and the withdrawal of the facility, the fiscal position of governments has become a substantial concern for the viability of commercial banks. Until now, the 
lender-of-last-resort facility was generally the subject for debate only as a matter between central banks and commercial banks; now it is also an issue for governments.

The role of collateral in sharing risk up until recent decades was relatively well defined, though it was still subject to variations in the value of collateral. It was a major element in bank loan contracts whereby the specialized knowledge of the borrower on the part of the lender led to a mutually satisfactory agreement as to how the borrower would compensate the lender in the event of default. Otherwise, collateral in the form of state support for banking and for the economy more generally was imperfectly specified, but it nevertheless inspired the convention of confidence. The success of the banking system, supported by the central bank, thus provided a good foundation for the massive growth of nonbank financial intermediaries and securities markets, based on confidence in the value of sovereign debt, the practices of the central bank, and the real assets of the economy.

But now the role of collateral in bank lending contracts is more diffuse and also more complex in the relations between the state and the private sector. Debt valuation came to rely less on the types of client relationship previously at the core of bank lending and more on pricing based on quantified risk models; transaction costs fell accordingly, encouraging a much wider participation in lending. The securitization encouraged by the introduction of capital adequacy requirements in the 1980s distributed the risk away from the originator of loans. Collateralized debt obligations and credit default swaps further redistributed risk, such that the knowledge of the original borrower and collateral became ever more diffuse. Further, the globalization of finance meant that the collateral ultimately backing assets could be located in a wide range of countries of which borrowers might have limited knowledge, rendering the ultimate borrower even more anonymous. This diffusion was compounded by the sheer scale of the financial superstructure relative to the collateral base represented by the real economy and the support of the state.

In retrospect, markets realized the weak knowledge base on which these assets had been acquired and bets placed; the connection between structured product valuation and the value prospects of the underlying assets was very tenuous such that the valuation relied more on an amorphous (and as it turned out, unwarranted) confidence in financial-sector pricing. When that confidence was punctured, the value of collateral fell dramatically across the board. Contrary to the conventional view-based on the efficient markets hypothesis and the capital asset pricing model - that any deviation of prices from their "true" value would be reversed by market processes, defaults and the freezing of markets in particular assets ensued; these were discontinuities which further eroded confidence. The social conventions which had been built up to support the financial system thus broke down, resulting in a financial crisis. This challenge to confidence in market forces refocused attention on central banks for a solution to the crisis. Central banks were thus forced to address the policy goal of financial stability rather than inflation control and to design new instruments fit for this purpose.

\section{Central Banks and Financial Stability}

While maintaining financial stability had continued to be one of the formal roles of most central banks during the Great Moderation period, in practice it had taken a 
back seat to the primary role of inflation targeting, a development dubbed historically as "idiosyncratic" (Epstein 2013) or an "aberration" (Cobham 2012). ${ }^{3}$ Indeed, the content of, and emphasis on, a range of different functions of central banks has varied over the decades (Goodhart 2011; Buiter 2012; Cobham 2012). These functions have included the provision of a safe money asset; regulation, monitoring and supervision of the banking system; exchange rate management; debt management; and lending to government as required, subject to maintaining the value of the currency. ${ }^{4}$ These functions can be summarized as promoting financial stability as the basis for private sector decision making. But in addition, as Epstein (2013) points out, central banks in developed and developing countries have also played an active part in supporting, and indeed promoting, economic development, in particular by encouraging commercial bank lending to finance investment in particular sectors and regions. Measures have included credit controls, capital controls, exchange rate management, and financing the state.

Central banks have thus historically played an important part in promoting economic goals alongside financial stability. ${ }^{5}$ Following the narrowing of central bank functions in recent decades around the inflation-targeting function, central banks have now reverted to a much wider range of functions in order to address the current crisis; while the form of the instruments may differ, the principles arguably are close to what was normal in many countries before the Great Moderation.

The focus on inflation targeting had meant inattention in particular to the role of banks, and how their practices may impact on the financial system, and on the real economy. Deregulation had meant that, while retail banks had traditionally held loan contracts along with (primarily sovereign) debt, now they had securitized loans, and also extended their asset base to include structured products that had a weak backing of collateral. Bank regulation had become focused almost exclusively on capital adequacy ratios, based on an assumption that the risk profile of bank assets was measurable and that the assets counted as capital were of sound value. But violent swings in asset prices, and thus valuation of collateral, challenged these assumptions and damaged confidence in the operations of the financial sector. If the role of the central bank as promoting financial stability founded on the provision of a safe money asset is to be taken seriously, then the first task is to ensure a sound retail banking system which inspires confidence in their liabilities.

Because many have identified the root of the banking crisis in the development of universal banking following deregulation dating from the 1970s, there is much support for some kind of ring fencing of traditional retail banking operations from other financial activities. According to the report by the UK's Independent Commission on Banking (2011; the Vickers Report), for example, only retail banks would have the liquidity support of the central bank, but with the quid pro quo of strict regulation, for example, of levels of liquidity and capital. Retail banks could thus continue to reap the benefits of fractional reserve banking, which gives them the capacity to engage in mediumand long-term debt contracts in advance of deposits, thus financing increased capital expenditure. But this privilege comes at a cost, associated with regulatory restrictions on portfolios, and the cost of higher liquidity holdings and capital than in recent decades. 
It was because of the costs of retail bank regulation and the increasing competition from non-bank financial intermediaries that banks pressured governments to deregulate them. Indeed, the buildup to the crisis was a symptom of a shift in power from central banks to commercial banks.

For some commentators, a reversal of that shift to the status quo ante is not enough. Other proposals have thus been aired which would put the provision of money more or less completely into the hands of the central bank, effectively putting an end to fractional reserve banking altogether (see e.g. Kotlikoff 2010; Jackson, Dyson, and Hodgson 2013). If the cause of the crisis is identified as being too much credit, the solution is seen to be the removal of the capacity of retail banks to create credit. Yet it is credit to finance speculation, causing asset bubbles, that has been seen as the problem rather than credit to finance productive activity. Full nationalization of banking could ensure the direction of credit to productive purposes only (an opportunity missed currently in the UK, where two major retail banks have substantial public ownership). Nevertheless, credit would still be provided outside retail banking, even if not created in advance of deposits. Indeed, even outside the net of liquidity support from the central bank, what can be classified as "shadow banking" has already increasingly provided substantial proportions of total credit, and narrow banking proposals would, if anything, encourage even more recourse to shadow banking.

The role of the central bank can be seen partly in terms of redistributing risk. Much of the discussion of bank reform with respect to the "too big to fail" problem has been focused on reducing the risk exposure of the public sector. Beyond that, the proposals to segment retail from investment banking, with the lender-of-last-resort facility available only to the former, aim to minimize its risk, even at the expense of increasing it in the latter. In effect, according to this view central banks should aim to protect retail depositors by providing collateral in the form of access to liquidity in the repo market. At the same time, central banks should aim to provide retail banks with sufficient protection to encourage them to lend to business. But the danger is that the interconnectedness of financial markets would spread instability from non-retail banking to retail banking, threatening the provision of a safe money asset and the capacity to lend to business. There is the danger of a fallacy of composition such that, at one end of the spectrum, there could be a systemic collapse of asset values across the board, while at the other end, there could be a run on retail banks for which fractional reserves provide inadequate protection. While separating off retail banking has been presented (e.g. by King 2009) as a mechanism for making banks small enough to fail, to contemplate retail bank failure would subvert the goal for central banks of providing a safe money asset (without the need for calculative assessment by the general population). The goal rather should be to have banks too well regulated and supervised to fail.

Nevertheless, separating off retail banking (either in the private sector or moving it into the public sector) would not be a solution to the possibility of systemic collapse in asset markets. The success of retail banking in the past provided a secure foundation on which all the rest of the financial superstructure grew, and grew exponentially. As Chick (1986) explains, it was the success of mutual support between central banks and retail banks that encouraged the growth of non-bank financial intermediaries; but then 
retail banks lobbied, successfully, for deregulation to allow them to compete. Investment banking was then increasingly conducted alongside retail banking within "universal" banks and subject to its own regulation. But shadow banking added a further, largely unregulated, layer to this inverted pyramid, stoking the boom in asset markets and paving the way for the crisis. The success of retail banking, when combined with deregulation, thus carried the seeds of its own destruction. As Minsky (1986) had argued, stability breeds instability. The danger continues to lie particularly in the capacity of shadow banking to take up the slack left by the ring-fenced retail banks but without the liquidity support of the central bank. Successfully ring-fenced retail banking would ensure that a safe money asset was provided, but it would still leave the wider scope for financial instability. Therefore, while ring fencing would be a step in the right direction, it would not on its own be enough to prevent a further crisis.

It is insufficient therefore to aim to redistribute risk, but in addition, the aim for central banks should be to reduce risk in aggregate. Macroprudential policies aim to reduce aggregate risk by stabilizing bank portfolios directly - for example, by countercyclical capital adequacy requirements or by limiting leverage ratios. Such policies carry their own risks; as Minsky had explained in Schumpeterian terms, regulatory constraints are a spur to innovation. Haldane (2012) accordingly argues for macroprudential regulation to be as simple as possible (e.g. limits on the size of institutions) because of the danger of unintended consequences, what he calls the "risk of backdoor complexity." Even ring fencing retail banking might be subverted in a way which even complex regulation would find it difficult to control.

Admati and Hellwig (2012) identify bank capital as the fundamental weakness that threatens to spread risk around the system (increasing systemic risk), and thus advocate markedly higher capital requirements. Again, while increased capital would encourage more confidence in banks' capacity to absorb losses and thus reduce the risk of banking crises, it is by no means sufficient to prevent or resolve crises caused by liquidity constraints (Tymoigne 2010). In particular, it does not address the problem of financial activity outside the regulatory net, which stricter regulation of course encourages, and its capacity to create unwarranted swings in asset prices, and thus liquidity problems.

Frydman and Goldberg (2011) argue that the focus of monetary policy should be on stabilizing asset markets, given that imperfect knowledge prevents markets from equilibrating themselves. Mehrling (2011) also sees risk spreading across the system, arising from unstable asset prices and even frozen asset markets. Shadow banks, which provide capital markets with essential credit, operate matched books with the aid of derivative products (unlike fractional reserve retail banks) but are still vulnerable to price swings beyond the risk measures of derivatives. He argues therefore that central banks should act as "dealer of last resort" in order to provide liquidity to a range of asset markets and to stabilize asset prices. Just as we argued above that the capacity for credit creation provided by fractional reserve banking potentially performs a vital social function, so potentially does the rest of the financial system. But this potential is only reached if unstable asset markets do not divert financial activity into self-reinforcing asset bubbles (and crashes). 
But it is important not to confine the discussion to financial institutions and financial markets. The risk of value fluctuations (particularly in a downward direction) also arise from real economic activity. While uncertainty prevents markets from identifying "true" asset values, such that conventional valuations prevail, these valuations are not purely subjective. While these valuations may take on a life of their own for a considerable time (as in the long boom prior to the crisis), eventually reality (particularly in the form of defaults, but also new data on real economic conditions) breaks through. Against this backdrop of conventional valuations, the state of banks' expectations about real conditions influences their willingness to extend credit to business activity rather than financial activity. Expectations with respect to the real economy, and actual levels of output and employment, are also influenced by the government's fiscal stance, which in turn is influenced by market pressures. Aggregate risk can thus be addressed by increasing confidence in asset valuation, not just on the basis of financial-market behavior, but grounded in evidence of public sector efforts to support the economy, which can include the efforts of the central bank.

Fiscal policy is relevant, not only in terms of its effect on real economic conditions, but also in terms of the sustainability of sovereign debt. The rapid growth of the financial superstructure had increased the need for collateral as a way of giving confidence to asset holders. At the same time, the crisis eroded confidence in a range of assets that might have inspired confidence, and this has extended to sovereign debt. There is a particular problem for the Eurozone: that its design allowed for a range of sovereign debt of varying quality, while maintaining a common interest rate policy. This has been a concern from the start (see e.g. EG 1990), but it was overridden by the priority to proceed with monetary union. This priority can be seen as primarily political, yet there was an argument current in the early days of discussion of monetary union by those dubbed the "monetarists" that monetary union itself would generate the forces for economic convergence. The Maastricht Treaty sided with the "economist" argument that convergence was a precondition for monetary union. Nevertheless, the varying perceived quality of sovereign debt within the Eurozone has caused a crisis situation, to be addressed by the European Central Bank (ECB). Some of the doubts about the value of sovereign debt arise from the necessity, given central bank independence, for any central bank involvement in government finance to require public negotiation and dispute. We therefore turn now to the issue of central bank independence.

\section{Central Bank Independence}

While central banks have perforce become more interventionist again in order to deal with the crisis, the institutional framework is very different from before the Great Moderation in that central bank independence in some form is now the norm. ${ }^{7}$ When central banks were not independent, intervention was generally designed by government and implemented by central banks. Thus, for example, Goodhart $(2011,140)$ characterizes the role of the Bank of England during the period of the 1930s to the 1960s as being to provide policy advice, to administer a system of controls, and to manage markets. It was accepted that there was a simple accounting relationship between fiscal policy, its 
finance by borrowing from the central bank or by central bank issuance of sovereign debt, central bank management of the stock of public debt, and monetary policy; the resulting scope for conflict had to be managed.

But the new era of intervention is being implemented within a sometimes uncomfortable process of negotiation between governments and independent central banks. For those who anticipate a continuing need for intervention, or simply accept the accounting interdependencies between fiscal policy and monetary policy, independence poses problems, particularly for systems of governance (as in the UK), which are otherwise highly centralized. For those who regard the current era of intervention as a temporary response to an exogenously generated crisis, normality (including inflation targeting) can soon be restored, including full central bank independence. It is time to revisit the reasons why the norm of central bank independence was promoted in the first place.

The Maastricht Treaty provided the impetus for central banks in Europe to be made independent, even if, as in the UK, membership of the European Monetary Union (EMU) was not pursued. The rationale, as provided in the summary of European Community research on EMU (EG 1990), was that an independent central bank was more likely to achieve price stability, because it would be free from the political temptation to try to engineer a boom for electoral purposes. Political independence would thus enhance credibility in inflation targeting. The Maastricht conditions specified that, in order to make central bank independence sustainable, governments would need to accept restrictions on fiscal deficits. The argument was that either financing large deficits or dealing with a financial crisis if governments were forced to default would threaten central bank independence; this would damage the capacity of the central bank to meet its inflation target.

The argument for central bank independence (and for fiscal constraints on governments) was accordingly expressed in terms of the primacy attached to the inflation target. ${ }^{8}$ The foundation for this argument is general equilibrium theory, which portrays real outcomes (production levels, employment, etc.) as determined in the long run by real productive capacity. Because fiscal policy in general is seen as interfering with equilibrating market forces, thus reducing growth, limits on fiscal policy are seen as having beneficial real consequences. Money and prices are separable from the real, but they have the capacity to interfere with real equilibrating forces in the short run by confusing expectations; an unexpected increase in the money supply, for example, can raise false expectations of conditions which warrant increased production levels and new investment, which later need to be reversed. The inflation that is assumed to follow inevitably from an increased rate of growth in the money supply thus imposes costs that reduce growth.

The central bank independence literature has thus been focused almost exclusively on measuring success in relation to controlling inflation. ${ }^{9}$ The ultimate test is taken to be how far inflation is lower in countries with more independent central banks. While the EC (1990) research reported the outcome of these studies as "clearly" indicating a positive relationship between degree of independence and success in inflation control, there has in fact been a conflicting range of conclusions drawn from the data in the many subsequent studies. Indeed, in any case, questions arise as to the direction of causation between central bank independence and inflation. Thus, even judged in narrow terms 
against the inflation target, the case for central bank independence is by no means unassailable.

The primacy of the inflation target also distracted attention from the central bank goal of financial stability, which in many cases continued as a formal requirement, even if abandoned in practice as unnecessary, given the presumption of efficient markets (see further Borio 2011). There was a concern that pressure to set interest rates with an eye to financial stability could conflict with inflation targeting (see e.g. Goodhart and Schoenmaker 1995). While there is inevitably scope for conflict between the two goals, the response in terms of institutional arrangements was conditioned by a second theoretical separation, between monetary policy and bank regulation. The former was based on general equilibrium macroeconomic theory, which dealt in aggregates without reference to financial institutions, ${ }^{10}$ while bank regulation was taken to refer to microeconomic theory of banks as firms and/or institutional theory. The outcome was thus an institutional separation between monetary policy on the one hand and bank regulation and supervision on the other, just as monetary policy had been institutionally separated from fiscal policy.

But these separations broke down in the face of the crisis, exposing the weakness of their theoretical foundation. Monetary policy in the form of setting the official (repo) rate proved to be powerless in the face of escalating rate premia on interbank lending and even of the drying up of the interbank market. Banks' collateral in the repo market was viewed as involving the real possibility of default risk in an environment of collapsing asset values and highly leveraged portfolios, and thus brought about high-risk premia as a markup on the official rate. Monetary policymakers turned to asset purchases (quantitative easing) in an effort to drive down long rates - without the effect on inflation predicted by general equilibrium theory. While these purchases included private sector debt, the bulk took the form of sovereign debt. Given the fiscal costs of bank bailouts and the fiscal effects of the recession arising from the bank crisis, this surge of central bank funding proved to be crucial. While in the past sovereign debt had been regarded as a safe asset for underpinning credit creation by banks, now the risk of sovereign default had become a real possibility, further undermining banks' own collateral. It was central banks' actions that formed a backstop insofar as they could inspire confidence in their capacity to manage the crisis together with governments; this confidence provided the broad collateral that has allowed the financial system to survive the crisis (so far).

But the process of addressing interdependencies was made more difficult by the institutional separation between monetary policy and fiscal policy on the one hand and between monetary policy and bank supervision on the other. This has been the case particularly in the Eurozone, where overcoming institutional separations requires multilateral, international negotiations. If in fact the crisis was in part at least caused by these institutional separations, then the case is even stronger to develop new, formal institutional arrangements which address the inevitable interdependencies between monetary policy, fiscal policy, debt management, and bank regulation and supervision, as well as more generally between real and financial variables. To do so requires an articulation of a different type of theoretical framework that takes seriously the real experience of monetary policy and bank regulation, and the importance of institutional 
arrangements, as in the body of work of Goodhart, Haldane, and Borio, and work in the post-Keynesian tradition, of which a few examples are Arestis and Sawyer (1998), Bibow (2009), Chick (2013), Dow (2013c), Dymski (2010), Gabor (2011), Kregel (2009), and Morgan (2009).

Any theory abstracts by setting conceptual boundaries - for example, between the macro and the micro levels. But where these separations are not mirrored in reality, any policy advice based on these separations may be seriously misguided. The classical dichotomy, purported to hold between real and financial variables, had been critical for institutional (and policy) design, yet the evidence of the financial and economic crisis has demonstrated that this dichotomy does not hold in reality. This general equilibrium approach, which provided the rationale for independent central banks, is expressed in terms of the rational expectations view that monetary policy in the form of interest rate setting would be transmitted to the general price level by means of expectations, which accorded with rational expectations general equilibrium modeling itself. Any financial instability would be the result of some external shock. Such shocks have been explained variously as real technology shocks, or some kind of irrationality captured by the terms "uncertainty" or "animal spirits," or even by sunspots (see further Dow 2013a, 2013b). According to this approach, the central bank can promote stability by efforts to keep expectations as close as possible to long-run equilibrium values, which are themselves determined by other, real forces. Indeed, financial instability had previously been explained by deviations of money supply growth from its equilibrium path, something which central bank independence was explicitly designed to prevent.

New Keynesian theory has reinforced the importance of central bank communications as a means of ensuring that information is as far as possible symmetric. According to this view, the current financial crisis is explained by various factors that distorted markets and their capacity to equilibrate naturally. Of these, the main distortions have been identified as asymmetric information about risk, on the one hand, and the moral hazard created by the lender-of-last-resort facility provided by central banks on the other. The aim is to make the subject matter as close as possible to the general equilibrium world, so that markets may themselves promote financial stability. The role of the central bank remains one of interest rate setting in order to meet an inflation target, such that real expectations are not distorted by inflation uncertainty. For New Keynesians, the classical dichotomy holds, at least in the long run. There is no reason for the central bank not to be independent.

But we have seen the central role played by confidence (in banks and in the central bank) in the successful functioning of the financial system and in the economy it serves. Confidence is only robust if backed up by real experience, and the most profound, recent real experience has been of financial and economic crisis. This experience has made clear the interdependencies between the government's fiscal stance and the value of sovereign debt, restrictions on and monitoring of bank behavior, monetary policy, and the viability of the banking system. More generally this experience has demonstrated the interdependencies between financial stability and economic stability. Confidence is only now gradually being restored through the experience of central banks intervening in 
sovereign debt markets, attempting direct bank lending, and being more actively engaged in promoting financial stability by designing new macroprudential policies.

While in some countries, as in the UK, institutional change has already occurred in recognition of the need for central banks to be more actively engaged with the goal of financial stability, the need for more formal recognition of the need for coordination between government and central banks has not been addressed. Yet, the importance of sovereign debt as collateral for the banking system, and thus of debt management, means that central banks are dependent on the fiscal stance of governments when aiming to provide a secure financial system as well as pursuing monetary policy. At the same time, in pursuing their goals with respect to growth and economic development, governments are dependent on central banks. During the Great Moderation period, this was taken to mean dependence on central bank success in meeting an inflation target. The crisis has demonstrated that such success cannot prevent financial instability and indeed that prioritizing inflation control may actually facilitate a crisis (Borio 2011). Once the potential contribution of the financial sector to growth and development is more fully recognized and understood, there is scope for considering a range of policy instruments for central banks, such as a more active role in directing credit.

The new skepticism about the capabilities of market forces in allocating credit paves the way for considering how central banks might produce more socially beneficial outcomes. Indeed, such thinking is already evident in the actions of many central banks. But then, since it was inflation targeting that was the basis for central bank independence, a move toward wider goals addressed to economic as well as financial conditions calls for the relationship between central banks and governments to be reconfigured in order for these goals to be pursued as effectively as possible. This is not to argue that central banks should be completely subservient to government. Central banks could be assigned a goal such as financial stability, for which they can then be advocates; as Borio (2011) argues, a financial-stability goal may require central banks insisting on "taking away the punchbowl" in the face of booming asset markets, something which may be politically unpalatable to government. Rather it is a matter of designing institutional arrangements to both reflect and manage the real interdependencies between fiscal policy, debt management, monetary policy, and financial regulation.

Within this more complex account of behavioral and institutional interdependencies, it is misguided to seek a "better" macroeconomic model or to seek an alternative singular quantitative target and policy instrument (Morgan 2009). Rather, models and policy instruments should be regarded as simply some of the tools available to central banks in a pluralist approach to knowledge and to policy. For this purpose, it is important to draw on theory which recognizes interdependencies in real economic relations and the importance of institutional arrangements for processes. Further, the institutional arrangements and logistics of policy design and implementation require input from theory as to behavior within institutions and as to the role of judgment. Policy is more effective the more robust the knowledge base and the mechanisms for communication, implying recourse to microeconomic theory of financial market behavior as well as attention to signs of systemic instability at the macro level. Finally, if, as this line of argument suggests, central banks go beyond the pursuit of a single, quantified target set 
by government, then they are engaging in active policymaking, such that independence from the democratic process becomes an important issue again.

\section{Conclusion}

The urgent need for a policy response to the crisis highlighted the limitations of a central bank being required to put a priority on inflation targeting and relying on official rate setting as the policy instrument. The crisis demonstrated that central banks needed to return to their traditional role of regulating and monitoring bank behavior, as well as managing government finance and public debt, thus internalizing the interdependencies with monetary policy. The provision of a safe money asset and the capacity for banks to finance capital investment requires a sound basis for depositors to redeposit and for banks to lend - that is, good collateral on the part both of banks and their customers. This requires good bank regulation and monitoring, reliable sovereign debt, and a sound economy; these in turn rely on financial stability. In other words, the central bank and the government are interdependent. Central bank independence, designed explicitly for inflation targeting, is no longer fit for the expanded purposes of central banks, given their interdependencies with government policy.

Returning to a broader set of functions will inevitably involve conflict and therefore the exercise of judgment. Markets prefer clarity and the absence of uncertainty. But economic processes are complex and central bank knowledge is inevitably uncertain. Further, central banks can only influence developments; attempts to control them by regulation will generally prompt innovation designed to subvert them. It is important therefore to adopt a "belt and braces" approach to promoting financial stability, with a range of regulatory measures acting alongside efforts to stabilize asset prices. Reducing risk in aggregate is the most effective way to deal with a massive financial superstructure built on a limited stock of real capital - that is, to address the problem of insufficient collateral. Success would provide a sound basis for private sector decision making and thus for economic growth.

\section{Notes}

1 It was the securing of debt by collateral that Heinsohn and Steiger (2006) identify as the sign of monetization of the economy; the collateral was both productive in itself and also generated new credit.

2 It was a notable feature of the banking crisis beginning in 2007 that there was very limited public knowledge of the system of deposit insurance; the safety of bank deposits was taken for granted. Only when the risk of default became real did the safety of bank deposits become a matter of any calculation.

3 Even where central banks had additional formal goals, along with inflation targeting, with respect to financial stability and economic stability, the potential conflicts between these goals tended to be resolved in recent decades (up to the crisis) by giving primacy to the inflation target.

4 Goodhart (2011) includes in the latter function constraining the financing of the state in normal times.

5 This interventionist role has waxed and waned over time. There has tended to be a pattern of a less interventionist stance before a crisis, followed by arguments for a more interventionist 
stance to resolve the crisis; Epstein points out that current debates on the role of the central bank mirror those in the 1930s, when events similarly required interventionist central banking.

6 There is a range of opinion as to how exactly to define shadow banking, e.g. whether it includes investment banking.

7 The USA is a notable exception. But there governance is dispersed among a range of agencies to allow a system of checks and balances in a way that would be difficult to achieve in other, more centralized systems. Among other countries, the degree of independence is highly variable.

8 While this was the main rationale, other possible rationales include preventing governments distorting fiscal policy because of their ability otherwise to borrow easily and cheaply from the central bank.

9 Quantifying the degree of independence has required particular attention, given the different organizational arrangements and conventions in different countries.

10 As Borio (2011) points out, these models were effectively real rather than monetary models; see further Morgan (2009).

\section{References}

Admati, A., and M. Hellwig. 2012. The Bankers'New Clothes: What's Wrong with Banking and What to Do about It. Princeton, NJ: Princeton University Press.

Bibow, J. 2009. Keynes on Monetary Policy, Finance and Uncertainty: Liquidity Preference Theory and the Global Financial Crisis. London: Routledge.

Borio, C. 2011. "Central Banking Post-crisis: What Compass for Uncharted Waters?” BIS Working Papers, no. 353. Basel: BIS.

Buiter, W. H. 2012. "The Role of Central Banks in Financial Stability: How Has It Changed?" CEPR Discussion Paper, no. 8780. London: GEPR.

Chick, V. 1992 [1986]. "The Evolution of the Banking System and the Theory of Saving, Investment and Interest." Economies et sociétés (Monnaie et production, no. 3): 111-26. Reprinted in On Money, Method and Keynes, edited by P. Arestis and S. C. Dow. London: Macmillan.

Chick, V. 2013. "The Current Banking Crisis in the UK: An Evolutionary View." In Financial Crises and the Nature of Capitalist Money: Mutual Developments from the Work of Geoffrey Ingham, edited by G. Harcourt and J. Pixley, 148-61. London: Palgrave Macmillan.

Chick, V., and S. Dow. 2013 'forthcoming' deleted. "Financial Institutions and the State: A Re-examination." In Contemporary Financial Capitalism: Analyses of the Recent Financial Crisis, Its Current Transformation, and Its Future Prospects, edited by L.-P. Rochon and M. Seccareccia, 99-111. Cheltenham: Edward Elgar.

Cobham, D. 2012. "The Past, Present and Future of Central Banking." Oxford Review of Economic Policy 28 (4): 729-49.

Colander, D. 2002. "The Lost Art of Economics." Journal of Economic Perspectives 6 (3): 191-8.

Commission of the European Communities, Directorate-General for Economic and Financial Affairs (EC). 1990. "One Market, One Money: An Evaluation of the Potential Benefits and Costs of Forming an Economic And Monetary Union." European Economy 44, October.

Committee on International Economic Policy and Reform. 2011. Rethinking Central Banking. London: House of Commons.

Dymski, G. 2010. "Why the Subprime Crisis is Different: A Minskyian Approach." Cambridge fournal of Economics 34 (2): 239-55.

Dow, S. C. 2012a. "Policy in the Wake of the Banking Crisis: Taking Pluralism Seriously." International Review of Applied Economics 26 (2): 161-75.

2012b. "What are Banks and Bank Regulation For? A Consideration of the Foundations for Reform." Intervention 9 (1): 39-56.

2013a. "Endogenising Uncertainty." Presented to the INET Annual Conference, Hong Kong, April. Online: http://ineteconomics.org/sites/inet.civicactions.net/files/Dow\%20 Paper_0.pdf (accessed August 17, 2014). 
. 2013b. "Animal Spirits and Organisation: A Structural Approach." Paper presented to the AHE Annual Conference, London, July.

. 2013c. "The Real (Social?) Experience of Monetary Policy." In Financial Crises and the Nature of Capitalist Money: Mutual Developments from the Work of Geoffrey Ingham, edited by G. Harcourt and J. Pixley, 178-95. London: Palgrave Macmillan.

Epstein, G. 2013. "Developmental Central Banking: Winning the Future by Updating a Page from the Past." Review of Keynesian Economics 1 (3): 273-87.

Frydman, R., and M. D. Goldberg. 2011. Beyond Mechanical Markets: Asset Price Swings, Risk, and the Role of the State. Princeton, NJ: Princeton University Press.

Gabor, D. 2011. Central Banks and Financialization: A Romanian Account of How Eastern Europe Became Sub-prime. London: Palgrave Macmillan.

Goodhart, G. A. E. 2011. "The Changing Role of Central Banks." Financial History Review 18 (2): 135-54.

Goodhart, C. A. E., and D. Schoenmaker. 1995. "Should the Functions of Monetary Policy and Banking Supervision Be Separated?" Oxford Economic Papers 47 (4): 539-60.

Haldane, A. G. 2012. "The Dog and the Frisbee." Speech given at the Federal Reserve Bank of Kansas City's 36th economic policy symposium, "The Changing Policy Landscape," Jackson Hole, WY, August 31.

Heinsohn, G., and O. Steiger. 2006. "Interest and Money: The Property Explanation." In $A$ Handbook of Alternative Monetary Economics, edited by P. Arestis and M. Sawyer, 490-507. Cheltenham: Edward Elgar.

Independent Commission on Banking. 2011. Report. London: House of Commons.

Jackson, A., B. Dyson, and G. Hodgson. 2013. The Positive Money Proposal. London: Positive Money.

King, M. 2009. Speech to Scottish business organisations, Edinburgh. Online: http://www. bankofengland.co.uk/publications/speeches/2009/speech406.pdf (accessed August 17, 2014).

Kregel, J. 2009 "Background Considerations to a Regulation of the US Financial System." Levy Institute Working Paper, no. 557. Annandale-on-Hudson, NY: The Levy Economics Institute of Bard College.

Mehrling, P. 2011. The New Lombard Street: How the Fed Became the Dealer of Last Resort. Princeton, NJ: Princeton University Press.

Morgan, J. 2009. "The Limits of Central Bank Policy: Economic Crisis and the Challenge of Effective Solutions." Cambridge Fournal of Economics 33: 581-608.

Kotlikoff, L. J. 2010. Fimmy Stewart Is Dead: Ending the World's Ongoing Financial Plague with Limited Purpose Banking. New York: John Wiley.

Minsky, H. 1986. Stabilizing an Unstable Economy. London: Yale University Press.

Tymoigne, E. 2010. "Minsky and Economic Policy: 'Keynesianism' All Over Again.” In The Elgar Companion to Hyman Minsky, edited by D. B. Papadimitriou and L. R. Wray, 47-83. Cheltenham: Edward Elgar. 



\section{Chapter 15}

\section{IS NEW GOVERNANCE THE IDEAL ARCHITECTURE FOR GLOBAL FINANGIAL REGULATION?}

\section{Annelise Riles ${ }^{1}$}

\section{Introduction: Regulatory Pluralism and the Interrelationship of Legal Regimes}

The central transnational regulatory challenge of the moment is how to manage large cross-border institutions that can jeopardize the health of the entire global economy. So-called global systemically important financial institutions (G-SIFIs) are cross-border institutions that are so large or interconnected that they are potentially too big to fail (TBTF). Equally importantly, such institutions are subject to multiple, overlapping, and even sometimes conflicting legal regimes.

From the legal perspective, the challenge G-SIFIs pose to global financial regulation is the problem of the interdependence of regulatory regimes in a global system that is inherently pluralistic. The threat of regulatory arbitrage that underlies much of the push for the harmonization of financial regulation is plausible only if legal regimes are sufficiently fungible and interconnected on the one hand, and yet sufficiently different in regulatory substance or approach on the other, that in some circumstances they can become viable alternatives from the market participants' point of view. Conversely, where markets are interconnected, one approach to regulatory oversight in one jurisdiction produces externalities in other regulatory regimes.

This article examines the way the international financial regulatory system is addressing this challenge, as exemplified by one of the prime organs of global financial regulation today: the Financial Stability Board (FSB). The G20 launched the FSB as its technocratic arm of policy creation and implementation in 2009, transforming an earlier organization. Its core functions and methodologies are coordination, standard setting, implementation of global standards, and identification and assessment of cross-border financial risks.

One cannot but be impressed with the sheer volume of initiatives the FSB has undertaken since its relaunch, and by the remarkable leadership, energy, and acumen behind these. In this article, I take the FSB as a target of critical analysis precisely because the FSB represents arguably the state of the art in international financial governance: it 
is an experimental, purposeful, and energetic institution that deploys the most innovative international financial regulation methodology today.

The FSB's approach, like that of most domestic and international regulators, is to tackle discrete, pressing problems through tailored policy initiatives - for example, determining which banks should be designated as G-SIFIs, drafting rules on executive compensation, or deciding how much and what kind of capital such banks should be required to set aside. These are complex questions that leave little time for an "eagle's eye view" of all of this activity taken as a whole. And yet, built into the structure of the Basel Accords and of the numerous activities of the FSB, there nevertheless is an inchoate but distinct ambition that this activity will ultimately add up to a larger global financialgovernance project.

Thus, it is important to carefully consider the sum of all these parts, to reflect on where this flurry of activity is leading, and to evaluate whether the implied target of these activities is sufficient to face future financial crises. The question of regulatory form - of the nature, strengths, and weaknesses of the emerging global financial architecture - remains surprisingly underexamined by both academics and policymakers. For example, to date, the FSB has never clearly articulated, let alone defended, its model of regulatory form - what I will call the new governance (NG) architecture.

We know that regulatory architecture - the form regulation takes (i.e. rules versus standards, hard law versus soft law, penalties versus rewards, etc.) - impacts upon the efficacy of regulatory initiatives, the legitimacy of regulation, and its distributive effects. For example, self-regulation is a regulatory architecture that was once taken for granted by many as the best way of achieving certain regulatory objectives, and yet it is widely acknowledged today that it has clear limitations. Indeed, the understanding that regulatory architecture matters is precisely the premise of NG initiatives (described in Part III): for its proponents, NG offers a more effective and just regulatory form for achieving the same substantive policy goals that one might pursue through either so-called commandand-control regulation or self-regulation.

This article aims to initiate a debate and propose a research agenda regarding the emerging form of international financial governance architecture. It does so by bringing together what is known in other legal and social scientific fields about the particular regulatory technologies deployed by the FSB. The aim of this article is not to propose an alternative architecture, but rather to lay the groundwork for thinking through alternatives by suggesting how we might approach a more careful diagnosis of the potential problems with the current approach.

It is often taken for granted that the current system is the only plausible alternative to an older form of governance sometimes disparaged as "command and control" regulation. This older view is, to some extent rightly, seen as outmoded and ill-suited to current regulatory challenges. However, it is sometimes then assumed that any criticism of the current approach is also an implicit argument for a return to command and control, or conversely, that a criticism of command and control is in itself an argument for NG regulation, as if there can only be two possibilities. A more rational approach might consider the strengths and weaknesses of the NG approach on its own terms. 
Only once we evaluate the efficacy of the current model can we determine whether it is indeed the best option and how it might be reformed.

The analysis proceeds as follows. In Part II, I describe the pervading understanding of "the problem" of G-SIFIs at successive layers of complexity, and then discuss what kind of practical policy response to this problem is entailed in the regulatory approach of the FSB. In Part III, I analyze the problems and solutions outlined in Part II from the standpoint of the body of regulatory theory that most directly corresponds to (and has most directly influenced) this approach. This body of regulatory theory - the so-called NG literature - claims developments in global financial governance as a prime example of its applications, and has indirectly influenced the architecture of global financial governance via models borrowed from initiatives in Europe and the USA.

In Part IV, I evaluate NG as implemented by the FSB as an architecture of international financial governance. Experts in financial regulation who have focused on the effects of particular NG initiatives prior to and since the financial crisis are far less enthusiastic than proponents of NG about its practical prospects for success in this area. Indeed, much of the initiative for current transnational rule making derives from concerns about the potential pitfalls or limitations of pre-financial crisis, NG-style initiatives as applied in the USA and in Europe to the relationship between regulators and financialmarket participants. And yet ironically, at the very moment at which the FSB is busy creating rules and procedures to supplement the failures of pre-2008 domestic regulation that, in many North Atlantic countries, was largely inspired by NG, the FSB is itself applying much of the same regulatory architecture, with little critical evaluation, to the relationship between international and domestic regulators - as a tool of international regulatory coordination. To make matters worse, in the process of transposing NG into a tool of international regulatory coordination, some of the most innovative aspects of NG have been lost, diluted, or disregarded in practice.

As described in the conclusion (Part V), a preliminary hypothesis emerges from this analysis: NG mechanisms may be effective in resolving some kinds of problems caused by the interrelationship of legal regimes in a pluralistic regulatory order, but they are unlikely to be suitable to all problems. This in turn suggests an agenda for future research: detailed study of the precise conditions in which NG tools may or may not be effective in international financial governance is sorely needed.

\section{Part II: The FSB Approach to Global Financial Architecture}

\section{A. The challenge of G-SIFIs as a problem of international legal coordination}

As mentioned at the outset, the challenge of G-SIFIs is that they are difficult to control from the perspective of any singular jurisdiction, and yet their failure can have serious consequences for the entire global economy. The regulation of G-SIFIs is therefore an inherently transnational problem that demands both practical coordination among regulators and an understanding of how national and international regulatory regimes interact. The proposed responses to the risks posed by G-SIFIs can be divided into 
the operationally desirable but politically unpalatable on the one hand and the more politically feasible but difficult to operationalize on the other.

\section{Option 1: Break up the G-SIFIs}

If certain institutions are too systemically important and complex to fail, then the most logical proposal is to break them up into smaller entities. Several prominent academic commentators, and even some prominent market participants, have questioned whether the increasingly large size of financial conglomerates contributes to wider economic welfare to a degree that is proportionate to the global economic externalities they impose. Legal scholars, likewise, have proposed that existing antitrust law might be used to break up some of these conglomerates (Reich 2010). However, most policymakers believe that this approach is, for the moment, unfeasible due to the opposition of powerful financial institutions (Krugman 2010).

\section{Option 2: Government liquidation or nationalization in conditions of crisis}

If the failure of a G-SIFI spreads risk throughout the financial system and imposes costs on taxpayers, another logical proposal would be to give regulators the authority to nationalize or liquidate banks whose capital ratio falls below a certain level. However, again, many observers believe this is politically unfeasible at least in the USA due to the public's distaste for government ownership of private assets and regulators' fear that liquidation is an admission of regulatory failure.

\section{Option 3: Preparedness}

The dominant approach, therefore, has been to focus on drafting firm-specific plans for a more orderly resolution of these institutions. This is the approach embodied in the American Dodd-Frank legislation, as well as in the focus on identifying G-SIFIs, and requiring that they hold up to an additional 2.5 percent of capital in reserve, in addition to the amount enshrined in the Basel III Accords and implemented in recent framework documents promulgated by the FSB.

The centerpiece of this approach is the imposition of additional capital requirements on G-SIFIs, both to guard against and ultimately insulate taxpayers from bearing the cost of resolution. Other proposals include mandating that financial institutions create "living wills" that purport to define how they would be resolved at times of crisis and shifting the burden of loss to bond holders by mandating that certain categories of bonds stipulate that they will convert to ordinary shares when a bank's capitalization drops to a certain level (so-called CoCos). There are also proposals to impose additional taxes on G-SIFIs to create a fund that would cover resolution costs or to ask other financial institutions to cover the cost of the bailout of one of their peers after a crisis.

Problems remain with these efforts to prepare for the next failure of a G-SIFI. First, many question whether the preparations are enough. Lehman itself, for example, probably would not have been required to post the additional capital requirements 
demanded of G-SIFIs under the current regime. CoCos raise a host of problems, from how to price such instruments, to whether they are open to legal challenge, to their possible contagion effects at times of crisis. More generally, planning for the future is difficult and the experience of past crises is not always a good guide.

\section{The corollary: Coordination among regulators}

The backstop to this preparedness approach therefore is better coordination among regulators with the hope that it will lead to increased trust and coordination during a future crisis. This focus on building channels for coordination and information sharing responds directly to the failures of coordination between US and UK regulators during the Lehman crisis. Yet commentators and policymakers alike have decried inadequate levels of information sharing regarding G-SIFIs among national regulators.

In particular, the failure of a G-SIFI creates potential conflicts of interest between a G-SIFI's home jurisdiction and the host jurisdictions in which the G-SIFI does business. In a situation of G-SIFI failure, regulators and courts are often tempted to favor their own nationals over other creditors. Because home and host regulators anticipate such behavior at moments of the failure of a G-SIFI, they may be reticent to share information for fear of creating tactical advantages for other jurisdictions.

Hence, the problem of coordination between home and host regulators is a central focus of the FSB. Its stated task is to "significantly step up cooperation amongst authorities to prepare feasible and credible G-SIFI resolution plans."

\section{B. The limits of harmonization as a coordination technique}

In order to understand why NG emerges as an appealing regulatory architecture for the FSB as it addresses these coordination problems, it is necessary to understand what NG innovates against - international harmonization. Up to now, most attempts at financial regulatory coordination have emphasized a more classical, international legal solution to coordination: harmonized rules agreed upon at the interstate level and translated into substantially similar national laws by domestic legislatures or enforced by domestic regulators.

Why did this kind of formal harmonization traditionally seem like a necessary form of coordination? As domestic regulators in jurisdictions such as the USA pursued domestic reforms, they confronted a steady drumbeat of threats that markets would respond to additional regulatory burdens by moving business to jurisdictions that do not have heightened regulatory requirements (Gonzalez and Schipke 2011). National regulators responded to this threat of regulatory arbitrage by attempting to ensure that other jurisdictions had roughly the same regulatory burdens (Eubanks 2010). Thus, international harmonization of regulatory standards has traditionally been seen as the necessary corollary of domestic regulatory reform.

In practice, this causes numerous problems. First, harmonization typically takes the form of substantive rules, such as capital adequacy requirements for systemically important financial institutions. One practical reason for the emphasis on harmonizing 
rules at the Basel Committee and the FSB is that rules are relatively easy to identify, describe, and produce compared to regulatory standards or practices. Yet harmonized rules mean little if the degree of supervision concerning adherence to those rules varies widely from one jurisdiction to another.

A related problem with harmonization as an international governance structure is a pervasive lack of support from domestic politicians, banks, the public, and even regulators in many jurisdictions for rule making at the international level. Global agreements require domestic support for implementation; but in many jurisdictions, domestic constituencies have proven profoundly skeptical of newly harmonized rules. The consequence is often the practical impossibility of full compliance.

Likewise, the lack of will for coordination among regulators themselves - the sense of national competition that often pervades the sense of the common good-also impedes harmonization efforts. Unwillingness on the part of national regulators to adhere to internationally harmonized standards is likely to be even stronger in cases of emerging markets not represented at the FSB or the G20.

For all these reasons, even many proponents of international legal harmonization agree that full or substantial harmonization of regulatory standards in the short to medium term is likely impossible. Yet many commentators and policymakers also argue that even if it were achievable, harmonization is not desirable in the first place.

First, different jurisdictions face different conditions. For example, as Jeffrey Gordon has noted, the US focus on the liquidation of G-SIFIs reflects options available to US regulators given the size of the US economy and of the Treasury relative to the size of failing financial institutions that may not be available to other countries (Verstein and Romano 2011). For other countries, the focus rather must be on preventing the failure of institutions that are "too big to save" through higher capital adequacy requirements and bail-ins.

Equally importantly, where systemic risk is created by "herd mentalities" in which market participants pursue common strategies, different regulatory approaches may act as stopgaps against contagion by incentivizing different business models. As Takafumi Sato, former commissioner of Japan's Financial Services Agency, explained, "A global community adopting a uniform platform is vulnerable to a virus, as we have witnessed during the current financial pandemic. Capital adequacy regulations should be designed to foster diversity in business models" (Sato 2009).

On these points, experts interested in international financial regulation would likely benefit from more active engagement with state-of-the-art international regulatory theory more generally. The inability of regulators to deliver on promises made in international forums in the face of domestic pressure is a well-documented problem. Competition among national representatives and the lack of will for coordination among regulators is another problem that repeats itself in numerous international regulatory fields. These problems have been addressed in different ways and with varying degrees of success at different periods in international legal history - from state-to-state agreements to the construction of international institutions, to the development of customary international law (Krisch and Kingsbury 2006). Moreover, an extensive literature on global legal pluralism now demonstrates that legal pluralism is a given condition of transnational legality that cannot ever be entirely eliminated. In fact, this literature demonstrates that 
pluralism has numerous advantages and must be incorporated into transnational legal governance. The challenges posed by global harmonization initiatives in international financial regulation are not unique to this field.

\section{Three key elements of FSB methodology}

The FSB has acquired credibility as a site for coordinating financial regulatory standards and for creating soft law mechanisms to ensure compliance. However the FSB's formal legal authorities are extremely limited. The FSB charter only grants the FSB authority to "assess vulnerabilities affecting the global financial system," to "promote coordination and information exchange," "monitor and advise on market developments," and "advise and monitor on best practice in meeting regulatory standards." As if to underline the point, the final article of the charter states, "This Charter is not intended to create any legal rights or obligations" (FSB 2009).

With these limited powers, how does the FSB tackle a coordination problem that standard international legal tools have proven incapable of resolving? The FSB's approach is innovative. It aims to address, on one hand, the interrelatedness of domestic regulatory systems, and on the other hand, the political difficulties associated with achieving and implementing international consensus on harmonized rules through a new set of institutional tools borrowed directly from recent innovations in the EU and the USA. Three principal kinds of initiatives deserve attention: standard-setting projects, peer review, and cross-border, firm-specific coordination.

\section{Standard setting}

In theory at least, the FSB circumvents some of the problems of harmonization initiatives by emphasizing broad standards or "best practices" for regulators rather than hard rules. Standards are seen as preferable tools of global financial regulation because they allow for pluralism within a framework of common baselines and shared regulatory values. Standards are also viewed as more flexible than rules and hence more able to accommodate unforeseen future problems.

Yet in practice, these standards seem to shade into a regime that takes on more and more of the trappings of traditional international legal rules and norms. In the area of G-SIFIs, for example, the FSB in October 2011 promulgated what then chairman Mario Draghi ambiguously described as "a new international standard [for the resolution of financial institutions] as a point of reference for consistent reform of national resolution regimes" (Draghi 2011). In this slippery language, a mere standard or "point of reference" also becomes something more than that - the basis for "consistent reform" and "a new international standard."

\section{Peer review}

Peer review is a soft law technique for implementing harmonized regulatory standards. Countries report on their progress in implementing particular standards, and these 
reports are in turn evaluated by a committee of peers. The secretariat engages those who fail to comply in a "confidential dialogue" that can ultimately lead to public "naming and shaming" (Walter 2010). An FSB "scoreboard" on its website "tracks progress across the full range of reforms" (Draghi 2011).

The FSB's own official objectives for peer review span a number of analytically disparate purposes, from the rather benign goal of information exchange, to the more interventionist goal of evaluating FSB members' adherence to their commitments, to norm building, to evaluating the content of international regulatory standards and approaches themselves. The last of these is important to the peer-review ideal: as NG proponents Sabel and Zeitlin explain, the peer-review process creates a kind of accountability that "anticipates the transformation of rules in use." In the future, the FSB promises even "more intense monitoring in priority areas: the Basel capital and liquidity framework; OTC derivatives market reforms; compensation practices; G-SIFI policy measures; resolution frameworks; and shadow banking" (Sabel and Zeitlin 2012).

Peer review as practiced by the FSB is a governance regime that carries only a possible reputational sanction. What defines this particular implementation of peer review as a mode of governance is not so much the sanction, as the regularized practice of periodic and extensive self-evaluation and reporting requirements. On this front, the FSB has instituted a busy schedule of self-reporting requirements whereby national regulators must complete questionnaires concerning their regulatory activities and their compliance with international standards.

For example, a questionnaire developed for a thematic review on risk governance contains approximately fifty detailed questions, to be answered by busy national regulators in just over one month. The questionnaire is posted on the website but responses are not public. Although the questions are framed as merely for information-gathering purposes, many assume a clear normative framework and set of policy preferences, and the survey prompts national regulators into a kind of self-evaluation according to those policy preferences. For example, question 1.1 reads:

Please describe your jurisdiction's overall approach to assessing firms' risk governance frameworks (e.g. legislation, regulation or supervisory guidance). Please provide links to relevant documents. Has your jurisdiction evaluated whether such guidance is consistent with the BCBS or OECD principles on corporate governance or other recommendations provided by the industry? (FSB 2012, 3)

The message is clear: member states should be evaluating themselves according to international standards. Regulators completing this survey may find it embarrassing to answer any part of this question in the negative. Moreover, "risk governance" is defined quite specifically in the questions to include the internal institutional structures in place within private firms for monitoring and managing risk. Regulators may also find it uncomfortable to have to admit to their global peers that financial institutions in their jurisdiction do not have exactly this kind of organizational structure for managing risk. Hence, the peer-review process of answering these questions also encourages regulators to set up similar levels of review among the market participants they regulate. 
Supervisory colleges

A third architectural innovation worthy of mention is the so-called supervisory colleges aimed at the cross-border regulation of individual financial institutions and in particular the coordination of home and host regulators.

What is new here, from the standpoint of international law, is that regulation is not generally applicable, but is specific to a particular non-state actor: regulators convene to develop specific protocols for information sharing concerning a specific financial institution. Rules, procedures, and information sharing across borders are being developed - tailored and applicable only to one particular target of regulation. In the environmental or security context, by way of contrast, one does not create environmental regulations that apply to only one polluter, or security laws that apply to only one terrorist organization (even if, in practice, general rules are often created in response to a specific case). Thus, the model dispenses with the traditional formal model of regulation in favor of something more pragmatic, and it also recognizes that regulation is conducted by real people - and that personal relationships among regulators is as significant a source of regulatory stability and strength as, for example, sanctions against governments for failure to share information might be.

\section{Conclusion to Part II}

In sum, the FSB responds to the challenges of an interrelated but plural global regulatory environment with some new tools and approaches borrowed largely from the European experience in coordinating among diverse regulatory authorities within the EU. These tools and approaches are not particularly legal in nature; indeed, the FSB has minimal formal legal authority over its members. They are rather pragmatic and problem oriented. And they are sociologically and institutionally grounded: they emphasize relationships, reputations, and the gradual evolution of norms and standards through repeat encounters.

\section{Part III: The New Governance Approach}

The FSB initiatives described in the previous section draw powerfully on one popular body of regulatory theory known as NG.

\section{A. What is new governance?}

The term "new governance" captures a variety of regulatory approaches that emphasize a shift away from so-called command-and-control regulation toward more reflexive, collaborative, and experimental forms of governance. Here, the task of government is to coordinate and facilitate collective information sharing and learning.

While the term has been applied to a broad range of processes and practices, according to Ford, there are three related convictions that underlie most NG strategies implemented in the EU and USA: (i) an emphasis on "learning by doing" that includes 
structured learning processes that pull experience into the creation of regulation in selfreflexive ways; (ii) a recognition of the necessity for regulatory revisability, as documented in practices such as notice-and-comment rules, which allow for quick decisions by relevant actors; and finally, (iii) humility about the fact that regulators cannot know more about everyday operations than the practitioners themselves (Ford 2010a).

One classic element of the NG approach to regulation is to set broad targets and allow regulated entities to reach those targets in their own ways. Another key value of the NG approach is its emphasis on experimentation and collaboration. In the USA, the concrete impetus for this new approach to regulation lies in the search by center-left academics and policymakers in local, state, and national government for a pragmatic response to market-based critiques of the legitimacy of state regulation. On this point, the NG argument is that markets cannot always be counted on to produce the kind of efficient and welfare-maximizing coordination that neoliberals imagined would emerge through the institution of price. On the other hand, NG is not a call for a return to state control: it takes seriously neoliberal critiques of the inefficiencies and injustices of state "command and control" and therefore seeks a "third way" between free markets on the one hand and state regulation on the other.

What this highlights is that the architecture now used by the FSB to coordinate among national regulators was developed first to address a problem in relations between state regulators and private parties that were the target of regulation. Thus the deployment of NG techniques by the FSB stretches those techniques further to address the statestate relations - relations between national regulators, mediated by an international organization, and the compliance of national governments with international law.

\section{B. Addressing the democracy deficit}

The standards for evaluating or ranking jurisdictions are often produced by "expert committees," and hence in the NG approach, non-elected technocrats yield considerable implicit power through such instruments. As such, NG is open to standard domestic criticisms of international organizations as undemocratic and unaccountable to domestic constituencies.

But for NG proponents, one great promise of the approach is its contribution to the challenges of creating legitimacy and accountability for international institutions directed by non-elected experts. Sabel and Simon (2006) write in "Accountability without Sovereignty" that peer review actually provides better popular accountability than the traditional formal "principal-agent" model of democratic accountability because the deliberative process entailed in peer review entails a more substantive and meaningful form of accountability than formal electoral accountability.

\section{Conclusion to Part III}

Many of the core values of NG, such as fostering regulatory pluralism, mutual learning, and principled-based self-regulation are admirable. In theory, NG represents a substantial innovation over traditional approaches to international law and institutions because it 
addresses the political difficulties with creating binding rules at the international level. And yet the observations of experts in financial regulation concerning some applications of these approaches, together with social scientific and legal studies of the outcomes of NG approaches in other areas of international regulation suggest that the reality of NG may be somewhat different from the theory. In the next section, we explore these studies, and their implications for the FSB.

\section{Part IV: New Governance in Practice: A Gritical Appraisal}

Despite all the framework agreements, all the peer-review documents, the supervisory college meetings, and networking opportunities, many regulators privately confess to considerable skepticism about how much progress really has been made on cross-border coordination in the case of a failing G-SIFI since 2008. The view of many seems to be that if a systemically important financial institution were to fail today, the level of coordination would be the same, or only slightly better, than at the time of the Lehman crisis.

This should give us pause for thought. If these regulators are correct in their skepticism, then one might ask whether all this novel activity is really delivering enough value to justify the tremendous time and expense involved. Surprisingly, to date, no serious empirical research on this subject has been undertaken in the area of global financial regulation. The intuitive appropriateness of the NG model has more or less been taken for granted by regulators.

In the absence of such research, this part draws together what can be known about the strengths and weaknesses of the NG architecture in two ways. To begin with, NG methods were deployed in many sectors of domestic financial regulation prior to the crisis of 2008, and the weaknesses of these methods in the domestic context are widely appreciated. Remarkably, the same methods are now being redeployed in transnational financial governance.

This time, the targets of regulation are not private firms, but domestic regulators in FSB member jurisdictions, and it is possible that this difference somehow eliminates the problems documented in the domestic context. On the other hand, it is also possible that this difference exacerbates the problems: a review of the implementation of NG by the FSB suggests a number of ways in which, in this new application, NG has actually lost some of its more innovative aspects. Secondly, I analyze the known aspects of the FSB governance structure. Where appropriate in this section, I draw analogies to available research on the application of NG techniques in other fields of transnational regulation. This analysis suggests both some potential weaknesses of NG as an architecture of international financial governance overall, and also some possible conditions for determining when the method might be most effective and when it might not.

\section{A. Lessons learned from new governance in financial regulation prior to 2008}

Few NG experts claim any substantive knowledge of international financial regulation. The exception is Ford (Ford 2011, 2010b), whose work lies squarely at the intersection 
of both fields. Ford's survey of three recent examples of failure or underperformance of NG-style financial regulation prior to the financial crisis gives us a more limited and pessimistic picture of how NG might be used in financial regulation. One example is regulators' past reliance on market participants' own risk-management models to determine the nature and size of risks in the global economy. Although from a NG perspective this might have seemed like a wonderful collaborative approach to regulation, Ford (2010b, 281) concludes that "regulatory faith in industry actors' competence, if not literally their bona fides, proved to have been misplaced to catastrophic effect."

From this and other examples, Ford finds a number of potential weaknesses in the NG approach, at least as it has been applied to date in real-world financial regulatory contexts. First, information-based governance relies too heavily on regulated parties for information. Second, the enthusiasm in the NG project for local experimentation assumes too quickly that industry representatives will make choices that are in the public interest. Third, the NG emphasis on coordination fails to fully take into account how powerful market participants may be, relative to regulators, both in terms of their influence over the political process, and their ability to shape the dominant consensus about how markets should be regulated.

\section{B. Practical shortcomings in the application of new governance by the FSB}

Ford's research highlights potential concerns about NG as applied pre-2008 to public regulation of private market participants. And yet, just at the moment at which these failures are widely acknowledged, the same regulatory methods are being applied at the international level to coordination among national and international regulators. Moreover, a review of the application of NG by the FSB suggests new challenges to regulatory success and ways in which some of the more innovative or hopeful dimensions of NG actually have been lost in translation.

\section{Limited participation}

NG posits an expanded community of stakeholders in which regulatory legitimacy is generated by including as many possible interested parties in the process of creating and implementing standards. But the FSB remains a closed organization that purports to make standards that apply to non-members as well as members. Some important emerging economies, including economies which are touted as possible relocation sites for financial institutions seeking to avoid North Atlantic regulatory burdens, do not participate in the FSB process. This poses a serious challenge to the FSB's legitimacy.

Likewise, the NG approach imagines collective governance in which all viewpoints are heard and coordinated. Yet in the FSB, although decisions are made by consensus, in practice some members have considerably more authority than others. In the individual committees in which important policies are often debated and drafted, the representation of North Atlantic regulators is still unduly large in relation to these economies' global market share. 


\section{Limited public-private coordination}

As described above, one of the central innovations of NG was its emphasis on new forms of collaboration between public and private actors. Yet, so far, the FSB process has mainly engaged representatives of governments and international bureaucracies, with private parties participating only through more attenuated opportunities for public comment.

This exclusion of private actors is unfortunate because it fails to recognize the practical authority of organizations such as the International Swaps and Derivatives Association in constructing their own forms of international financial governance beyond the state. The FSB's initiatives to address the problem remain in the embryonic stage.

\section{Standards slide into rules}

Another innovative aspect of NG theory was its emphasis on governance through broad standards rather than rules. In practice, however, the FSB regime is increasingly rule oriented, leading to a number of problems.

One of the problems with rule-based governance - precisely the problem NG sought to address - is that rules can easily be diluted or ignored altogether at the national implementation phase and hence impose weighty compliance monitoring costs on regulators. Despite the fiercely committal language in FSB reports and communiqués, the FSB lacks any formal power to hold member states to agreements they have made at the international level.

Another problem with rules is that they encourage private actors to "game" the system or develop other forms of resistance. This was the global experience with capital adequacy standards under Basel II, where market participants devised all kinds of financial products and accounting methods to "game" the regulatory standards.

In theory, peer review is meant to address this problem of non-compliance. Yet in practice, peer review also has its limits. For example, participation in peer review is still largely voluntary in many practical respects. Although the FSB charter states that peer review is a requirement of membership, the FSB peer-review handbook acknowledges that volunteers will be taken first, and in practice to date, country peer reviews have been strictly voluntary.

\section{Pluralism slides into harmonization}

A related innovation of the NG approach was its emphasis on regulatory pluralism; yet in practice, the FSB is moving toward greater emphasis on compliance with harmonized rules and practices. Consider, for example, the following official explanation of the new FSB standards on SIFIs. According to the then secretary-general Draghi, the new standards were:

designed to address gaps in legal frameworks and tools for effective intervention in failing systemic firms, including those that operate in multiple jurisdictions, and to 
remove impediments under existing national law to cross-border resolution. Their implementation will require legislative changes in many jurisdictions. (Draghi 2011, 2)

As one FSB report explains, likewise, peer reviews are now "focused on the implementation and effectiveness of international financial standards and of policies agreed upon within the FSB."

\section{Problems with the sociological approach}

One innovation of $\mathrm{NG}$, as we saw, is its emphasis on sociological rather than legal tools for achieving outcomes. Yet some observers query whether, in the case of international financial regulation, a community of regulators who are collectively committed to careful deliberation and individually susceptible to group pressure when they fail to meet international targets is in fact so easily achieved.

\section{Learning slides into surveillance}

And these limitations to deliberation lead to another problem. One of the greatest values of NG tools such as peer review is the opportunity they provide for comparison and learning. In practice, peer review often slips into a tool of surveillance in which participants evaluate themselves and submit to evaluation according to how closely they conform to a given standard-leaving little opportunity to deliberate about the appropriateness of the standard itself. Although in theory NG supports a plurality of regulatory approaches, often it is used more to monitor and self-monitor according to a predetermined policy or institutional choice.

Equally importantly, the unexamined common sense solutions found in jurisdictions that exercise larger influence at the FSB secretariat continue to dominate to the exclusion of other possibilities and at a cost to the international legitimacy of the organization as a whole. A failure of deliberation and the transformation of NG instruments into tools of surveillance exacerbates problems of democratic accountability.

\section{Audit culture}

Finally, although NG tools can be effective means of learning and consensus building, many regulators suggest a degree of frustration with the volume of paperwork produced by NG initiatives, and a concern that the time demands of these assignments do not produce sufficient practical rewards.

In an era of seriously curtailed government budgets, time spent on peer review, on international meetings, and on information exchange is time that is not available for other regulatory initiatives. Furthermore, many of these reviews in turn make requests for information that place demands on market participants, and these demands have also mushroomed to the point that risk-management staff in some banks claim to spend 
almost half of their time responding to regulators' requests for information- often so that such information can be sent to international organizations.

Social scientists have begun to explore the costs of so-called audit cultures or audit societies - governance systems rooted principally in self-reporting strategies. These costs include lost labor resources devoted to wasted reporting efforts, but they also include information overload, "anxious preoccupation with how one is seen by others," and an erosion of trust within institutions.

The reasons why such processes may begin to seem like "paperwork" rather than true exercises in deliberation relate once again to how these tools become standardized and institutionalized into fairly rigid models. This suggests that at a minimum more attention needs to be paid to designing a peer-review and self-monitoring process that fosters meaningful dialogue and deliberation by making room for respondents to challenge the terms of the question or the assumptions behind the review itself.

\section{Part V: Conclusion}

The attention of policymakers, market participants, and many of their interlocutors in the academy has focused on the details of particular policy initiatives of the moment without much regard for the wider sum of the regulatory parts. The predominant architecture deployed by the FSB - the NG architecture - may have been chosen largely by default, and perhaps without sufficient critical analysis or empirical study.

However, recent coordination challenges surrounding financial regulation in the EU that have surfaced in the past year, together with the weaknesses of the American collaborative approach to regulation demonstrated by the financial crisis of 2008, suggest that at a minimum this model should not be adopted without reflection. The aim of this article therefore has been to initiate a debate about the range of available approaches, and the strengths and weaknesses of each in international financial regulation to be deployed by the FSB in particular, as it addresses the challenges of G-SIFIs.

Thus, a preliminary hypothesis for future research emerges from this analysis: NG mechanisms may be effective in resolving some kinds of problems caused by the interrelationship of legal regimes in a pluralistic regulatory order, but they are unlikely to be suitable to all problems. That is, at the very least, a robust international financial governance structure necessitates some other kinds of international legal arrangements alongside NG mechanisms. This hypothesis merits empirical study, and also suggests the need for debate about the full range of possible legal alternatives for a global financial architecture. In short, the general validity of the NG model should not simply be accepted as an untested and unchallenged article of faith.

\section{A. Possible avenues for reform}

The research into uses of NG techniques in other international institutional contexts, together with lessons learned from the application of NG techniques by national regulators 
to domestic financial markets, does preliminarily suggest that a number of reforms of, or limitations on, NG mechanisms might improve their efficacy. These include:

\section{A more inclusive process}

More attention should be paid to the form through which consensus about such reform initiatives as capital adequacy requirements for G-SIFIs is reached in the first place. Market participants point out that they have very few opportunities even to learn about negotiations at the FSB, let alone to participate in them meaningfully, until after the agreement is complete. While the FSB rule-making procedure allows for a public comment period, market participants argue that they have little sense of whether their comments have any impact on outcomes at all. The same is largely true of domestic legislators.

One of the lessons of recent innovations in international law and institutions is that bringing a wider range of actors into the negotiation process creates far greater success at the implementation stage. One early example of the use of soft law techniques to create global consensus was the United Nations World Conference model, in which national delegations were expected to include representatives from a wide range of governmental and non-governmental organizations, and in which virtually any legitimate nongovernmental organization was allowed to participate as an observer to the process. In practice, such conferences have proven to be quite successful in generating broad and deep consensus for reform in individual nations on difficult social topics.

Of course it may not be possible to open up the financial regulatory process to this extent. Many national regulators express a need for a space for discussion and coordination away from the political pressures they experience from market participants in which to construct rules that serve the wider social good. Regulators involved in the FSB rule-making process have concerns about the impact of openness on the ability to reach consensus, on how confidential information can be shared, and even on potential questions of sovereignty and national security in opening this process to a wider range of public and private actors. While these are legitimate concerns, the exclusion of the full range of interested parties from the negotiations creates its own practical costs as well as challenges to the legitimacy of the consensus reached through NG methods.

There is also another reason to favor openness in the FSB process. A broader and more diverse FSB membership could be a benefit to better governance by helping to preserve the plurality and diversity of views that is vital to the success of NG techniques. Ironically, the premise of NG, that through such techniques a broad base of stakeholders can and should be enrolled in decision-making processes, has been sidelined as NG has been translated into an international regulatory structure at the FSB.

\section{Better procedural regulation of $\mathcal{N} G$ processes}

We saw that although the ideals behind NG are often laudable, the implementation can stray far from those ideals. We also saw that NG processes impose substantial burdens on national regulators and on the private sector. Finally, we saw that there are increasing 
concerns about the legitimacy of the authority of a small group of technocrats at the FSB secretariat and of small, unelected subcommittees of the FSB plenary.

Concerns about similar processes in other international institutional contexts has led legal scholars to ask whether this explosion of law making within international technocratic organizations should not be subject to greater procedural safeguards, just as the rule of law requires subjecting domestic administrative agencies to procedural safeguards. Kingsbury and his colleagues in the Global Administrative Law project at the NYU Law School have identified this "accountability deficit" as a primary target for international legal reform across numerous policy areas (Krisch and Kingsbury 2006).

These safeguards could include, for example, greater disclosure about the positions national representatives take at international meetings, more detailed rules concerning the process of agreement at meetings and the process of producing and evaluating peer-review reports that would constrain bureaucrats' discretion and provide greater opportunities for input from a wider range of participants, more detailed rules concerning standards of proof and evaluation in reaching conclusions, and opportunities for some higher or alternative level of appeal for review of FSB procedures.

\section{More narrowly tailored assessment tools}

Comparative research in other fields suggests that NG methods are most effective when the problem they seek to address is very narrowly tailored. In such cases, peer review can be more focused, and discussions in supervisory colleges can be more specific and meaningful.

\section{Greater resources for monitoring and deliberation activities}

Finally, many of the problems associated with implementing NG ideals stem from lack of adequate resources.

\section{B. Recommendation}

Mount a cross-disciplinary, cross-jurisdictional research project aimed at evaluating the strengths and weaknesses of the FSB experience with NG methodologies to date, and at identifying the conditions under which those methodologies are successful, and those in which they require supplementation with other methods.

What is needed now is a detailed study, based upon several case studies of particular, specific regulatory or compliance initiatives that would provide a detailed, empirical picture of how NG methodologies are currently being used both from the point of view of the FSB secretariat and committee structures, and from the point of view of national bureaucracies and national interest groups in several representative jurisdictions. The focus should be on the microprocesses by which consensus over compliance is or is not reached. The few studies we have suggest that the process of reaching consensus between peer-review committees and regulated states is a far more complex process than the official procedures suggest, and that there is some room for variation and contestation. 
The emphasis should be on the relationship between these microprocesses and "issues of implementation, effectiveness, and local impact" across different jurisdictions with different market challenges and regulatory approaches. This requires a detailed, objective picture of the social and institutional processes at work in regulatory technologies such as peer review, standards making, and supervisory colleges. What is the experience of regulation by those who are subject to these processes and how does it shape their behavior? How do these practices alter or realign existing power dynamics in the market and among nations? Under what precise conditions are such practices effective and when are they ineffective?

Since the very problem to be studied is the efficacy of questionnaire- and committeebased information-gathering processes, this study cannot rely entirely on such processes. Rather, what is needed is a combination of observational and interview-based methods. On the basis of this empirical information, it will be possible to determine when NG techniques are the ideal governance tools in international financial governance and when they should be supplemented with other kinds of governance tools.

\section{Note}

1 Jack G. Clarke professor of Far East legal studies, Cornell Law School. The author thanks the Bank of Japan's Institute for Monetary and Economic Studies for hosting me during the course of this research, and Minoru Aosaki, Michael Dorf, Cristie Ford, Mikari Kashima, Naoko Shindou, and Hirotaka Hideshima for their very helpful comments and criticisms. Chika Watanabe, Diana Biller, and Yi Zhang provided excellent research assistance. This article is an abridged version of an article published in Monetary and Economic Studies (November 2013, vol. 31) by the Institute for Monetary and Economic Studies, Bank of Japan. This abridged edition is published with the permission of the Institute for Monetary and Economic Studies, Bank of Japan.

\section{References}

Draghi, Mario. 2011. "Progress of Financial Regulatory Reforms," Financial Stability Board letter to G20 leaders, October 31, 2011. Online: http://www.financialstabilityboard.org/ publications/r_111104ff.pdf (accessed August 18, 2014).

Eubanks, Walter W. 2010. The Status of the Basel III Capital Adequacy Accord. Congressional Research Service report for Congress, October 28. Washington, DC: CRS. Online: http://www.fas.org/ sgp/crs/misc/R41467.pdf (accessed August 18, 2014).

Financial Stability Board (FSB). 2009. Financial Stability Board Charter. Basel: FSB. Online: http:// www.financialstabilityboard.org/publications/r_090925d.pdf (accessed August 18, 2014).

2010. FSB Framework for Strengthening Adherence to International Standards. January 9. Basel:

FSB. Online: http://www.financialstabilityboard.org/publications/r_100109a.pdf (accessed August 18, 2014).

2012. SCSI Thematic Review on Risk Governance: Questionnaire for National Authorities. April 3. Basel: FSB. Online: http://www.financialstabilityboard.org/publications/r_120404.pdf (accessed August 18, 2014).

Ford, Cristie L. 2010a. "New Governance in the Teeth of Human Frailty: Lessons from Financial Regulation." Wisconsin Law Review 2010: 441-87.

2010b. "Principles-Based Securities Regulation in the Wake of the Global Financial

Crisis." McGill Law Fournal 55: 257-307. 
. 2011. "Macro and Micro Level Effects on Responsive Financial Regulation." University of British Columbia Law Review 44 (3): 589-626. Online: http://papers.ssrn.com/sol3/papers. cfm?abstract_id=2008495 (accessed August 18, 2014).

Gonzalez, Maria, and Alfred Schipke. 2011. "Bankers on the Beach." Finance and Development 48 (2): 42-5.

Krisch, Nico, and Benedict Kingsbury. 2006. "Introduction: Global Governance and Global Administrative Law in the International Legal Order." European Fournal of International Law 17 (1): 1-13.

Krugman, Paul. 2010. "Financial Reform 101." New York Times, April 1. Online: http://www. nytimes.com/2010/04/02/opinion/02krugman.html (accessed August 18, 2014).

Reich, Robert. 2010. "Why Obama Must Take on Wall Street." Financial Times, January 12. Online: http://www.ft.com/intl/cms/s/0/0666adfe-ffb6-11de-921f-00144feabdc0.html (accessed August 18, 2014).

Sabel, Charles H., and William Simon. 2006. "Epilogue: Accountability without Sovereignty." In Law and New Governance in the EU and the US, edited by G. De Búrca and Joanne Scott, 395-412. Oxford: Hart.

Sabel, Charles H., and Jonathan Zeitlin, eds. 2012. Experimentalist Governance in the European Union: Towards a New Architecture. New York: Oxford University Press.

Sato, Takafumi. 2009. "Tightening Capital Rules Could Increase Risk-Taking." Financial Times, June 30. Online: http://www.ft.com/intl/cms/s/0/f5d750b8-659d-11de-8e34-00144feabdc0. html\#axzzluCfBmYqk (accessed August 18, 2014).

Verstein, Andrew, and Roberta Romano. 2011. "Assessing Dodd-Frank." John M. Olin Center for Studies in Law, Economics, and Public Policy Research Paper, August 11: 1-150.

Walter, A. 2010. "Can the FSB Achieve Effective Surveillance of Systemically Important Countries?" In The Financial Stability Board: An Effective Fourth Pillar of Global Economic Governance, edited by E. Helleiner, S. Griffith-Jones, and N. Woods, 32-5. Ontario: Centre for International Governance Innovation. 



\section{LIST OF CONTRIBUTORS}

Anat R. Admati, PhD, George G. C. Parker Professor of Finance and Economics at the Graduate School of Business at Stanford University. She has written extensively on information dissemination in financial markets, trading mechanisms, portfolio management, financial contracting and, most recently, on corporate governance and banking. Since 2010, she has been active in the policy debate on financial regulation, writing research and policy papers and commentary. She is co-author of the book, The Bankers'New Clothes: What's Wrong with Banking and What to Do about It (Princeton University Press, 2013).

Paul Atkinson has held a number of positions at the Organization for Economic Cooperation and Development (OECD) for most of the period between 1981 and 2005 including as editor of OECD Economic Outlook for a number of years - after which he was appointed senior research fellow with the Groupe d'Economie Mondiale at Sciences-Po, Paris. He has also worked on macroeconomic policies and structural reform issues at the New Zealand Treasury in Wellington and spent two years at the Institute of International Finance in Washington D. C.

Nina Boy is a senior researcher at the Peace Research Institute Oslo and coordinates a work package on finance-security relations for the EU-funded Societal Security Network. She holds a PhD in Politics from Lancaster University and an MA in International Studies and Diplomacy from the School of Oriental and African Studies, University of London. Her work explores the security dimensions of sovereign creditworthiness, collateral, social imaginaries and the modern co-evolution of finance, society and the public. She has been a management team member of the COST Action System Risk, Financial Credit and Crisis from 2010 to 2014 and led the working group Credit, Crisis and Culture: Historical, Sociological and Literary Perspectives. She co-edited a special issue of Security Dialogue on the global governance of security and finance in 2011 with Anna Leander and J. Peter Burgess.

Adrian Blundell-Wignall, $\mathrm{PhD}$, special advisor to the secretary-general on financial markets and deputy director in the Directorate for Financial and Enterprise Affairs at the OECD. He is the co-author of numerous papers, including most recently "Bank Lending Puzzles: Business Models and the Responsiveness to Policy" and "Business Models of Banks, Leverage and Distance-to-Default." 
Claudio Borio is head of the Monetary and Economic Department and former director of research and statistics at the Bank for International Settlements. From 1985 to 1987, he worked as economist at the OECD in the country studies branch of the Economics and Statistics Department. Prior to that he was a lecturer and research fellow at Brasenose College, University of Oxford. He is the author of numerous publications in the fields of monetary policy, banking, finance and issues related to financial stability. Recent work includes "Unconventional Monetary Policies: An Appraisal" and "Global Imbalances and Financial Stability: Rethinking the Role of International Finance" (both co-authored with P. Disyatat).

Martin Čihák, PhD, Advisor at the International Monetary Fund (IMF). His previous work includes leading the World Bank's Global Financial Development Report (2013) on "Rethinking the Role of the State in Finance" and Global Financial Development Report (2014) on "Financial Inclusion." Čihák has written broadly on matters of financial regulation, and specifically contributed to the debate on special bank resolution regimes with the 2009 IMF Working Paper "The Need for Special Resolution Regimes for Financial Institutions: The Gase of the European Union," published in Harvard Business Law Review (2012) (co-authored with Erlend Nier).

Peter M. DeMarzo, PhD, Mizuho Financial Group Professor of Finance at the Stanford Graduate School of Business. Professor DeMarzo's research is in the area of corporate finance, asset securitization and contracting, as well as market structure and regulation. Recent work has examined issues of the optimal design of securities, the regulation of insider trading and broker-dealers, and the influence of information asymmetries on corporate investment and financing. His publications include "Endogenous Information Flows and the Clustering of Announcements" and "Optimal Security Design and Dynamic Capital Structure in a Continuous-Time Agency Model," as well as the leading MBA finance textbook, Corporate Finance (Pearson Prentice Hall, 2014).

Sheila G. Dow, emeritus professor of economics, University of Stirling, Adjunct Professor of Economics, University of Victoria, and former special adviser on monetary policy to the UK Treasury Select Committee. She has published a range of books, book chapters, journal articles and reports on the theory and practice of money and banking, monetary policy, bank regulation and regional finance. Her latest publication on money and banking, co-authored with Victoria Chick, is "Financial Institutions and the State: A Re-examination" (2013). Her current research is focused on questions of banking reform in the wake of the crisis.

Ismail Ertürk, senior lecturer, Manchester Business School. His research interests include financialization, central bank unconventional policies, bank business models, financial innovation, corporate governance, executive pay, financial literacy, household financial portfolios and cultural economy. He is the co-author of After the Great Complacence (Oxford University Press, 2011), "Central Bank-Led Capitalism?," "Reconceptualizing Financial Innovation: Frame, Conjuncture and Bricolage" and "Banks as Continuous Reinvention." 
Daniela Gabor, associate professor, University of the West of England. She is interested in critical macro-finance. Her research focuses on three connected themes - the rise and regulation of shadow banking (new forms of money); new discourses and practices of central banking in market-based financial systems; and global governance of capital flows and global banks. She is the author of "The IMF's Rethink of Global Banks," Governance (2014) and "Learning from Japan: The ECB and the European Sovereign Debt Crisis," Review of Political Economy (2014).

Charles Goodhart, PhD, emeritus professor of banking and finance, director of the Financial Regulation Research Programme, Financial Markets Group, London School of Economics and Political Science. Besides having published widely on monetary theory and history, he is a prolific researcher and a central figure in the post-crisis debate on crafting effective resolution regimes. See, for example, Emilios Avgouleas, Charles Goodhart and Dirk Schoenmaker, "Bank Resolution Plans as a Catalyst for Global Financial Reform," Journal of Financial Stability (2011).

Andrew G. Haldane, chief economist at the Bank of England and executive director, Monetary Analysis and Statistics. He is a member of the bank's Monetary Policy Committee. He also has responsibility for research and statistics across the bank. In 2014, TIME magazine named him one of the 100 most influential people in the world. Andrew has written extensively on domestic and international monetary and financial policy issues. He is co-founder of Pro Bono Economics, a charity which brokers economists into charitable projects.

Martin F. Hellwig, PhD, director at the Max Planck Institute for Research on Collective Goods and Vice-Chair, Advisory Scientific Committee of the European Systemic Risk Board. He has conducted research in many areas of economics, in particular, financial markets and financial institutions. In the 1990s, he wrote several papers on the role of banks in the economy and on systemic risk in banking and finance. More recently, he has co-authored (with Anat Admati) the book, The Banker's New Clothes (Princeton University Press, 2013). Other recent publications include "Systemic Risk in the Financial Sector: An Analysis of the Subprime-Mortgage Financial Crisis" and "Financial Stability, Monetary Policy, Banking Supervision and Central Banking."

David G. Mayes, PhD, professor of banking and financial institutions, director of the Europe Institute, director of the New Zealand Governance Centre, University of Auckland. He has previously held positions as chief economist and chief manager at the Reserve Bank of New Zealand and advisor to the board at the Bank of Finland. He has conducted a number of comparative studies of national bank resolution regimes, notably "Banking Crisis Resolution Policy: Different Country Experiences," Norges Bank Staff Memo no. 10 (2009) and "Who Pays for Bank Insolvency" with Aarno Liuksila. He has published widely, particularly in the field of economic, financial and 
monetary integration. He is an editor of Economic fournal and a member of the Australia and New Zealand Shadow Financial Regulatory Committee.

Erlend Nier, PhD, deputy division chief with the IMF's Monetary and Capital Markets Department. In his position with the IMF, he covers monetary policy and financial stability, including the implications of the financial crisis for public policy. Prior to joining the IMF, he was Research Manager with the Bank of England's Financial Stability Directorate, leading research and policy work in areas such as bank transparency and market discipline, the pro-cyclicality of capital requirements, liquidity risk and regulation, and public policy in clearing and settlement systems. Erlend Nier has published his research in official publications, a number of academic journals, as well as a book, The Economics of Large-Value Payments and Settlement (Oxford University Press, 2009).

Paul Pfleiderer, PhD, G. O. G. Miller Distinguished Professor of Finance at the Stanford Graduate School of Business. Much of his research has been focused on issues arising in financial markets when traders are asymmetrically informed. He has developed theoretical models to analyze how information is incorporated in prices through trading and how information flows determine trading volume. He has also analyzed how information is sold to investors when the value of the information is reduced the more widely it is disseminated. In addition he has studied problems in measuring active funds' performance, contracting concerns in venture financing, policy issues related to disclosure requirements and explanations for the stock market crash of 1987. His current research concerns corporate governance and the regulation of financial institutions.

María Retana is an economist in the Danish think tank, DEA. Before being recruited by DEA, María was research assistant at the Danish Institute for International Studies (DIIS) and co-organizer of the Central Banking at a Crossroads conference. Prior to her employment with DIIS, she was a junior professional associate in the Education Division of the World Bank, Washington D. C.

Annelise Riles, Jack G. Clarke Professor of Law in Far East Legal Studies, professor of anthropology at Cornell and director of the Clarke Program in East Asian Law and Culture. Her work focuses on the transnational dimensions of laws, markets and culture across the fields of comparative law, conflict of laws, the anthropology of law, public international law and international financial regulation. Her most recent book, Collateral Knowledge (Chicago Press, 2011), is based on ten years of fieldwork among regulators and lawyers in the global derivatives markets. Her recently published article "Managing Regulatory Arbitrage: A Conflict of Laws Approach" in the Cornell International Law Journal explores what conflict of laws can contribute to global financial regulation. She is the founder and director of Meridian 180, a virtual think tank on Pacific Rim issues. She also writes about financial markets regulation on her blog, http://blogs.cornell.edu/ collateralknowledge/. 
Caroline Roulet, PhD, economist at the OECD. Caroline is co-author of a number of papers with Adrian Blundell-Wignall, including "Business Models of Banks, Leverage and the Distance-to-Default" and "Long-Term Investment, the Cost of Capital and the Dividend and Buyback Puzzle."

Manmohan Singh, PhD, senior economist at the IMF in Washington D. C. He writes extensively on topical issues including deleveraging in financial markets, rehypothecation of collateral, money and collateral, and counterparty risk in OTC derivatives. He has written a new book, Collateral and Financial Plumbing (Risk Books, 2014) that looks at all the above issues from the lens of financial collateral. He has led workshops for the IMF on strategic asset allocation and regulatory proposals to official sector policy makers.

Jakob Vestergaard, PhD, senior researcher at the Danish Institute for International Studies. He has published a number of articles on various aspects of global economic governance and is the author of Discipline in the Global Economy? International Finance and the End of Liberalism (Routledge, 2009). 



\section{INDEX}

Numbers in bold refer to tables and figures.

Abe, Shinzō 217

Abenomics 217

Acharya, Viral 77

aggregate demand 159, 198

aggregate risk 235-36

aggregation 22, 26, 53, 114

algorithms 225; risk-weighted 21

Amagerbanken 118

American International Group (AIG) 62, 110

Anglo-Irish Bank 129, 133

antitrust law 248

arbitrage $16,23,51,62,159$; regulatory 6,46 , 53, 249; and self-regulation 18

asset bubbles 217, 234-35

asset management 115-16, 148

asset markets, stabilization of 235

asset price volatility 62

Asset Purchase Facility 224

Asset Purchase Programme 147, 224

asset sales 52

asset valuation correlation (AVC) multiplier 56

assets: accumulation of 201; allocation of 22;

bad 52; banking book 20; clean vs. toxic 115; illiquid 161-62; risk-weighted 2; safe 143; sales of 52; targeted purchase of 160-61; see also collateral

audit culture, in FSB 258-59

Australia: deposit guarantee in 127; influence on New Zealand 126-28

Austria: bank capitalization in 78; funding sources in 164; sovereign bond portfolios of 167; special resolution powers in 111

average risk weights 17; and leverage ratio 18; for UK banks 23; for UK banks under different approaches $\mathbf{2 6}$

backstop measures 77

bailing in 7, 99, 125, 138n16; in New Zealand 128-32; see also open bank resolution bailouts 33, 40-41, 75, 109-10, 125, 171

balance sheet policies 194-95, 197, 223

balance sheet recessions 205, 208

balance sheet threshold 113

balance sheets: of Bank of England 221, 224; of central banks 220,226; and equity requirements 35-36; post-bubble debris on 226

bank capital: and Basel III 16; regulation of 4 -6; see also capital

Bank for International Settlements (BIS) 178, 221

bank lending channel 158; see also lending Bank of England (BoE) 9, 58, 106, 125, 147, 180, 184n1, 185n3, 218-19; agreement with FDIC 100; balance sheet of 221, 224 ; founding of 179,183 ; liquidity provided by $224-25 ; 1930$ s to $1960 \mathrm{~s}$ 236-37; quantitative easing by 220

Bank of Japan 160-61, 205, 218; monetary policy extremism in 217

Bank of New York (BNY Mellon) 146, 148, 154

Bank Regulation and Supervision Survey 7

bank resolution 6-8; beyond the SRR 117-19; cross-border issues 119-20; in the EU 135-36; framework for 112-17; during the global financial crisis 111-12; industry-funded 118; need for SRRs 109-11; see also New Zealand bank resolution

bank-holding companies (BHCs) 57

Banking Act (2009; UK) 114

Banking Regulation and Supervision Survey (World Bank) 112

banking resolution fund 104-5

bankruptcy 6-7, 97; corporate 109-10, 111; of problem banks 116

banks and banking: bridge 115; causes of failure in 52; collateralized funding 
of 9 ; cost of rescue 4 ; cross-border 2, 8, 99-102; deposit 6; distressed 1; Eurozone 220; factors encouraging runs 8; failing 6-7, 97-98; financial services 97; fractional reserve 234-35; global 106n2, 164; history of and the role of collateral 230-32; investment 235, 242n6; lending abilities of 35-37; leverage of 17; levy imposed on 106; multinational 119; nationalization of 234, 248; partnerships with other entities 98; problem 7; regulation of 1-2, 238; systemic 39 ; taxes paid by $62,64,105$; transnational 1, 164; universal 99-102, 233, 235; see also bank resolution; business models of banks; central banks; cross-border banking; problem banks; retail banks and banking; shadow banks and banking

Baring crisis 178

Basel Committee of Bank Supervisors (BCBS) 1, 19-20, 27, 51, 54, 57, 59-60, $70,85,250$

Basel I Agreement 15-16; objectives of 18, 20; requirements of $52-53$

Basel II Agreement 1, 2, 16; changes from Basel I 53, 70; problems with 53-54, $72 \mathrm{n} 13$; revision of 51

Basel III Agreement 2, 5-6, 16, 29, 33, 78, 146-47, 153, 248; assessment of 58-59; capital-regulation reforms of 54-57; complexity problems 59-61; cost of implementing 25; and the European banking system 76, 84-86; inadequacy of requirements 85-86,

86; issues addressed by 51 ; leverage problems 59-61; Liquidity Rules (LCR) 3 ; national approaches to address shortcomings of 57-58; as replacement for Basel II 65

Basel system, history of 52

Bear Stearns 113

Belgium: repo transactions in 166; sovereign bond portfolios of $\mathbf{1 6 7}$

Bernanke, Ben 161, 217-18

BETA (systemic importance variable) 67

BlackRock 181, 184

BNP Paribas 78

bond indexing 183

bonds: bail-inable 104-6; corporate 9, 56-57, 219, 224; covered 129, 174n5, 174n7;
Eurozone government bonds 149; foreign government bonds 167-68, 167; see also government bonds; sovereign bond markets; sovereign bond portfolios

booms 17-18, 191-92, 194-201, 203, 205, 207-208, $21 \ln 27,235-237,240$; -andbust cycles 43, 48n16, 196, 203; credit and asset price $209 \mathrm{n} 9$

Borio, Claudio 21 7, 221, 227

borrowing rates $40-41$

bridge banks 115

Brown, Sherrod 29

Brown-Vitter proposals 29

Buiter, Willem 224

Bundesbank $21 \ln 29,218$

Burns, Arthur 202

business models of banks $51-52,54$; risk issues 58-59, 61-62, 65

Calomiris, G. W. 103

Canada, special resolution powers in $111,113,115$

Canadian banking regulator (OSFI) 115

Canadian deposit insurance agency (CDIC) 115

capital: base 54; cost of 38-39; defined 34-35; high quality 87 ; inflows of 199; intangible 97 ; misallocation of 196 , 201, 222; raising quality consistency and transparency of 54 ; regulation of 5-6, 25-26, 33-34; risk-based measures of 23, 29; see also bank capital; equity capital; money

capital adequacy 1 ; assessment of 20; regulations 250; standards $16,18,29$

capital buffers 5, 51, 54, 201; countercyclical 2, 54, 56, 88-89, 91n 10

Capital Purchase Program 48n14 capital ratios 4; capital to asset 6; capital to total assets 75 ; ceiling on 88-89; increasing 6 ; risk-based 21; to riskweighted assets 2; see also leverage ratios

Capital Requirement Directive (CRD) 87; see also CRD4

Capital Requirement Regulation (CRR) 86-87; see also CRD4

capital requirements 34-35, 235, 260; contingent 118; variability in 19; see also equity requirements 
capitalism 10, 226; and the central banks 226; low-growth 11, 221-26; role of central banking in sustaining 2; varieties of 163 capitalization 5; market 183; study of

European banks 79-84

Caruana, Jaime 178

cash net outflow 56

CDS hedging 62

CDS spreads 30n1

Central Bank Governors 27

central bank intervention 3; during crisis

159-65, 196, 218; during normal times 158-59; rise of unconventional policies 218-21; skepticism regarding unconventional policies of 217-18; unconventional monetary policies of 221-22, 226-27; see also intervention and interventions

central banking: and market-based finance 2; challenges faced by 10 ; during crisis, 173-74; effect of global financial crisis on 191; future of 191-92, 202-3; history of and the role of collateral 232; see also central banks

central banks: balance sheets of 220, 226; challenges and open questions 1,3 , 297, 200-202; and collateral 8, 146-48; collateral management strategies 165-68; and the collateral market 143-44; in core capitalist countries 217-27; as dealers of last resort 1 , 235; developments since 2010 203-9; goals of 229, 24ln3; importance of independence for 11, 200-201, 206, 210n19, $211 \mathrm{n} 29$, 230, 236-41; influence of over financing conditions 157; and the intellectual backdrop 192-95; large-scale asset purchases by 223-26; as lender of last resort 2-3, 159, 193, 217-18, 226, 231-32, 234; long position on low-growth capitalism 221-23; as nexus between banks and non-banks 154; and non-tradable assets 11; policies of 204; proposed adjustments to policy regimes 199-200; as providers of liquidity 193; providing protection for retail banks 234; purchase of financial assets by 218; QE by 153 ; realistic expectations of 201-2; relationship with governments 4, 229-41; repo market funding
165-68; risk of overburdening 208; risks of 207-8; role of $11,234,241$; and sovereign debt 11, 229; sovereign funding costs and debt issuance 165; working hypotheses for the future 195-99; see also central banking; central bank intervention

central clearing counterparties (CCPs) 55, 63-64, 146-47, 149

central security depositories (CSDs) 146-47

Chile, sovereign risk in 185n9

Citi/Citigroup 133, 224

Clearstream Banking SA 147-48

CoCos: see contingent convertible capital collateral: and central banks 146-47; changing collateral space 145-50, 146; custodians of 8, 146-48; demand for 61; and financial plumbing 154; gross credit exposure of $\mathbf{6 1}$; implications with exit strategies 153-55; importance of 143; insufficient 11; intermediation 2; internationalization of 9; liquid 148; management strategies for 158, 163, 173-74; and monetary policy 150-53; and new (net) debt issuance 149; new regulations regarding 147; political economy of 157-74; price of 9, 144-45; rehypothecation of 154; relationship with money 2 ; reuse of $8,174 \mathrm{n} 9$; role of in risk sharing 232 ; shortages of 8,172 ; sovereign 166 ; transformation of 8 ; unwinding of 153 ; velocity of $8,147,150-51$

collateral buffers 146 collateral calls $63, \mathbf{6 3}$ collateral channel 161, 163 collateral discrimination 171 collateral markets: liquidity of 167 ; stabilization of 170

collateral policies: adjustments to 161-62; via the IS/LM framework 150-53

collateral rates 144, 153; Eurozone vs. US 144; see also repo rates

collateral space: changes in $145-50, \mathbf{1 4 6}$; reshaping 8

collateral swaps 221

collateralized market funding (repo funding) 165-68

Collins Amendment to Dodd-Frank Act (2010; US) 28, 57

Commerzbank 78 
committed liquidity facility (CLF) 150

commodity fetishism 183

common equity T1 (CET1) 54, 58

Comprehensive Capital Analysis and Review (CCAR) 57

confidence 239-40

consumer society 183

contingent convertible capital (CoCos) 118 , 129, 248-49

coordinated market economies (CMEs) 217

coordination 259; public-private 257; among regulators 250

Core Tier 1 (CT1) ratio 78, 79-80, 79; in European banks $76-85$

corporate bonds 9, 56-57, 219, 224

Council of the European Union (EU) 87-88

counterparties 159; creditworthiness of 218; see also central clearing counterparties (CCPs)

counterparty credit risk (CCR) 51-53, 55, 58,148

covered bonds 129, 174n5, 174n7

CRD4 (fourth Capital Regulation Directive) 5-6, 58, 75, 87-89

credit: control 223; creation of 200; crunches 43 ; provision of 46 ; suppliers and availability of 234

credit lines, zero-weighted 24

credit ratings $30 \mathrm{nl}$

credit valuation adjustments (CVA) 55; charges 70-71; leading to concentration bias 65; zero charge 63

creditors: bail-in of 7; losses for 116-17

crisis management and prevention 200

cross-border banking 4, 119, 125, 137n5, 163-65, 245

cross-currency flows and inflows 197, 199

Crown Retail Deposit Guarantee Scheme 134

cultural criticism, modern and postmodern 183

currency: global reserve 185n8; value of 11; see also money

currency overshooting 198

currency wars 208

CVA: see credit valuation adjustments

Cyprus, resolution procedures in 7

Danske Bank 137n7

De Grauwe, Paul 158

debt: as collateral 2, 9, 177-78, 232;

convertible 118; as financing vehicle 97; increasing value of, 42; issuance of 146 , 149; Latin American 24; management of 233, 238; national 179; non-financial 204; social costs of 40; tax and bailout subsidies associated with 39-40; tax subsidies on 40-41; subordinated 48n14, 129; valuation of 232; see also government debt; public debt; public sector debt; sovereign debt

debt overhangs 41-42, 48n19, 201, 222 debt-to-GDP ratio 203 default 201, 222; risk of 40-41, $7 \ln 5$ default probabilities, variability in 19, 19 deleveraging 48n19, 52, 106, 151, 163, $174 n 9,203$

democracy deficit 254

Denmark: bank resolution in 138n14; resolution tools in 118; sovereign bond portfolios of 167; special resolution powers in 111; subordinated debt in 129

deposit banking 6

deposit insurance 41; lack of 8; lack of in New Zealand 133-34; limit raised 103-4

depositors: as funders of large global banks 106n2; protection of 234; uninsured 132

Depository Trust and Clearing Corporation (DTCG) 154

deposits, liquid 46

deregulation 52, 233, 235

derivatives: business 70-71; counterparty 62-65; exposure 55-56; gross credit exposure of $61, \mathbf{6 1}$; in the leverage ratio 61 ; market 64 ; netted 60 ; origination 6, 51, 62; OTC 147; risk 53, 68, 70; trading 1

Deutsche Bank 78

distance to default (DTD) 65-68; determinants of 69; modeling 66-70; 2012 US vs.

Europe 67

Dodd-Frank Act (2010; US) 1, 25, 57, 65, 118, 146-47, 248; Collins Amendment 28,57

double-entry bookkeeping 180

Draghi, Mario 251

Druckenmiller, Stanley 218

East Asia, debt crisis in 178

East India Company 180, 185n3

ECB: see European Central Bank 
Economic and Financial Affairs Council (ECOFIN) 87

economic fictions, and public credit 181-84 economic recovery, and bank resolution 109 economics, monetary 10, 192, 24ln1; neoclassical 10

efficient market hypothesis 157-58, 160

EMIR 146

endowment effect 210n11

Enhanced Credit Support Strategy 168, 220

Enhanced Disclosure Task Force (EDTF) $27-28$

equilibrium state 7,106

equity capital 2, 5-6, 44, 76

equity cushions 44

equity funding 33

equity ratios, unweighted 44

equity requirements 33-34; alternative responses to 36, 36; arguments against 56; and bank lending 42-44; capital adequacy 104; in European banking system 85-86; fallacies regarding 34-39; increasing 46; see also capital requirements

euro crisis 3, 157, 220

Euro Overnight Index Average (EONIA) $159,174 \mathrm{n} 1$

Euroclear Bank 147-48

Europe: banking crisis in 90; external financing in $174 \mathrm{n} 4$; monetary policy extremism in 217; sovereign debt crisis in 1, 3; see also European Union; Eurozone

European bank recapitalization 75-77, 89-90; and the CRD4 86-89; equity capital requirements too low 85-86; German and French banks as core of problem 82-84; misleading characterization of 75-76; results of study $80-82$; stress tests and recapitalization exercises 76-77, 89; study methodology 79-80; summary and conclusion 75-76, 89-90; weakness of capital requirements 84-85

European Banking Authority (EBA) 6, 30n2, 75-76, 119; stress test performed by 76-77, 89

European banks: Basel III monitoring exercise 76; capitalization of, 75-79, 79; collateralized funding in 158; continued undercapitalization of 79-84; equity requirements in 85-86;
EU capital exercise 76; resilience of 76; scapegoating of Southern European banks 77-79; stress test performed 76-77, 89; systemic risk to 90; and the US financial system 164; see also European bank recapitalization; European Central Bank (ECB) European Central Bank (ECB) 3, 9, 48n14, 102, 126, 135, 137n4, 147, 236; and collateral 149, 155, 166; dilemmas of 168-73; interventions by 159 ; introduction of unconventional policies by 218-19; long-term refinancing operation of $\mathbf{2 2 5}$; non-marketable assets held by 226 ; and QE 145; providing liquidity in the Eurozone 220; response to financial crisis 218; unconventional crisis policies of 169; see also European bank recapitalization; European banks; Securities Market Programme

European Commission 87, 170

European Financial Stability Fund (EFSF) 171 European Monetary Union (EMU) 237

European stability mechanism (ESM) 102 European System of Central Banks

(ESCB) 221

European Union (EU): bank resolution in 125; cross-border banking in 119; future of banking in 101; response to banking crisis by central banks in 218; special resolution powers in 111 ; see also Europe; Eurozone

Eurozone: bank capitalization in 76-79; banking metamorphosis in 136; banks in 220; collateral in 147, 155; collateral/ repo rates 145; cross-border bank funding in 163-64; ECB's long position on economy in 226; government bonds 149; importance of repo markets in 166-67; post-crisis recovery in 217; problems unique to 236; see also European Union; Europe

exchange rates 194; flexible 197; and the global financial crisis 198-99; management of 223; relationships 208

exit strategies 162-65, 169, 173, 226; collateral implications of 153-55, 172 expectations gap 208 expected exposure at default (EED) 53 
extended collateral term repo facility

(ECTRF) 224

externalities, negative 22, 33, 39-40, 109

Fannie Mae 144, 219

fear of floating 197, 210n13

Fed: see US Federal Reserve Bank

Federal Deposit Insurance Corporate Improvement Act (FDICIA) 103

Federal Deposit Insurance Corporation (FDIC) 68, 106, 113, 125, 129; agreement with Bank of England 100

Federal Open Market Committee

(FOMC) 219

Ferguson, Niall 208

fiat money arrangements 200-202

fictional realism 10, 182, 184

finance: collateral-based 8-10; market-based 2

finance theory 22

financial crisis: see global financial crisis

financial imbalances, indicators of 201

financial institutions, regulation and supervision of 194

financial lubrication 9, 151

Financial Policy Committee (FPG) of Bank of England 58

financial regulatory process 10,250

financial stability 4, 10, 192, 194-95, 202, 238, 240; and central banks 232-33, 240; financial 194; macroeconomic 193-94; monetary and financial 10, 192; price 193; see also price stability

Financial Stability Authorities (FSAs) $7 \ln 8$

Financial Stability Board (FSB) 1, 11, 27, 102, 117-18, 245; approach of 246; audit culture of 258-59; as closed organization 256; and global financial architecture 247-53; learning and surveillance 258; and the new governance approach 253-55; peer reviews in 257-58; standard setting 251; and the supervisory colleges 253

Financial Stability Report (IMF, 2012) 222

"fire sales" 143

fiscal policy 197, 238; limits on 237; and monetary policy 230

Fisher, Paul 218

Fisher, Richard 223

fixed-income securities 223

Flandreau, Marc 178

foreign bank organizations (FBOs) 57 foreign government bonds 167-68, 167

fractional reserve banking 234-35

France: bank capitalization in $75, \mathbf{7 9}, 80, \mathbf{8 1}$, 82-83, 84, 90; capital adequacy ratios in 83; as core of banking problem 82-84; downgrade of credit ratings in 220 ; equity to assets ratio in 6 ; influence of Liikanen proposal in 65; leverage ratios in $79, \mathbf{8 3}$; repo transactions in 166; sources of funding in 164, 164; sovereign bond portfolios of $\mathbf{1 6 7}$

Freddie Mac 144, 219

French Mississippi Company 180

funding: collateralized 158; markets 9; stable $6,51,56-57$; strategies 164-65

Funding for Lending 106

G7 international macroeconomic policy $21 \ln 29$

G20 27, 245

GAAP (Generally Accepted Accounting Principles) 55

general collateral finance (GCF) 154

general collateral (GC) repos 166

general equilibrium theory 230, 238-39

Geneva Report 7 1n8

Germany: asset relief program 120n8; bank capitalization in $75,78, \mathbf{7 9}, 80, \mathbf{8 1}$, 82-83, 84, 90; capital adequacy ratios in $\mathbf{8 3}$; collateral market in 173 ; collateralized repos in 172; as core of banking problem 82-84; dedicated resolution funds in 118; equity to assets ratio in 6; influence of Liikanen proposal in 65; leverage ratios in 79, 83; opposed to Securities Market Programme 157; repo transactions in 166; sources of funding in 164, 164; special resolution powers in 111

Glass-Steagall Act (1933; US) 52

global banks 106n2, 164

global financial crisis (GFC) 1, 3, 33, 103, 208, $24 \ln 2$; and bank resolution 109-10; bank resolution changes during 111-12, 112; causes of 5; effect on central banking 10, 191; effect in New Zealand 123; lessons learnt from 2; recovery from 203; response to $1-2,7$, 109, 241

Global Financial Stability Report (IMF) 143 global financial system, fragmentation of 106 
global legal pluralism 250

global systemically important financial institutions (G-SIFIs) 1 1, 59, 71, 72n18; capital adequacy requirements for 260; challenges of 259; coordination between home and host regulators 249; and derivative origination 62 ; and the DTD 66-68; identification of 246; vs. non-G-SIFI banks 60, 60; options for dealing with 248-49; overlapping regulatory and legal regimes of 245; understanding the problem of 247-249; see also systemically important financial institutions (SIFIs)

Global Taylor Rule $\mathbf{2 0 7}$

globalization 198, 208, 210n22, 232

gold standard 201

Gordon, Jeffrey 250

Goux, Jean-Joseph 181

government: fiscal constraints on 237; role of $2-4,264$

government bailouts: see bailouts

government bonds 157, 185n6; in Eurozone 149; interest rate on 161; purchased by Bank of England 224; purchased by Federal Reserve 220, 224; as "risk free" 87,161

government debt 196; as collateral 9, 177-78; purchase of 204-5; see also sovereign debt government guarantees, implicit or explicit $40-41$

government interventions 48n21, 52, 62, 72n16 granularity 16, 23, 28

Great Financial Crisis: see global financial crisis Great Moderation 1, 164, 191, 193-94, 202, 229, 232, 236, 240

Great Recession 191; see also recessions Greece: bailouts in 172; collateral market in 173; crisis in 171; default in 185n7; risk associated with collateral 170 ; sovereign bond portfolios of $167, \mathbf{1 6 7}$

Greenspan, Alan 217

Gross, Bill 227

gross credit exposure (GCE) 61, 61 gross domestic product (GDP) 229 gross market value (GMV) 61, 67

Growth and Stability Pact 167

G-SIB capital surcharge 86, 91n10

G-SIFI: see global systemically important financial institutions haircuts 143, 153, 166, 172, 174n6

Haldane, Andrew 85

harmonization, as coordination technique 249-51

HBOS 125

hedge funds 132, 149, 153-55

Heinzelman, Kurt 181

Herring, R. 103

high-quality liquid assets (HQLAs) 56

household mortgages 154; see also mortgagebased securities

HRE 113

hypothetical portfolio exercises (HPEs) 18-20, 28

Iceland, bank resolution in 119, 128

IFRS (International Financial Reporting Standards) 55, 67

IMF (International Monetary Fund) 118, 143

income redistribution 229

incremental risk charge (IRC) 55

index funds 183

inflation 10, 196, 198, 202, 206, 208, 209n6; controlling 237-38, 241; low and stable 194; reaction to 3; stabilization of 174n8, 193

inflation banking, universal 233

infrastructure 22, 115

insurance trade 180

intellectual backdrop 192; pre-crisis 193-94; post-crisis 194-95

interbank markets 151, 157, 159, 165; global 219 interconnectedness/interconnectivity/ interrelatedness 4, 11, 22, 33, 245, 253 ; in the repo market $62-63$

interconnectedness risk 55-56, 61-62; new empirical evidence on $65-70$

interdependencies 53, 238 interest on excess reserves (IOER) 144 interest rates 4, 152-53, 195, 199; hedges 72n17; low 221; measures of 3; policy for 195, 197; short-term 158-59, 193; short- vs. long-term 160; low 195; swaps 62; via Taylor Rule 152; ultra-low 201, 205, 209n10, 210n16, 210n22

intermediate holding companies (IHCs) 57 internal models 28, 51 internal ratings-based (IRB) approach 53 international bank models 6 international bank regulation, evolution of 16 
international financial governance architecture 246; see also Financial Stability Board (FSB)

international financial regulation 250 international law and institutions 255, 260 international policy cooperation 201 intervention and interventions 7, 114-15; by central banks 236-37; design of 168; by ECB 169; exit strategies 162-65; market vs. bank-based measures 160-63, 168, 169, 170; non-standard 157-58; portfolio-rebalancing 160; regulatory 28; signaling 160; timing of 102-3; see also central bank intervention

interventionism 233, $24 \ln 5$

investment banking 235, 242n6

Ireland: bank resolution in 120n6; collateral discrimination against 171; collateral market in 173; effect of exit strategies on 172; risk associated with collateral 170; sovereign bond portfolios of $\mathbf{1 6 7}$; special resolution powers in 111

IS/LM (investment, saving / liquidity preference, money supply) framework 150-53, 150, 152

issuance weighting 183-84

Italy: bank capitalization in 75, 79, 80, 81-82, 83, 84, 90; capital adequacy ratios in 83; collateral discrimination against 171; equity to assets ratio in 6 ; leverage ratios in $79, \mathbf{8 3}$; repo transactions in 166; sources of funding in 164, 164; sovereign bond market in 172-73, 220; sovereign bond portfolios of $\mathbf{1 6 7}$

J. P. Morgan/J. P. Morgan Chase 18, 40n13, $146,148,154$

James, Harold 208

Japan: bank resolution in 128; collateral in 147 ; economic recovery in 217 ; fiscal crisis in 196; market-based interventions in 160-63, 174n3; sources of funding in 164; special resolution powers in 111,115

JGBs 147

Keen, Steve, 217-18

Key Attributes of Effective Resolution for Financial Institutions (FSB) 102

Keynesians 227; see also New Keynesian Theory King, Mervyn 103
Kiwibank 123

Krugman, Paul 226-27

Lady Credit 180

Landsbanki 129

Latin America: debt 24; debt crisis in 178

LCH Clearnet 172

legal pluralism, global 250

Lehman Brothers crisis 62, 109, 113, 147, 151, 164, 168, 183, 217, 219

lending: appropriate decisions regarding 43, 46-47; to banks 221; effect of equity requirements on 42-44; stopped by banks 218

LEV equation 67

leverage 4, 60-61; buildup of 53; counterparty derivatives and repo risk separable from 62-65; new empirical evidence on 65-70; ratchet effect 48n 12; reduction of $41-42$; risk 68,70

leverage ratios 2, 5, 21, 23-24, 26, 29, 51, $54-55,60,71,75,79, \mathbf{7 9}$; defining undercapitalization 113-14; in European banks 83, 90; watering down 88

liberal market economies (LMEs) 217

liberalisms 223

LIBOR 5, 15, 64

life insurance 148

Liikanen Report 2, 8, 52, 58, 65, 126, 130, 137n $4,138 \mathrm{n} 16,158$

liquidity 35, 185n8, 218; bank-based measures 161-62; constraints on 235; coverage issues 56 ; crises 52 ; crunch 109; in the Eurozone 220; policies 15860, 163; provided by Bank of England 224-25; ratios $6,51,147$; regulation 3 ; requirements 2 ; short-term 144 ; support 194

liquidity coverage ratio (LCR) 56, 58-59

Lloyds Group 125

loan-to-value ratios 201

London stock market 180

long-term asset managers 148

long-term refinancing operations (LTROs)

48n14, 160-61, 168, 170, 172, 220

loss given default (LGD) 53

loss-absorbency requirements 59

Maastricht Treaty 157, 159, 236, 237

macroeconomic models 193 
macroprudential perspectives $3,4,10,58,66$, 68, 71n8, 88, 105, 192, 194-95, 198-

202, 205-7, 210n17, 210n19, 235, 240

Mallaby, Sebastian 226-27

margin calls 63

margin standards 201

marginal refinancing operations (MROs) 159

margining periods 56

market discipline, transparency and 26-28

market economies: coordinated 11, 217;

liberal 10-11

market risk (MR) 53

Market Risk Amendment 16

market-based measures 158

Marsh, Nicky 181

maturity mismatch 98

Memorandum of Cooperation on Trans-

Tasman Bank Distress Management 127

Mexico: sovereign debt crisis in 178; special resolution powers in 111,115

MF Global 149

microprudential perspectives 10, 51, 58, $71 \mathrm{n} 8$, 98, 105, 192-94

Minskian view 10, 217, 226

Minsky, Hyman 217, 235

modeling, risks from 21, 23

modern novels, and reality $182-83$

monetary easing: see quantitative easing (QE)

monetary economics 10, 192

monetary policy/policies 9, 195, 197, 206,

$21 \ln 29$, 238; and collateral 150-53;

easing of 195, 204; and the financial

crisis 195; and fiscal policy 230; focus

of 235; functions of 210n19; global

198; improvised 218; via the IS/LM

framework 150-53; regimes 194;

response 201; spillovers 200, 206;

strategies 199-200; unconventional

10-11, 194

money: price of 9, 144 45; relationship

with collateral 2; see also capital;

currency

money market funds (MMF) 63, 153

money market mutual funds (MMMFs) 148, 153, 155

money multiplier channel 161

mopping up 217, 226

mortgage-backed securities $174 \mathrm{n} 7,194$,

219-20, 227

mortgage institutions, competition among 62 mortgage risk weights 22
National Bank of New Zealand 126

national regulators 260

national reserve system $185 \mathrm{n} 8$

nationalization: of banking 234; of G-SIFIs 248

neoliberalism 226254

net stable funding ratio (NSFR) 56, 58-59

Netherlands, sovereign bond portfolios of $\mathbf{1 6 7}$

new economic criticism (NEG) 10, 178, 181

New Governance (NG) 11, 264; architecture

246-47; assessment tools 261; better regulation of processes 260-61; financial regulation prior to 2008 255-56; limited participation in 256; limited publicprivate coordination 257; as more inclusive process 260; need for study 261-62; pluralism and harmonization 257-58; practical shortcomings in the application of 256-59; in practice 255-59; problems with sociological approach 258; recommendations for future 261-62; as regulatory architecture 249; standards slide into rules 257; use of techniques for reform 259-60

New Keynesian theory 158, 160, 226, 239; see also Keynesians

New Zealand, lack of deposit insurance in 124

New Zealand bank resolution 7-8, 123-25, 135-36; bailing in 128-32; error over deposit insurance 133-35; estimated impact of implementing OBR 131; influence of Australia on 126-28; open bank resolution (OBR) 124-25; splitting the bank 125-26; statutory management 123-24; swift action 132-33

non-bank financial intermediaries 234; see also shadow banks

Norges Bank 206

Northern Rock 113

Norway, as isolated from external shock 184

OECD (Organisation for Economic Co-operation and Development) 58

one instrument-one objective framework 159 open bank resolution (OBR) 7, 124-25, 136n3; and the bail-in 130-31; destabilizing nature of 134; impact of 131, 131; influence of Australia on 126-28; and the problem of deposit insurance 134 35; see also bailing in

open-market operations 159

Operation Twist 145, 147 
operational risk (OR) 53

Outright Monetary Transactions (OMT) program 157, 173, 204

peer review 251-53

pension funds 132,148

Peregrine 149

points of entry (BoE/FCID) 100-102; single-point-of-entry (SPE) approach 101-102, 106

policy and policies: implementation of during crisis 173; objectives of 3 ; proposed adjustments to 199-200; recommendations for 44-46; see also fiscal policy

political economics 197

political economy 182; and economic challenges 201, 227

Ponzi schemes 217

Poovey, Mary 181-82

portfolio invariance principle 53, 58

Portugal: bailout in 172; collateral discrimination against 171 ; sovereign bond portfolios of $\mathbf{1 6 7}$

price stability $4,10,159,193-94,202$; in central banks 237

price-to-book ratios 26

prime brokering 6,51

private debt securities 166, 196

probability of default (PD) 53

problem banks: acquisition of 115 ; additional capital requirements for 118 ; bankruptcies of 116; and bridge banks 115; good bank/bad bank solution 115,117 ; liquidation of 116 ; public ownership of 116,117 ; resolution of 7 ; sale of 116; transfer of assets to asset management company 115-16

procyclicality 5, 51, 53-54, 58, 194 prompt corrective action (PCA) 132 Prudential Regulatory Authority (PRA) 58 public credit, and economic fictions 181-84 public debt 179, 192; monetization of 157, 159 public sector debt 202-3

quantitative easing (QE) 3, 8-9, 11, 145, 161, 221, 226, 238; by Bank of England $147,220,223$; by central banks, 153 ; in Japan 217; and the LM shift 151; QE3 147, 227; reversal 153; in USA 147, 152,223 ratios: debt-to-GDP 203; loan-to-value 201;

loss-absorbing capital to RWA 98; underweighted equity 44; see also capital ratios; leverage ratios

RBA: see Reserve Bank of Australia RBNZ: see Reserve Bank of New Zealand real wage rigidities $209 \mathrm{n} 3$

recapitalization 2, 6, 126; of bank creditors

7, 124; of European banking system 75-77, 89-90; in New Zealand 127-29; reluctance 90; by shareholders 103; see also European bank recapitalization recessions 191, 196; balance sheet 205, 208 Recovery and Resolution Directive (RRD) 126, 129, 137nn5-6

Recovery and Resolution Plans (RRPs) 7, 99, 126

reform initiatives, consensus regarding 260 regulation and regulations 2-3, 24, 246; riskbased 21; attempts at circumvention of 45-46; pluralism 254-55; revisability 254

Regulatory Consistency Assessment Program (RCAP) 57, 60, 72n12

Reinhart, Carmen 161, 178

re-pledging 9

repo rates 144, 153, 288; see also collateral rates repos 3, 6, 8, 61, 70, 129, 165-68, 224; general collateral (GC) 166; reverse repo programs 8, 147, 149, 155; tripartite 63, 145, 148, 154, 166; see also repo rates required stable funding (RSF) 56-57

Reserve Bank of Australia (RBA) 8, 150 Reserve Bank of New Zealand (RBNZ) 123, 130-33, 136

resolution regimes, fiscal cost and systemic impact in $\mathbf{1 1 0}$

resources, misallocation of 196, 208

retail banks and banking $1-2,11,58,100-101$, 103, 123, 130, 163, 230-31, 233-36

return on equity (ROE) 5, 37-38, 43, 59-60, 106; in banking 104-5; effect of increased equity on $\mathbf{3 9}$

ring fencing 1, 58, 235

risk and risks: balance of 210n18; bank 57; of change in economic regimes 208; of default 40-41, 7 ln5; determination of 22; of expectations gap 208; externalities 22; governance of 252; management of 225; market-based measures of 30n1; of overburdening central banks 208; perception of 201; 
redistribution of 234-35; reduction of 241; repo 62-65; sensitivity to 21-23; shifting 23-25; of sovereign default 238; standards based on 16; time inconsistency 196-97, 207; of value fluctuations 236; wrong-way 55-56; see also counterparty credit risk; riskweighted assets; risk weights and risk weighting; sovereign risk; systemic risk

Risk Management Association (RMA) 155 risk weights and risk weighting $6, \mathbf{1 7}, 51$, 71n5; of Basel I 53; calculation of 16, 28; introduction of floors on 28; and leverage ratio 18; manipulation of $72 \mathrm{n} 14$; miscalibration of 24 ; optimization of 59; prudence in 28; theoretical objections to 22; trust in $\mathbf{2 7}$; variability in $19, \mathbf{1 9}, 20, \mathbf{2 0}$

risk-taking channel 164

risk-weighted assets (RWA) 6, 16, 51; calculation for 53, 59, 72n13; confidence in 25; in CRD4 89; in European banks 75, 78, 80-86; optimization of 18 ; ratio to total assets 59-60, 60

robustness 23-25, 29

Rogoff, Kenneth 178

Rosenhek, Zeev 218

Royal Africa Company 185n5

Royal Bank of Scotland 125

Sampo Bank 137n7

Sato, Takafumi 250

Securities Market Programme (SMP) 157-58, 171-72, 220

securitization 62,143

securitization-based structures (SIVs) 145 self-regulation: and arbitrage 18; emergence of 15-16; growth of 29-30; intended consequences of 17-24; problems with 15; unintended consequences of $24-27$

separability 52,126

separation $58,65,71$

shadow banks and banking 4, 166, 235, 242n6

shareholders: concerns of 38-39; losses to 116-17; recapitalization by 103

Shell, Marc 181

Shirakawa, Masaaki 218

shocks 151; exogenous 193; external 239; vulnerability to 75
SIFIs: see systemically important financial institutions

simple rule leverage ratio (LEV) 67

Singapore, sovereign risk in 185n9

Single Resolution Board 135-36, 137n4

Single Resolution Regulation (SRR) 137n4

Single Supervisory Mechanism (SSM) 126

Smaghi, Bini 166

small and medium-sized enterprises (SMEs), financing 22, 221

Societé Generale 78

Solvency II 25

South Canterbury Finance 123, 134

South Korea, special resolution powers in 111,115

South Sea Company 180, 185n3

Southern Europe, as bank scapegoat, 77-79 sovereign bond markets 9, 158, 166, 174 sovereign bond portfolios 167-68, 167 sovereign debt: crises and defaults 9, 178, 218; in the Eurozone 236; history of sovereign safety $178-81$; instruments 159; OECD 24; pressures of 165; purchase by central banks 238; as risk-free 181; as safe collateral 9-10, 177-78; sustainability of 236

sovereign funding costs 165

sovereign risk 192; in central bank balance sheets 217; index 184

Spain: bank capitalization in 75, 79, 80, $\mathbf{8 1}$, 83, 84, 90; capital adequacy ratios in 83; collateral discrimination against 171; equity to assets ratio in 6 ; leverage ratios in $79, \mathbf{8 3}$; repo transactions in 166; sources of funding in 164, 164; sovereign bond market in 172-73, 220; sovereign bond portfolios of $\mathbf{1 6 7}$

Special Liquidity Scheme of the Bank of England 224

special resolution regimes (SRRs) 98, 109; for banks 6; early intervention 114-15; principles of 112-13; scope of 113; thresholds of 113-14; tools 115-17 stability: see financial stability; price stability Stability and Growth Pact $174 \mathrm{n} 10$ stabilization 4, 41 State Street 148 statutory management 129 Strategies of Bank Funding 163 subprime crisis 62 swap facilities 64, 219, 221 
swaptions 64

Sweden: bank resolution in 120n6; dedicated resolution funds in 118; as isolated from external shock 184; sovereign bond portfolios of 167; "triage" approach to problem banks 116

SWFs 148

Swiss Bank 52

Swiss National Bank (SNB) 28, 146-47, 155

Switzerland, as isolated from external shock 184

systemic issues 53

systemic risk 33, 117; buffers 88-89; tax 25 systemically important financial institutions (SIFIs) 123, 149; in the EU 136; failure of 131; see also global systemically important financial institutions (G-SIFIs)

Taiwan, sovereign risk in $185 \mathrm{n} 9$

Target 2 Securities (T2S) system 147-48 taxation: on banks 5, 105; collection 180; complexity of 24; of G-SIFIs 248; tax codes and debt 40

\section{Taylor Rule $\mathbf{1 5 2}$}

Tier 1 (T1) ratios 67-68; in European banks $78, \mathbf{7 9}, 82-83$

time inconsistency risk 196-97, 207

too big to fail (TBTF) 5, 25, 29, 40, 51, 54, 234,245

too big to save, G-SIFIs as 250

Trading Book reforms of 200855

transnational banks 1, 164

transparency 26-28, 54

Trans-Tasman Council on Banking

Supervision 127

Treasury securities 145, 219

tri-party repo (TPR) market 63, 145, 148, 154, 166

"Triumph of Central Banking, The?" (Volcker) 202

Troubled Assets Relief Program (TARP) 48n14, 120n8

UK: bank capitalization in $\mathbf{7 9}, \mathbf{8 4}$; bank resolution for SIFIs 125; and Basel III 58; capital adequacy ratios in $\mathbf{8 3}$; central banks' response to banking crisis 218; institutional change in 240; largescale asset purchases of government debt in 204; leverage ratios in $\mathbf{8 3}$; not participating in the EU bank resolution system 136; post-crisis recovery in 217; price of money in 144; quantitative easing in 223; response to financial crisis by $1-2$; sovereign GC collateral in 166; special resolution powers in 111 , 115; stock market indices 222, 223; Treasury bills 224

undercapitalization 43; of European banks 75-76; as trigger for intervention 132

under-collateralization 166

unemployment 3-4, 205, 221

United Nations World Conference, as model 260

universal banks and banking 99-102, 233, 235

US Federal Reserve Bank 3, 9, 41, 57, 118 , 143, 147, 205, $21 \ln 28$; balance sheet 219, 221; purchases by 219,224 ; and the QE 145; release of collateral by 8 ; reverse repo program of 155; response to financial crisis 218; valuation of collateral by 225 ; see also US Treasuries; USA

US Treasuries 147, 149, 183, 205

USA: bank resolution for SIFIs 125; checks and balances in 242n7; commercial paper in 219; large-scale asset purchases of government debt in 204; monetary policy extremism in 217; post-crisis recovery in 217; powers to improve resolvability in 118; price of money in 144; quantitative easing in 223 ; repo market growth in 166 ; sources of funding in 164; special resolution powers in $111,113,115$; stock market indices 222, 223; threshold limits in 113-14

value fluctuations 236

variability (VaR) models 60; of default probability 19, 19; range of 19; of risk weights 19-20, 19-20

Vickers Independent Commission on Banking 100

Vickers Report 1, 8, 52, 58, 65, 106, 233

virtual property $179-80$

Vitter, David 29

Volcker, Paul 52, 202

Volcker Rule 57, 65 
Wachovia 120n7, 133

Washington Mutual 115

Weidman, Jens 218

Wells Fargo 133

wholesale financing $138 \mathrm{n} 12$

Williams, Joh 227

World Bank 7 write-downs 118-19, 124, 128, 130, 133-35, 138n12, 138n14

wrong-way risk 55-56

zero-risk weight $24,40,44,56$

zero velocity $8,147,155 \mathrm{n} 1$

zero-weighted credit lines 24 
